\title{
SEISMIC RESPONSE OF REINFORCED CONCRETE ELEVATED WATER TOWERS
}

\author{
by \\ Aren Nazari, B.Eng, \\ Ryerson University, 2009
}

\author{
A Thesis \\ presented to Ryerson University \\ in partial fulfillment of the \\ requirements for the degree of \\ Master of Applied Science \\ in the program of \\ Civil Engineering
}

Toronto, Ontario, Canada, 2009

(C) Aren Nazari 2009 
I hereby declare that I am the sole author of this thesis.

I authorize Ryerson University to lend this thesis to other institutions or individuals for the purpose of scholarly research.

I further authorize Ryerson University to reproduce this thesis by photocopying or by other means, in total or in part, at the request of other institutions or individuals for purpose of scholarly research. 


\begin{abstract}
SEISMIC RESPONSF OF REINFORCED CONCRETE ELEVATED WATER TOWERS

Modern composite elevated storage tanks were developed in late 1970's in response to increasing demand for a reliable, economical and low-maintenance water storage system in Canada and the US. The popularity of composite elevated water towers rose tremendously in the last 30 years, as the new type of construction offered many advantages over traditional elevated water storage tanks. Despite the increasing rate of construction, the performance of this type of structure under ground motions is not fully understood. During the recent earthquake of Bhuj 2001, many shaft staging elevated water towers experienced severe damages, signifying the lack of considerable ductility, redundancy and energy dissipation in the system.
\end{abstract}

This thesis investigates the current approach to the design of shaft staging elevated towers, and also summarizes a comprehensive literature review of structural theories, latest research and studies. The response of a selected concrete shaft staging elevated tower, designed according to the currant practice and subjected to gradually increasing lateral load was investigated through a non-linear static finite element analysis. Additionally, the seismic performance of the structure during four different ground motions with various peak ground accelerations was studied through several time-history non-linear finite element analyses. The results of static and dynamic finite element analyses were used to evaluate and establish the response modification factor used for design of these types of structures. 


\section{Acknowledgement}

I would like to express my sincere thanks to my supervisor, Dr. Reza Kianoush, for his continuous support and encouragement during this research and my two years of graduate studies, whose profound comments and advises helped me with the refinement of this thesis.

In addition, I am grateful to Dr. Anwar Hossain and Dr. Arnold Yuan for providing me with their helpful comments for the enhancement of this thesis.

Last but not least, I offer my heartfelt gratitude and love to my wife, Alma, whose unconditional love and support is the driving force behind my achievements. 


\section{Table of Contents}

List of Figures viii

List of Tables ix

Nomenclature $\mathrm{X}$

Abbreviations xii

1. INTRODUCTION

1.1 General 1

1.2 Objectives.. 4

1.3 Scope. 5

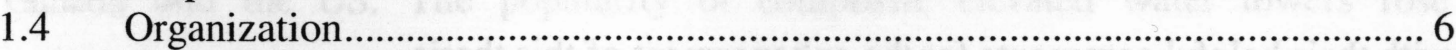

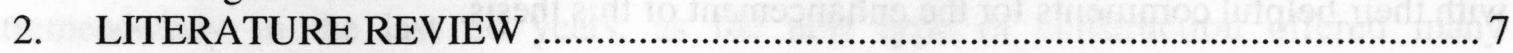

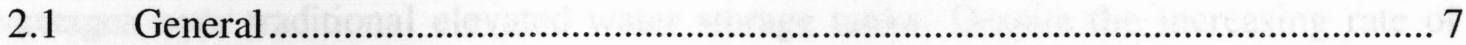

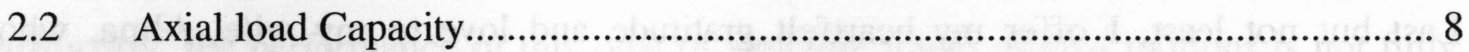

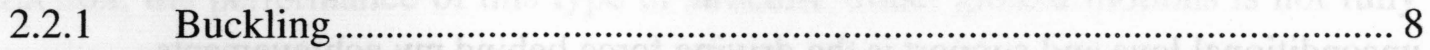

2.2.2 Accidental Eccentricities ................................................................. 10

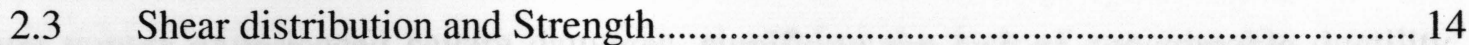

$2.4 \quad$ Second Order Analysis .............................................................................. 18

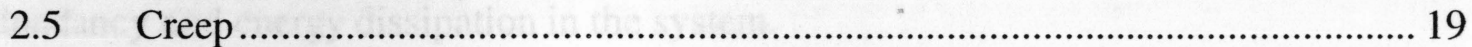

2.6 Seismic Response of Elevated Water Towers .................................................. 19

2.7 Seismic Reduction/Modification Factor $(R)$.............................................. 25

2.8 Performance of $\mathrm{R} / \mathrm{C}$ shaft staging elevated water tanks in recent earthquakes 31

3. DESIGNING THE SUPPORTING STRUCTURE OF ELEVATED WATER

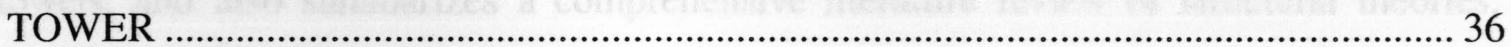

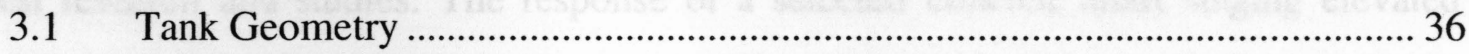

3.2 Earthquake Loads...................................................................................... 37

3.3 Design for Earthquake Loads......................................................................... 38

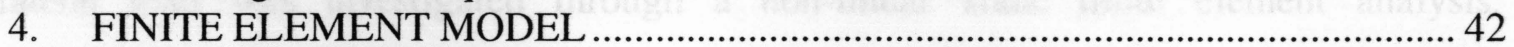

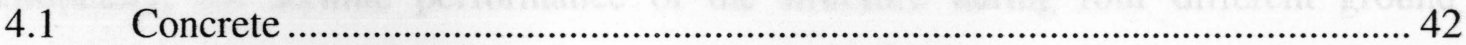

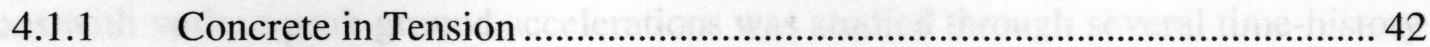

4.1.2 Concrete Behavior in Compression ......................................................... 45

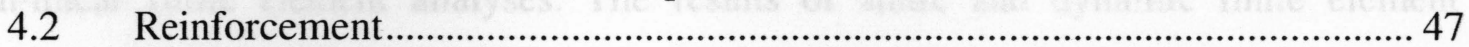

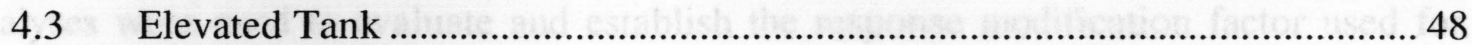

5. GENERALIZED SINGLE DEGREE OF FREEDOM SYSTEM …….................... 50

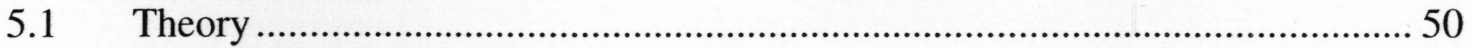

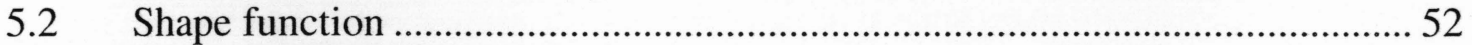

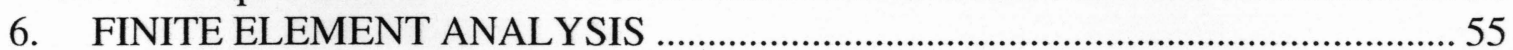

6.1 Static Non-Linear Finite Element Push-Over Analysis ..................................... 55

6.2 Non-Linear Time-History (Transient) Finite Element Analysis........................ 61

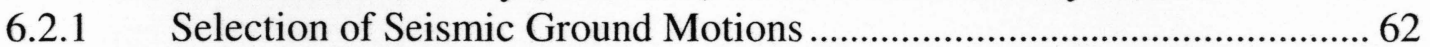

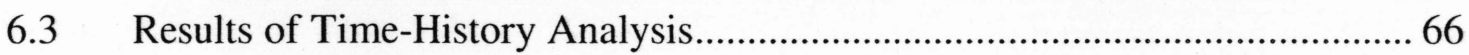

7. CALCULATION OF RESPONSE MODIFICATION FACTOR …......................... 76 
7.1 Static Push-Over Analysis Approach................................................................. 76

7.2 Non-linear Time-History Analysis Approach.................................................... 78

8. CONCLUSIONS, SUMMARY AND RECOMMENDATION FOR FUTURE

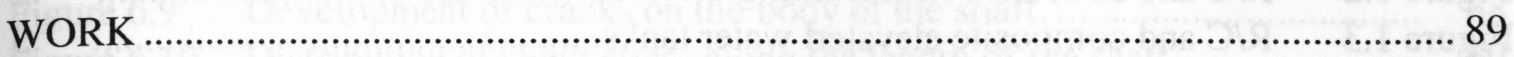

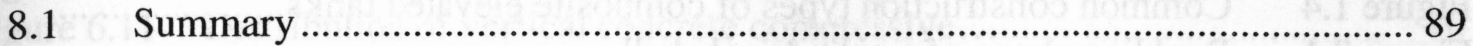

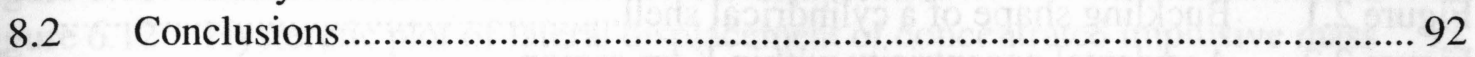

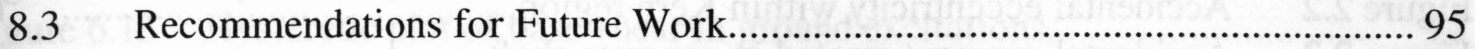

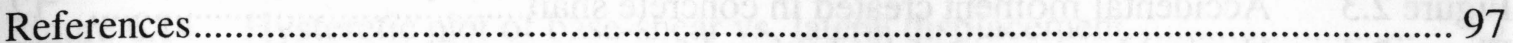

Appendix A- Geometric Properties of Circular Segment .................................................. 102

Appendix B - Dynamic equations of a single degree of freedom System ....................... 103

Appendix C- Calculation of Seismic base shear.............................................................. 106

Appendix D - Designing Support Structure for Axial and Lateral Loads ..................... 113

Appendix E - Seismic Redution Factor (R) Calculation .................................................. 117 


\section{List of Figures}

Figure 1.1 Water storage and distribution system.................................................... 1

Figure 1.2 R/C and structural steel framing elevated water tanks............................ 2

Figure 1.3 R/C and composite elevated water tanks............................................. 3

Figure 1.4 Common construction types of composite elevated tanks........................ 4

Figure 2.1 Buckling shape of a cylindrical shell................................................... 9

Figure 2.2 Accidental eccentricity within Kern region.......................................... 11

Figure 2.3 Accidental moment created in concrete shaft....................................... 12

Figure 2.4 Vertical load eccentricity initiated from construction errors................... 13

Figure 2.5 Variation of flexural stresses in cross section....................................... 14

Figure 2.6 Theoretical and Idealized shear stress distribution.................................. 15

Figure 2.7 Idealized shear stress distribution with/without openings....................... 16

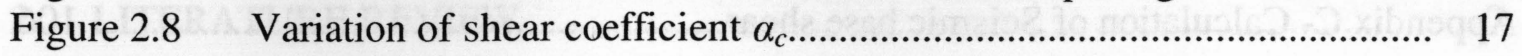

Figure 2.9 Dynamic equilibrium of a single degree of freedom system.................. 20

Figure 2.10 Pseudo-velocity response spectra for El Centro earthquake and 22 normalized design response spectrum.

Figure 2.11 Amplification factors for design spectra in different site conditions......

Figure 2.12 Spectral acceleration response curve as specified in ASCE 7-05.......... 24

Figure 2.13 Design seismic base shear based on reduced elastic response of stature 27

Figure 2.14 Ductility demand spectra in 4 elasto-plastic systems with fixed yield 28 reduction factors

Figure 2.15 Variation of ductility factor $(\mathrm{R} \mu)$ over a rang eof period of vibration....

Figure 2.16

Figure 2.17

Elastoplastic model and $\mathrm{R}$ factor.

Figure 2.18

Modified Clough model and $\mathrm{R}$ factor.

Figure 2.19

Figure 2.20

Epicenter and PGA of Bhuj 2001 earthquake.

Seismic acceleration response spectra in Bhuj 2001 earthquake............ $\quad 32$

Figure 3.1

Seismic demand spectra of IBC 2000, IS:1983-1984 and 2002.

Figure 3.2

Vertical cross section of composites elevated water tower.

Horizontal cross-section of the shaft...................................................... 38

Figure 3.3 Axial vs. lateral load interaction diagram near the base of the structure

Figure 4.1

Figure 4.2

Solid65 element.

Tensile stress relaxation in concrete.

Figure 4.3

Stress-strain response of a concrete element subjected to cyclic loading.

Figure 4.4

Stress-strain response of ANSYS $®$ Link8 3D truss element.

Figure 4.5

Finite element model of an elevated water tower.

Figure 5.1

Response of first mode of vibration of an elevated water tower.

49

Figure 5.2

Optimization of shape function in SDOF generalization of th

Figure 6.1 Numerical equation solvers for static analysis in ANSYS $₫$....................

Figure 6.2 FE axial vs. lateral load interaction diagram near the base of the 56 structure

Figure 6.3 Development of shear force at base vs. lateral displacement at c.g........

Figure 6.4 Variation of vertical displacement along the horizontal cross section of 58 the shaft

Figure 6.5 Variation of total vertical strain in the cross section. 
Figure 6.6

Figure 6.7

Figure 6.8

Figure 6.9

Figure 6.10

Figure 6.11

Figure 6.12

Figure 6.13

Figure 6.14

Figure 6.15

Figure 6.16

Figure 7.1

Figure 7.2

Figure 7.3

Figure 7.4

Figure 7.5

Figure 7.6

Figure 7.7

Figure 7.8

Selected seismic acceleration waveforms

Fourier amplitude spectra..................................................................... 64

Pseudo acceleration response spectra........................................................ 65

Development of cracks on the body of the shaft.................................. 68

Distribution of shear stress along the length of the shaft......................... 69

Distribution of vertical concrete compressive ...................................... $\quad 70$

Hysteretic plot of lateral displacement of concentrated impulsive mass 71

Hysteretic plot of base-shear in ground excitations................................. $\quad 72$

Hysteretic plot of base-shear vs. lateral displacement............................ $\quad 73$

Hysteretic stress-strain plot of a selected longitudinal reinforcement.... $\quad 75$

Maximum linear and non-linear structural responses shown in static 75 push-over graph

Elasto-plastic approximation of non-linear response of structure........... $\quad 76$

Variation of seismic reduction factor vs. ductility demand...................... $\quad 79$

Variation of seismic reduction factor based vs. characteristic period of 80 earthquake and response ratio of equivalent elastic models

Approximation of elastic structural stiffness......................................... 81

Normalized spectral displacement response........................................... 83

$\begin{array}{ll}\text { Normalized spectral acceleration response } & 84\end{array}$

Variation of seismic reduction factor $(\mathrm{R})$ vs. ratio of spectral responses 85 of elastic and inelastic period of vibrations

Variation of seismic reduction factor (R) calculated based on NBCC

88

\section{List of Tables}

Table 2.1 Mapped Maximum considered earthquake spectral response 24 acceleration parameters for different site conditions.

Table 2.2 Summary of damage assessment for $19 \mathrm{RC}$ shaft staging elevated 33 towers affected by the Bhuj 2001 earthquake.

Table 2.3 Geometrical and mechanical properties of $8 \mathrm{RC}$ shaft staging elevated 34 water tanks affected by the Bhuj 2001 earthquake.

Table 3.1 Calculated design lateral load, shear \& over-turning moment at each 38 level of shaft.

Table 6.1 Maximum linear and non-linear structural responses. 


\section{Nomenclature}

$\mathrm{a}_{1}$

$\mathrm{A}_{\mathrm{cv}}$

$\mathrm{A}_{\mathrm{s}}$

$\mathrm{A}_{\mathrm{w}}$

$b_{w}$

c

$\mathrm{C}_{\mathrm{e}}$

$\mathrm{C}_{\mathrm{s}}$

$\mathrm{C}_{\mathrm{w}}$

$\mathrm{d}_{\mathrm{W}}$

E

e

$\mathrm{E}_{\mathrm{C}}$

$\mathrm{e}_{\mathrm{g}}$

$f_{c}^{\prime}$

$f_{c k}$

$\mathrm{f}_{\mathrm{o}}$

$f_{y}$

$\mathrm{h}_{\mathrm{w}}$

I

$\mathrm{k}$

$\mathrm{k}_{\mathrm{d}}$

$\mathrm{k}_{\mathrm{e}}$

$\mathrm{L}_{\mathrm{g}}$ (or $\mathrm{L}_{\mathrm{cg}}$ )

m

$\mathrm{M}_{1 \mathrm{~s}}$

$\mathrm{M}_{2 \mathrm{~s}}$

$\mathrm{M}_{\mathrm{u}}$

n

$\mathrm{P}(\tau)$

$\mathrm{P}_{\mathrm{nw}}$

$\mathrm{P}_{\mathrm{u}}$

$\mathrm{R}$

$\mathrm{R}_{\mathrm{o}}$

$\mathrm{R}_{\mathrm{R}}$

$\mathrm{R}_{\mathrm{s}}$

$\mathrm{R}_{\text {size }}$

$\mathrm{R}^{\mathrm{t}}$ $a_{1}$ is a parameter related to the damping properties, $s^{-1}$

gross area of wall cross-section, $\mathrm{mm}^{2}$

area of longitudinal reinforcements, $\mathrm{mm}^{2}$

gross cross-sectional area of unit length of the wall circumference, $\mathrm{mm}^{2}$

unit length of the wall, $\mathrm{mm}$

Damping coefficient, $\mathrm{kN} . \mathrm{s} / \mathrm{m}$

axial load eccentricity coefficient

seismic shear coefficient, $\mathrm{g}^{-1}$

axial load eccentricity coefficient

mean diameter of the shaft, $\mathrm{m}$

modulus of elasticity, $\mathrm{MPa}$

axial the load eccentricity, $\mathrm{mm}$

modulus of elasticity, $\mathrm{MPa}$

horizontal eccentricity of tank vessel, $\mathrm{mm}$

specific compressive strength of concrete, $\mathrm{MPa}$

characteristic strength of concrete, $\mathrm{MPa}$

peak elastic response, $\mathrm{kN}$

yield strength of reinforcement

wall thickness, mm

Seismic importance factor

buckling coefficient

post decay stress softening coefficient

elastic stiffness, $\mathrm{kN} / \mathrm{m}$

distance form bottom of foundation to centroid of stored water, $\mathrm{m}$

Mass, $\mathrm{kg}$

first order moment, kN.m

second order Moment, kN.m

factored moment, kN.m

curve fitting factor

time dependent dynamic load, $\mathrm{kN}$

nominal axial strength, $\mathrm{kN}$

factored axial load, $\mathrm{kN}$

seismic reduction / modification factor

over-strength related reduction factor

redundancy related reduction factor

strength related seismic modification factor

standard over-size section related reduction factor

tensile stress relaxation coefficient 


\begin{tabular}{|c|c|}
\hline $\begin{array}{l}\mathrm{R}_{\mathrm{w}} \\
\mathrm{R}_{\mu}\left(\text { or } \mathrm{R}_{\mathrm{d}}\right)\end{array}$ & $\begin{array}{l}\text { radius of the wall cross-section, } m \\
\text { ductility related modification factor }\end{array}$ \\
\hline $\mathrm{R}_{\varphi}$ & Strength reduction related factor modification factor \\
\hline $\mathrm{Sa}\left(\mathrm{T}_{\mathrm{e}}\right)$ & elastic spectral acceleration response, $\mathrm{g}^{-1}$ \\
\hline $\mathrm{Sa}\left(\mathrm{T}_{\mathrm{ie}}\right)$ & inelastic spectral acceleration response, $\mathrm{g}^{-1}$ \\
\hline $\mathrm{S}_{\mathrm{D} 1}$ & design acceleration response spectra, $\mathrm{g}^{-1}$ \\
\hline $\mathrm{S}_{\mathrm{DS}}$ & design acceleration response spectra, $\mathrm{g}^{-1}$ \\
\hline $\mathrm{S}_{\mathrm{pa}}(\xi, \omega)$ & pseudo-acceleration spectral response, $\mathrm{g}^{-1}$ \\
\hline $\mathrm{S}_{\mathrm{pv}}(\xi, \omega)$ & pseudo-velocity spectral response, $\mathrm{g}^{-1}$ \\
\hline $\mathrm{t}$ & Mean wall thickness, mm \\
\hline $\mathrm{T}$ & fundamental period of vibration, $s$ \\
\hline $\mathrm{T}_{\mathrm{g}}$ & characteristic period of ground movement, $\mathrm{s}$ \\
\hline $\mathrm{u}_{\mathrm{m}}$ & large inelastic deformation, $\mathrm{mm}$ \\
\hline $\mathrm{u}_{\mathrm{o}}$ & elastic displacement, $\mathrm{mm}$ \\
\hline $\mathrm{u}_{\mathrm{y}}$ & yield displacement, $\mathrm{mm}$ \\
\hline $\mathrm{V}$ & shear force, $\mathrm{kN}$ \\
\hline$V_{d}$ & design base shear, $\mathrm{kN}$ \\
\hline $\mathrm{V}_{\mathrm{e}}$ & elastic base shear, $\mathrm{kN}$ \\
\hline $\mathrm{V}_{\mathrm{m}}$ & maximum available strength of structure, $\mathrm{kN}$ \\
\hline$V_{n}$ & nominal shear strength, $\mathrm{kN}$ \\
\hline $\mathrm{V}_{\mathrm{nl}}$ & non-linear base-shear, $\mathrm{kN}$ \\
\hline $\mathrm{V}_{\mathrm{u}}$ & factored shear, $\mathrm{kN}$ \\
\hline $\mathrm{V}_{\mathrm{y}}$ & yielding strength level, $\mathrm{kN}$ \\
\hline$x(t)$ & relative mass displacement, $\mathrm{m}$ \\
\hline$\dot{\mathrm{x}}(\mathrm{t})$ & relative mass velocity, $\mathrm{m} / \mathrm{s}$ \\
\hline$\ddot{\mathrm{x}}_{\mathrm{t}}(\mathrm{t})$ & total mass acceleration, $\mathrm{m} / \mathrm{s}^{2}$ \\
\hline$\ddot{x}_{g}(t)$ & ground acceleration, $\mathrm{m} / \mathrm{s}^{2}$ \\
\hline$\ddot{\mathrm{x}}(\mathrm{t})$ & relative mass acceleration, $\mathrm{m} / \mathrm{s}^{2}$ \\
\hline $\mathrm{Z}(\mathrm{t})$ & relative displacement of center of gravity of water, $\mathrm{mm} / \mathrm{s}$ \\
\hline $\begin{array}{l}\alpha_{c} \\
\beta^{c}\end{array}$ & $\begin{array}{l}\text { shear coefficient } \\
\text { shear transfer coefficients for closed cracks }\end{array}$ \\
\hline$\beta^{t}$ & shear transfer coefficients for open cracks \\
\hline $\begin{array}{l}\beta_{w} \\
\varepsilon_{c}^{\prime}\end{array}$ & $\begin{array}{l}\text { slenderness coefficient } \\
\text { peak compressive stress level }\end{array}$ \\
\hline $\begin{array}{l}\theta_{\mathrm{g}} \\
\kappa\end{array}$ & $\begin{array}{l}\text { foundation tilt, degrees } \\
\text { the impedance ratio }\end{array}$ \\
\hline $\begin{array}{l}v \\
\xi\end{array}$ & $\begin{array}{l}\text { Poisson ratio } \\
\text { damping ratio, } \%\end{array}$ \\
\hline$\xi_{\text {cr }}$ & critical damping ratio \\
\hline$\rho_{h}$ & ratio of horizontal reinforcements \\
\hline
\end{tabular}


$\varphi_{\mathrm{v}} \quad$ shear reduction factor

$\psi(\mathrm{x}) \quad$ the shape function

$\omega \quad$ undamped angular frequency

$\omega_{\mathrm{D}} \quad$ damped angular frequency, $\mathrm{rad} / \mathrm{s}$

\section{Abbreviations}

ACI American Concrete Association

NBCC National Building Code of Canada

ATC Applied Technology Council

ACI

American Concrete Association

FEA Finite Element Analysis

FEM Finite Element Model

ASCE American Society of Civil Engineers

IBC International Building Code

UBC Uniform Building Code

IS

Indian Standard

$\mathrm{RC}$

Reinforced Concrete

MCE

Maximum Considered Earthquake 


\section{INTRODUCTION}

\subsection{General}

Elevated water tanks are part of water distribution system in many urban and rural areas in many countries including Canada and US. They play an important role in providing a steady water flow in peak demand hours of the day without applying excessive pressure on water distribution network. Use of elevated water tanks also eliminates the need for heavy pumping facilities that are often costly to construct and operate.

Water which is collected from dams, underground basins, rivers and lakes (Lake Ontario in Toronto) is pumped into water treatment facilities where water is filtered and cleaned throughout an intricate process in order to decrease the physical, chemical and biological impurities (City of Toronto 2008). Potable water is then stored in large underground storage tanks from where it is pumped into elevated water towers for distribution as shown in Figure 1.1.

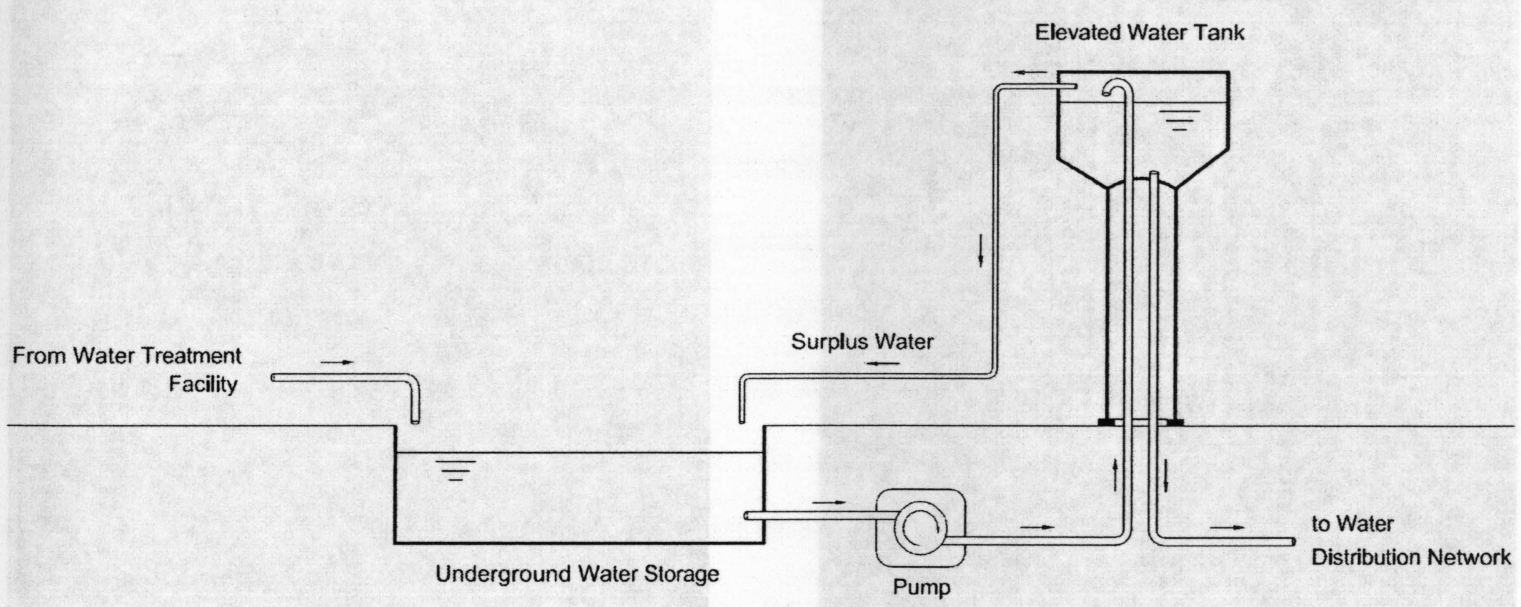

Figure 1.1 - Schematic view of water storage and distribution system

The capacity of the tank and pumping facility is selected in such a way that during hours of peak water demand, the tank can reasonably maintain the required water pressure without increasing pumping capacity. During low demand hours, the elevated tank can be efficiently replenished by energy efficient pumping mechanism. However water tanks are sometimes disconnected from the system since direct pumping can satisfy the demand. 
Elevated water tanks are also very beneficial for satisfying fire requirements and minimizing the damage. They also remain operational for several hours during power outage or pump failure. Being one of vital infra-structures in a post disaster area, elevated water towers must be designed and constructed with special attention in order for structure to remain fully functional even after a major natural disaster, where immediate access to clean and drinkable water is extremely crucial for survivors of a major disaster.

Elevated water towers are commonly designed and constructed in two conventional structural systems: framed structure and concrete shaft structure. Both structural steel and concrete framing systems are commonly used in towers with frame supporting structures as shown in Figure 1.2

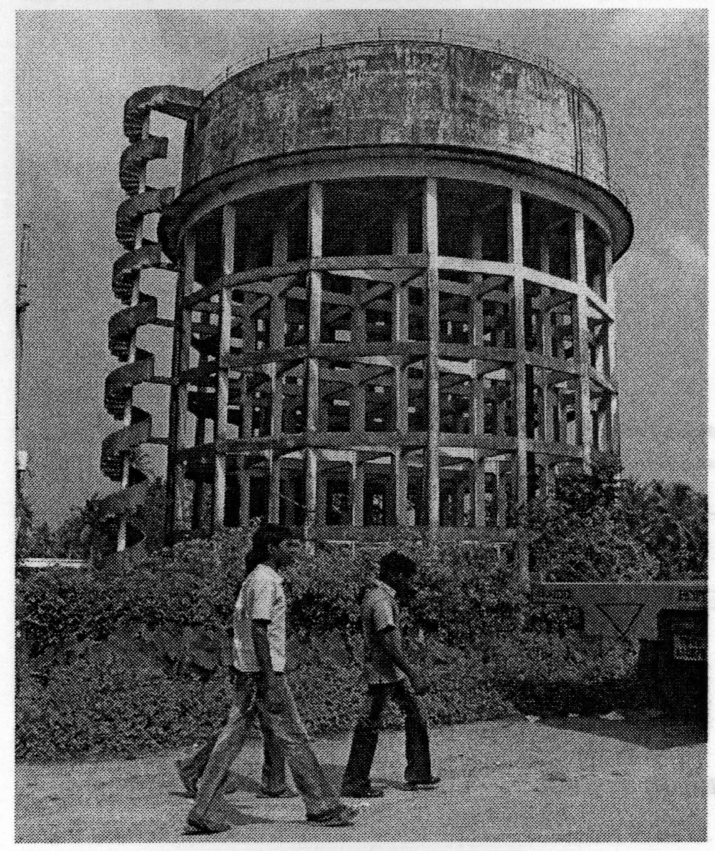

a)

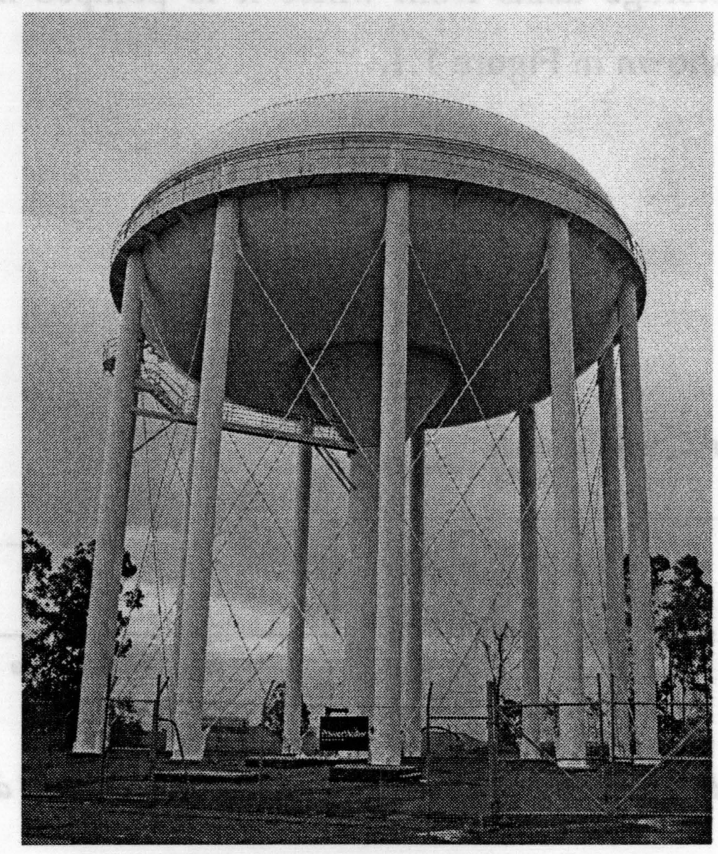

b)

Figure 1.2 - Structural framing supported elevated water tanks; a) Reinforced concrete framing water tank in India - photo by Richard Northover, b) Structural steel framing supported water tank, Darwin Airport Australia - photo by Bidgee 
Frame supporting structure benefits from high redundancy factor, owing to many structural components, where failure of one member does not lead to collapse of entire structure and the load is redistributed between still functioning members. Framed structures also can be design and constructed to exhibit moderate to high ductility, redundancy, energy dissipation and damping capabilities which are important aspect of reducing seismic strength demand. However, construction and maintenance of this type of structures are often costly which enforces authorities and designers to consider concrete pedestal shaft as an alternative structural system. Concrete pedestal tanks can be either made entirely from reinforced concrete, or steel tank and concrete support as shown in Figure 1.3.

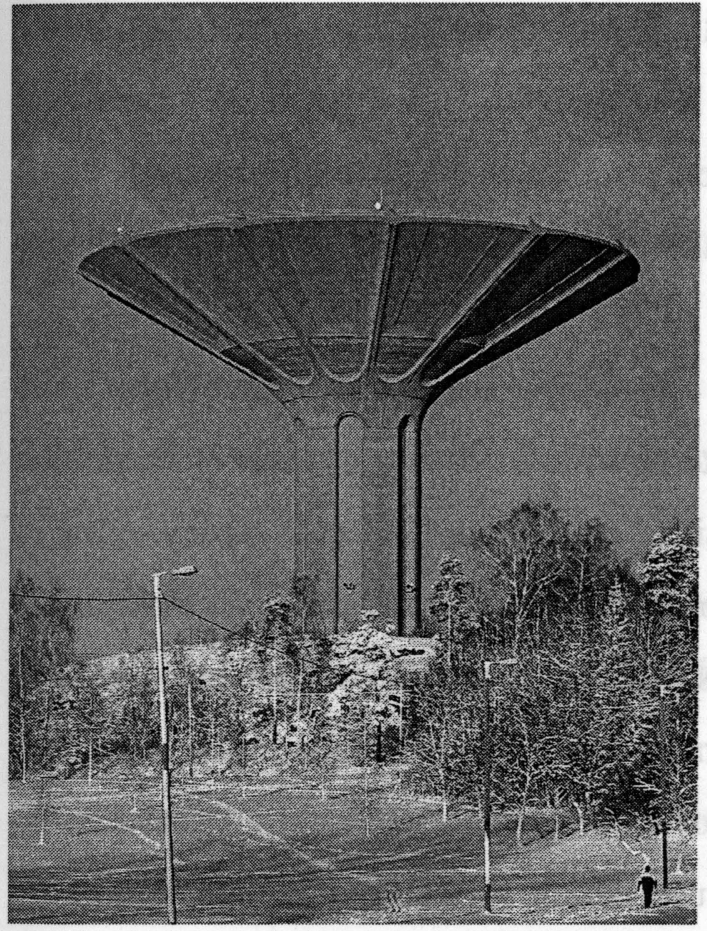

a)

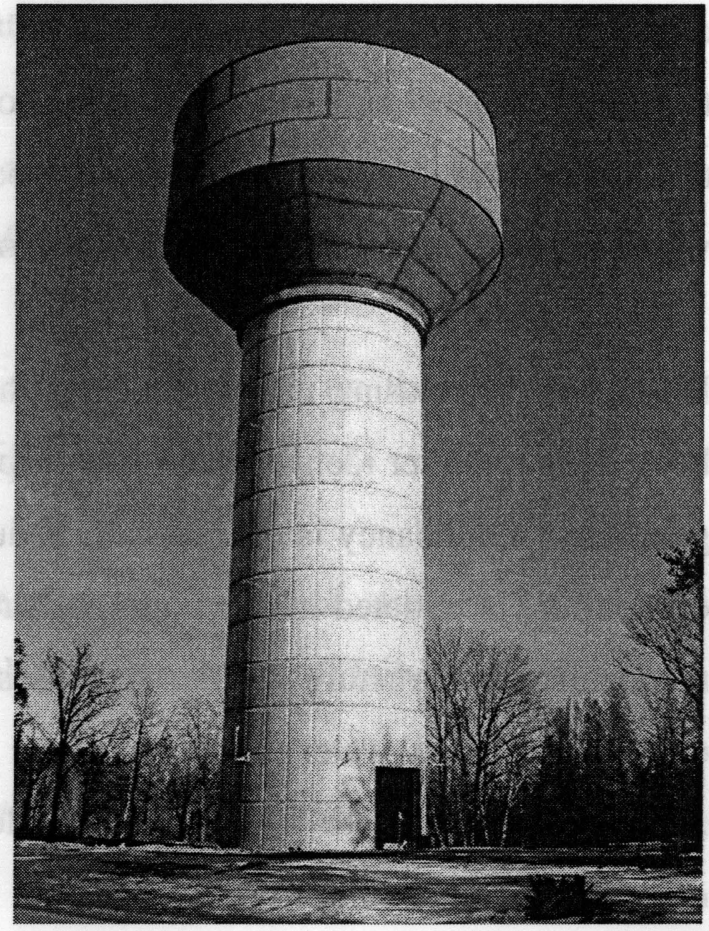

b)

Figure 1.3 - R/C shaft supported elevated water tank: a) Concrete elevated water tank in Roihuvuori, Helsinki Finland - photo by Otto-Ville Mikkelä, b) Composite elevated water tank in Bemidji, Minnesota, USA - Photo by M.W. Persons and Associates.

Composite pedestal towers which are investigated in this study, are usually constructed in three common types: Dome floor, slab floor and suspended steel floor (ACI 371-08) as shown in Figure 1.4 


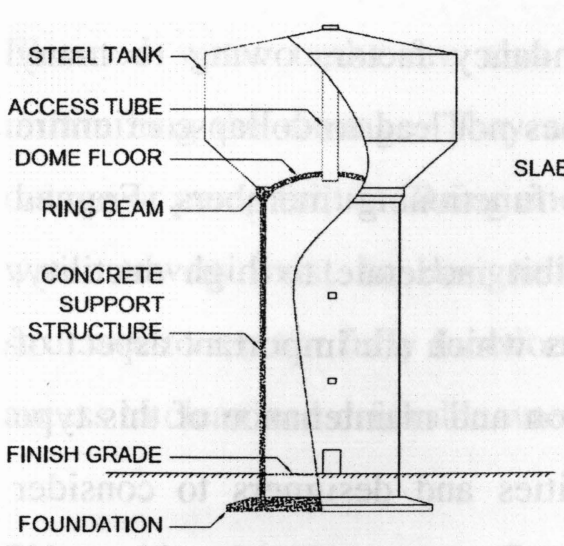

a)

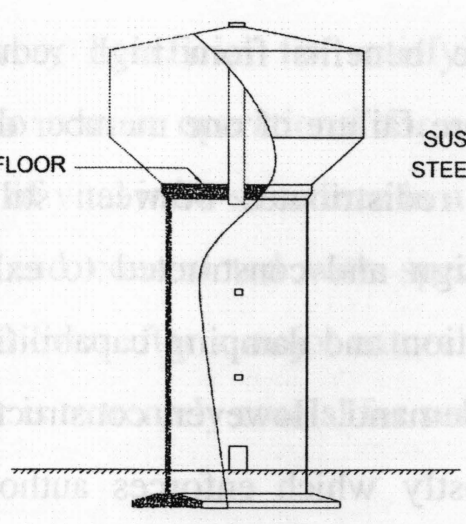

b)

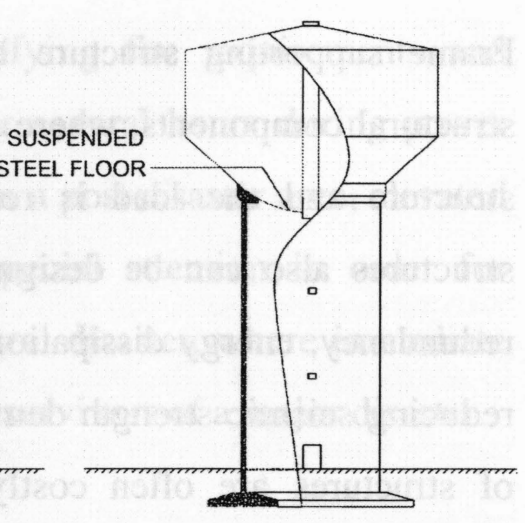

c)

Figure 1.4 - Three common construction types of composite elevated tanks: a) Dome-floor tank, b) Slabfloor tank, c) Suspended-steel-floor

Among three types of composite construction, the dome-floor system is preferred to the others, since the horizontal component of the axial thrust of the dome is canceled out by the one from steel tank, resulting in a smoother load transfer. However, there are several advantages and disadvantages in each type of construction as specified by Meier (2002), which play an important role in selection of construction type.

Despite the increasing use of concrete shaft as supporting structures, little efforts have been done to better identify their true response to seismic loads. As a result of its unique geometry, redundancy is dramatically reduced since alternative load path barley exits, in case failure is initiated in one region of structure. Lack of a substantial energy dissipation mechanism in structure further increases the seismic demand. However, the sloshing effects of stored water may contribute to energy dissipation if carefully designed. Additionally, concrete shaft structure does not undergo large inelastic deformation, despite general assumption for building structure which offsets the seismic reduction factor $(R)$ for calculating seismic demand.

\subsection{Objectives}

The main objectives of this study are:

1) Performing a comprehensive literature review on reinforced concrete structures, dynamics of structures, earthquake engineering, theory of finite element analysis, finite 
element analysis software $\left(\mathrm{ANSYS}^{\circledR}\right.$ ), applicable building codes, recent studies and studies in the field of concrete shaft staging elevated water towers.

2) Designing the structure of a shaft staging elevated water tower to withstand the gravitational and seismic loads based on current design approach.

3) Preparing a finite element model of structure in ANSYS ${ }^{\circledR}$ environment where the geometry and mechanical properties of structure can be easily modified to accommodate changes.

4) Investigating the elastic response of structure, displacement and period of vibration through theoretical and free-vibration finite element analyses.

5) Performing non-linear static push-over analyses as needed for identifying the structural strength, responses, ductility and verifying manual design assumptions.

6) Performing non-linear time-history finite element analyses on the structure when subjected to selected seismic excitations with different intensities.

7) Investigating the structural performance and development of stresses, strains and cracks in the body of the shaft and identifying all possible modes of failures.

8) Calculating the seismic force modification/reduction factor based on results of finite element analysis.

\subsection{Scope}

The scopes of this thesis are as follows:

1) This study considers the seismic response of structure only on rock site conditions for seismic evaluation. 
2) Only one concrete shaft staging elevated water tower was designed and analyzed in this study.

3) A rigid support connection was considered for the selected structure.

4) The water inside tank vessel was modeled as an impulsive mass, and the convective behavior of the sloshing water was not considered in this study.

5) The supporting shaft structure was modeled without any wall openings and intermediate floors.

6) The seismic response of structure was investigated using only 4 major seismic records with different peak ground accelerations.

\subsection{Organization}

This thesis is divided into eight chapters. A brief summary of the literature including structural theories, building codes, computer aided FEA software and recent research in the field of elevated water towers is presented in Chapter 2. The geometry of selected elevated water tower is introduced in Chapter 3, along with calculation of axial gravitational load and lateral seismic loads followed by manual design procedure.

In the Chapter 4 of this thesis, a finite element model of the structure and the material properties of its components are discussed. A theoretical study of elastic response of structure is presented in Chapter 5. The results of non-linear static push-over and timehistory finite element analysis are described in Chapter 6. The estimated seismic force reduction capacity which is calculated based on FEA results is presented in Chapter 7. Finally, a brief summary of the work done in this thesis is presented in Chapter 8 , along with conclusions and recommendations for future work. 


\section{LITERATURE REVIEW}

\subsection{General}

This Chapter of thesis summarizes a comprehensive literature review of existing codes, guidelines, previous studies, structural theories and computer software. Although most recognized building codes such as ACI 318-08, ASCE-7 2005, NBCC 2005, IBC 2006, EuroCode-8 1998, etc. offer valuable recommendations for loading and design of this type of structures, the guideline presented by ACI Committee 371 thoroughly covers most of the design aspects of concrete/composite elevated water tower structures. Even though the theory behind most of the loading and design consideration is adopted from building structures, some characteristics are unique to elevated water towers and are hardly observed in other structures.

Surprisingly, limited number of literature is available that investigates the nonlinear seismic behavior of concrete shaft staging. Several attempts have been made in recent years to explain and model the liquid-structure interaction in elevated towers using different liquid sloshing models over the past few decades by Shepherd (1972), Haroun and Ellaithy (1985), Ibrahim and Soundarajan (1983) and Liavog and Dogangu (2006). The influence of base-isolation in seismic response of water towers was also studied by Shenton and Hampton (1999). However, the seismic behavior of pure reinforced concrete shafts, excluding the liquid sloshing, was never thoroughly investigated.

Similar to conventional structures, the elastic response of structure is adjusted by seismic reduction factor $(R)$, in order to incorporate redundancy, over-strength, energy dissipation, and the most importantly, ductility which plays the most important role in reducing seismic loads. Unlike building structures which can undergo relatively large non-linear deformation, available ductility is limited in concrete shaft staging elevated water towers. 


\subsection{Axial load Capacity}

Axial load capacity of shaft wall which ultimately translates to flexural capacity of shaft, is influenced by strength of wall constituents (concrete and reinforcements), wall geometry and load eccentricities. The effects of these factors in vertical load capacity are investigated in the following sections.

\subsubsection{Buckling}

Concrete shaft staging for composite water towers is designed and constructed in variety of geometry, in order to maintain the two main design requirements of water distribution network: pressure and water capacity. The diameter of the shaft is then determined in proportionate to tank diameter to control the axial thrust in conical segment of steel tank. However, other parameters may alter the geometry if required. Theoretically, the shaft geometry may change between very short and large diameter to slender and tall. In very large diameter staging, buckling shape may be modeled as the buckling of elastic straight plates (Timoshenko and Woinowsky-Krieger 1959) as follows,

$$
\sigma=k \frac{\pi^{2} E}{12\left(1-v^{2}\right)}\left(\frac{h_{w}}{b_{w}}\right)^{2}
$$

Where $E$ is the modulus of elasticity of concrete, $v$ is Poisson's ratio of concrete, $h_{w}$ is wall thickness and $b_{w}$ is width of unit length of the wall. In the above equation, $k$ is the buckling coefficient which is calculated based on boundary conditions. Reducing the shaft diameter, the shaft wall tends to buckle in diamond shape pattern, similar to buckling mode of thin cylindrical shapes as shown in Figure 2.1. 


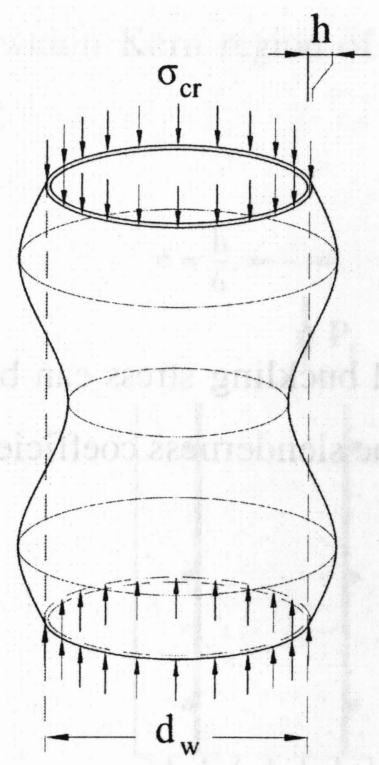

Figure 2.1 - Buckling of a cylindrical shell

Using classical elastic bucking theory of thin wall cylindrical elements, critical bucking stress is calculated as follows,

$$
\sigma_{\mathrm{cr}}=\frac{\mathrm{E}}{\sqrt{3\left(1-v^{2}\right)}}\left(\frac{2 \mathrm{~h}_{\mathrm{w}}}{\mathrm{d}_{\mathrm{w}}}\right)
$$

Above equation is further simplified in ACI 371-98 as,

$$
\sigma_{c r}=\gamma C_{c} E\left(\frac{2 h_{w}}{d_{w}}\right)
$$

Where, $C_{C}$ is equal to 0.59 for Poisson's ratio of $0.20 . \gamma$ is a reduction factor equal to $1 / 6.6$ and it accounts for residual stresses and geometric imperfections along the length of element. $h_{W}$ is the wall thickness excluding architectural rustification and $d_{W}$ is the mean diameter of the shaft. In above equation $E$ is modulus of elasticity of the wall. In the 2008 edition of ACI-371, the parameter $\gamma C_{C}$ is replaced with $C$ which is calculated based on experiments on thin metal cylindrical members as follows,

$C=0.6[1.0-0.9(1.0-e-\theta)]$ Eq. 2.4 
where,

$$
\theta=0.0442 \sqrt{\frac{d_{w}}{h_{w}}}
$$

And $e$ is the load eccentricity. Critical buckling stress can be expressed as a function of specific compressive strength. Thus, the slenderness coefficient $\beta_{w}$ is calculated as,

$$
\beta_{w}=\frac{\gamma C_{c} E}{f^{\prime} c}\left(\frac{2 h}{d_{w}}\right) \leq 1
$$

Above equation is further simplified in ACI 371-08 by taking into account the long term modulus of elasticity due to creep. Also a compressive strength of $4.0 \mathrm{ksi}$ is considered in calculation. Therefore, ACI 371-08 suggests using following equation for limiting slenderness,

$$
\beta_{w}=80 \frac{h}{d_{w}} \leq 1
$$

As the height of the shaft increases, the possibility of overall column buckling also increases. Thus, the critical axial load capacity can be calculated as,

$$
\mathrm{P}_{\mathrm{cr}}=\pi^{2} \frac{\mathrm{EI}}{(\mathrm{kL})^{2}}
$$

\subsubsection{Accidental Eccentricities}

An additional reduction factor $\left(C_{w}=0.55\right)$ is recommended in ACI 371-98 for calculating vertical load capacity of cylindrical wall members to account for accidental eccentricity in loading of wall element originated from geometrical changes and imperfections and other disturbances. A $45 \%$ reduction in compressive force is deemed to be adequate for a 
compressive force that lies within Kern region of cross section (Mofid et al. 2000 and 2001) as shown in Figure 2.2.

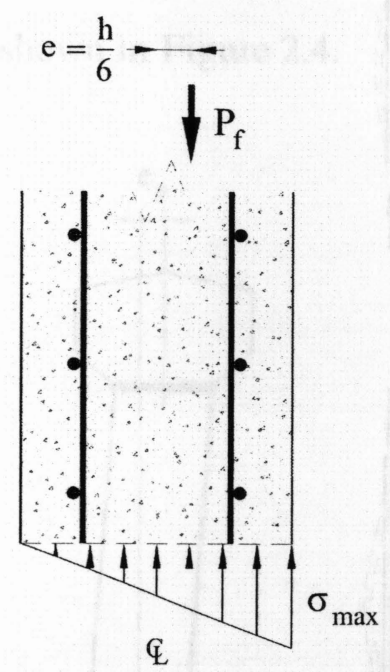

Figure 2.2 - Accidental eccentricity within Kern region

The parameter $C_{W}$ is later replaced by $C_{e}$ in ACI 371-08, which is calculated as,

$$
C_{e}=1-\frac{2 e}{h_{w}}
$$

where,

$0.56 \leq \mathrm{C}_{\mathrm{e}} \leq 0.80$

However, in many cases such as an eccentrically loaded ring beam, radial rotation of flexible raft foundation, eccentrically loaded annular ring foundation and differential settlement of concentrically loaded annular ring foundation, the actual accidental eccentricity in wall element may exceed the above value and must be calculated. (Figure 2.3) 


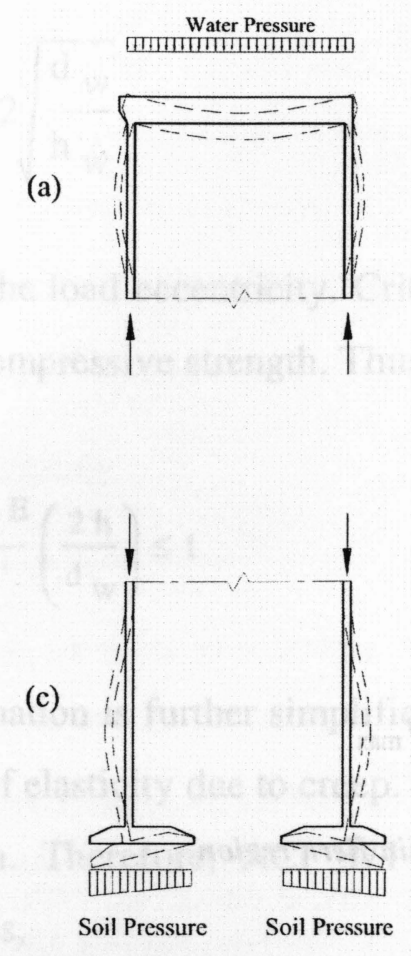

(b)

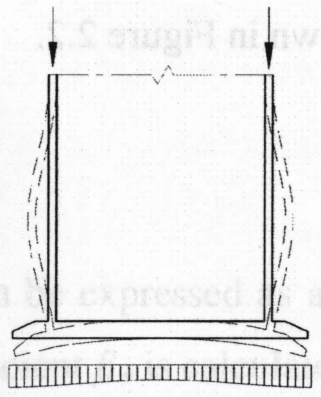

Soil Pressure

(d)

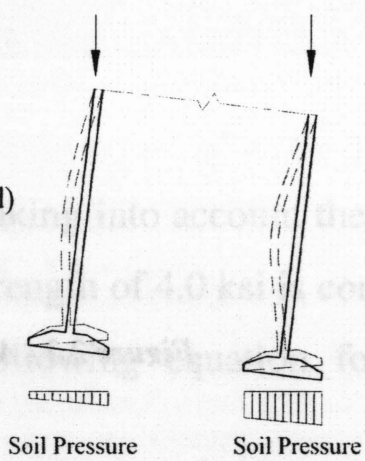

Figure 2.3 - Accidental moment created in concrete shaft: a) Torsional effects of eccentrically loaded ring beam, b) Radial rotation of flexible raft foundation attributed to ground settlement, $c$ ) Rotation of eccentrically loaded annular ring foundation in ground settlements, $d$ ) Rotation of concentrically loaded ring foundation as a result of differential settlements in non-homogeneous soil.

Allowing for accidental eccentricity and web buckling, ACI 371-98 limits the maximum nominal vertical load capacity per unit length of circumference $\left(P_{n w}\right)$ as follows,

$$
P_{n w}=\beta_{w} C_{w} f_{c}^{\prime} A_{w}
$$

Where, $\beta_{w}$ is the slenderness coefficient, $A_{W}$ is the gross cross-sectional area of unit length of the wall circumference, neglecting additional contribution from reinforcement. The equation for nominal axial strength is modified in ACI 371-08 to include the reinforcement as follows,

$$
\mathrm{P}_{\mathrm{nw}}=\mathrm{C}_{\mathrm{e}}\left[0.85 f_{c}^{\prime}\left(\mathrm{A}_{\mathrm{w}}-\mathrm{A}_{\mathrm{s}}\right)+f_{y} \mathrm{~A}_{\mathrm{s}}\right]
$$



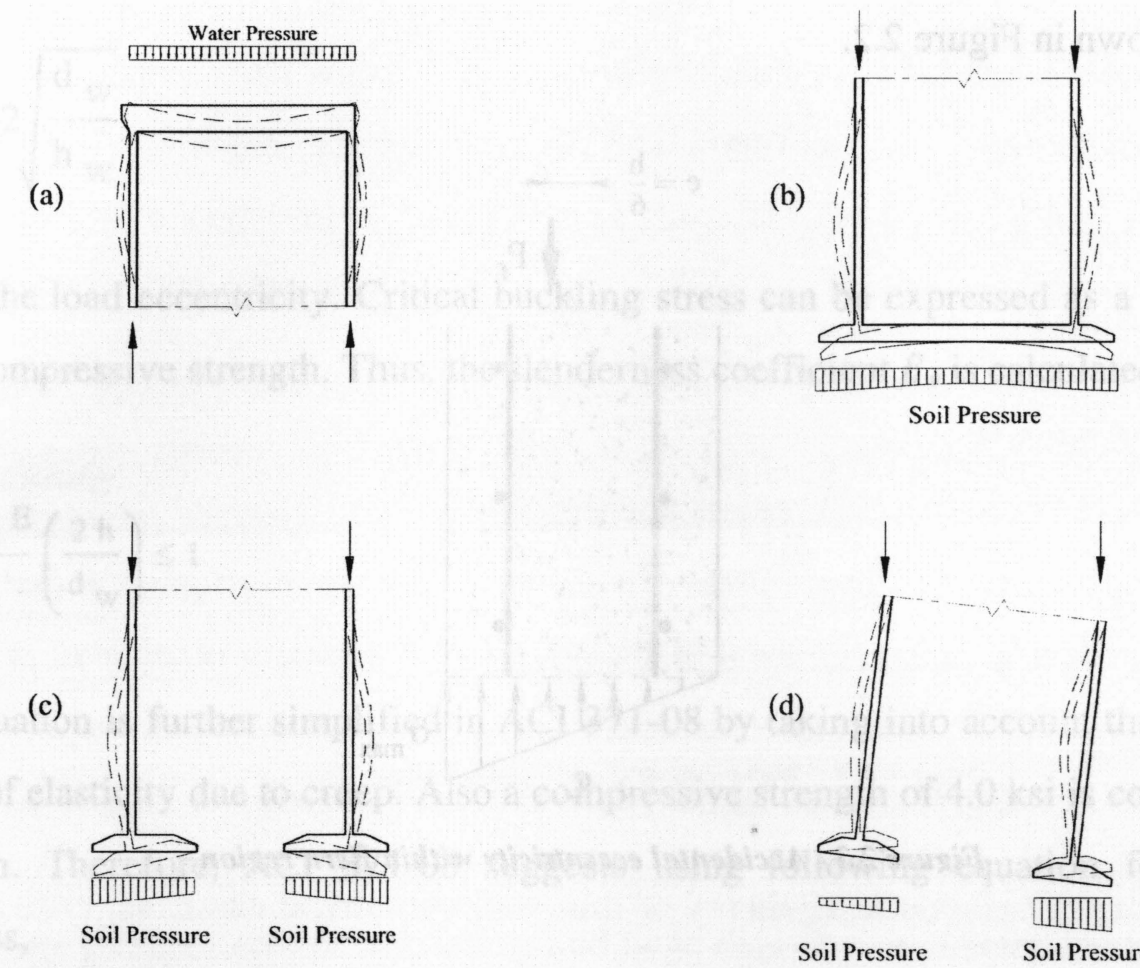

(d)

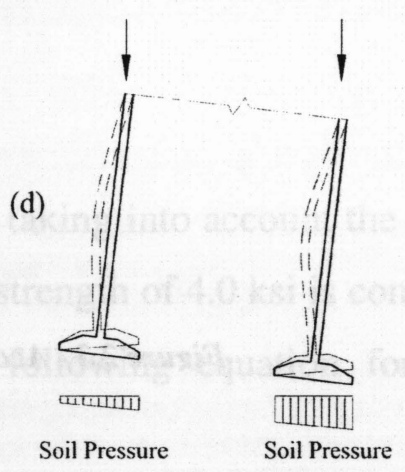

Figure 2.3 - Accidental moment created in concrete shaft: a) Torsional effects of eccentrically loaded ring beam, b) Radial rotation of flexible raft foundation attributed to ground settlement, $c$ ) Rotation of eccentrically loaded annular ring foundation in ground settlements, $d$ ) Rotation of concentrically loaded ring foundation as a result of differential settlements in non-homogeneous soil.

Allowing for accidental eccentricity and web buckling, ACI 371-98 limits the maximum nominal vertical load capacity per unit length of circumference $\left(P_{n w}\right)$ as follows,

$P_{n w}=\beta_{w} C_{w} f_{c}^{\prime} A_{w}$

Where, $\beta_{w}$ is the slenderness coefficient, $A_{W}$ is the gross cross-sectional area of unit length of the wall circumference, neglecting additional contribution from reinforcement. The equation for nominal axial strength is modified in ACI 371-08 to include the reinforcement as follows,

$\mathrm{P}_{\mathrm{nw}}=\mathrm{C}_{\mathrm{e}}\left[0.85 f_{c}^{\prime}\left(\mathrm{A}_{\mathrm{w}}-\mathrm{A}_{\mathrm{s}}\right)+f_{y} \mathrm{~A}_{\mathrm{s}}\right]$ 
The slenderness coefficient $\left(\beta_{w}\right)$ is not needed to be included in the calculation, as long as slenderness limit is not exceeded. ACI 371-08 also distinguishes three types of vertical load eccentricities initiate from construction errors that contribute to over turning moment in elevated water tower as shown in Figure 2.4.

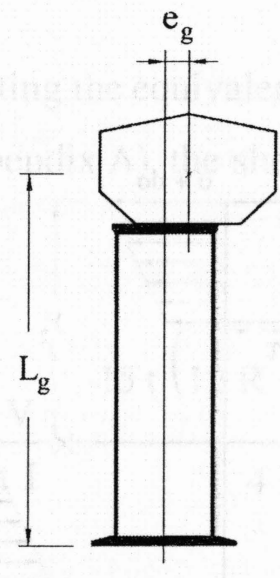

(a)

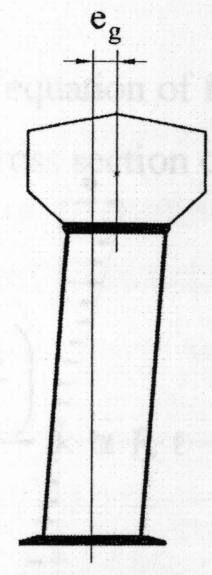

(b)

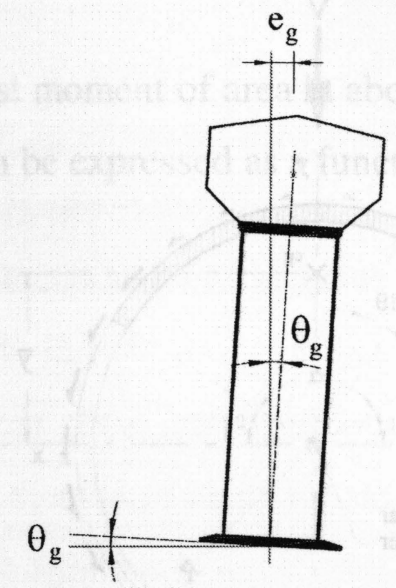

(c)

Figure 2.4-Types of vertical load eccentricity initiated from construction errors: a) Tank offset, b) Outof-Plumpness of staging, $c$ ) Tilted foundation.

While the first two types of eccentricity are arising from poor construction, the tilted foundation may also be initiated from differential settlement in non-homogenous soil condition. Thus, vertical load eccentricity can be calculated as follows to incorporate the described eccentricities.

$$
e_{g}=\mid \begin{aligned}
& e_{o}+\frac{L_{g}}{400} \geq \text { lin if } \tan \left(\theta_{g}\right) \leq \frac{1}{800} \\
& e_{o}+L_{g}\left(\frac{1}{800}+\tan \left(\theta_{g}\right)\right) \geq \operatorname{lin} \text { if } \tan \left(\theta_{g}\right)>\frac{1}{800}
\end{aligned}
$$

In above equation, $e_{o}$ is the minimum vertical accidental load eccentricity equal to $25 \mathrm{~mm}$, $L_{g}$ is the distance from base of the structure to the centroid of stored water 


\subsection{Shear distribution and Strength}

Following the fundamentals of mechanics of material, shear stress distribution in a thin wall cylindrical section can be determined through equilibrium of internal forces as shown in Figure 2.5.

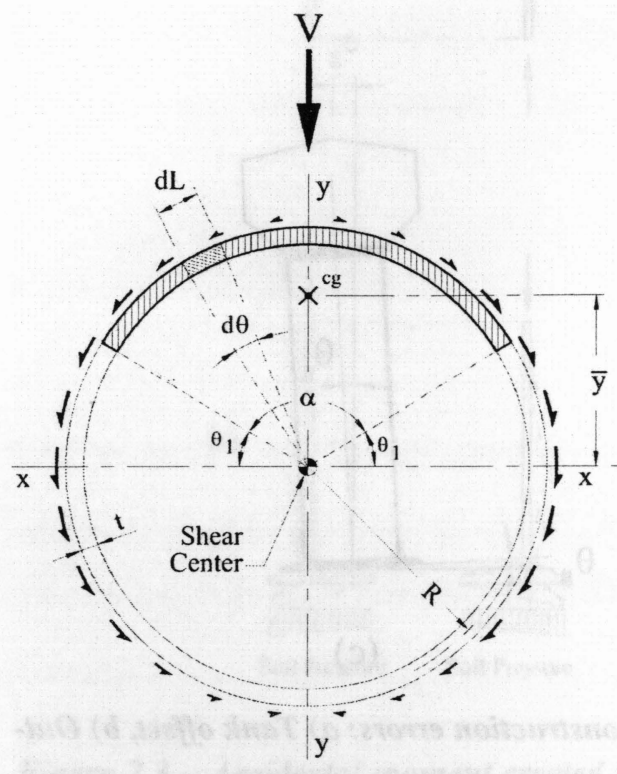

a)

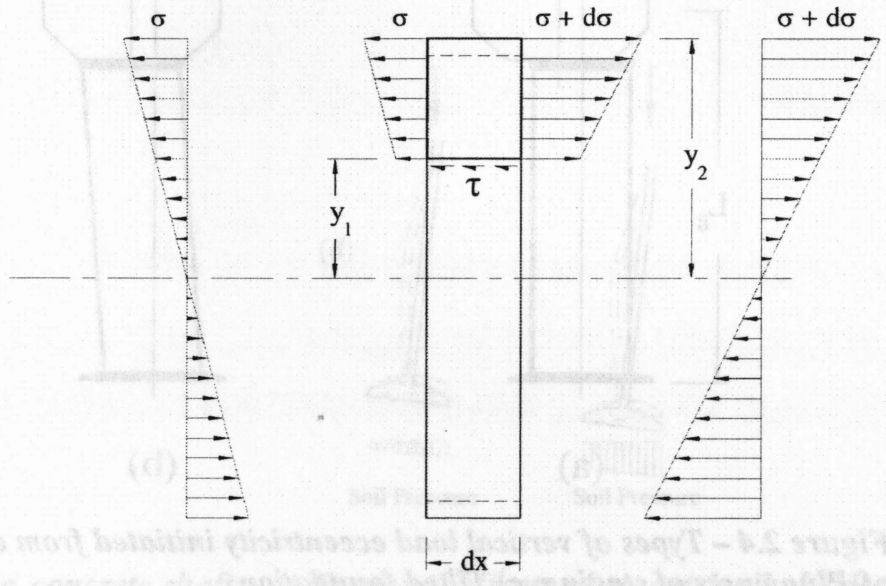

b)

Figure $2.5-a)$ Normal cross section of a thin wall cylindrical section, b) Variation of flexural stresses in cross section

Based on the variation of flexural stresses in two successive cross-sections of a thin wall cylindrical member as shown in Figure $2.5 \mathrm{~b}$, shear stress in the cross section can be calculated from equilibrium of the internal forces as follows,

$$
\int \sigma d A+2 \tau d x t=\int(\sigma+d \sigma) d A
$$

Flexural stresses can be expressed as function of bending moment. Thus, after substitution and further simplifications, the above equation can be re-written below,

$2 \tau d x t=\int \frac{d M \cdot y}{I} d A$ 
Variation of moment over length of the member $(d M / d x)$ is the equivalent of the shear force along the member. Thus, the above equation can be re-written as,

$$
\tau=\frac{V}{2 t I} \int y d A
$$

Substituting the equivalent parametric equation of first moment of area in above equation (See appendix A), the shear stress in cross section can be expressed as a function of $\alpha$ as follows,

$$
\tau(\alpha)=\frac{V}{t I} \times \frac{15 t\left(12 R+t^{2}\right)^{2} \sin \left(\frac{\alpha}{2}\right)}{4 R \pi \alpha} \times \alpha R t
$$

where, $V$ is the shear force applied at cross-section, $t$ and $R$ are mean thickness and radius of the cross-section.; $\alpha$ is the central angle corresponding to location of calculated shear stress. Theoretical calculation suggests a parabolic distribution of shear stresses over the depth of thin wall cylindrical cross-section as shown in Figure 2.6a.

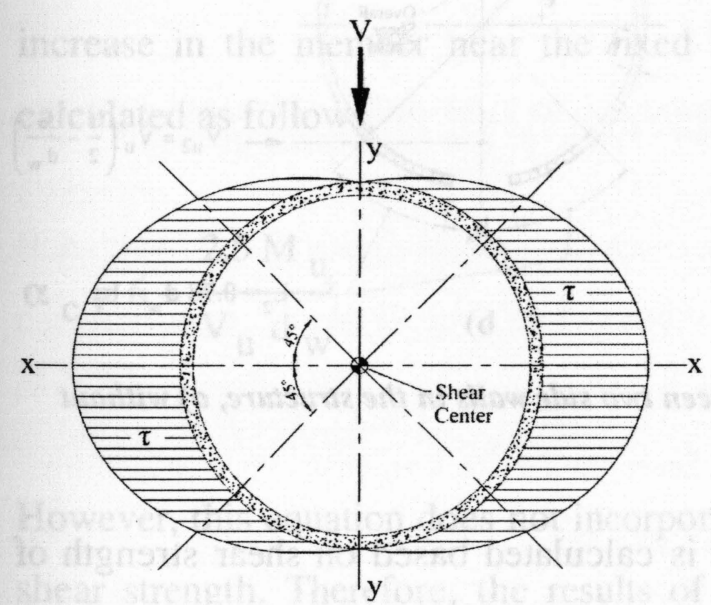

a)

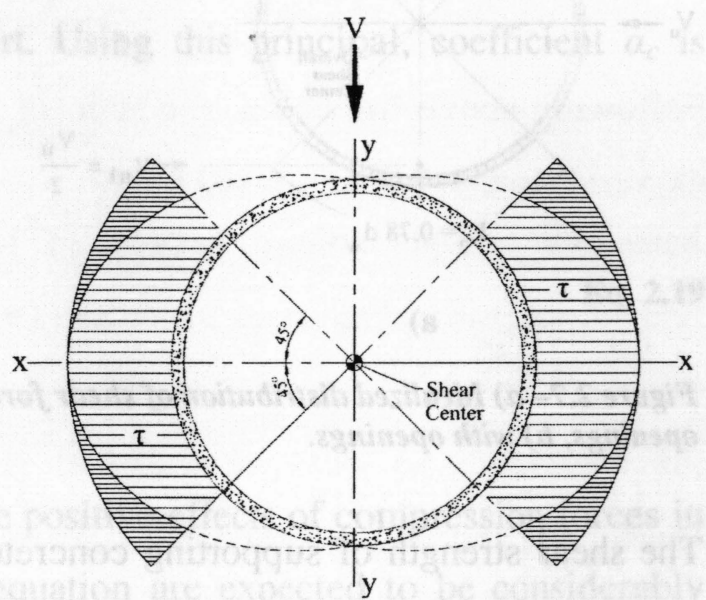

b)

Figure 2.6 - a) Theoretical shear stress distribution in thin wall cylindrical section, b) Idealized shear distribution recommended by ACI 371-08 
However, as recommended by ACI 371-08, shear stress distribution can be idealized as uniformly distributed over the middle half area of thin wall section as shown in Figure $2.6 \mathrm{~b}$. The length of thin wall section with uniformly distributed stress can be calculated as follows,

$\mathrm{L}=\frac{\pi}{2} \times \frac{\mathrm{d}_{\mathrm{w}}}{2}=0.785 \mathrm{~d}_{\mathrm{w}}$

In a cross section with no openings, the overall shear center of the cross section is located in the center of the cylinder, which aligns with the direction of the applied force. As a result, shear force is divided equally between two sides as shown in Figure 2.7a. In presence of openings, the overall shear center of the section is shifted from the center toward the un-interrupted wall; resulting a considerable eccentricity between line of action and center of shear resistance as shown in Figure 2.7b.

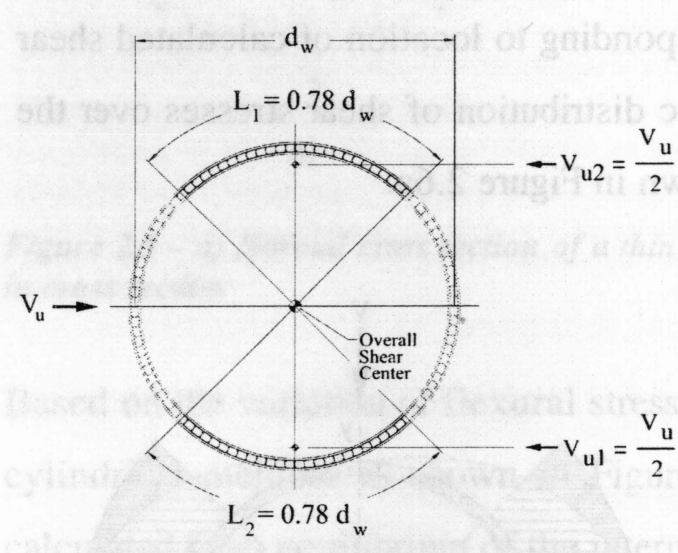

a)

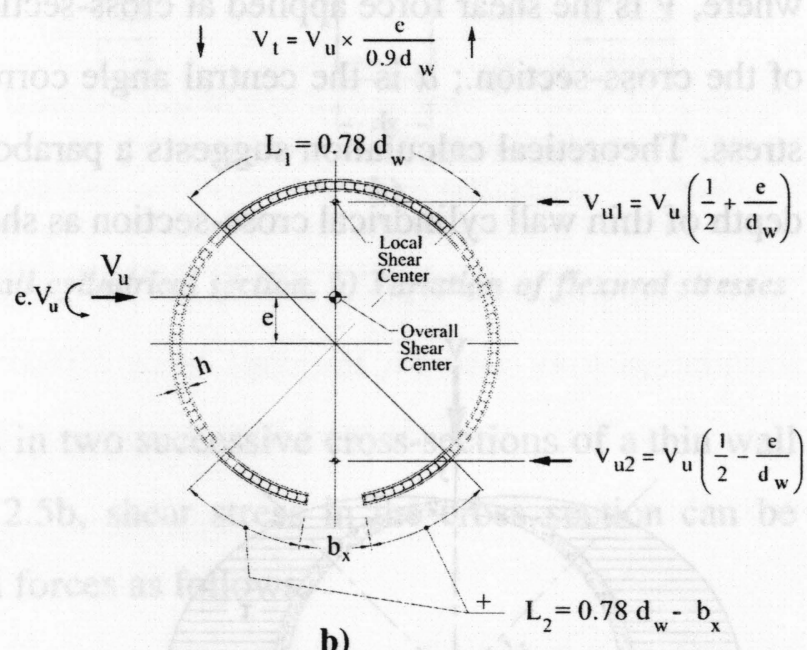

b)

Figure 2.7-a) Idealized distribution of shear force between two side walls in the structure, a) without openings, b) with openings.

The shear strength of supporting concrete wall is calculated based on shear strength of especial structural walls as recommended in ACI 318-08 where nominal shear strength $\left(V_{n}\right)$ is calculated as follows,

$v_{n}=A_{c v}\left(\alpha_{c} \lambda \sqrt{f^{\prime}}+\rho_{h} f_{y}\right)$ 
where, $A_{c v}$ is the gross area of wall cross-section. $\rho_{h}$ is the ratio of horizontal reinforcements. $f_{y}$ and $f_{c}^{\prime}$ are specific yield strength of reinforcement and specific compressive strength of concrete respectively. Shear coefficient $\alpha_{c}$ is a function of $h_{w} / L_{w}$ shown in Figure 2.8, which incorporates the effect of flexural stresses in shear strength.

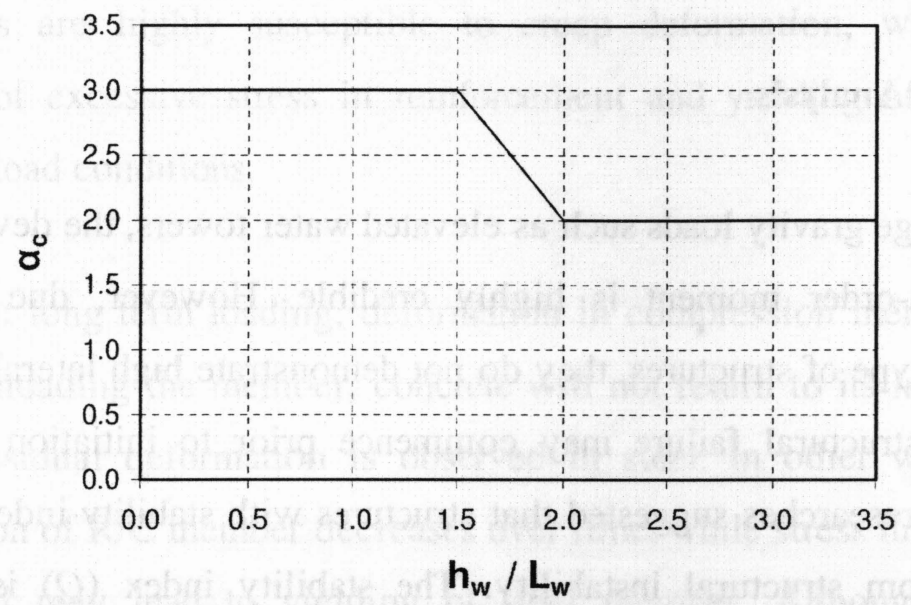

Figure 2.8- Variation of shear coefficient $\left(\alpha_{c}\right)$ over the ratio of height to width of shear wall

The shear cracks are generally tensile cracks in nature, since they appear in the member where the principal tensile stress exceeds the modulus of rupture of concrete. Thus, upon increasing the height of the wall, bending moment and consequently tensile stresses increase in the member near the fixed support. Using this principal, coefficient $\alpha_{c}$ is calculated as follows,

$$
\alpha_{c}=6-\frac{2.5 \mathrm{M}_{u}}{v_{u} d_{w}}
$$

However, this equation does not incorporate the positive effects of compression forces in shear strength. Therefore, the results of this equation are expected to be considerably conservative when predicting shear strength of concrete. This explains the minimal shear cracks and damages to the concrete shaft staging of affected water tower (Bhuj 2005 earthquake). To avoid the brittle shear failure in walls, ACI 371-08 limits the maximum shear strength of the wall section to $8 \sqrt{f_{c}^{\prime}} A_{c v}$ in un-disrupted section and to $10 \sqrt{f_{c}^{\prime}} A_{c v}$ 
in sections with openings. These limitations suggest that in case of additional required strength, the geometry of the concrete cross section must be increased rather than adding horizontal reinforcement.

\subsection{Second Order Analysis}

In structures with large gravity loads such as elevated water towers, the development of a considerable second-order moment is highly credible. However, due to thin wall construction of this type of structures, they do not demonstrate high lateral displacement capability and the structural failure may commence prior to initiation of secondary moment. Analytical researches suggested that structures with stability index $(Q)$ of more than $25 \%$ suffer from structural instability. The stability index $(Q)$ is the ratio of secondary moments to first-order moment as suggested by ACI 318-08 as follows,

$$
\mathrm{Q}=\frac{\sum \mathrm{P}_{\mathrm{u}} \Delta_{\mathrm{o}}}{\mathrm{v}_{\mathrm{us}} \mathrm{L}_{\mathrm{c}}} \leq 0.25
$$

Following above limitation, the ratio of total moment to first order moment must not exceed below 1.4 as expressed below,

$$
\frac{M_{1 \mathrm{st}}+M_{2 \mathrm{nd}}}{M_{1 \mathrm{st}}} \leq 1.4
$$

where $M_{1 s}$ and $M_{2 n d}$ are the first and second order moments respectively. 


\subsection{Creep}

Creep is a form of permanent deformation of concrete under long term compressive forces, which is believed to be due to re-arrangement and moving of hydration products in the concrete. Sustaining high level of compressive forces, the supporting structure of elevated tanks are highly susceptible to creep deformation, which may result in development of excessive stress in reinforcement and yielding of reinforcement bars under service load conditions.

Under constant long term loading, deformation in compression members increases over time. Upon unloading the member, concrete will not return to its initial length whereas little or no residual deformation is observed in steel. In other word, the stresses in concrete portion of $\mathrm{R} / \mathrm{C}$ member decreases over time, while stress in steel is significantly increasing and may lead to yielding of steel member. Although presence of high compressive stress in reinforcement may not be of much concern, reduction in compressive stress in concrete explains abundance of early flexural crack in the circumference of the shaft wall.

\subsection{Seismic Response of Elevated Water Towers}

Behavior of elevated water towers subjected to ground motion can be evaluated considering a Single Degree of Freedom (SDOF) system or as so called Single Lumped Mass Approximation as recommended by ACI 371-08, as long as the weight of water comprises $80 \%$ or more of total dead load of structure. In order to understand the behavior of this type of structures, the general dynamic equations of motion are studied (Clough and Penzien 2003, Chopra 1995 and Chen and Liew 2003) and briefly presented in Appendix B of this study. 


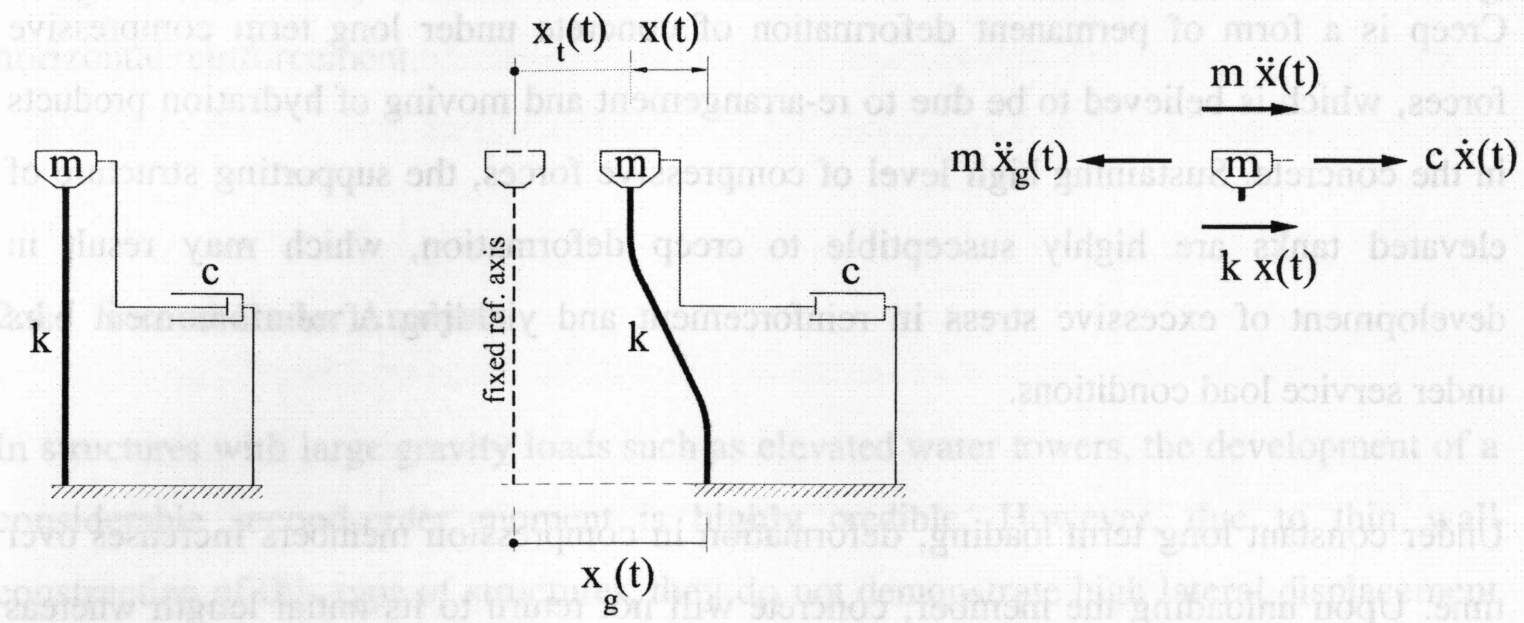

a)

b)

c)

Figure 2.9-a) Idealized single degree of freedom system and its basic dynamic components, b) Influence of ground excitation on the system, c) Equilibrium of dynamic forces in the system.

A SDOF system can be represented by three parameters: $m$ (mass), $\mathrm{k}$ (stiffness) and c (damping coefficient) as show in Figure 2.9a. Dynamic load, which is applied in the form of ground movement, initiates deformation in the structure shown in Figure2.9b. Based on dynamic equilibrium of forces, the dynamic equation of motion is expressed as follows,

$m \ddot{x}_{t}(t)+c \dot{x}(t)+k x(t)=0$

where, $\mathrm{x}(\mathrm{t}), \dot{\mathrm{x}}(\mathrm{t})$ and $\ddot{\mathrm{x}}_{\mathrm{t}}(\mathrm{t})$ are relative mass displacement, velocity and total mass acceleration, respectively. In above equation the inertial force generated by mass is a function of total acceleration, whereas velocity and damping forces are related to relative motion. The total acceleration comprises ground acceleration and relative acceleration as follows,

$\ddot{x}_{t}(t)=\ddot{x}_{g}(t)+\ddot{x}(t)$ 
Where, $\ddot{\mathrm{x}}_{\mathrm{g}}(\mathrm{t})$ and $\ddot{\mathrm{x}}(\mathrm{t})$ are ground acceleration and relative mass accelerations.

Substituting in above equation, the equilibrium of dynamic forces can be re-written as,

$$
m \ddot{x}(t)+c \dot{x}(t)+k x(t)=-m \ddot{x}_{g}(t)
$$

Using Duhamel integral, the relative displacement function of an under critically damped oscillating mass subjected to arbitrary acceleration applied to support can be calculated as follows,

$$
x(t)=\frac{1}{m \omega_{D}} \int_{0}^{t} P(\tau) \sin \left(\omega_{D}(t-\tau)\right) \cdot e^{-\xi \omega(t-\tau)} d \tau
$$

where, $\omega$ and $\omega_{D}$ are undamped and damped angular frequency of vibrations, respectively. $P(\tau)$ is time dependent dynamic load and $\xi$ is damping ratio. As suggested by numerical calculations, a subtle difference exists between $\omega$ and $\omega_{D}$ for low ratios of damping $(\xi<10 \%)$. Therefore, undamped angular frequency may be used in calculation. Since the amount of generated force in the oscillator's spring mechanism is ultimately controlled by maximum mass displacement $\left(f_{s_{-} \max }=k x_{\max }\right)$, therefore the maximum absolute value of response (or spectral relative displacement) can be calculated by maximizing displacement function as follows,

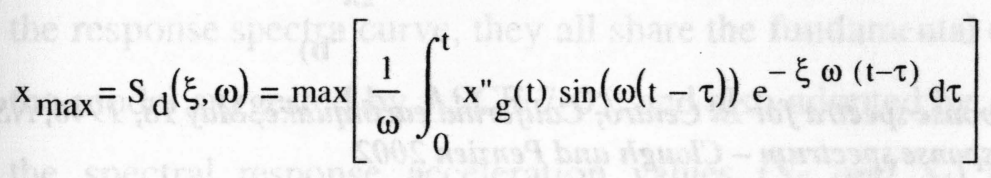

However, it is sometimes more convenient to calculate and use the maximum velocity and acceleration for a seismic excitation. In addition, presenting three parameters gives a better understanding of seismic nature. Having in mind the sinusoidal characteristics of free vibration function of a SDOF system (Gaberson 2007), a false maximum velocity as so called pseudo-velocity spectral response can be defined as follows,

$$
\mathrm{S}_{\mathrm{pv}}(\xi, \omega)=\omega \mathrm{S}_{\mathrm{d}}(\xi, \omega)
$$


Similarly, pseudo-acceleration spectral response is expressed as,

$$
\mathrm{S}_{\mathrm{pa}}(\xi, \omega)=\omega \mathrm{S}_{\mathrm{pv}}(\xi, \omega)
$$

Numerical calculations suggest that above equations are true for damping ratios less than $20 \%$ which is the case in most structures. Since, a simple linear relationship can be established between response parameters, they can also be illustrated simultaneously in a response spectrum graph shown in Figure 2.10a. As suggested by Newmark and Hall (1982), response spectrum curve can be normalized for peak ground acceleration of $1.00 \mathrm{~g}$ considering the scalar relation between response spectrum curve and maximum response acceleration, velocity and displacement shown in Figure $2.10 \mathrm{~b}$.

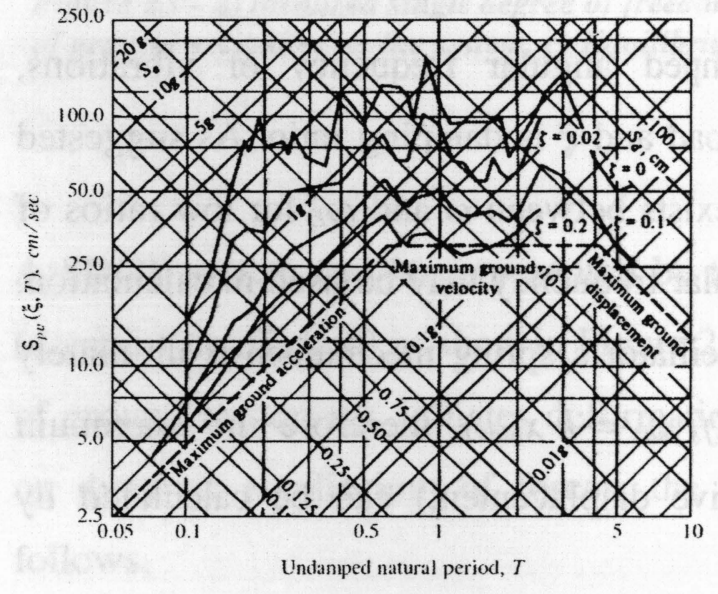

a)

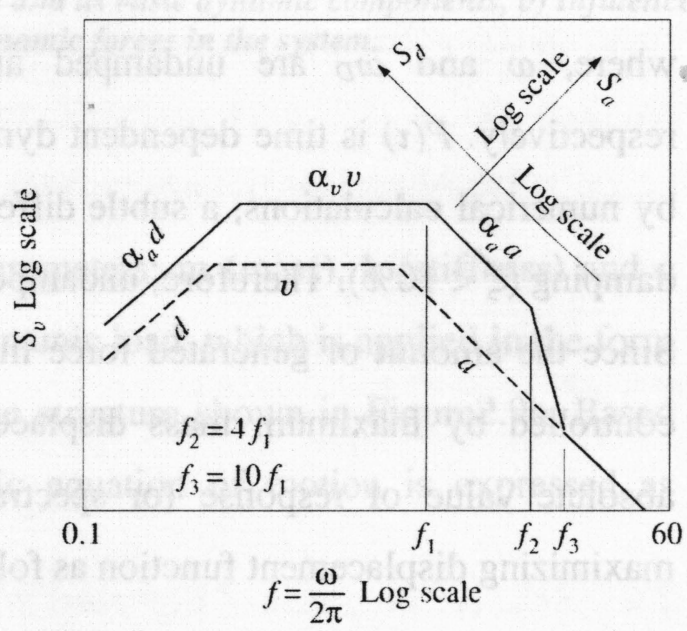

b)

Figure 2.10 - a) Pseudo-velocity response spectra for El Centro, California earthquake, May 18, 1940, NS component, b) Normalized design response spectrum - Clough and Penzien 2002

Considering historical and geological data, a design response spectrum is constructed for every region for rock-site conditions, which often includes a conservative damping coefficient. The response spectral curve is then amplified for different soil properties, for seismic acceleration increases as soil gets softer. This behavior can be explained by the basic theory of elastic layer suggested by Finn and Wightman (2003) and adopted in NBCC 2005 as follows,

$$
A=\frac{1}{\kappa+\beta_{\mathrm{s}} \frac{\pi}{2}}
$$


where $\beta_{s}$ is the critical damping ratio and $\kappa$ is the impedance ratio. As appears in above equation, upon decreasing the impedance ratio (stiffness), the seismic wave which is assumed to be propagating from rock layer is also amplified as shown in Figure 2.11a. However, as earthquake intensity increases, the hysteretic damping of soil also increases and shear capacity decreases. Therefore for very high ground accelerations the soil losses the capacity to transfer seismic wave (Idriss 1990) as shown in Figure 2.11b.

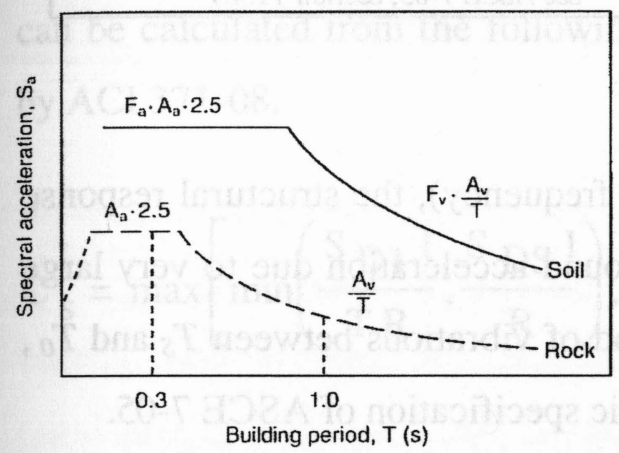

a)

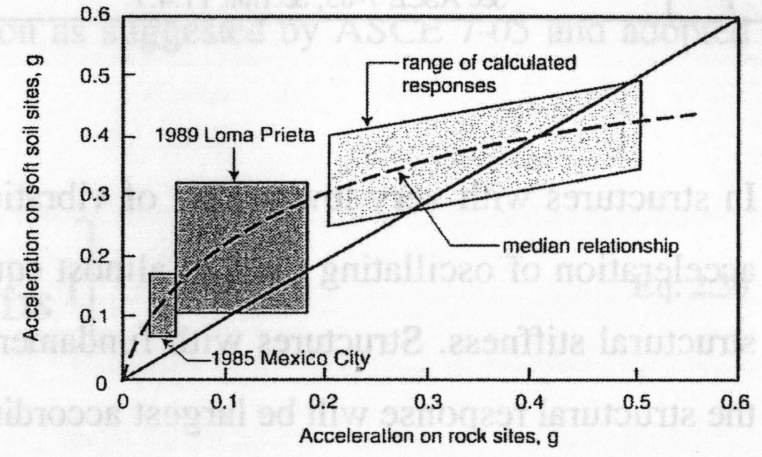

b)

Figure 2.11 - a) Design spectra based on period-dependant site amplification factors, Building Seismic Safety Council (1995), b) Acceleration on soft soil and associated rock sites, Idriss (1990) - User's Guide NRCC/NBC (2005)

Although different building codes prescribe a slightly different procedure for constructing the response spectra curve, they all share the fundamental concept as described before. In the model suggested by ASCE 7-05, and also adopted by ACI 371-08 and IBC 05, using the spectral response acceleration values $\left(S_{S}\right.$ and $\left.S_{l}\right)$ for structures with period of vibration of $0.2 \mathrm{~s}$ and $1.0 \mathrm{~s}$, and considering specified regional long period of vibration $\left(T_{L}\right)$ the design response acceleration spectra is determined after applying soil amplification factors $F_{v}$ and $F_{a}$. The mapped spectral response parameters $\left(S_{D S}\right.$ and $\left.S_{D I}\right)$ are available for site class B, which represents rock-site condition. Calculated response is then amplified or reduced based on local soil condition as shown in Table 2.1. 
Table 2.1 - Mapped maximum considered earthquake spectral response acceleration parameters, $F_{a}$ and $F_{v}$ for different soil conditions.

\begin{tabular}{|c|c|c|c|c|c|c|c|c|c|c|}
\hline \multirow{2}{*}{ Site Class } & \multicolumn{3}{|c|}{$\begin{array}{c}\text { Mapped Maximum Considered Earthquake Spectral } \\
\text { Response Acceleration Parameter }\left(F_{\mathrm{a}}\right) \text { at Short Period }\end{array}$} & \multicolumn{2}{c|}{$\begin{array}{c}\text { Mapped Maximum Considered Earthquake Spectral } \\
\text { Response Acceleration Parameter }\left(F_{\mathrm{v}}\right) \text { at 1- }\end{array}$} \\
\cline { 2 - 12 } & $\mathrm{S}_{\mathrm{S}} \leq 0.25$ & $\mathrm{~S}_{\mathrm{S}}=0.50$ & $\mathrm{~S}_{\mathrm{S}}=0.75$ & $\mathrm{~S}_{\mathrm{S}}=1.00$ & $\mathrm{~S}_{\mathrm{S}} \geq 1.25$ & $\mathrm{~S}_{\mathrm{S}} \leq 0.25$ & $\mathrm{~S}_{\mathrm{S}}=0.50$ & $\mathrm{~S}_{\mathrm{S}}=0.75$ & $\mathrm{~S}_{\mathrm{S}}=1.00$ & $\mathrm{~S}_{\mathrm{S}} \geq 1.25$ \\
\hline $\mathrm{A}$ & 0.8 & 0.8 & 0.8 & 0.8 & 0.8 & 0.8 & 0.8 & 0.8 & 0.8 & 0.8 \\
\hline $\mathrm{B}$ & 1.0 & 1.0 & 1.0 & 1.0 & 1.0 & 1.0 & 1.0 & 1.0 & 1.0 & 1.0 \\
\hline $\mathrm{C}$ & 1.2 & 1.2 & 1.1 & 1.0 & 1.0 & 1.7 & 1.6 & 1.5 & 1.4 & 1.3 \\
\hline $\mathrm{D}$ & 1.6 & 1.4 & 1.2 & 1.1 & 1.0 & 2.4 & 2.0 & 1.8 & 1.6 & 1.5 \\
\hline $\mathrm{E}$ & 2.5 & 1.7 & 1.2 & 0.9 & 0.9 & 3.5 & 3.2 & 2.8 & 2.4 & 2.4 \\
\hline $\mathrm{F}$ & \multicolumn{3}{|c|}{ See ASCE 7-05, Section 11.4 .7} & \multicolumn{6}{c|}{ See ASCE 7-05, Section 11.4.7 } \\
\hline
\end{tabular}

In structures with very low period of vibration (high frequency), the structural response acceleration of oscillating mass is almost equal to ground acceleration due to very large structural stiffness. Structures with fundamental period of vibrations between $T_{S}$ and $T_{0}$, the structural response will be largest according seismic specification of ASCE 7-05.

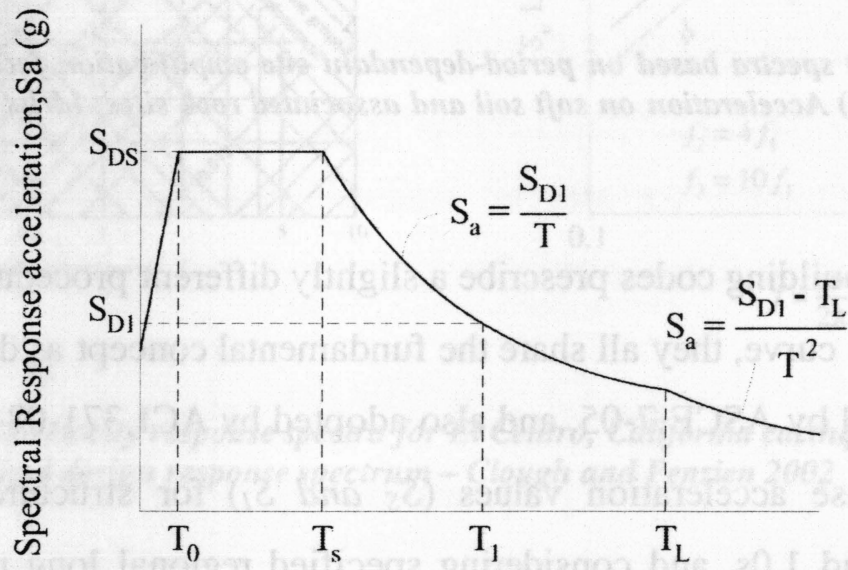

Period, T (s)

Figure 2.12- Spectral acceleration responses curve as specified in ASCE 7 - 2005

A similar process is followed for design spectrum calculation in NBCC 2005, where five mapped acceleration responses; $S_{a}(0.2 s), S_{a}(0.5 s), S_{a}(1.0 s)$, and $S_{a}(2.0 s)$ are available for different regions of Canada which suggests a more accurate estimation of seismic characteristics. 
Once the design spectrum is established, the design spectral acceleration that corresponds to the period of vibration of structure can be determined. In a SDOF system approach, the fundamental period of vibration of structure is used to calculate the elastic response. Where, the period of vibration is calculated based on un-cracked cross-section which exhibits linear elastic behavior as suggested ASCE 7-05. A similar approach is used in ACI 371-08, NBCC 05 and EuroCode 1998 since elastic period of vibration can be easily calculated using established techniques in mechanics of material. Subsequently, the seismic response coefficient which determines the base shear for elevated water tower can be calculated from the following equation as suggested by ASCE 7-05 and adopted by ACI 371-08.

$$
\mathrm{C}_{\mathrm{S}}=\max \left[\min \left(\frac{\mathrm{S}_{\mathrm{D} 1} \mathrm{I}}{\mathrm{T} \mathrm{R}}, \frac{\mathrm{S}_{\mathrm{DS}} \mathrm{I}}{\mathrm{R}}\right), 0.044 \mathrm{~S}_{\mathrm{DS}} \mathrm{I}\right]
$$

In above equation, $I$ is the importance factor, $\mathrm{T}$ is the fundamental period of vibration. $S_{D S}$ and $S_{D 1}$ are the parameters of design acceleration response spectra for short period and $1.0 \mathrm{~s}$ period structures, respectively. Also, $R$ is the seismic reduction factor for elevated water towers which is explained in next section.

\subsection{Seismic Reduction/Modification Factor $(\boldsymbol{R})$}

As customary in the building codes of many developed countries, seismic forces are calculated for structures at their elastic state, which is then adjusted for non-elastic response by applying a reduction factor. Seismic reduction factor $(R)$ as so called in north American building Code or structural behavior factor $(q)$ in Eurocode-8 or structural performance coefficient $(C)$ in Chinese Code, symbolizes many structural characteristic such as ductility, energy absorption, redundancy, etc. However, the main feature in this parameter is ductility which is obtained from large non-linear deformation of structure. Since seismic load are normally categorized as rare loads, it is economical to use every bit of strength available in the structure. Hence, the influence of all structural strength is 
taken in to consideration in a study done by Mitchell el at. (2005) which is later adopted in NBCC-06. In this study, the effects of different structural characteristics are recognized through two major components as follows,

$$
\mathrm{R}=\mathrm{R}_{\mathrm{d}} \mathrm{R}_{\mathrm{O}}
$$

Where, $R_{d}$ is ductility related modification factor and $R_{o}$ is modification factor arising from over strength of structure, which is defined as:

$\mathrm{R}_{\mathrm{o}}=\mathrm{R}_{\text {size }} \mathrm{R}_{\phi} \mathrm{R}_{\text {yield }} \mathrm{R}_{\text {sh }} \mathrm{R}_{\text {mech }}$

In above equation $R_{\text {size }}$ incorporates the effects of larger section geometry in commercially available members. $R_{\varphi}$ reverses the reduction in strength arising from material reduction factor and is equal to $1 / \varphi$. $R_{\text {yield }}$ accounts for conservatively labeled yield strength in materials. $R_{s h}$ is the strain-hardening factor that may develop over large deformations. $R_{\text {mech }}$ accounts for extra strength in the system prior to development of a collapse mechanism. As indicated by Mitchell et al (2005), the last parameter may only be considered in structures that are redundant and yielding in its component occurs one after another.

Applying the ductility related seismic reduction factors $\left(R_{d}\right)$ to the structure is expected to reduce the spectral elastic base shear $\left(V_{e}\right)$ to the yielding strength level $\left(V_{y}\right)$ as shown in Figure 2.13a. However, a considerable amount of reserved strength still exists in the system, which would be overlooked if structure was designed for calculated yield strength $\left(V_{y}\right)$. Therefore, using a proper secondary reduction factor $\left(R_{d}\right)$ the design base shear is further reduced, allowing for structure to achieve the ultimate structural strength during a major earthquake. A portion of seismic force reduction is also attributed to structural damping $\left(R_{\xi}\right)$ as specified by Applied Technology Council (ATC-19 95), since structures usually do not poses a significant natural damping properties $(\xi \leq 5 \%)$, and its effect is usually integrated in calculation of seismic acceleration response spectra. 


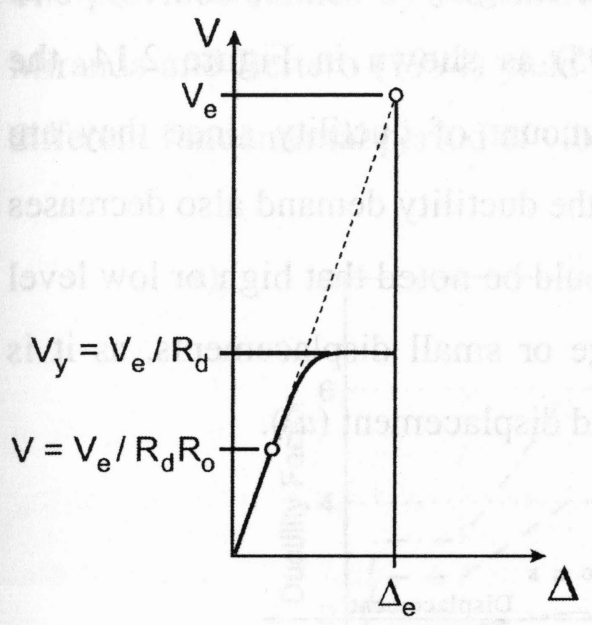

a)

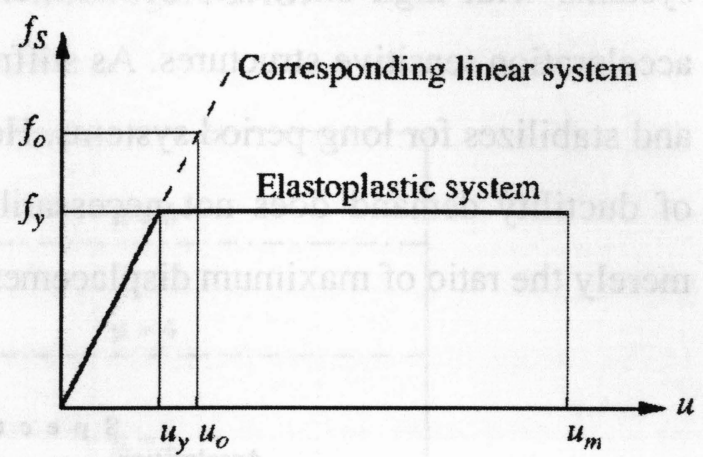

b)

Figure $2.13-a)$ Calculation of design seismic base shear based on reduced elastic response of stature, Mitchell el at. (2005), b) Elastoplastic system and its corresponding linear system, Chopra (1995)

The ductility related modification factor $\left(R_{d}\right)$ is the most important component of seismic force modification factor $(R)$, which is in direct relationship with inelastic deformation of structure In an elastoplastic idealization of structural response as shown in Figure 2.13b, considering the peak elastic response $\left(f_{o}\right)$ and its corresponding elastic displacement $\left(u_{o}\right)$, along with the yield strength $\left(f_{y}\right)$ and displacement $\left(u_{y}\right)$, the yield reduction factor $(R y)$ can be defined as follows,

$$
R_{y}=\frac{f_{o}}{f_{y}}=\frac{u_{o}}{u_{y}}
$$

Although, there is limited stiffness available in the system beyond yield strength, the elastoplastic system will momentarily accommodate the seismic load through exhibiting a large inelastic deformation $\left(u_{m}\right)$ until the direction of loading is reversed. The ratio of maximum deformation $\left(u_{m}\right)$ to yield displacement $\left(u_{y}\right)$ is called ductility demand and is defined as follows,

$\mu_{\mathrm{d}}=\frac{\mathrm{u}_{\mathrm{m}}}{\mathrm{u}_{\mathrm{y}}} \leq \mu_{\mathrm{c}}$ 
Investigating the variation of ductility demand for four category of elastoplastic systems subjected to El Centro Earthquake by Chopra (1995) as shown in Figure 2.14, the systems with high stiffness; demand an extensive amount of ductility since they are acceleration sensitive structures. As stiffness reduces, the ductility demand also decreases and stabilizes for long period systems. However, it should be noted that high or low level of ductility demand does not necessarily means large or small displacements, as it is merely the ratio of maximum displacement $\left(u_{m}\right)$ to yield displacement $\left(u_{y}\right)$.

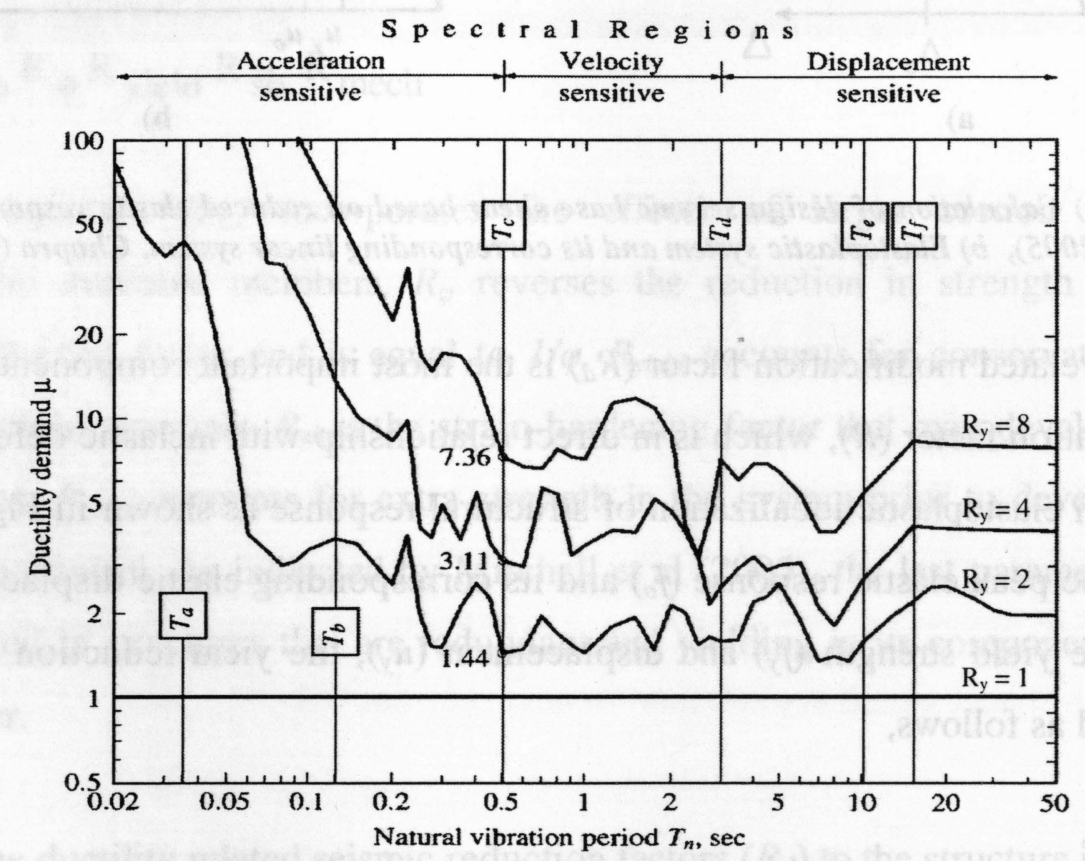

Figure 2.14 - Ductility demand spectra in four elasto-plastic systems with yield reduction factors of $R_{y}=1,2,4$ and 8, subjected El Centro earthquake - Chopra 1995

Since limited amount of ductility is available in a system the ductility demand must remain bellow the ductility capacity during an episode of ground excitation. Thus, many experimental and numerical studies have been done in the past to establish a relationship between ductility related modification factor $\left(R_{\mu}\right)$ and elastic period of vibration of structure $\left(T_{e}\right)$ with fixed value of ductility demand $\left(\mu_{d}\right)$. 
The previous studies by Newmark and Hall (1982), Nassar and Krawinkler (1991) and Miranda and Bertero (1994) yield similar results for variation of ductility factor $\left(R_{\mu}\right)$ for different fundamental period of vibrations as shown in Figure 2.15.

a)

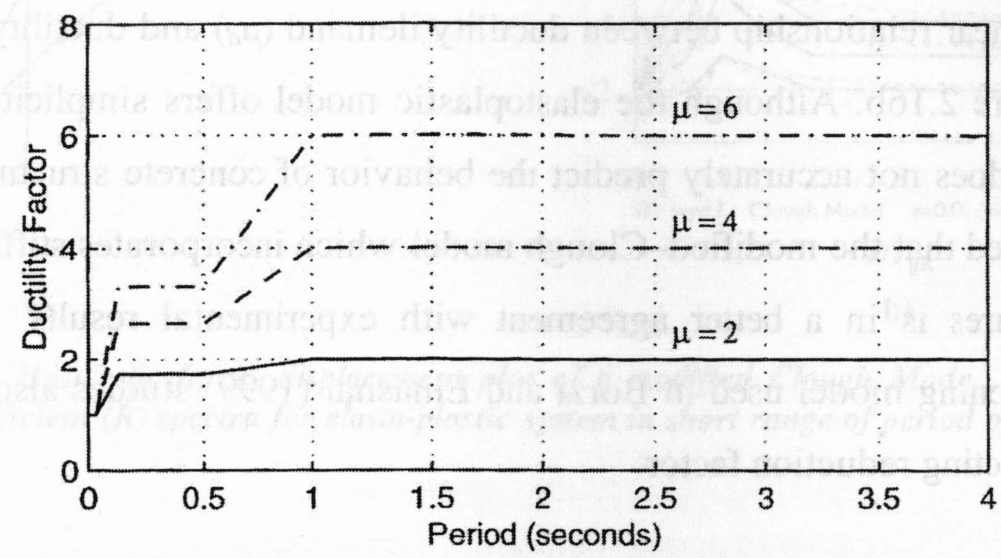

b)

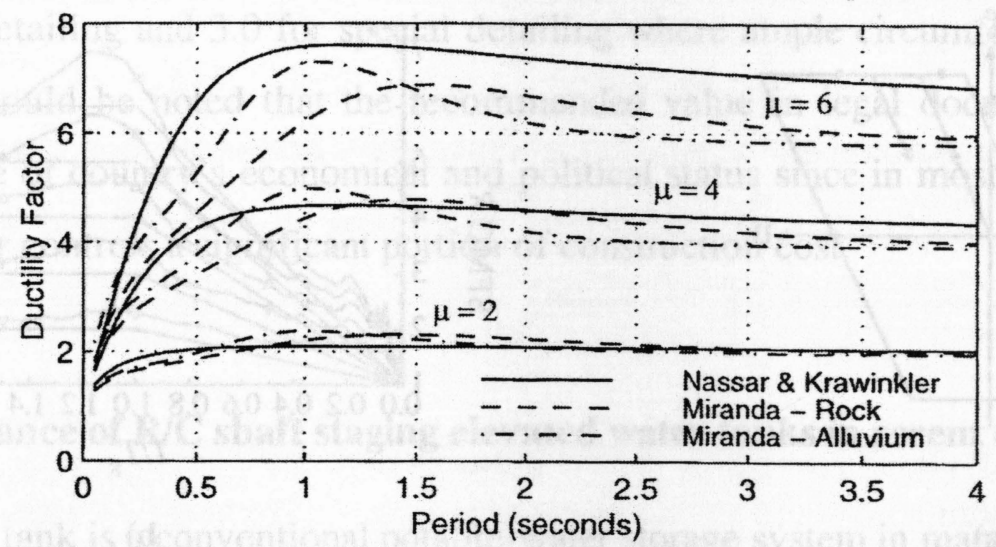

Figure 2.15- Variation of ductility factor $\left(R_{\mu}\right)$ over a range period of vibrations $(T)$ for fixed ductility demands ( $\mu$ ), a) Newmark and Hall (1982), b) Nassar and Krawinkler (1991) and Miranda and Bertero (1994)

In a similar study by Vidic et al. (1994) and Fajfar (1995), the relationship between ductility demand for elasto plastic systems and seismic reduction factor is expressed as follows,

$$
R_{\mu}=\mid \begin{aligned}
& 1+\left(\mu_{d}-1\right) \frac{T}{T_{g}} \text { if } 0 \leq T \leq T_{g} \\
& \mu_{d} \text { if } T \geq T_{g}
\end{aligned}
$$


where, $T$ is the fundamental period of vibration, $T_{g}$ is the characteristic period of ground movement which represents the fundamental period of vibration of a $5 \%$ damped structure with the highest spectral acceleration response. Numerical studies by Tong et al (2005) using 374 earthquake records on elastoplastic systems (Figure 2.16a) also supports the linear relationship between ductility demand $\left(\mu_{d}\right)$ and ductility factor $\left(R_{\mu}\right)$ as shown in Figure 2.16b. Although the elastoplastic model offers simplicity to numerical calculation, it does not accurately predict the behavior of concrete structures. Saidi et al (1981) suggested that the modified-Clough model which incorporates stiffness degrading in $\mathrm{R} / \mathrm{C}$ structures is in a better agreement with experimental results. The hysteretic hardening-softening model used in Borzi and Elnashai (1999) studies also yields similar results in predicting reduction factor.

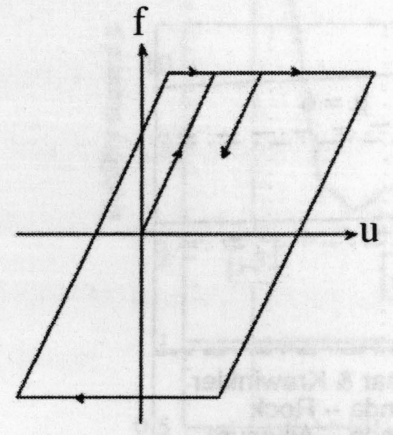

a)
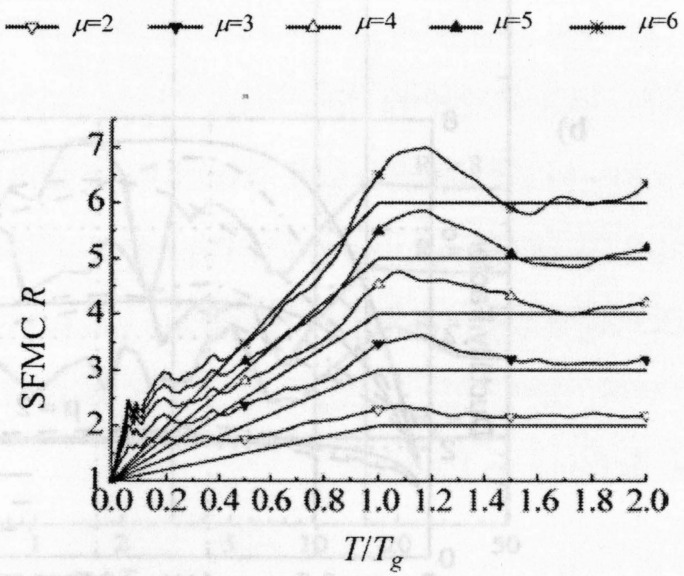

b)

Figure 2.16 - a) Hysteretic force- displacement plot of a elasto-plastic model, b) Seismic force modification coefficient $(R)$ spectra for elasto-plastic system in short range of period of vibration, Tong

In a recent study, Tong et al (2005) points out that a significant jump is expected in the calculated spectrum for R-factor using modified-Clough model as shown in Figure 2.17a, which is most of the time eliminated in direct averaging process used by pervious researchers. The rise in the suggested spectrum as shown in Figure 2.17b, appears where the period of vibration $(T)$ is in the vicinity of characteristic period of ground motion $\left(T_{g}\right)$ in different soil conditions. This is believed to be due to the resonance of large displacement characteristics of structure with seismic wave, which leads to a significant increase in efficiency of seismic reduction. 


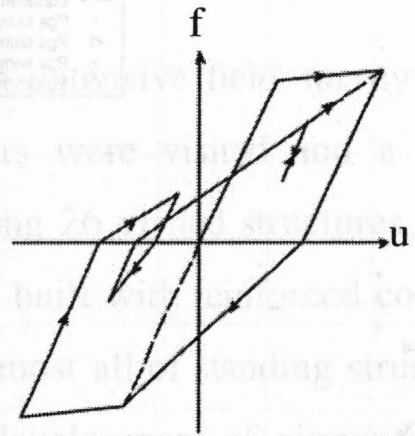

a)

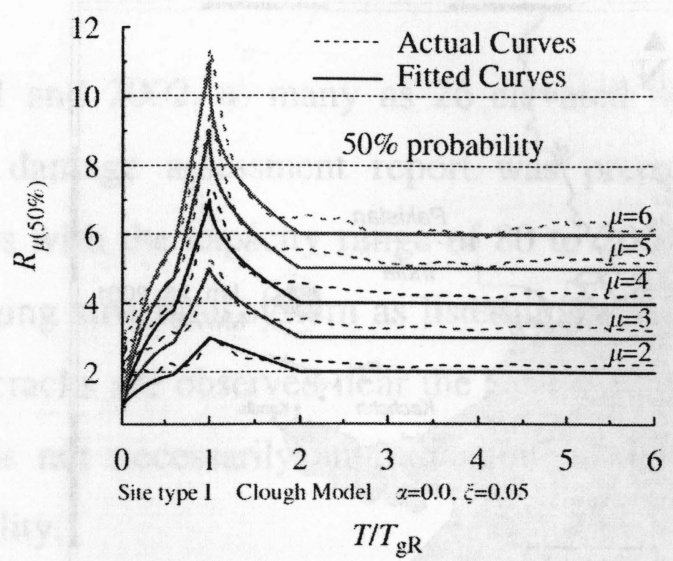

b)

Figure 2.17 - a) Hysteretic force- displacement plot of a modified Clough Mode,, b) Seismic force modification coefficient $(R)$ spectra for elasto-plastic system in short range of period of vibration, Tong et al (2007)

Seismic reduction factor $(R)$ for R/C elevated towers is specified as 2.0 in ASCE 7-05 for conventional detailing and 3.0 for special detailing where ample circumferential ties are provided. It should be noted that the recommended value in legal documents may be under influence of country's economical and political status since in most cases, seismic reduction factor controls a significant portion of construction cost.

\subsection{Performance of $\mathrm{R} / \mathrm{C}$ shaft staging elevated water tanks in recent earthquakes}

Elevated water tank is a conventional potable-water storage system in many rural areas of India. Following the Bhuj earthquakes in January 26, 2001, several water towers experienced minor to severe damages and in some cases damages led to total collapse of structure. The epicenter of that earthquake was determined to be at $65 \mathrm{~km}$ North-East of city of Bhuj in Gujarat province with a relatively large magnitude $\left(M_{W}\right)$ of 7.6 as shown in Figure 2.18a. Although, the seismic waveform was not recorded through special seismographic instruments, the seismic data was generated and analyzed using the data registered through other geological accelerometers by Iyengar and Kanth (2002). The analysis suggests a maximum Peak Ground Acceleration (PGA) value of $0.34 \mathrm{~g}$ EastWest, $0.38 \mathrm{~g}$ North-East directions and $0.38 \mathrm{~g}$ vertically in Bhuj area as shown in Figure $2.18 b$. 


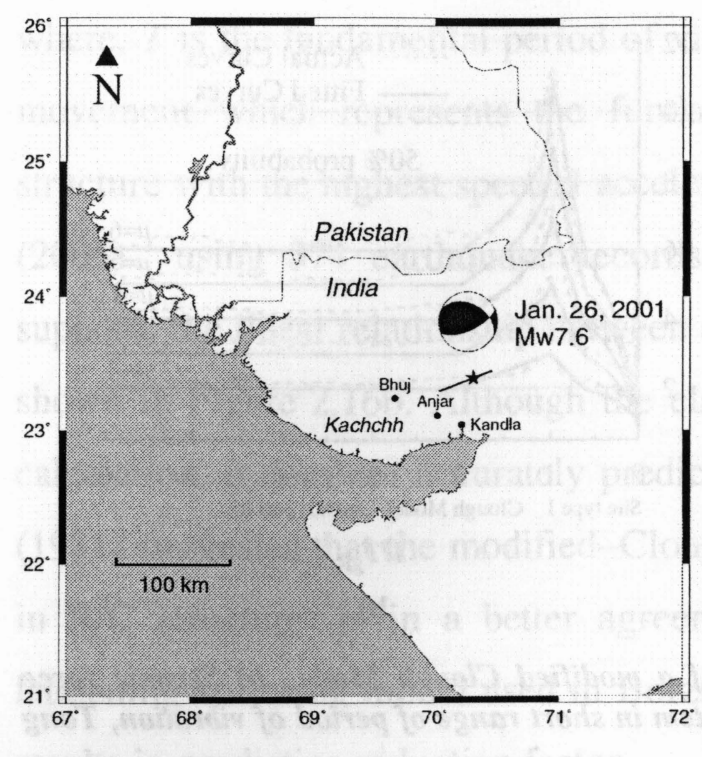

a)

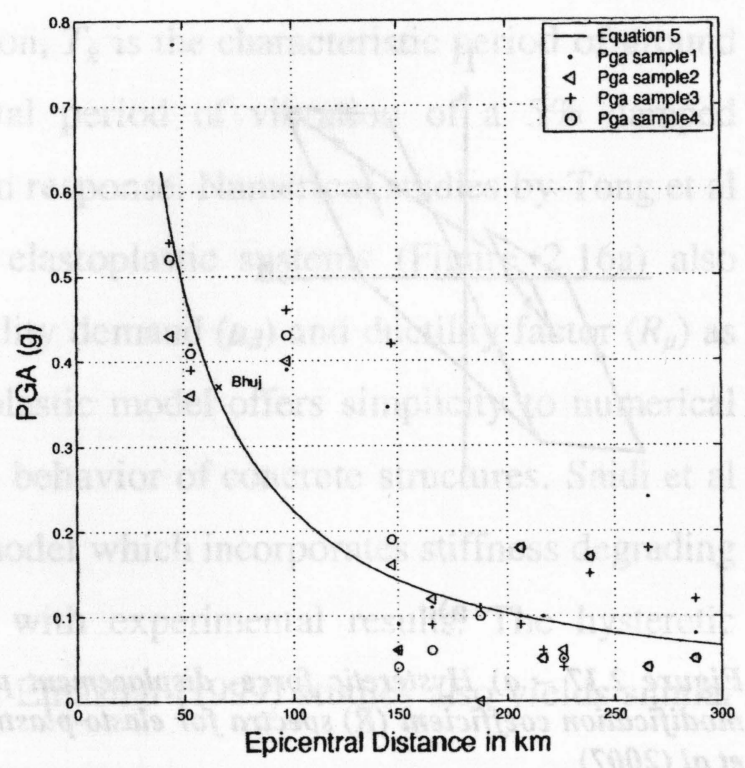

b)

Figure 2.18 - a) Epicenter of Bhuj 2001 earthquake ( $\star$ ) at Gujarat province in India. Straight line indicated the pseudo-fault direction and length as identified by Yagi and Kikuchi (2001) and Hough et al (2002), b) Scale of Peak Ground Acceleration (PGA) in the city of Bhuj and surrounding area, Iyengar and Kanth (2002), Iyengar and Kanth (2002)

Even though the earthquake lasted 200 seconds, $98 \%$ of energy was released in first 70 seconds. The energy content of seismic waveform in vertical and two orthogonal directions were determined by calculating elastic response spectra as shown in Figure 2.19 .
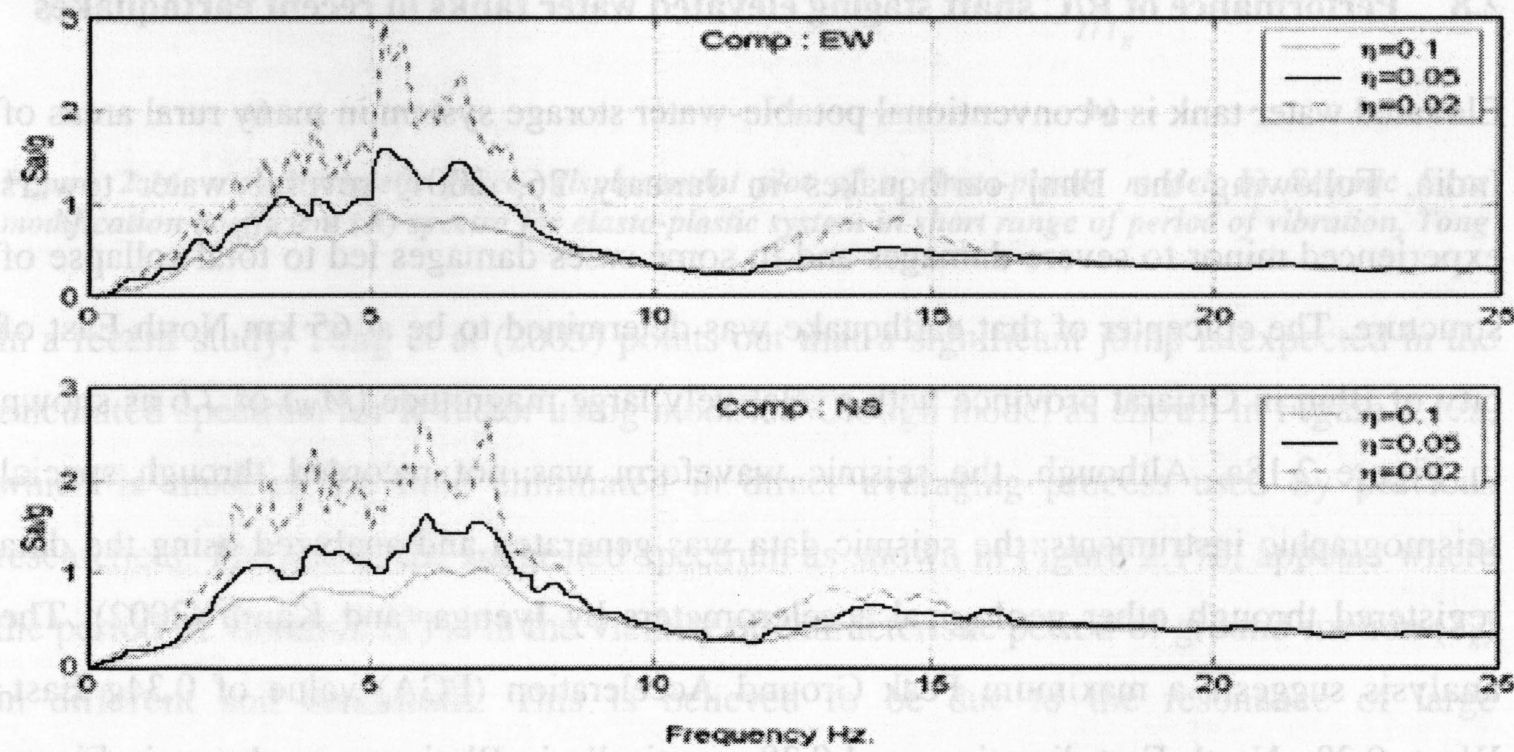

Figure 2.19 - Seismic acceleration response spectra in East-West, North-East and vertical, directions for three different damping ratios: $\eta=10 \%, 5 \%$ and $2 \%$ - Iyengar and Kanth (2002) 
In an extensive field survey by Rai in 2001 and 2002, as many as 26 elevated water towers were visited and a comprehensive damage assessment report was prepared. Among 26 visited structures, 19 water towers with the capacity range of 80 to $2000 \mathrm{~m}^{3}$ were built with reinforced concrete shaft staging structural system as listed in Table 2.2. In almost all of standing structures, flexural cracks are observed near the base. Although the development of circumferential cracks is not necessarily an indication of flaw, it promotes the probability of flexural vulnerability.

Table 2.2 - Summary of damage assessment for 19 RC shaft staging elevated towers affected by Bhuj 2001 earthquake - Rai (2001)

\begin{tabular}{rlrrrl} 
№ & Location & $\begin{array}{c}\text { App. Dis. From } \\
\text { Epicenter } \mathbf{( k m )}\end{array}$ & $\begin{array}{r}\text { Capacity } \\
\left(\mathbf{m}^{3}\right)\end{array}$ & $\begin{array}{r}\text { Approximate } \\
\text { Water Level }(\%)\end{array}$ & Observed Damage \\
\hline 1 & Bhachau & 5 & 200 & 0 & Cracks \\
2 & Chobari & 20 & 265 & 50 & Collapsed \\
3 & Samakhili & 20 & 80 & 0 & Cracks \\
4 & Anjar & 45 & 1000 & 33 & Cracks up to $1 / 4$ shaft \\
5 & Sapeda & 45 & 100 & $?$ & Cracks near Base \\
6 & Khiari & 47 & 100 & 80 & Cracks near Base \\
7 & Gala & 55 & 300 & 0 & Cracks near Base \\
8 & Bhindiari & 73 & $?$ & $?$ & Collapsed \\
9 & Gamardi & 76 & 200 & $?$ & Cracks near Base \\
10 & Bhuj Railway station & 75 & 200 & $?$ & Cracks near Base \\
11 & Bhuj mahadeo & 75 & 300 & $?$ & Cracks near Base \\
12 & Bhuj Campground & 75 & 100 & 100 & No Crack \\
13 & Chopadwawa & 77 & 1000 & 0 & Cracks near Base \\
14 & Morabi & 80 & 500 & 0 & Cracks up to 3/4 shaft \\
15 & Sitada & 90 & 150 & 100 & Cracks near Base \\
16 & Varahi & 115 & 650 & 0 & Cracks \\
17 & Sami & 130 & 1000 & $?$ & Cracks near Base \\
18 & Sami Village & 130 & $?$ & $?$ & Collapsed \\
19 & Chansama & 148 & 2000 & 100 & No Crack
\end{tabular}

Rai (2001) re-evaluates the strength of selected shaft staging's and compares the results with code recommended design loads. In his analysis, Rai used SDOF model as it is acceptable by applicable design codes. Cracking moment $\left(M_{c r}\right)$ was estimated using the following simplified equation, 
$f_{t}=\frac{-\gamma P}{2 \pi r t}+\frac{M_{c r}}{\pi r^{2} t}$

Eq. 2.36

In above equation, $\gamma$ is load factor which is taken as 0.9 since the effects of gravity loads $(P)$ is in favor of cracking moment, and $r$ is the mean radius of the wall and $t$ is wall thickness. The tensile strength of concrete $\left(f_{t}\right)$ is calculated as follows,

$f_{t}=0.7 \sqrt{f_{c k}}$

Where, $f_{c k}$ is the characteristic strength of concrete as per Indian Standard (IS). Rai (2001) concludes that the ultimate flexural strength of shaft calculated based on Pinfol (1989) is not significantly larger that the cracking moment. Hence, the cracking moment is a fair estimation of ultimate flexural strength for comparison as presented in Table 2.3

Table 2.3-Geometrical and mechanical properties of 8 RC shaft staging elevated water tanks affected bv Bhui 2001 earthauake-Rai 2001

Tank Geometry

Empty Tank

Full Tank

\begin{tabular}{|c|c|c|c|c|c|c|c|c|c|c|c|c|}
\hline № & Location & $C\left(m^{3}\right)$ & $R(m)$ & $t(m)$ & $H(m)$ & $H / R$ & $T(s)$ & $M_{c r}(M N . m)$ & $\mathrm{V}_{\mathrm{cr}} / \mathrm{W}_{\mathrm{s}}$ & $T(s)$ & $M_{c r}(M N . m)$ & $\mathrm{V}_{\mathrm{cr}} / \mathrm{W}_{\mathrm{s}}$ \\
\hline 1 & Anjar & 1000 & 3.800 & 0.225 & 16.0 & 34.2 & 0.26 & 44.00 & 0.45 & 0.44 & 60.80 & 0.20 \\
\hline 2 & Chopadwawa & 1000 & 4.000 & 0.250 & 14.6 & 3.7 & 0.24 & 54.30 & 0.46 & 0.34 & 72.00 & 0.25 \\
\hline 3 & Morabi & 500 & 3.300 & 0.200 & 16.0 & 4.8 & 0.31 & 30.10 & 0.37 & 0.40 & 37.40 & 0.23 \\
\hline 4 & Gala & 300 & 1.830 & 0.125 & 20.0 & 10.9 & 1.02 & 7.76 & 0.11 & 1.30 & 10.20 & 0.08 \\
\hline 5 & Chobari & 265 & 2.250 & 0.130 & 10.5 & 4.7 & 0.25 & 10.60 & 0.38 & 0.34 & 13.30 & 0.22 \\
\hline 6 & Bhachau & 200 & 2.000 & 0.150 & 11.0 & 5.5 & 0.28 & 8.00 & 0.33 & 0.38 & 9.76 & 0.20 \\
\hline 7 & Sapeda & 100 & 1.500 & 0.150 & 12.5 & 8.3 & 0.39 & 4.50 & 0.25 & 0.51 & 5.16 & 0.16 \\
\hline 8 & Samakhili & 80 & 1.375 & 0.175 & 11.5 & 8.4 & 0.36 & 4.25 & 0.28 & 0.45 & 4.73 & 0.19 \\
\hline
\end{tabular}

The shear strength of the structure was calculated in accordance with ACI 371-98 considering wall openings and torsional effects. Based on dynamic properties of the water tower, the seismic demand was calculated according to International Building Code IBC 2000 and Indian Standard IS: 1893 (1984, 1998 and 2002) as shown in Figure 2.20. As analysis reveals, while all investigated water towers were well above seismic demand based on IS:1893 (1984), none of them meet the strength requirement of IBC 2000, which explains excessive crack pattern observed on shaft circumference. 


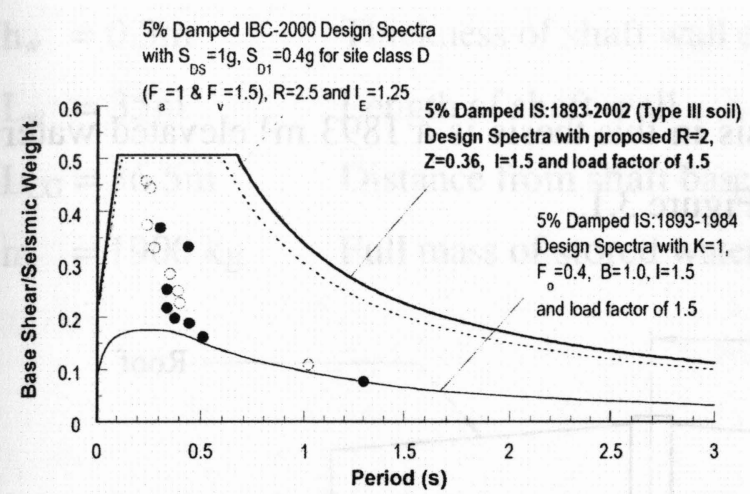

a)

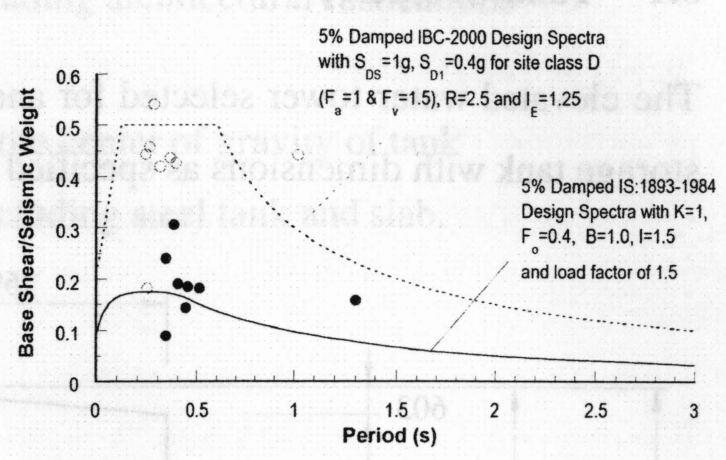

b)

Figure 2.20 - Seismic demand spectra of IBC 2000, IS:1983 (1984 and 2002), compared to lateral load resistant of the structure in empty $(\circ)$ and full $(\bullet)$ conditions based on available: a) Flexural strength and b) Shear strength - Rai (2001)

Rai (2001) concludes that IS: 1893 (1984) over-estimated the ductility of shaft staging and allowed for higher reduction factor. If the supporting structure of elevated water towers had been deigned precisely up to the Code recommended level of seismic demand, far greater damage and destructions would have been seen in aftermath of Bhuj earthquake. In the latest version of Indian code the R-factor is reduced to 2.0 following IBC 2000 . 


\section{DESIGNING THE SUPPORTING STRUCTURE OF ELEVATED WATER TOWER}

\subsection{Tank Geometry}

The elevated water tower selected for analysis in this thesis is a $1893 \mathrm{~m}^{3}$ elevated water storage tank with dimensions as specified in Figure 3.1.

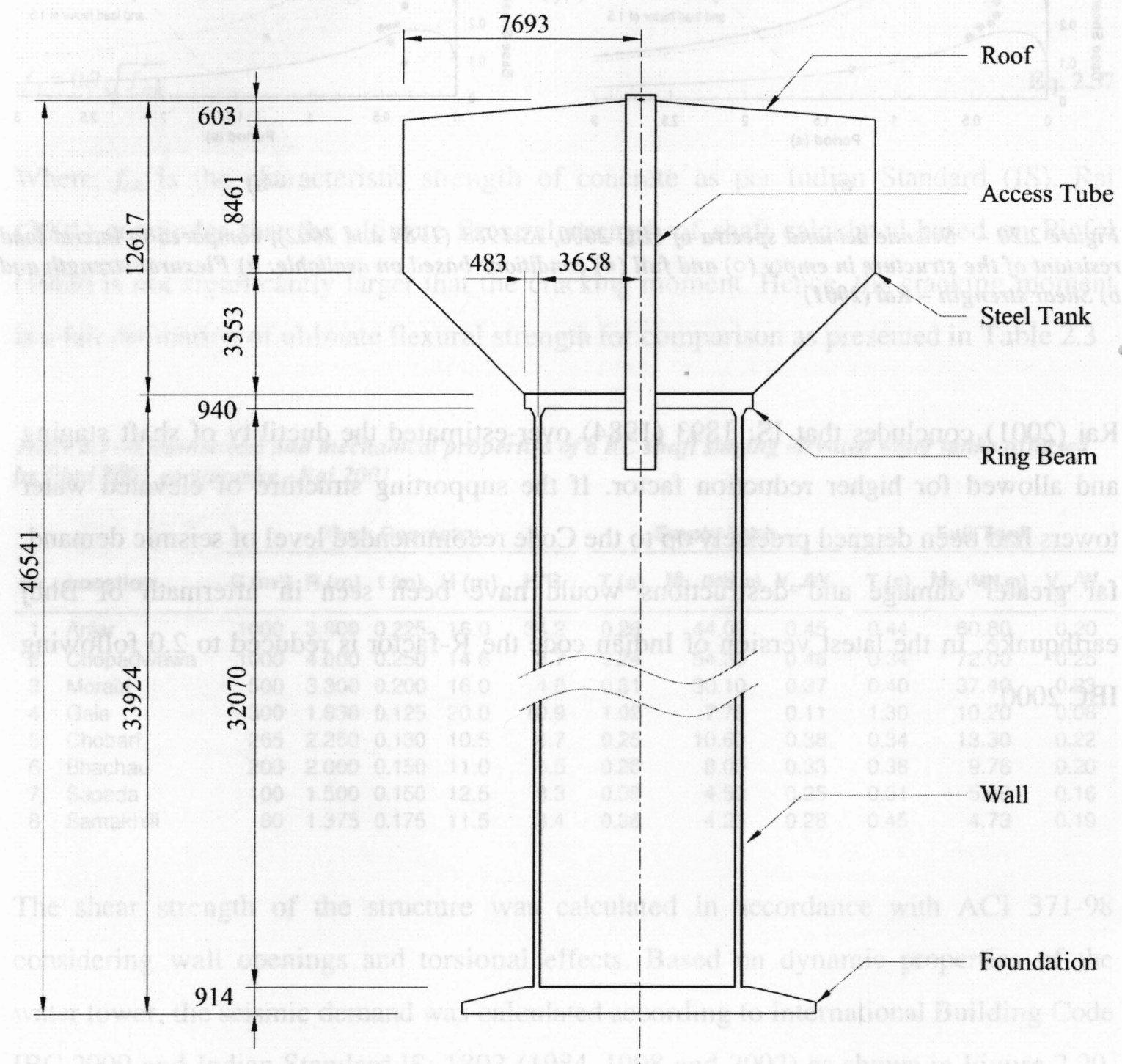

Figure 3.1 - Vertical cross section of studied composites elevated water tower.

Based on actual dimensions of the structure as specified in Figure 3.1, the key design parameters are determined and rounded-up for simplifications as expressed below, 


$$
\begin{array}{ll}
\mathrm{d}_{\mathrm{w}}=7.5 \mathrm{~m} & \text { Mean diameter of shaft wall } \\
\mathrm{h}_{\mathrm{w}}=0.3 \mathrm{~m} & \text { Thickness of shaft wall excluding architectural rustications } \\
\mathrm{L}_{\mathrm{w}}=35 \mathrm{~m} & \text { Length of shaft wall } \\
\mathrm{L}_{\mathrm{CG}}=36.5 \mathrm{~m} & \text { Distance from shaft base to the center of gravity of tank } \\
\mathrm{m}=1900 \mathrm{~kg} & \text { Full mass of stored water including steel tank and slab. }
\end{array}
$$

\subsection{Earthquake Loads}

Using seismic ground motion and long period transition maps available from ASCE 72005 , mapped spectral response acceleration parameters $\left(S_{S}\right.$ and $\left.S_{l}\right)$ were selected for an active region in San Francisco area in United States as $1.0 \mathrm{~g}$ and $0.57 \mathrm{~g}$ respectively. Once regional seismic parameters were selected, elastic seismic acceleration spectrum was determined for rock-site condition following the procedure prescribed in ASCE 7-05 and ACI 371-08 as described in Appendix C. Elastic response spectra was then adjusted to incorporate the importance factor of $(I)$ of 1.5 and seismic reduction fact $(R)$ of 2.0 , as recommended for concrete shaft staging as follows,

$$
\mathrm{C}_{\mathrm{S}}=\max \left[\min \left(\frac{\mathrm{S}_{\mathrm{D} 1} \mathrm{I}}{\mathrm{T} \mathrm{R}}, \frac{\mathrm{S}_{\mathrm{DS}} \mathrm{I}}{\mathrm{R}}\right), 0.044 \mathrm{~S}_{\mathrm{DS}} \mathrm{I}\right]=0.22
$$

Once seismic shear coefficient $\left(C_{S}\right)$ was calculated, the design base shear was determined as follows.

$$
\mathrm{V}_{\mathrm{d}}=\mathrm{C}_{\mathrm{s}} \times \mathrm{W}_{\text {Gravity }}=5.67 \mathrm{MN}
$$

Calculated design base shear $\left(V_{\text {total }}\right)$ is then used to determine lateral load, shear and overturning moment at each level of shaft as shown in Table 3.1. 
Table 3.1 - Calculated lateral load, shear and over-turning moment at each level of shaft

\begin{tabular}{cccccc}
$\mathbf{i}$ & $\mathbf{L}_{\mathbf{i}}(\mathbf{m})$ & $\mathbf{W}_{\mathbf{i}}(\mathbf{k N})$ & $\mathbf{F}_{\mathbf{i}}(\mathbf{k N})$ & $\mathbf{V}_{\mathbf{i}}(\mathbf{k N})$ & $\mathbf{M}_{\mathbf{i}}(\mathbf{M} \mathbf{N} \cdot \mathbf{m})$ \\
\hline 1 & 41.500 & 19,350 & 4,340 & 4,340 & 101.9 \\
2 & 32.964 & 848 & 190 & 4,530 & 122.8 \\
3 & 27.893 & 848 & 190 & 4,720 & 135.3 \\
4 & 22.821 & 848 & 190 & 4,910 & 147.7 \\
5 & 17.750 & 848 & 190 & 5,101 & 160.2 \\
6 & 12.679 & 848 & 190 & 5,291 & 172.6 \\
7 & 7.607 & 848 & 190 & 5,481 & 185.1 \\
8 & 2.536 & 848 & 190 & 5,671 & 197.5
\end{tabular}

\subsection{Design for Earthquake Loads}

After axial and lateral loads were determined, the vertical and horizontal reinforcements were designed accordingly as described in Appendix D. The theory of short columns was used to calculate the stress distribution in the cross section based on MacGregor (1997) and Nawy (2005). In order to simplify manual calculations, the longitudinal reinforcements which are usually placed in two wall-layers (i.e. inner and outer layers) were replaced with an equivalent steel ring, maintaining the same longitudinal reinforcement ratio as shown in Figure 3.2.

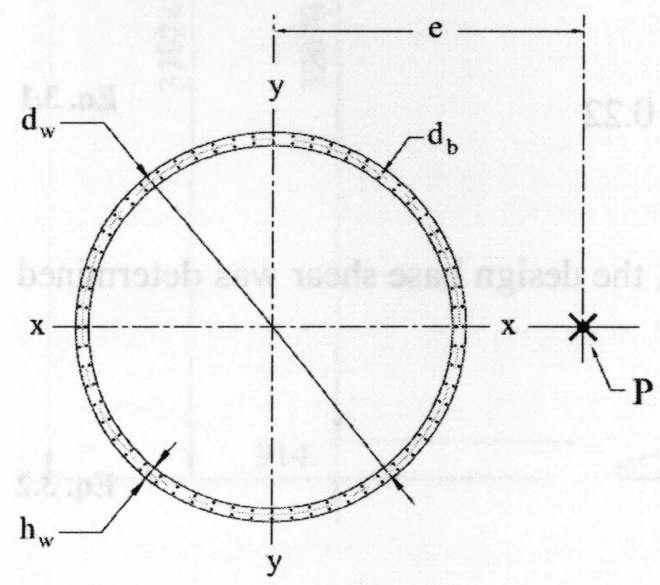

a)

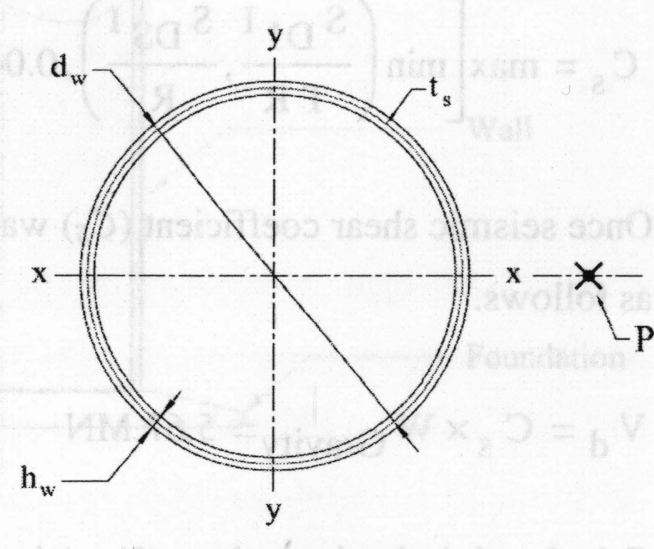

b)

Figure 3.2 - Horizontal cross-section of the shaft showing: a) Actual placement of longitudinal reinforcement, b) Equivalent reinforcing ring 
Since the ratio of shaft length to the diameter is fairly large $\left(L_{w} / h_{w}=4.66\right)$, in manual calculation it was assumed that the strain variation in the cross section remained linear in the region $0.5 d_{w}$ above the base, and the cross-section did not exhibit distortion and warping. Thus, assuming a linear strain variation in the cross section, the stress in concrete and reinforcement can be calculated anywhere in the cross section as shown in Figure $3.2 b$, based the non-linear stress-strain relationship in concrete and reinforcements as described in the next Chapter.

Assuming that maximum flexural strength will be achieved when the extreme concrete fiber in compression reaches the ultimate compressive strain $\left(\varepsilon_{c u}\right)$ of 0.003 , the amount of axial force created in the section can be easily calculated by integration over area of cross-section for corresponding depth of neutral axis $(c)$ as follows,

$P_{n}(c)=\int_{0}^{d} f_{s}(\varepsilon(x, c)) \frac{2 r_{w} h_{s}}{\sqrt{r_{w}{ }^{2}-\left(r_{w}-x\right)^{2}}} d x+\int_{0}^{d} f_{c}(\varepsilon(x, c)) \frac{2 r_{w}\left(h_{w}-h_{s}\right)}{\sqrt{r_{w}{ }^{2}-\left(r_{w}-x\right)^{2}}} d x$

Similarly, bending moment can be expressed as,

$M_{n}(c)=\int_{0}^{d} f_{s}(\varepsilon(x, c)) \frac{2 r_{w} h_{s}\left(r_{w}-x\right)}{\sqrt{r_{w}{ }^{2}-\left(r_{w}-x\right)^{2}}} d x+\int_{0}^{d} f_{c}(\varepsilon(x, c)) \frac{2 r_{w}\left(h_{w}-h_{s}\right)\left(r_{w}-x\right)}{\sqrt{r_{w}{ }^{2}-\left(r_{w}-x\right)^{2}}} d x \quad$ Eq. 3.4

In above equations, parameter $c$ is the depth of neutral axis which varies between $\infty$ and $c_{\min }$ as axial load eccentricities changes from 0 to $\infty$ respectively. Also, $r_{w}$ is the mean radius of wall, and $h_{s}$ is the equivalent thickness of reinforcement ring. The shear strength of cross section is calculated according to the procedure prescribed in ACI $371 \mathrm{R}-08$ where nominal shear strength $\left(V_{n}\right)$ is,

$\mathrm{V}_{\mathrm{n}}=\left(\alpha_{\mathrm{c}} \sqrt{f^{\prime}}+\rho_{\mathrm{s} \_ \text {horiz }} f_{y}\right) \mathrm{A}_{\mathrm{cv}}=7.66 \mathrm{MN}$ 
where $f^{\prime}{ }_{c}$ and $f_{y}$ are specific compressive strength of concrete and yield strength of reinforcements respectively. In above equation $\rho_{s_{-} \text {hoiz }}$ is the ratio of horizontal shear reinforcements. The concrete shear coefficient $\left(\alpha_{c}\right)$ is calculated as follows,

$$
\alpha_{\mathrm{c}}=\max \left[\min \left(0.5-\frac{0.21 \mathrm{M}_{\mathrm{u}}}{\mathrm{d}_{\mathrm{w}} \mathrm{V}_{\mathrm{u}}}, \frac{1}{4}\right), \frac{1}{6}\right]=0.167
$$

Thus, ultimate shear strength is then calculated as follows,

$$
\mathrm{v}_{\mathrm{r}}=\min \left(\phi_{\mathrm{v}} \mathrm{v}_{\mathrm{n}}, \mathrm{v}_{\mathrm{u} \_ \text {max }}\right)=5.74 \mathrm{MN}
$$

The shear reduction factor $\left(\varphi_{v}\right)$ is taken as 0.75 and maximum shear strength $\left(V_{u_{-} \max }\right)$ is calculated as,

$$
\mathrm{v}_{\mathrm{u} \_\max }=\frac{2}{3} \sqrt{f^{\prime}} \times \mathrm{A}_{\mathrm{cv}}=14.07 \mathrm{MN}
$$

At final stage of design, the calculated axial and flexural strengths are used to construct the axial/lateral strength interaction diagram near the base of the structures as shown in Figure 3.3. The shear strength and axial buckling strength of the shaft is also shown on the interaction diagram along with factored axial and lateral design loads.

The ratio of vertical reinforcements $\left(\rho_{s_{-} v e r t}\right)$ and horizontal reinforcements $\left(\rho_{s_{-} \text {hoiz }}\right)$ are determined as $1.61 \%$ and $0.29 \%$, respectively. The required ratio of reinforcement satisfies the ACI 371-08 minimum vertical and horizontal reinforcement ratio requirements of $0.5 \%$ and $0.25 \%$ respectively for the design 1.0 s period acceleration response $\left(S_{D I}\right)$ greater than $0.20 \mathrm{~g}$. 


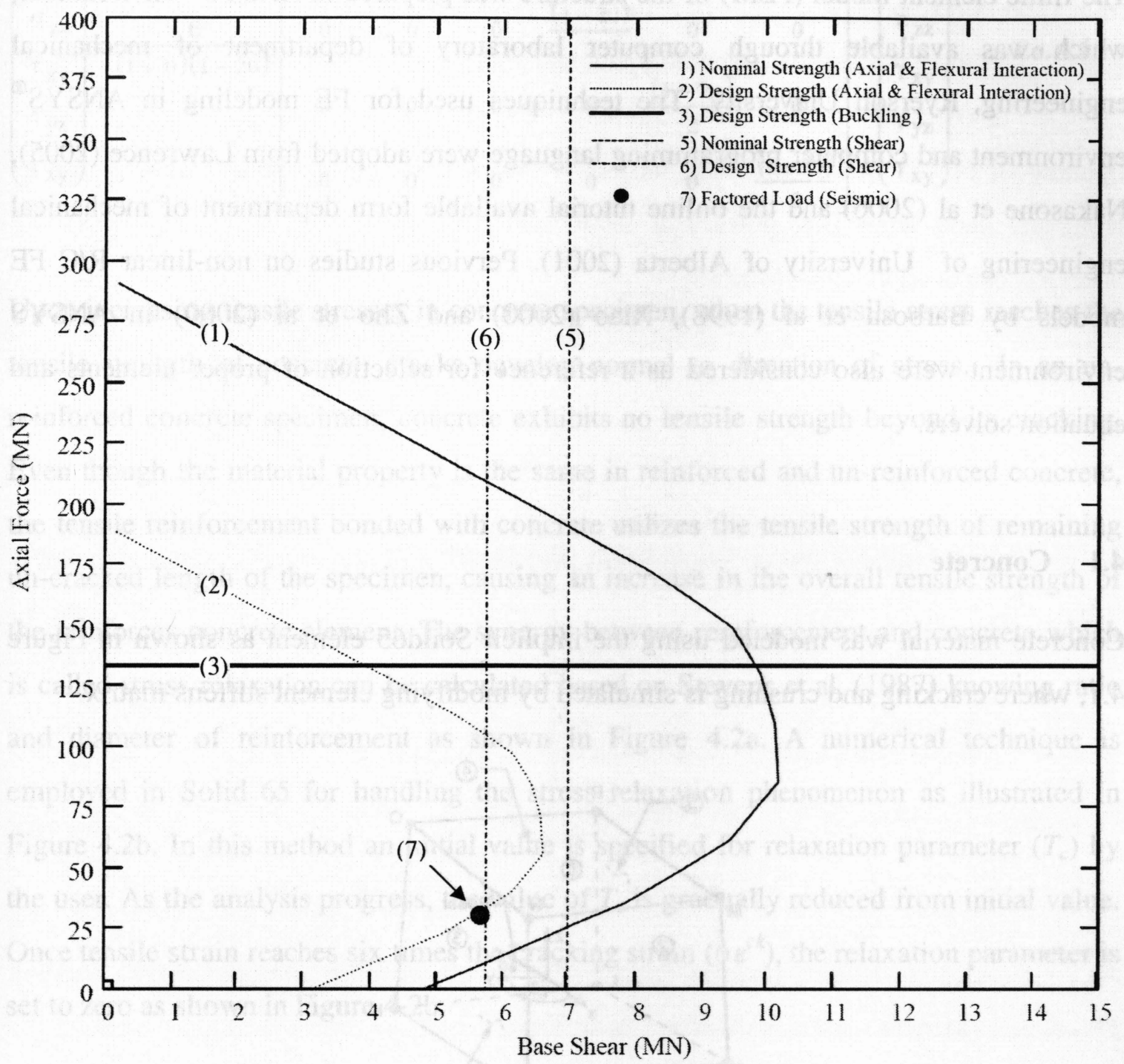

Figure 3.3- Axial vs. lateral load interaction diagram near the base of the structure 


\section{FINITE ELEMENT MODEL}

The finite element model (FEM) of the structure was prepared in ANSYS ${ }^{\circledR}$ environment, which was available through computer laboratory of department of mechanical engineering, Ryerson University. The techniques used for FE modeling in ANSYS ${ }^{\circledR}$ environment and computer programming language were adopted from Lawrence (2005), Nakasone et al (2006) and the online tutorial available form department of mechanical engineering of University of Alberta (2001). Pervious studies on non-linear R/C FE models by Barbosa et al (1998), Xiao (2000) and Zho et al (2000) in ANSYS environment were also considered as a reference for selection of proper elements and equation solvers.

\subsection{Concrete}

Concrete material was modeled using the implicit Soild65 element as shown in Figure 4.1 , where cracking and crushing is simulated by modifying element stiffens matrix.

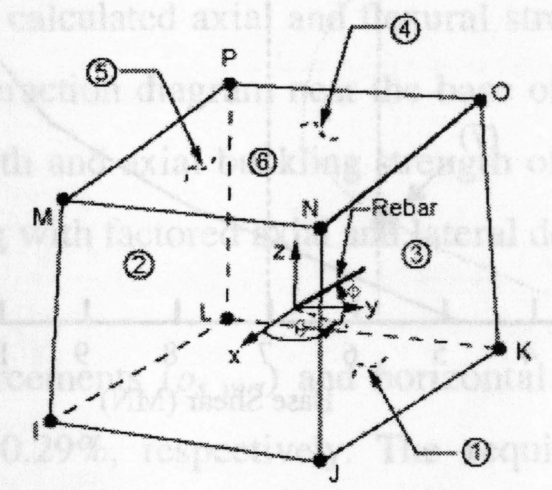

Figure 4.1 - Solid65 element used to model concrete material in FEM

\subsubsection{Concrete in Tension}

The behavior of concrete material in tension prior to cracking is modeled as linear elastic and the stiffness matrix is considered isotropic. Thus, the stress-strain relationship $([\sigma]=$ $[D] \cdot[\sigma])$ for an un-cracked concrete element in FEM is specified as follows, 


$$
\left(\begin{array}{c}
\sigma_{\mathrm{xx}} \\
\sigma_{\mathrm{yy}} \\
\sigma_{\mathrm{zz}} \\
\tau_{\mathrm{xy}} \\
\tau_{\mathrm{yz}} \\
\tau_{\mathrm{xy}}
\end{array}\right)=\frac{\mathrm{E}}{(1+v)(1-2 v)}\left[\begin{array}{cccccc}
(1-v) & v & v & 0 & 0 & 0 \\
v & (1-v) & v & 0 & 0 & 0 \\
v & v & (1-v) & 0 & 0 & 0 \\
0 & 0 & 0 & \frac{(1-2 v)}{2} & 0 & 0 \\
0 & 0 & 0 & 0 & \frac{(1-2 v)}{2} & 0 \\
0 & 0 & 0 & 0 & 0 & \frac{(1-2 v)}{2}
\end{array}\right] \times\left(\begin{array}{c}
\varepsilon_{\mathrm{xx}} \\
\varepsilon_{\mathrm{yy}} \\
\varepsilon_{\mathrm{zz}} \\
\gamma_{\mathrm{xy}} \\
\gamma_{\mathrm{yz}} \\
\gamma_{\mathrm{xy}}
\end{array}\right)
$$

Upon increasing tensile stresses in concrete specimen, when the tensile stress reaches the tensile strength of concrete, cracks develop normal to direction of stress. In an unreinforced concrete specimen, concrete exhibits no tensile strength beyond its cracking. Even though the material property is the same in reinforced and un-reinforced concrete, the tensile reinforcement bonded with concrete utilizes the tensile strength of remaining un-cracked length of the specimen, causing an increase in the overall tensile strength of the reinforces concrete element. The synergy between reinforcement and concrete which is called stress relaxation can be calculated based on Stevens et al. (1987) knowing ratio and diameter of reinforcement as shown in Figure 4.2a. A numerical technique is employed in Solid 65 for handling the stress relaxation phenomenon as illustrated in Figure $4.2 \mathrm{~b}$. In this method an initial value is specified for relaxation parameter $\left(T_{c}\right)$ by the user. As the analysis progress, the value of $T_{\mathrm{c}}$ is gradually reduced from initial value. Once tensile strain reaches six times the cracking strain $\left(6 \varepsilon^{c k}\right)$, the relaxation parameter is set to zero as shown in Figure 4.2b.

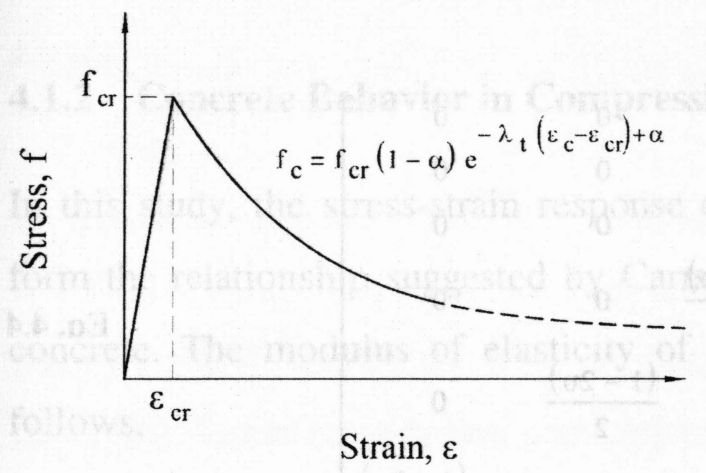

a)

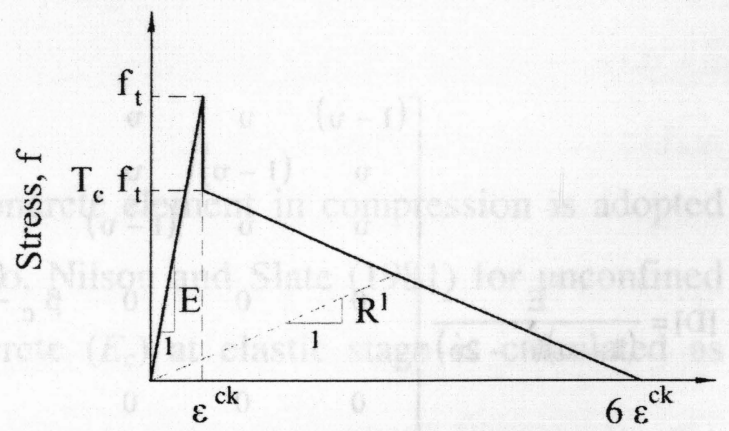

Strain, $\varepsilon$

b)

Figure 4.2 - a) Stress-strain curve for reinforced concrete in tension - Stevens et al 1987, b) Tensile stress relaxation in concrete element - ANSYS $^{\circledR}$ 
The development of tensile cracks in the element is simulated by applying tensile stress relaxation coefficient $\left(R^{t}\right)$, shear transfer coefficient for open cracks $\left(\beta^{t}=0.1\right)$ and close cracks $\left(\beta^{c}=0.9\right)$. Using these parameters cracking in one, two or three directions can be modeled in concrete element simultaneously. The stiffness matrix for the concrete after opening of cracks in one direction which is expected to appear in horizontal plane of front and back walls (i.e. portion of shaft wall perpendicular to direction of seismic acceleration) is adjusted as follows,

$$
[D]=\frac{E}{(1+v)}\left[\begin{array}{cccccc}
R^{t} \frac{(1+v)}{E} & 0 & 0 & 0 & 0 & 0 \\
0 & \frac{1}{1-v} & \frac{v}{1-v} & 0 & 0 & 0 \\
0 & \frac{v}{1-v} & \frac{1}{1-v} & 0 & 0 & 0 \\
0 & 0 & 0 & \frac{\beta_{t}}{2} & 0 & 0 \\
0 & 0 & 0 & 0 & \frac{1}{2} & 0 \\
0 & 0 & 0 & 0 & 0 & \frac{\beta_{t}}{2}
\end{array}\right]
$$

As the direction of loading changes and tensile stresses diminish, the open cracks become closed and stiffness matrix is modified as follows,

$$
[D]=\frac{E}{(1+v)(1-2 v)}\left[\begin{array}{ccccccc}
(1-v) & v & v & 0 & 0 & 0 \\
v & (1-v) & v & 0 & 0 & 0 \\
v & v & (1-v) & 0 & 0 & 0 \\
0 & 0 & 0 & \beta_{c} \frac{(1-2 v)}{2} & 0 & 0 \\
0 & 0 & 0 & 0 & \frac{(1-2 v)}{2} & 0 \\
0 & 0 & 0 & 0 & 0 & \beta_{c} \frac{(1-2 v)}{2}
\end{array}\right]
$$


Similarly, the stiffness matrix for doubly cracked concrete is adjusted as follows,

$$
[D]=E\left[\begin{array}{cccccc}
\frac{R^{t}}{E} & 0 & 0 & 0 & 0 & 0 \\
0 & \frac{R^{t}}{E} & 0 & 0 & 0 & 0 \\
0 & 0 & 1 & 0 & 0 & 0 \\
0 & 0 & 0 & \frac{\beta_{t}}{2(1+v)} & 0 & 0 \\
0 & 0 & 0 & 0 & \frac{1}{2(1+v)} & 0 \\
0 & 0 & 0 & 0 & 0 & \frac{\beta_{t}}{2(1+v)}
\end{array}\right]
$$

Eq. 4.5

When the cracks are closed in both directions, the stiffness matrix is adjusted as follows,

$$
[D]=\frac{E}{(1+v)(1-2 v)}\left[\begin{array}{ccccccc}
(1-v) & v & v & 0 & 0 & 0 \\
v & (1-v) & v & 0 & 0 & 0 \\
v & v & (1-v) & 0 & 0 & 0 \\
0 & 0 & 0 & \beta_{c} \frac{(1-2 v)}{2} & 0 & 0 \\
0 & 0 & 0 & 0 & \frac{(1-2 v)}{2} & 0 \\
0 & 0 & 0 & 0 & 0 & \beta_{c} \frac{(1-2 v)}{2}
\end{array}\right]
$$

\subsubsection{Concrete Behavior in Compression}

In this study, the stress-strain response of concrete element in compression is adopted form the relationship suggested by Carrsquillo, Nilson and Slate (1981) for unconfined concrete. The modulus of elasticity of concrete $\left(E_{c}\right)$ at elastic stage is calculated as follows, 
$\mathrm{E}_{\mathrm{c}}=3320 \sqrt{f_{c}^{\prime}}+6900$

The modulus of elasticity $\left(E_{C}\right)$ is used to calculate the compressive stress in elastic region of response, where the compressive strain is equal to 0.0002 or less. The compressive stress beyond 0.0002 is calculated as follows,

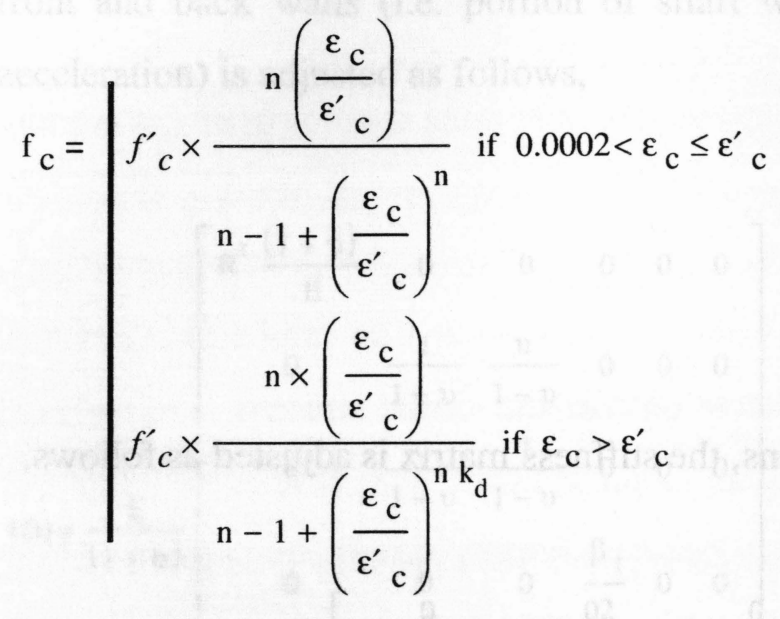

In above equation, the concrete strain at peak compressive stress level $\left(\varepsilon_{c}^{\prime}\right)$ is calculated as follows,

$\varepsilon^{\prime}{ }_{c}=-\frac{f_{c}^{\prime}}{\mathrm{E}_{\mathrm{c}}} \times \frac{\mathrm{n}}{\mathrm{n}-1}$

Eq. 4.8

The curve fitting factor $(n)$, and post decay stress softening coefficient $\left(k_{d}\right)$ are defined as,

$\mathrm{n}=0.8+\frac{f_{c}^{\prime}}{17}$

and,

$$
\mathrm{k}_{\mathrm{d}}=0.67+\frac{f^{\prime}{ }_{c}}{62}
$$

The stress-strain response curve is calculated for specific compressive strength $\left(f_{c}^{\prime}\right)$ of 35 MPa and the data in the FEM are used based on Multi Isotropic Hardening (MISO) material model. In order to verify the response of concrete element, a single un- 
reinforced element is subjected to few cycles of compression and tension as shown in Figure 4.3.

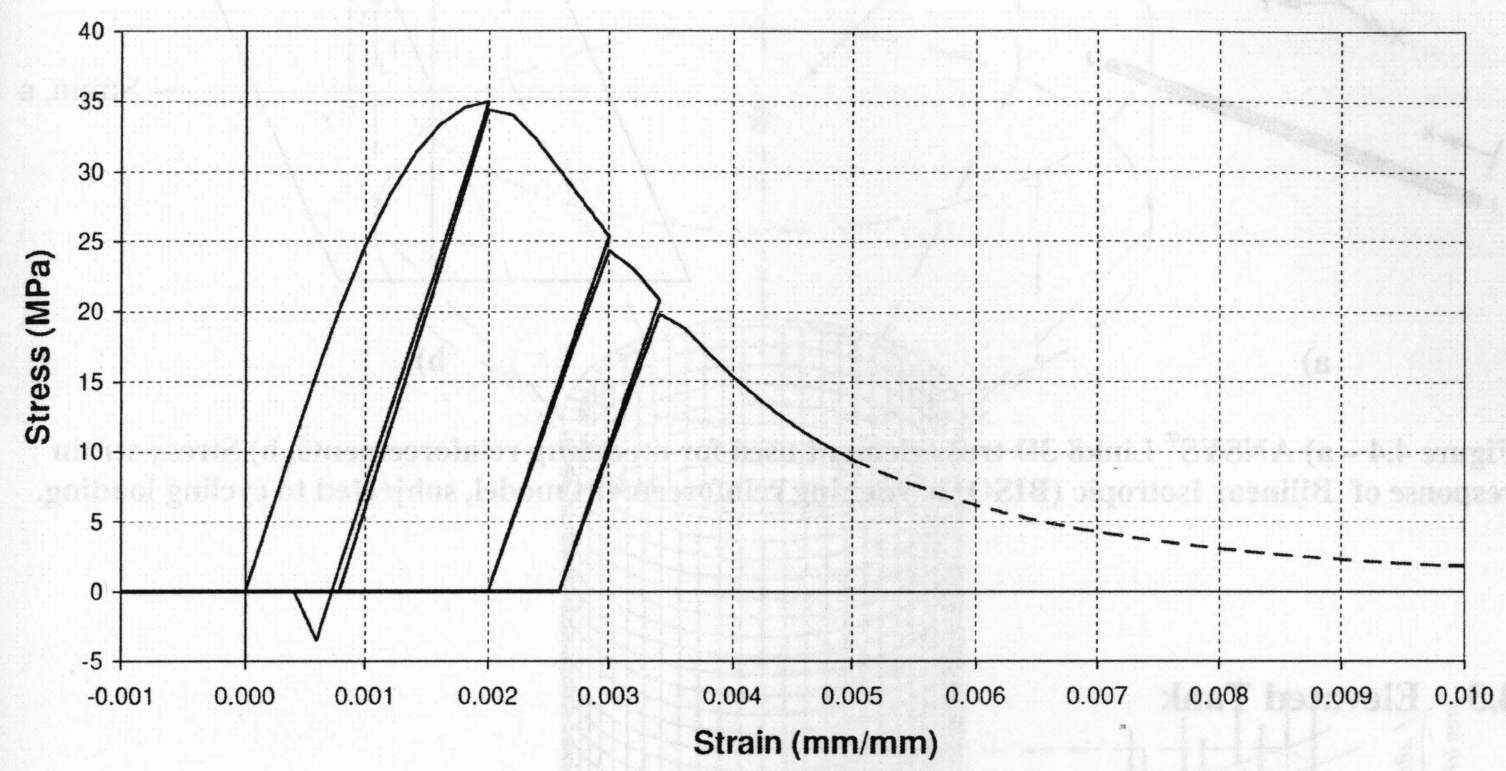

Figure 4.3 - Stress-strain responses of an unreinforced concrete solid65 element subjected to cyclic loading.

In this model, un-loading and re-loading stiffness are equal to initial modulus of elasticity of concrete $\left(E_{c}\right)$. However, the experimental results suggest that reloading stiffness is somewhat softer. Upon entering the nonlinear phase, a non-recoverable plasticity is generated. In higher compressive strain reign, the material exhibits strain-softening qualities, which is not easily achieved in ANSYS and requires using proper equation solver and relaxing few of convergence criterions

\subsection{Reinforcement}

Longitudinal and shear reinforcements are modeled using available Link8 element, which is a 3-dimensional truss element with tension and compression capabilities. The Bi-linear Isotropic (BISO) hardening material model is selected to model the elastic-plastic stressstrain behavior of longitudinal and horizontal reinforcements as shown in Figure 4.4. 


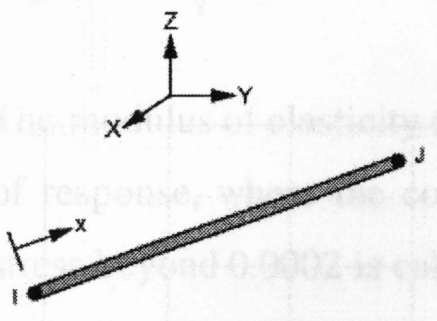

a)

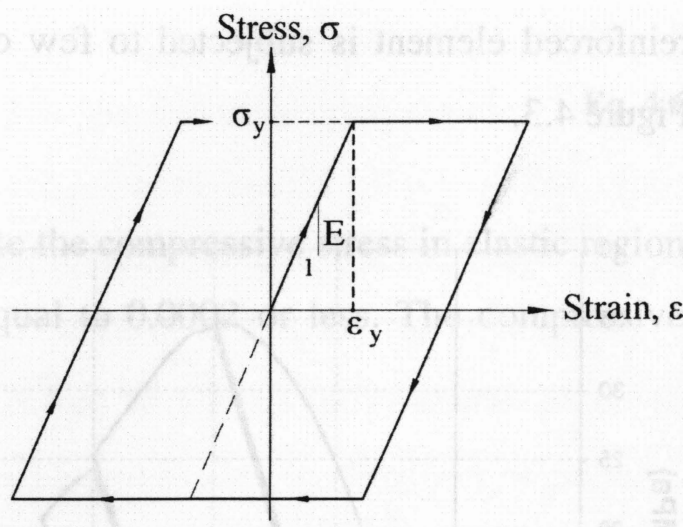

b)

Figure 4.4 - a) ANSYS ${ }^{\circledR}$ Link8 3D truss element used for modeling reinforcements, b) Stress-strain response of Bilinear Isotropic (BISO) hardening reinforcement model, subjected to cycling loading.

\subsection{Elevated Tank}

Once the material properties of concrete and reinforcement are determined, the geometry of the structure is introduced to the finite element model as shown in Figure 4.5. In the developed model, a total of 240 size 35M longitudinal reinforcement are placed at inner and outer surface of the wall at $392 \mathrm{~mm}$ spacing $\left(\rho_{s_{-} \text {long. }}=1.61 \%\right)$. Similarly, the $15 \mathrm{M}$ circumferential (horizontal) shear reinforcements are placed at inner and outer layers of the wall at $410 \mathrm{~mm}$ spacing along the length of shaft $\left(\rho_{s_{-} \text {horiz. }}=0.29 \%\right)$.

Additionally, in order to facilitate any future changes in geometry, mesh size and material properties, the entire finite element model was programmed as a compatible parametric text file. Although a single mass element was used to model the entire impulsive mass of water, the geometry and material properties of steel tank and fluid (water) are also devised in the finite element input text file for future development 


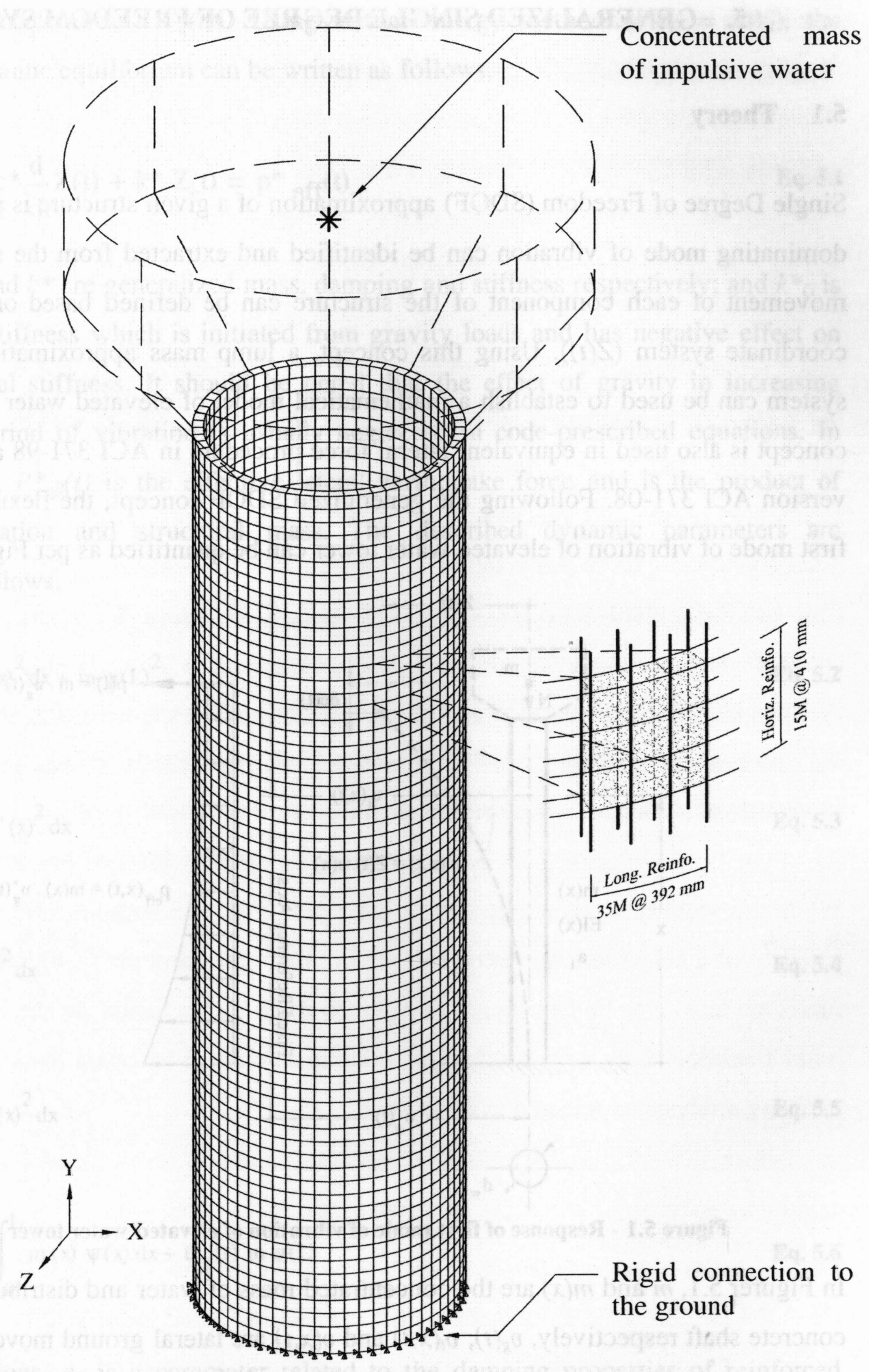

Figure 4.5 - Finite element model (FEM) of elevated water tower 


\section{GENERALIZED SINGLE DEGREE OF FREEDOM SYSTEM}

\subsection{Theory}

Single Degree of Freedom (SDOF) approximation of a given structure is possible when a dominating mode of vibration can be identified and extracted from the system, and the movement of each component of the structure can be defined based on a generalized coordinate system $(Z(t))$. Using this concept, a lump mass approximation of vibrating system can be used to establish a mathematical model of elevated water tank. A similar concept is also used in equivalent lateral force procedure in ACI 371-98 and in modified version ACI 371-08. Following the generalized SDOF concept, the flexural response of first mode of vibration of elevated water tower can be quantified as per Figure 5.1.

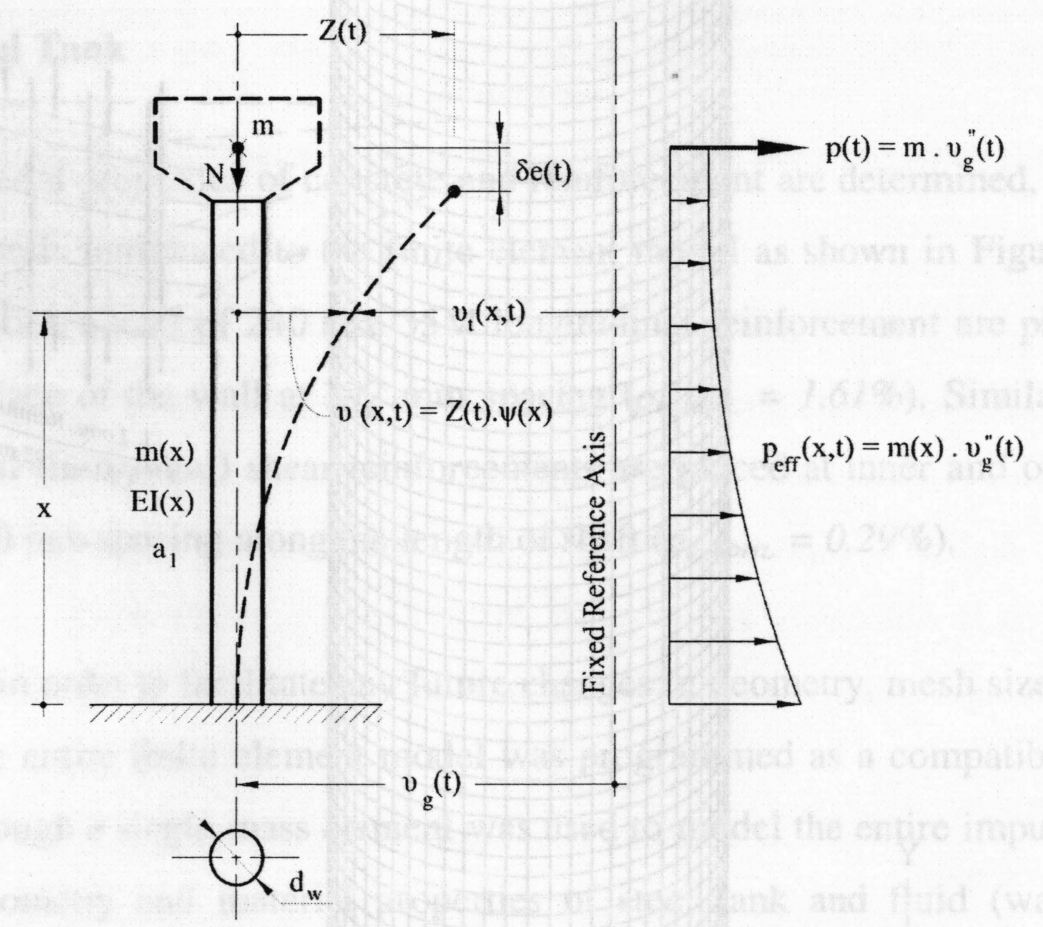

Figure 5.1 - Response of first mode of vibration of elevated water tower

In Figurer 5.1, $m$ and $m(x)$ are the concentrated mass of water and distributed mass of the concrete shaft respectively. $v_{g}(t), v_{t}(x, t)$ and $v(x, t)$ are lateral ground movement, total and relative lateral displacement along the length of the structure respectively. $P_{\text {eff }}(x, t)$ and $P(t)$ are the lateral forces of earthquake on the structural masses $(m(x)$ and $m)$ initiated 
from ground acceleration $\left(\ddot{v}_{g}(t)\right)$. Using virtual energy method $\left(\delta W_{E}=\delta W_{I}\right)$, the generalized dynamic equilibrium can be written as follows,

$$
\mathrm{m}^{*} \frac{\mathrm{d}^{2}}{\mathrm{dt}^{2}} \mathrm{Z}(\mathrm{t})+\mathrm{c}^{*} \frac{\mathrm{d}}{\mathrm{dt}} \mathrm{Z}(\mathrm{t})+\mathrm{k}^{*} \mathrm{Z}(\mathrm{t})=\mathrm{p}^{*} \operatorname{eff}^{(\mathrm{t})}
$$

where $m^{*}, c^{*}$ and $k^{*}$ are generalized mass, damping and stiffness respectively; and $k^{*}{ }_{G}$ is the geometric stiffness which is initiated from gravity loads and has negative effect on overall structural stiffness. It should be noted that the effect of gravity in increasing fundamental period of vibration is usually neglected in code-prescribed equations. In above equation, $P^{*}{ }_{\text {eff }}(t)$ is the effective lateral earthquake force and is the product of ground acceleration and structural mass. The described dynamic parameters are calculated as follows,

$$
\begin{aligned}
& m^{*}=\int_{0}^{L} m(x) \psi(x)^{2} d x+m \cdot \psi(L)^{2} \\
& c^{*}=a_{1} \int_{0}^{L} E I \cdot \psi^{\prime \prime}(x)^{2} d x \\
& k^{*}=\int_{0}^{L} E I \psi^{\prime \prime}(x)^{2} d x
\end{aligned}
$$

$k^{*} G=m g \int_{0}^{L} \psi^{\prime}(x)^{2} d x$

$p^{*} \operatorname{eff}^{(t)}=\ddot{u}_{g}(t) \int_{0}^{L} m(x) \psi(x) d x+\ddot{u}_{g}(t) m \psi(L)$

Eq. 5.6

In above equations, $a_{l}$ is a parameter related to the damping properties of reinforced concrete. Alternatively, $c^{*}$ can be calculated as follows,

$$
\mathrm{c}^{*}=\xi^{*} \mathrm{c}^{*} \mathrm{cr}
$$


where $\xi^{*}$ is generalized damping ratio equal to $5 \%$ and $c{ }^{*} r$ is the generalized critical damping coefficient calculated as,

$$
\mathrm{c}^{*} \mathrm{cr}=2 \times \sqrt{\left(\mathrm{k}^{*}-\mathrm{k}^{*} \mathrm{G}\right) \times \mathrm{m}^{*}}
$$

\subsection{Shape function}

As shown in Figure 5.1 relative displacement of shaft along the length $(v(x, t))$ is defined based on relative displacement of center of gravity of water $(Z(t))$ and the shape function $(\psi(x))$. Any mathematical function chosen to represent the shape function $(\psi(x))$, must satisfy two general criteria. Firstly, any selected shape function must satisfy the boundary conditions of displacement shape of the structure, which are zero lateral displacement and zero rotation at the base $\left(\psi(0)=\psi^{\prime}(0)=0\right)$. In addition, since the bending moment at the top of the structures is evidently zero, the curvature at the top also must be zero $\left(\psi^{\prime \prime}(L)=\right.$ 0 ). Secondly, the true shape of vibrating structure applies the least external constrains on the structure and consumes the least energy. Thus, it yields the lowest angular frequency of vibration $(\omega)$ or the highest period of vibration $(T)$.

While the validity of boundary conditions can be verified without difficulty, the energy property of a shape function is calculated in many steps and the results from other shape functions must also be considered in order to reach a conclusion. In the first attempt, the initial buckling shape of a cantilevered column calculated based on Rayleigh's method of buckling analysis, is selected as follows,

$$
\psi_{0}(\mathrm{x})=\left(1-\cos \left(\frac{\pi}{2} \cdot \frac{\mathrm{x}}{\mathrm{L}}\right)\right)^{1}
$$

Once the boundary conditions are confirmed, the accuracy of the shape function is then verified through application of Rayleigh's principal of energy conservation method. In this method, a distributed lateral load proportional to shape functions is applied to the structure which simulates the maximum velocity state in free vibration. The corresponding displacement function and shape function is calculated. Based on energy 
conservation theory, the kinematic energy due to initial distributed load must equate the potential energy of the calculated shape function. Following the Rayleigh's method, an angular frequency can be calculated for each assumed shape function. By testing different shape function, the one that produces the lowest angular frequency, yields the best approximation for shape function. In order to optimize the initial assumptions for shape function, the described process is applied to the elevated water tower at empty and full conditions. Additionally, a free vibration FEA is performed using developed FEM of elevated water tower in full tank conditions, and the displacement function of the fundamental mode of vibration is extracted from the output. The results form theoretical and FE analyses are illustrated in Figure 5.2a and 5.2b.

Considering Figure 5.2a and 5.2b, the theoretical responses of the structure to a distributed load proportionate to initial shape function $\left(\psi_{l}\right)$ at empty and full tank conditions, suggests a larger displacement near the base of structure, which is an indication of shear displacement. The shape functions are adjusted and re-applied several times as a lateral load to structure at the empty and full conditions. Subsequently, the following optimized shape functions were determined to yield the lowest frequency of vibration at empty and full tank condition respectively,

$\psi_{2}=\left(1-\cos \left(\frac{\pi x}{2 L}\right)\right)^{0.833}$

and,

$\psi_{2}=\left(1-\cos \left(\frac{\pi x}{2 L}\right)\right)^{0.950}$

Eq. 5.11

However, free vibration FEA reveals even larger displacement near the base in full tank conditions. A $6^{\text {th }}$ degree polynomial curve is calculated based on FEA results as follows,

$\psi_{3}=a_{2} x^{2}+a_{3} x^{3}+a_{4} x^{4}+a_{5} x^{5}$

Eq. 5.12

Where, $a_{2}, a_{3}, a_{4}$ and $a_{5}$ are $2.155 \times 10^{-3},-9.483 \times 10^{-5}, 2.371 \times 10^{-6}$ and $-2.155 \times 10^{-8}$ respectively. 


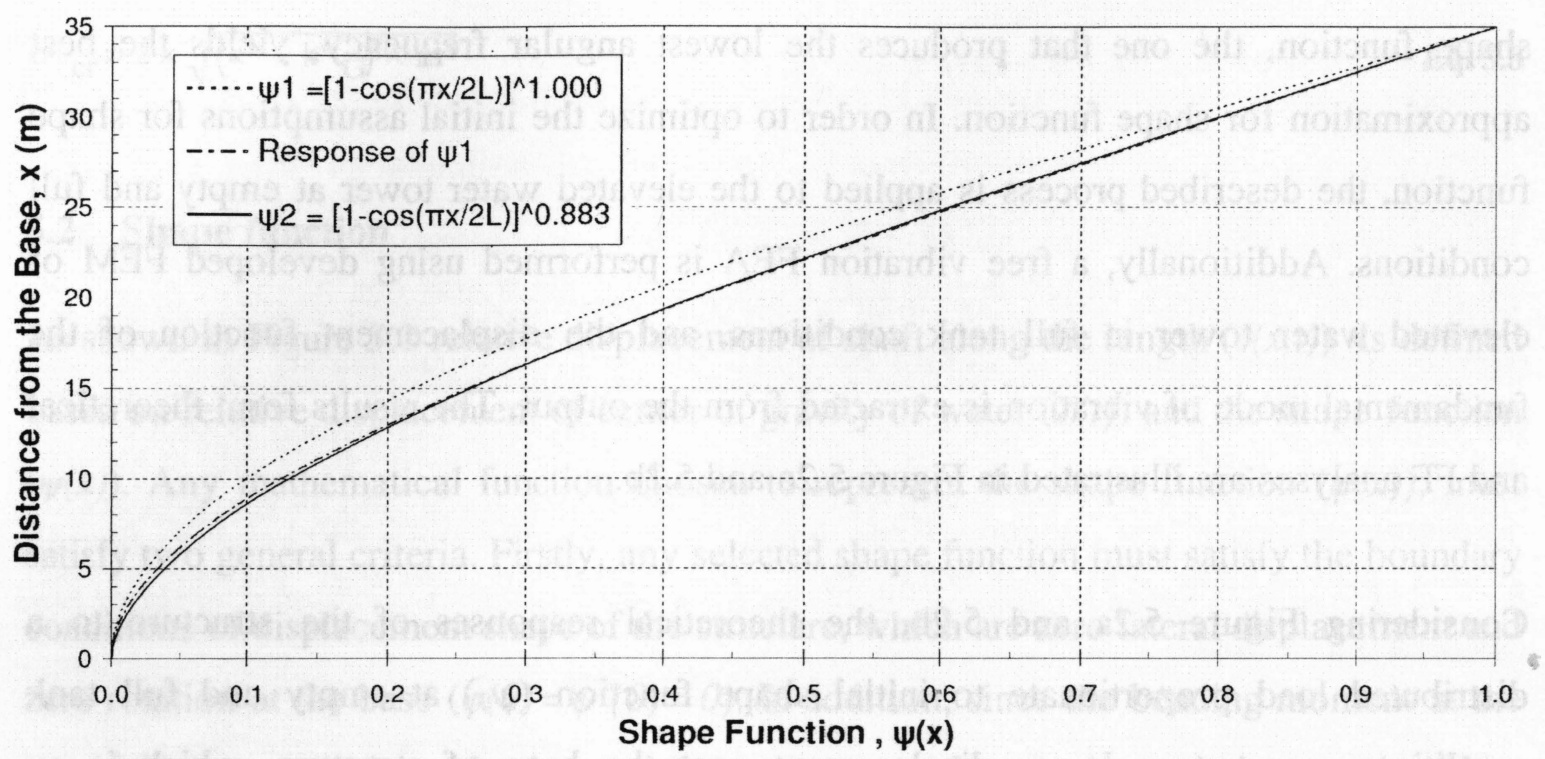

a)

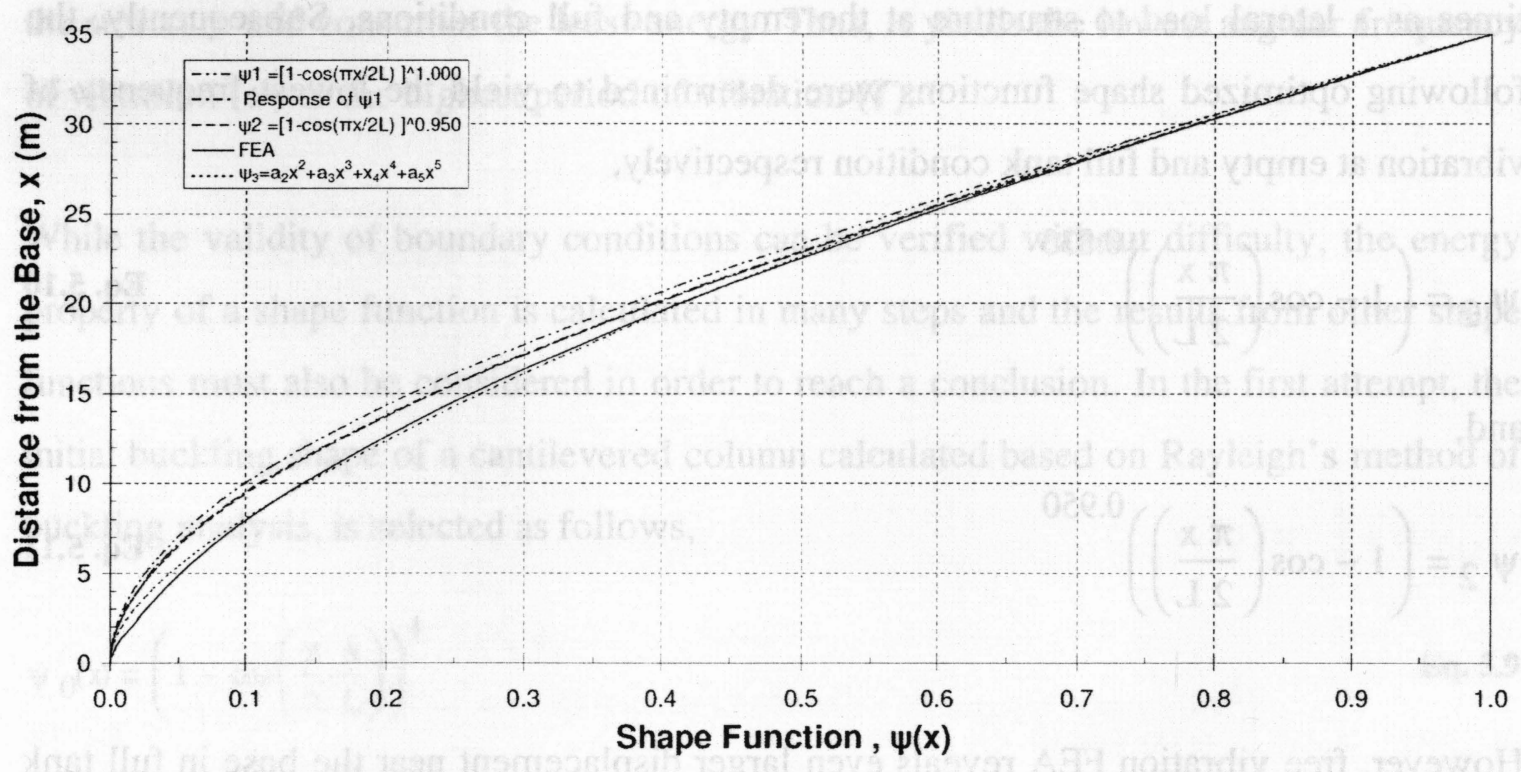

b)

Figure 5.2 - Optimization of shape function in SDOF generalization of the vibrating system in: a) Empty and b) full tank conditions compared to displacement function of FEA. 


\section{FINITE ELEMENT ANALYSIS}

\subsection{Static Non-Linear Finite Element Push-Over Analysis}

In this Chapter, a FE push-over analysis is performed to verify the assumption of linear strain distribution which were made earlier in the manual design process. Additionally, the maximum available ductility and structural responses to lateral load are also determined through push-over analysis.

In order to resemble actual loading sequence, the axial gravity load is applied to the structure first. After application of gravity loading, lateral load is applied in several load steps. Since the compressive strength of concrete is reduced after reaching the peak compressive strength (strain softening), special attention should be paid in choosing a proper equation solver to avoid numerical instability and convergence predicaments. There are three built-in numerical solvers available in ANSYS $^{\circledR}$ for static analysis as shown in Figure 6.1. Although there are certain advantages and disadvantage in using each method, the modified Newton-Rophson method is concluded to be a suitable solver since the initial slope is used in the analysis. This is less likely to encounter numerical instability due to stiffness softening.

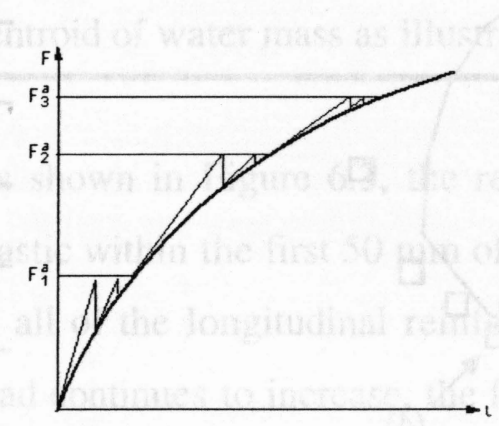

a)

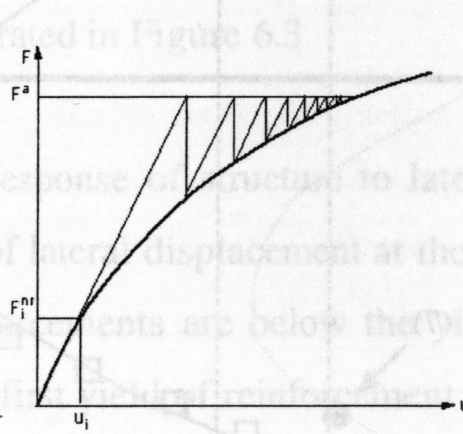

b)

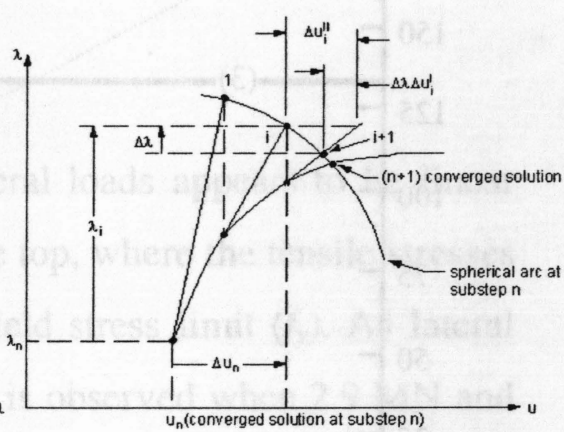

c)

Figure 6.1 -A schematic view of three numerical equation solvers available for static analysis in ANSYS $^{\circledR}$ : a) Newton-Raphson method, b) Modified Newton-Rophson method, and c) Arc-Length method 
In order to verify the theoretically developed axial-lateral strength interaction diagram, a total of eight static push-over analyses are performed using the FEM. In each case, a different axial gravity load is applied to the structure, and then the ultimate lateral strength is calculated by gradually increasing the concentrated lateral force at the centroid of impulsive water pressure. All of the obtained results are illustrated in theoretical strength interaction diagram for comparison as shown in Figure 6.2.

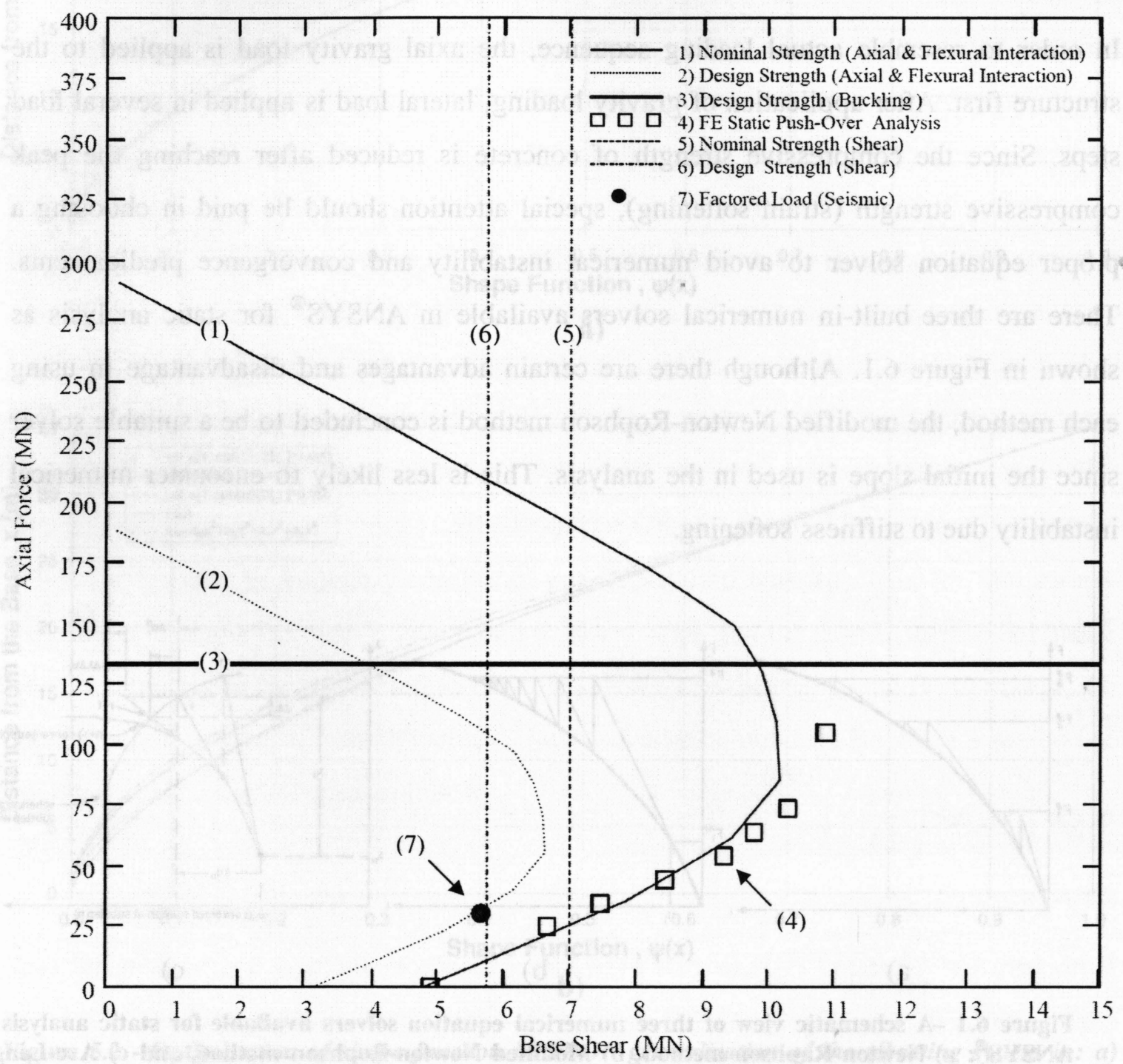

Figure 6.2 - Ultimate structural strength determined through FEA ( $\square$ ), illustrated in theoretical axial-lateral strength interaction diagram. 
The FE results appear to be in a good agreement with theoretical strength, calculated at $0.5 d_{w}$ above the base of the structure with linear strain distribution and un-confined concrete material properties.

Furthermore, the general pattern observed in FEA results follows the curvature of theoretical axial-flexural strength interaction diagram suggesting a flexural mode of failure and rejecting the possibility of shear failure. This is despite the fact that calculated ultimate lateral strength in shear is considerably smaller than the one in flexure. As pointed out before, the beneficial effects of axial load in shear strength is disregarded in ACI 371-08 recommendation for shear strength calculations. This explains the absence of shear of failure in this particular structure.

In the next step, two more non-linear push-over FEA are performed on the structure under actual gravity loads. In the first loading case, a concentrated lateral load is applied in much finer load steps to the centroid of impulsive pressure on the tank wall. In the second loading case, the lateral load is applied to the structure as a lateral constant inertial acceleration.. In each analysis, the lateral load is gradually increased while the structure reaches near-collapse conditions. The results of FEA are used to investigate the development of shear force at the base of the structure for every lateral displacement at centroid of water mass as illustrated in Figure 6.3

As shown in Figure 6.3, the response of structure to lateral loads appears to be linear elastic within the first $50 \mathrm{~mm}$ of lateral displacement at the top, where the tensile stresses in all of the longitudinal reinforcements are below the yield stress limit $\left(f_{y}\right)$. As lateral load continues to increase, the first yield of reinforcement is observed when $2.9 \mathrm{MN}$ and 3.3 $\mathrm{MN}$ base shear is developed at base and lateral displacement exceeds $53 \mathrm{~mm}$ and 58 $\mathrm{mm}$ in lateral concentrated and acceleration loading cases respectively. Using the obtained FEA results, structural stiffness $\left(K_{e}\right)$ at elastic stage is calculated as $50.0 \mathrm{MN} / \mathrm{m}$ and $62.3 \mathrm{MN} / \mathrm{m}$ in each loading cases of lateral concentrated and constant acceleration respectively. These values are close to the elastic structural stiffness $\left(K_{c}\right)$ of $58.1 \mathrm{MN} . \mathrm{m}$ calculated according simplified method of ACI 371-98. 
For the two cases of lateral concentrated and lateral constant acceleration loadings, an ultimate base shear of $5.7 \mathrm{MN}$ and $6.8 \mathrm{MN}$ is recorded respectively at base of structure which is accompanied with 236.6 MN.m and 274.7 MN.m bending moment. The maximum lateral displacement of centroid of the tank is determined to be $347 \mathrm{~mm}$ and $361 \mathrm{~mm}$ in lateral concentrated and acceleration loading cases respectively.

As shown in Figure 6.3, the structure is capable of demonstrating a considerable amount of lateral displacement prior to failure, which is near the maximum lateral drift limit ( $\Delta_{\max }$ $=0.01 h_{s}$ ) as recommended by ASCE 7-05 for post-disaster structures. However, large lateral displacement does not necessarily imply large ductility as discussed in Chapter 7 .

a)

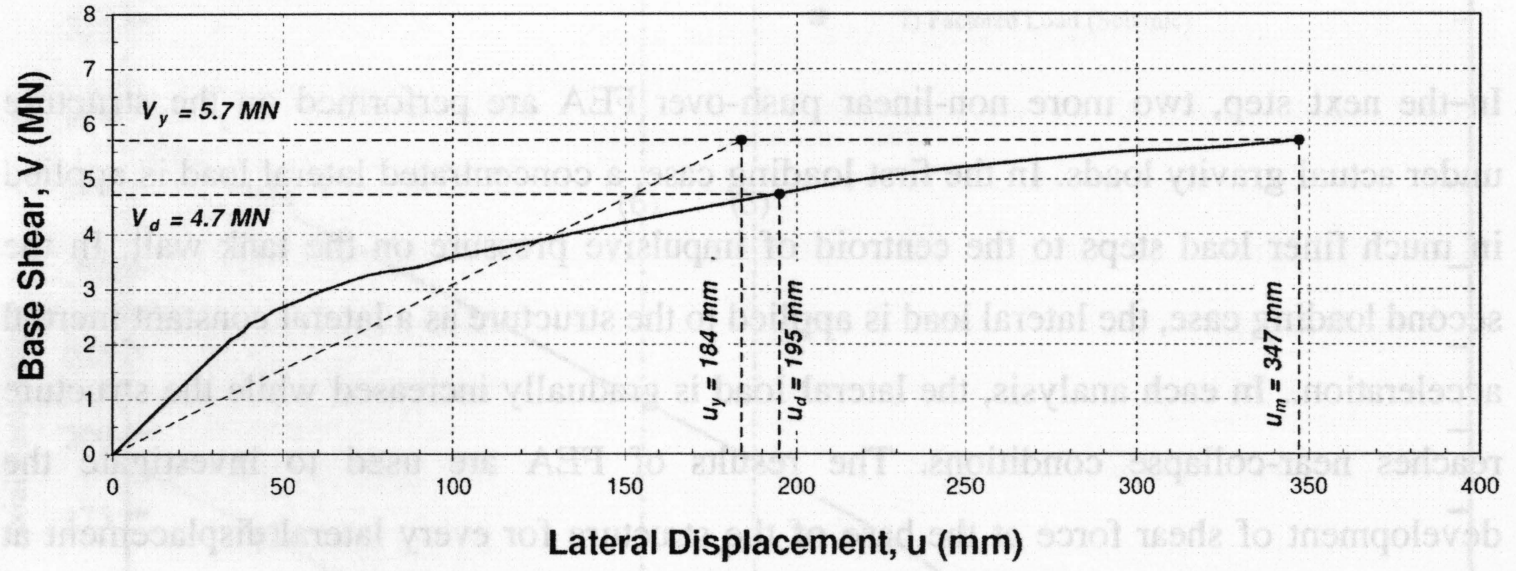

b)

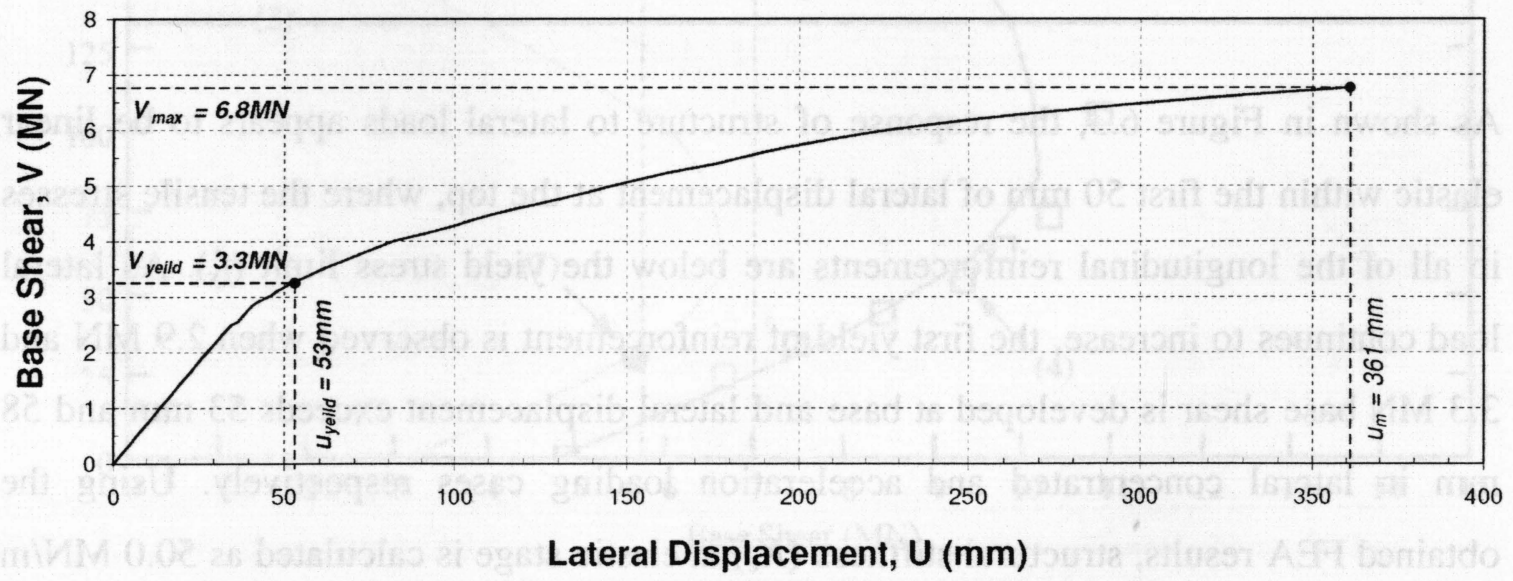

Figure 6.3 - Development of shear force at the base of the structure vs. the lateral displacement at centroid of water tank when subjected to: a) Lateral acceleration and b) Concentrated lateral force applied to the centroid of tank. 
One of the assumptions in the design process was that the horizontal cross section of shaft will not experience warping at elevation of $0.5 d_{w}$ above the ground. In order to verify this assumption, the nodal vertical displacement in non-linear static push-over analysis was extracted from results. Then, using statistical regression method, a $6^{\text {th }}$ degree polynomial curve was fitted to vertical displacement variation in each plane as shown in Figure 6.4.

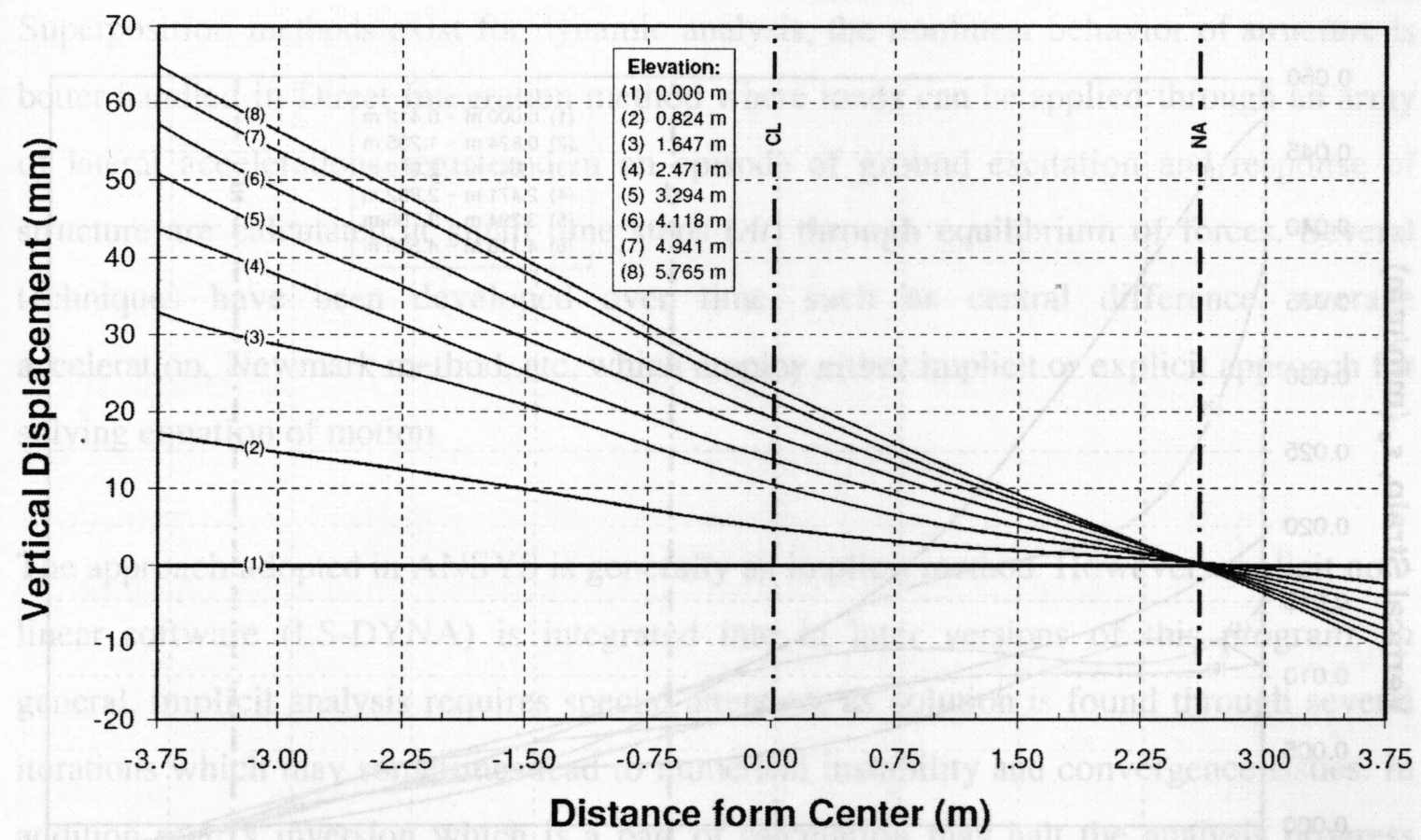

Figure 6.4 - Variation of vertical displacement along the horizontal cross section of the shaft in the first 15 consecutive planes with $0.412 \mathrm{~m}$ interval.

As expected, structure exhibits non-linear variation of vertical displacement or warping adjacent to foundation where it is rigidly connected. The identified disturbed region extends as much as $2.47 \mathrm{~m}$ or $0.33 d_{w}$. The neutral axis has been identified to be located at $2.67 \mathrm{~m}$ distance from center line or $1.10 \mathrm{~m}$ from the center of the wall through the thickness. 
Knowing the variation of nodal displacement throughout the section, total vertical strain between the nodes is determined as follows,

$$
\varepsilon_{\text {vert }}=\frac{\mathrm{u}_{\text {top }}-\mathrm{u}_{\text {bot }}}{\mathrm{h}_{\text {elem }}}
$$

Using the above equation, the vertical strain variations are calculated and the results are shown in Figure 6.5.

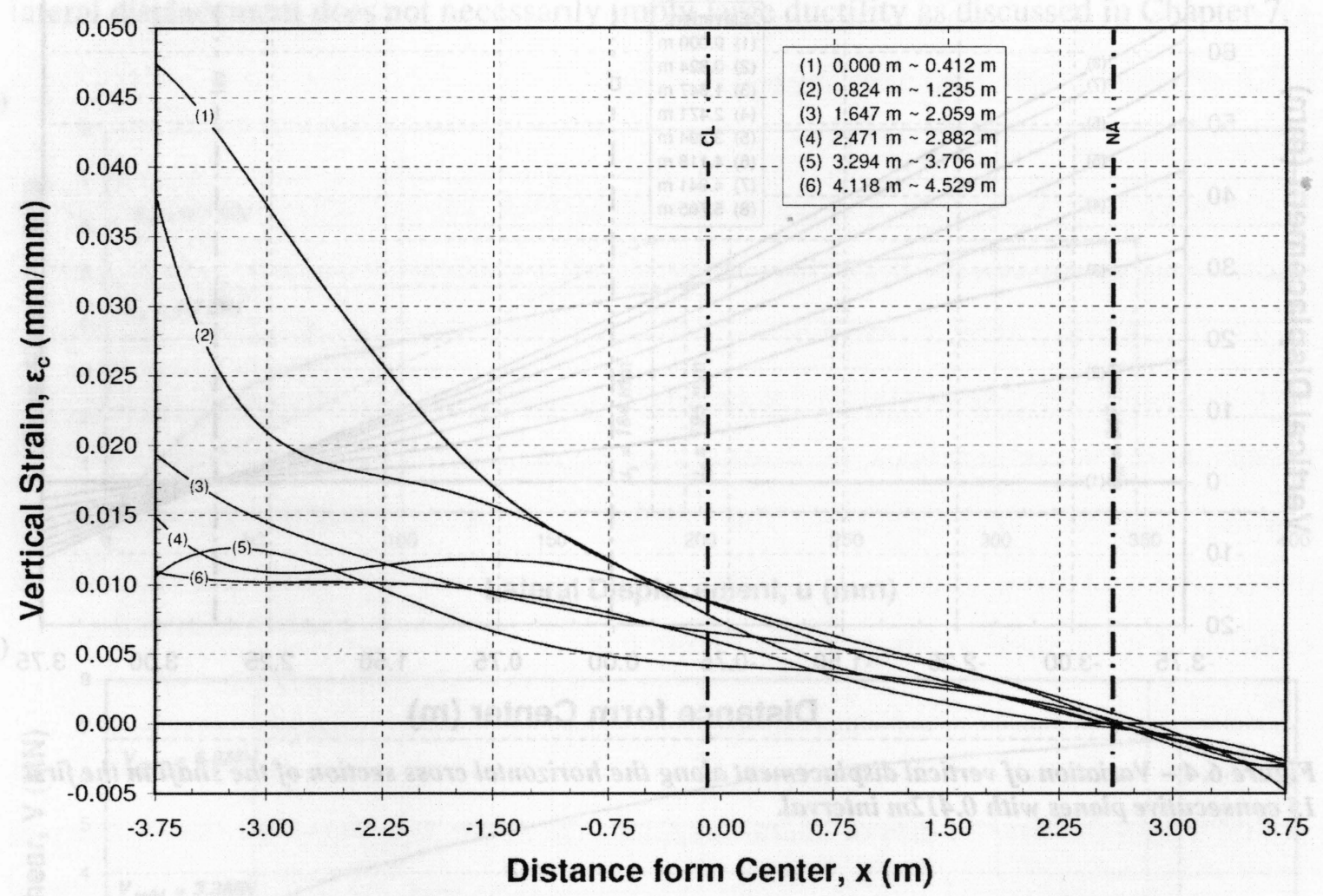

Figure 6.5 - Variation of total vertical strain in the cross section of the shaft in the first 11 consecutive planes with $0.412 \mathrm{~m}$ interval.

Similarly, a distinguished non-linearity has been identified in the region near the base extending as high as $2.471 \mathrm{~m}$. Although an intense and highly non-linear behavior appears in the tensile region near the base, it gradually fades away as ascending along the length of the shaft. Thus, the assumption for linear strain variation becomes practically valid at height of $0.5 d_{w}$. 


\subsection{Non-Linear Time-History (Transient) Finite Element Analysis}

In the next stage of this study, the FEM of elevated water tank was subjected to seismic ground motions. During the transient analysis, the vertical gravitational acceleration $(g)$ was kept constant similar to static push-over analysis and it was applied prior to start of transient loading during the first 5 seconds of analysis in order to set the initial conditions.

While two general approaches of Direct Integration (or Time-History) and Mode Superposition methods exist for dynamic analysis, the nonlinear behavior of structure is better handled in Direct Integration method where loads can be applied through an array of lateral accelerations registered in an episode of ground excitation and response of structure are calculated at small time steps $(\Delta t)$ through equilibrium of forces. Several techniques have been developed over time, such as central difference, average acceleration, Newmark method, etc, which employ either implicit or explicit approach for solving equation of motion.

The approach adopted in ANSYS is generally an implicit method. However, explicit nonlinear software (LS-DYNA) is integrated into in later versions of this program. In general, implicit analysis requires special attention, as solution is found through several iterations which may sometimes lead to numerical instability and convergence issues. In addition matrix inversion which is a part of calculation may halt the analysis progress upon encountering singularities. Also, non-linearities are not very well handled in implicit method. On the other hand explicit methods have none of these obstructions but they may require extremely small time stepping for accurate analysis.

In this study the modified-Newmark solver is used for analysis which is in fact an implicit technique. Among other implicit techniques, Newmark method or modifiedNewmark method is believed to be the most accurate which is adopted by many researchers. 


\subsubsection{Selection of Seismic Ground Motions}

While many historic seismic acceleration records are available through online sources, a total of 4 recent earthquakes are selected from database of United States Federal Emergency Management Agency's training software (NONLIN ${ }^{\circledR}$ v6.0), based on their energy content and characteristic period of vibration $\left(T_{g}\right)$ as shown in Figure 6.6. The seismic records were selected in such a way that a large portion of the seismic energy is delivered within the frequency ranges that includes the period of vibration of the structure in linear and non-linear phases. Although any other seismic motion could have been used for dynamic analysis regardless of its energy distribution, selecting an earthquake that targets the fundamental mode of vibration of structure would reduce the influence of secondary modes of vibrations. The energy content of selected ground motions were evaluated through Fourier amplitude spectrum as shown in Figure 6.7.

Since the magnitude of seismic Peak Ground Acceleration (PGA) varies between $0.15 \mathrm{~g}$ and $0.636 \mathrm{~g}$ in the selected earthquakes, the seismic accelerations are normalized for use in FEA in order to eliminate the intensity of each earthquake. During the normalization process, the ground acceleration data are divided by the peak ground acceleration of the earthquake. The acceleration data are then magnified until a single PGA is found for each record that produces the same elastic spectral response as the design spectral accelerations (Figure 6.8). Using the calculated PGA as an indicator of earthquake intensity, a total 50 PGA's are selected for FEA. The seismic acceleration data used in FEA are available only in $0.02 \mathrm{~s}$ time intervals in the database of FEMA.

However, when necessary for convergences and stability of Newmark-Hall iterative solver in time-history analysis, time intervals are reduced to $0.01 \mathrm{~s}$ and $0.005 \mathrm{~s}$, and intermediary data are generated by averaging available records. Additionally, the less active interval of seismic excitation was discarded; in order to minimize the amount of time elapsed in computer analysis. 
a)

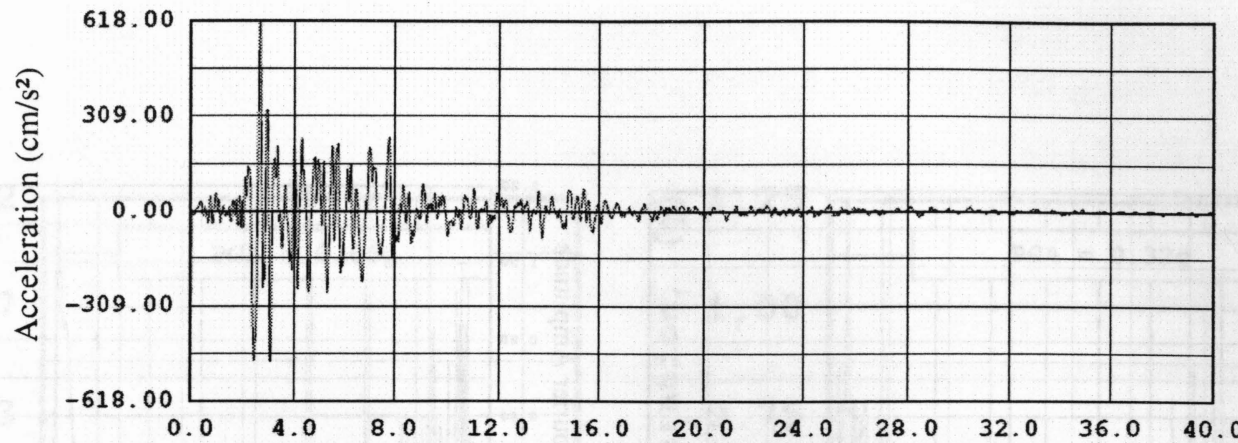

b)

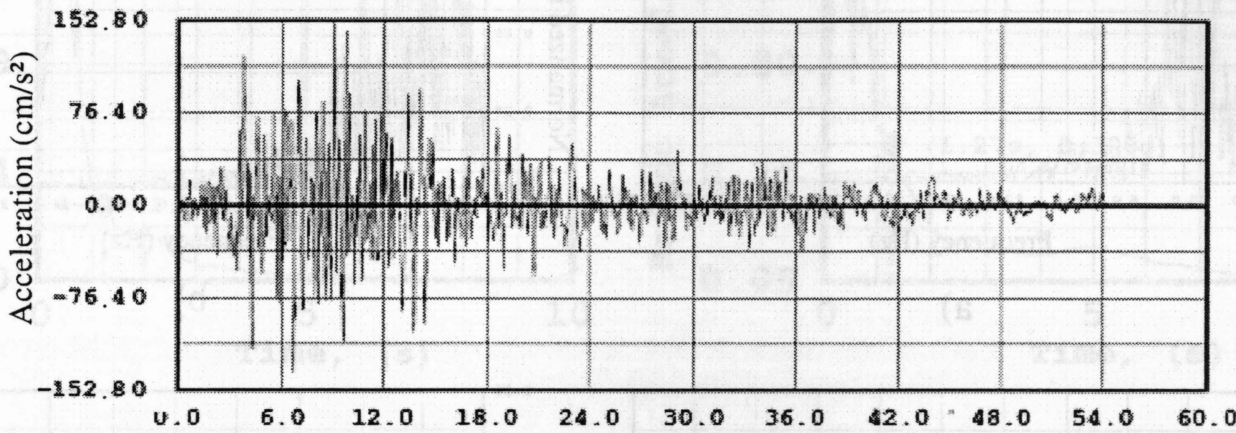

c)

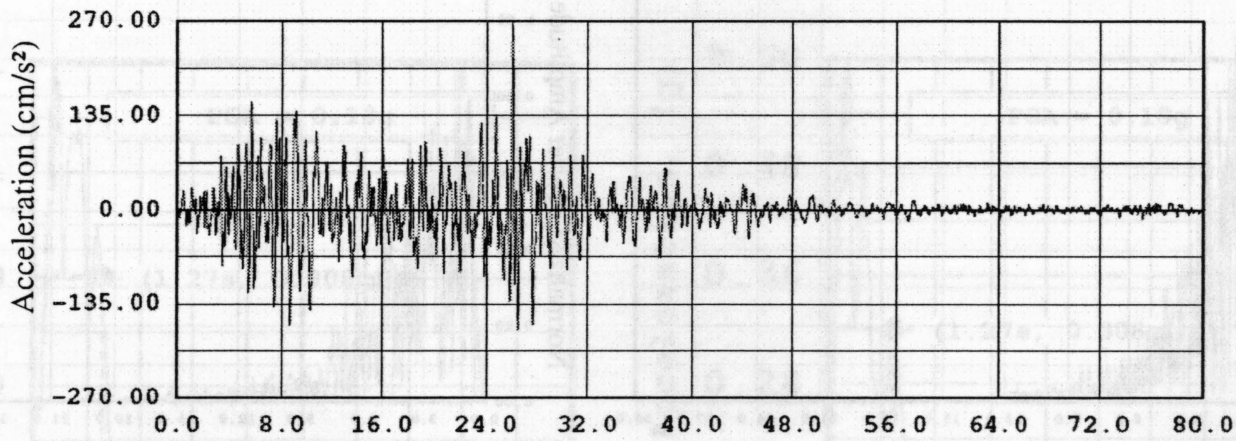

d)

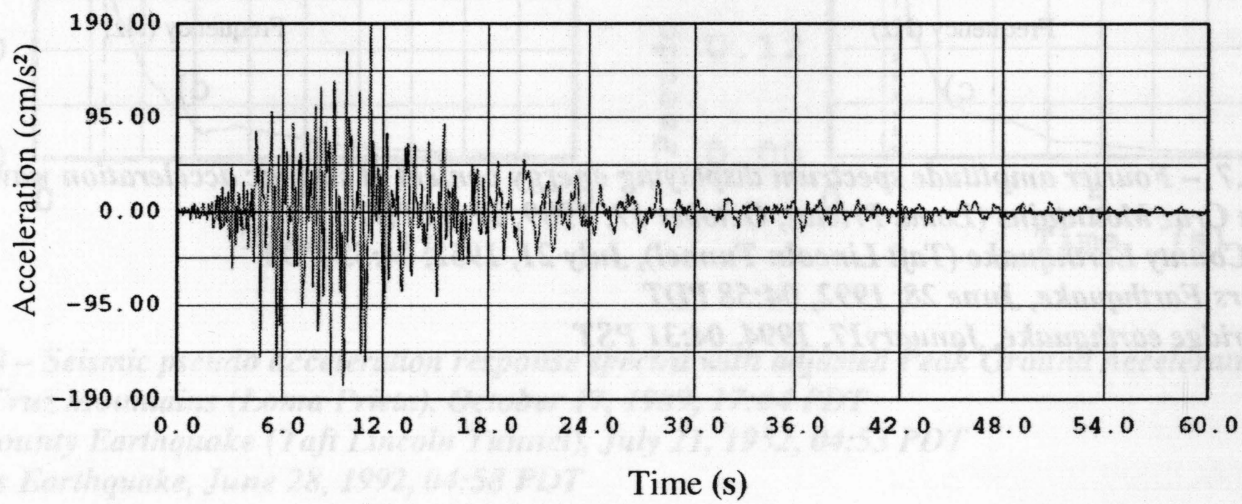

Figure 6.6-Selected seismic acceleration waveforms:

a) Santa Cruz Mountains (Loma Prieta), October 17, 1989, 17:04 PDT

b) Kern County Earthquake (Taft Lincoln Tunnel), July 21, 1952, 04:53 PDT

c) Landers Earthquake, June 28, 1992, 04:58 PDT

d) Northridge earthquake, January17, 1994, 04:31 PST 


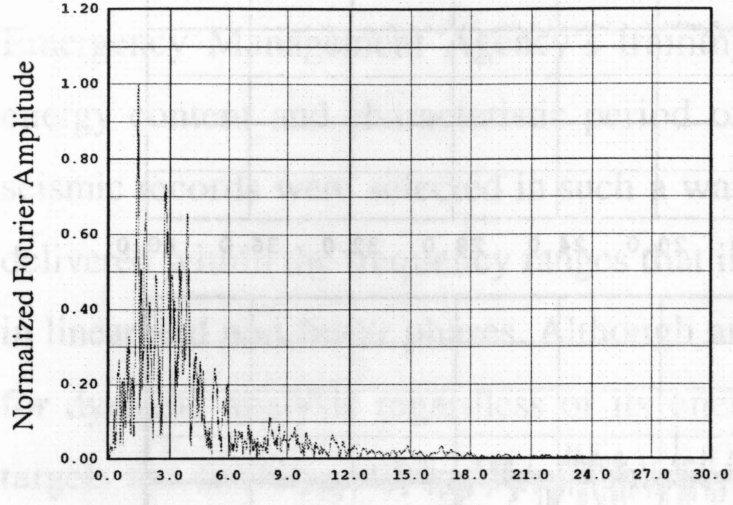

Frequency $(\mathrm{Hz})$

a)

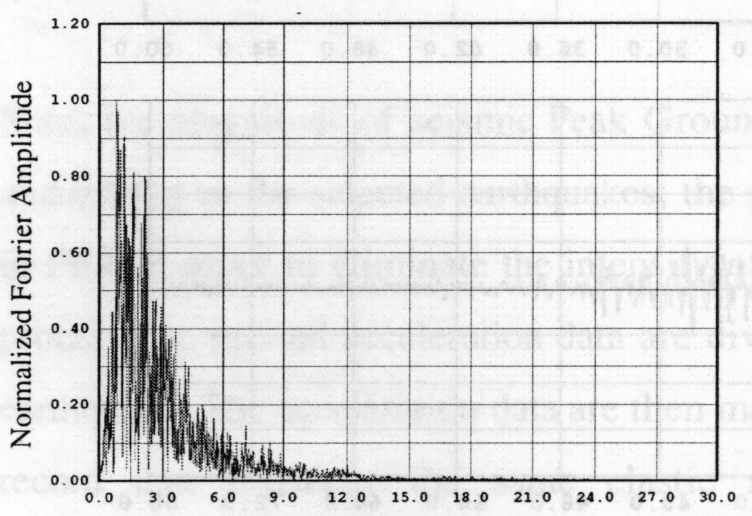

Frequency $(\mathrm{Hz})$

c)

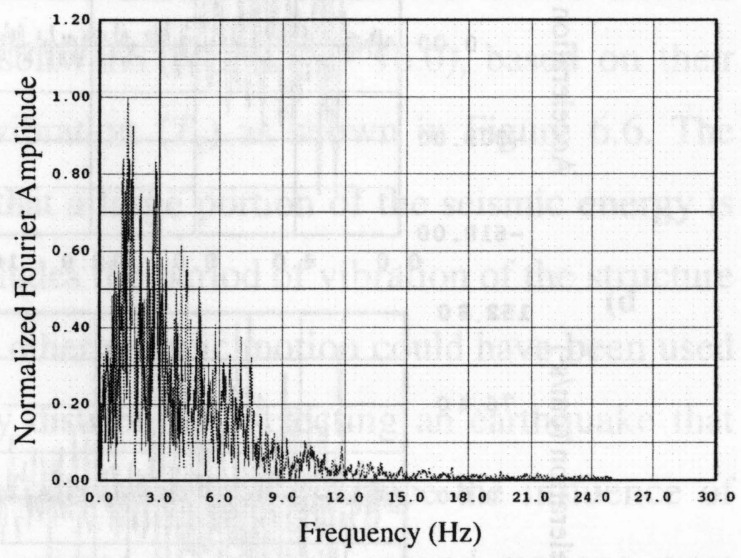

b)

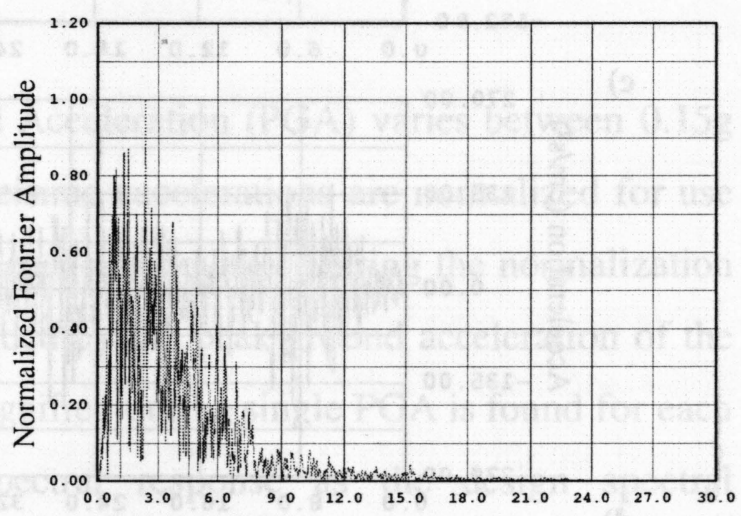

Frequency $(\mathrm{Hz})$

d)

Figure 6.7 - Fourier amplitude spectrum displaying energy content of seismic acceleration waveforms a) Santa Cruz Mountains (Loma Prieta), October 17, 1989, 17:04 PDT

b) Kern County Earthquake (Taft Lincoln Tunnel), July 21, 1952, 04:53 PDT

c) Landers Earthquake, June 28, 1992, 04:58 PDT

d) Northridge earthquake, January17, 1994, 04:31 PST 

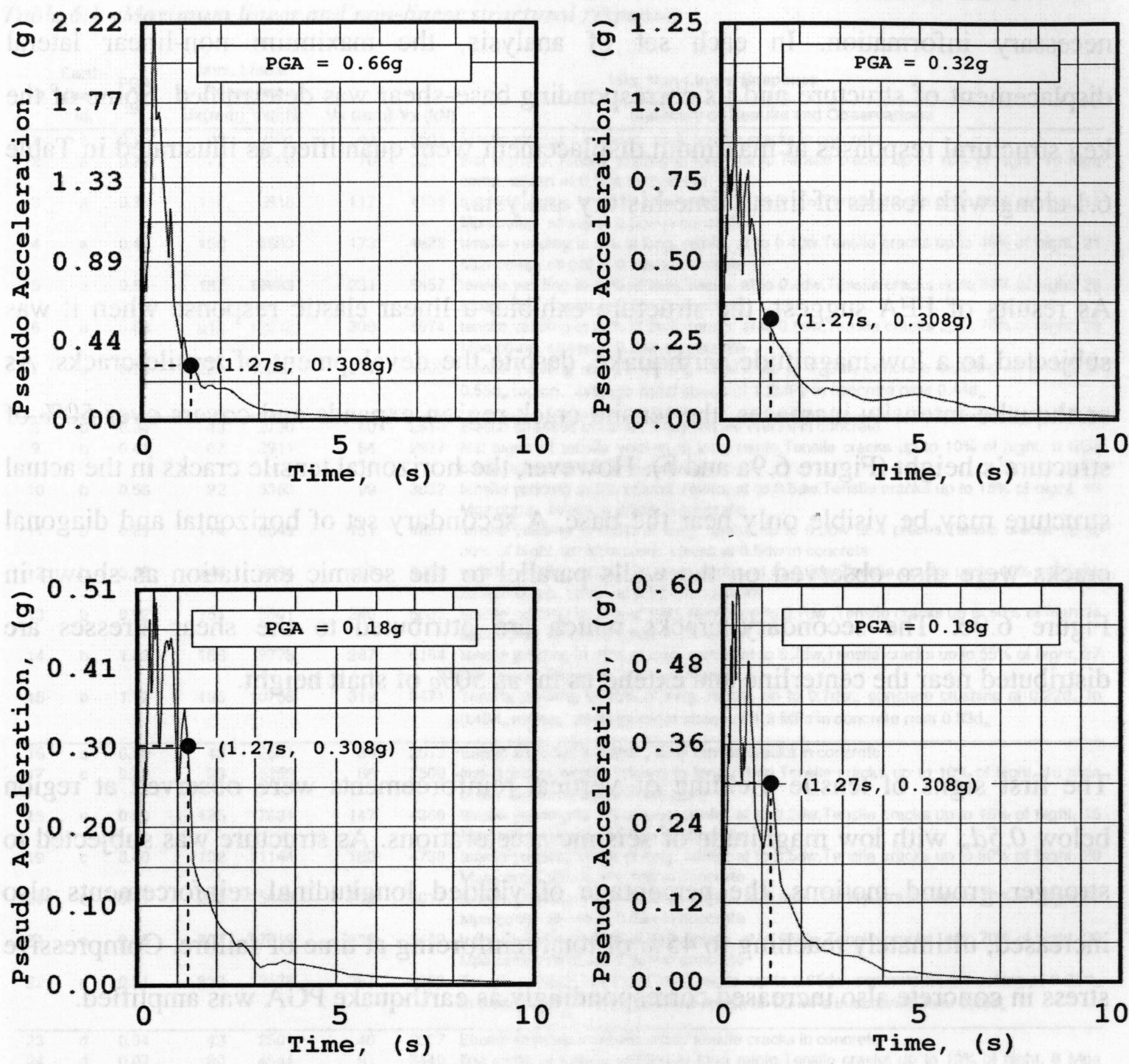

Figure 6.8 - Seismic pseudo acceleration response spectra with adjusted Peak Ground Acceleration (PGA):

a) Santa Cruz Mountains (Loma Prieta), October 17, 1989, 17:04 PDT

b) Kern County Earthquake (Taft Lincoln Tunnel), July 21, 1952, 04:53 PDT

c) Landers Earthquake, June 28, 1992, 04:58 PDT

d) Northridge earthquake, January17, 1994, 04:31 PST 


\subsection{Results of Time-History Analysis}

After performing over 50 time-history non-linear finite element analyses and gathering over $600 \mathrm{~GB}$ of data, 29 conclusive results were obtained which were later used to extract necessary information. In each set of analysis, the maximum non-linear lateral displacement of structure and its corresponding base-shear was determined. Some of the key structural responses at maximum displacement were quantified as illustrated in Table 6.1 along with results of linear time-history analysis.

As results of FEA suggest, the structure exhibits a linear elastic response when it was subjected to a low magnitude earthquake, despite the development of tensile cracks. As earthquake intensity increases, the tensile crack region expands and covers over $50 \%$ of structure's height (Figure 6.9a and b). However, the horizontal tensile cracks in the actual structure may be visible only near the base. A secondary set of horizontal and diagonal cracks were also observed on the walls parallel to the seismic excitation as shown in Figure $6.9 \mathrm{c}$. The secondary cracks which are attributed to the shear stresses are distributed near the centerline and extend as far as $50 \%$ of shaft height.

The first signs of tensile yielding of vertical reinforcements were observed at region below $0.5 d_{w}$ with low magnitude of seismic accelerations. As structure was subjected to stronger ground motions, the percentage of yielded longitudinal reinforcements also increased, ultimately reaching to $45 \%$ of total reinforcing at time of failure. Compressive stress in concrete also increased correspondingly as earthquake PGA was amplified.

Maximum shear stresses were observed near $0.5 d_{w}$ of the base of structure. The average shear stress in concrete was calculated approximately as $1.2 \mathrm{MPa}$ which is within the tolerance recommended by ACI $318-08$ as $1.0 \mathrm{MPa}$ and $1.5 \mathrm{MPa}$. The parabolic shear stress distribution was observed only in upper region of the shaft where the structure is still un-cracked as shown in Figure 6.10. The idealized uniform shear stress distribution suggested by ACI 318-08 was also observed in central region of the shaft. However the shear stress in concrete at critical lower section is highly non-linear and is controlled by 


\section{characteristic of concrete smeared crack model. A significant concentration of shear}

stresses was observed near the center line of the shaft at the base which is believed to be initiated from fixed support conditions.

\section{Table 6.1 - Maximum linear and non-linear structural responses}

\begin{tabular}{|c|c|c|c|c|c|c|c|}
\hline \multirow[t]{2}{*}{ № } & \multirow{2}{*}{$\begin{array}{l}\text { Earth- } \\
\text { quake } \\
\text { Id. }\end{array}$} & \multirow{2}{*}{$\begin{array}{l}\text { PGA } \\
\text { (g) }\end{array}$} & \multicolumn{2}{|c|}{$\begin{array}{l}\text { Max. Linear } \\
\text { Response }\end{array}$} & \multicolumn{3}{|r|}{ Max. Non-Linear Response } \\
\hline & & & $\overline{\mathrm{Ux}(\mathrm{mm})}$ & $\mathrm{Vx}(\mathrm{kN})$ & Ux $(\mathrm{mm})$ & $\mathrm{Vx}(\mathrm{kN})$ & Summary of Results and Observations \\
\hline 1 & $\bar{a}$ & 0.12 & 43 & 2501 & 43 & 2501 & Elastic stresses in reinfo., early tensile cracks in concrete \\
\hline 2 & a & 0.23 & 72 & 4200 & 70 & 3231 & $\begin{array}{l}\text { first signs of tensile yeidling in long reinfo, Tensile cracks up to } 10 \% \text { of hight, } 10 \mathrm{Mpa} \\
\text { comp. stress at } 0.5 \mathrm{dw} \text { in concrete }\end{array}$ \\
\hline 3 & a & 0.31 & 112 & 6518 & 117 & 4136 & $\begin{array}{l}\text { tensile yeilding in } 1 \% \text { of long. reinfo. at to } 0.1 \mathrm{dw} \text {, Tensile cracks up to } 25 \% \text { of hight, } 14 \\
\text { Mpa comp. stress at } 0.5 \mathrm{dw} \text { in concrete }\end{array}$ \\
\hline 4 & a & 0.41 & 150 & 8690 & 173 & 4822 & $\begin{array}{l}\text { tensile yeilding in } 5 \% \text { of long. reinfo. at to } 0.4 \mathrm{dw} \text {, Tensile cracks up to } 40 \% \text { of hight, } 21 \\
\text { Mpa comp. stress at } 0.5 \mathrm{dw} \text { in concrete }\end{array}$ \\
\hline 5 & a & 0.51 & 187 & 10863 & 231 & 5457 & $\begin{array}{l}\text { tensile yeilding in } 10 \% \text { of long. reinfo. at to } 0.4 \mathrm{dw} \text {, Tensile cracks up to } 50 \% \text { of hight, } 25 \\
\text { Mpa comp. stress at } 0.5 \mathrm{dw} \text { in concrete }\end{array}$ \\
\hline 6 & a & 0.63 & 212 & 12312 & 300 & 5974 & $\begin{array}{l}\text { tensile yeilding in } 28 \% \text { of long. reinfo. at to } 0.5 \mathrm{dw} \text {, Tensile cracks up to } 70 \% \text { of hight, } 29 \\
\text { Mpa comp. stress at } 0.5 \mathrm{dw} \text { in concrete }\end{array}$ \\
\hline 7 & a & 0.72 & 228 & 13268 & 351 & 6200 & $\begin{array}{l}\text { tensile yeilding in } 41 \% \text { of long. reinfo. up to } 0.5 \mathrm{dw} \text {, concrete crushing at } 0.16 \mathrm{~d}_{w} \text { to } \\
0.55 \mathrm{~d}_{w} \text { region, average shear stress of } 1.2 \mathrm{MPa} \text { in concrete near } 0.44 \mathrm{~d}_{w}\end{array}$ \\
\hline 8 & $\mathrm{~b}$ & 0.34 & 43 & 2730 & 40 & 2510 & Elastic stresses in reinfo., early tensile cracks in concrete \\
\hline 9 & b & 0.41 & 67 & 3911 & 64 & 2977 & $\begin{array}{l}\text { first signs of tensile yeidling in long reinfo, Tensile cracks up to } 10 \% \text { of hight, } 9 \text { Mpa } \\
\text { comp. stress at } 0.5 \mathrm{dw} \text { in concrete }\end{array}$ \\
\hline 10 & $b$ & 0.56 & 92 & 5353 & 99 & 3832 & $\begin{array}{l}\text { tensile yeilding in } 5 \% \text { of long. reinfo. at to } 0.5 \mathrm{dw} \text {, Tensile cracks up to } 15 \% \text { of hight, } 16 \\
\text { Mpa comp. stress at } 0.5 \mathrm{dw} \text { in concrete }\end{array}$ \\
\hline 11 & $b$ & 0.69 & 114 & 6649 & 151 & 4667 & $\begin{array}{l}\text { tensile yeilding in } 8.3 \% \text { of long. reinfo. up to } 0.5 \mathrm{dw} \text { at } 4 \text { places, Tensile cracks up to } \\
30 \% \text { of hight, } 20 \mathrm{Mpa} \text { comp. stress at } 0.5 \mathrm{dw} \text { in concrete }\end{array}$ \\
\hline 12 & b & 0.88 & 146 & 8494 & 197 & 5309 & $\begin{array}{l}\text { tensile yeilding in } 24 \% \text { of long. reinfo. at to } 0.5 \mathrm{dw} \text {, Tensile cracks up to } 40 \% \text { of hight, } \\
22 \mathrm{Mpa} \text { comp. stress at } 0.5 \mathrm{dw} \text { in concrete }\end{array}$ \\
\hline 13 & b & 0.92 & 151 & 8801 & 240 & 5633 & $\begin{array}{l}\text { tensile yeilding in } 37 \% \text { of long. reinfo. up to } 0.7 \mathrm{dw} \text {, Tensile cracks up to } 50 \% \text { of hight } 24 \\
\text { Mpa comp. stress at } 0.5 \mathrm{dw} \text { in concrete }\end{array}$ \\
\hline 14 & b & 1.02 & 168 & 9778 & 267 & 6164 & $\begin{array}{l}\text { tensile yeilding in } 40 \% \text { of long. reinfo. at to } 0.7 \mathrm{dw} \text {, Tensile cracks up to } 55 \% \text { of hight, } 27 \\
\text { Mpa comp. stress at ?dw in concrete }\end{array}$ \\
\hline 15 & b & 1.12 & 185 & 10756 & 319 & 6471 & $\begin{array}{l}\text { Tensile yeilding in } 45 \% \text { of long. reinfo. up to } 0.7 d w, \text { concrete crushing at } 0.22 d_{w} \text { to } \\
0.49 \mathrm{~d}_{w} \text { region, average shear stress of } 1.3 \mathrm{MPa} \text { in concrete near } 0.33 \mathrm{~d}_{w}\end{array}$ \\
\hline 16 & c & 0.06 & 43 & 2501 & & 13 & Elastic stresses in reinfo., early tens \\
\hline 17 & c & 0.30 & 90 & 5250 & 86 & 3500 & $\begin{array}{l}\text { first signs of tensile yeidling in long reinfo, Tensile cracks up to } 10 \% \text { of hight, } 10 \mathrm{Mpa} \\
\text { comp. stress at } 0.5 \mathrm{dw} \text { in concrete }\end{array}$ \\
\hline 18 & c & 0.20 & 135 & 7831 & 147 & 4360 & $\begin{array}{l}\text { tensile yeilding in } 1 \% \text { of long. reinfo. at to } 0.2 \mathrm{dw} \text {, Tensile cracks up to } 15 \% \text { of hight, } 15 \\
\text { Mpa comp. stress at } 0.5 \mathrm{dw} \text { in concrete }\end{array}$ \\
\hline 19 & $c$ & 0.40 & 192 & 11144 & 180 & 4730 & $\begin{array}{l}\text { tensile yeilding in } 4 \% \text { of long. reinfo. at to } 0.5 \mathrm{dw} \text {, Tensile cracks up to } 50 \% \text { of hight, } 20 \\
\text { Mpa comp. stress at } 0.5 \mathrm{dw} \text { in concrete }\end{array}$ \\
\hline 20 & C & 0.41 & 270 & 15662 & 203 & 5017 & $\begin{array}{l}\text { tensile yeilding in } 5 \% \text { of long. reinfo. at } 0.6 \mathrm{dw} \text {, Tensile cracks up to } 70 \% \text { of hight, } 22 \\
\text { Mpa comp. stress at } 0.5 \mathrm{dw} \text { in concrete }\end{array}$ \\
\hline 21 & c & 0.46 & 303 & 17619 & 239 & 5442 & $\begin{array}{l}\text { tensile yeilding in } 20 \% \text { of long. reinfo. at to } 0.6 \mathrm{dw} \text {, Tensile cracks up to } 70 \% \text { of hight, } 26 \\
\text { Mpa comp. stress at } 0.5 \mathrm{dw} \text { in concrete }\end{array}$ \\
\hline 22 & c & 0.51 & 337 & 19578 & 287 & 5963 & $\begin{array}{l}\text { Tensile yeilding in } 45 \% \text { of long. reinfo. up to } 0.65 \mathrm{dw} \text {, concrete near crushing at } 0.21 \mathrm{~d}_{w} \\
\text { to } 0.54 \mathrm{~d}_{\mathrm{w}} \text { region, average shear stress of } 1.2 \mathrm{MPa} \text { in concrete near } 0.65 \mathrm{~d}_{w}\end{array}$ \\
\hline 23 & $d$ & 0.04 & 43 & 2501 & 40 & 2507 & Elastic stresses in reinfo., early tensile cracks in concrete \\
\hline 24 & d & 0.07 & 80 & 4644 & 81 & 3440 & $\begin{array}{l}\text { first signs of tensile yeidling in long reinfo, Tensile cracks up to } 10 \% \text { of hight, } 8 \mathrm{Mpa} \\
\text { comp. stress at } 0.5 \mathrm{dw} \text { in concrete }\end{array}$ \\
\hline 25 & d & 0.10 & 101 & 5847 & 147 & 3853 & $\begin{array}{l}\text { tensile yeilding in } 12 \% \text { of long. reinfo. at to } 0.1 \mathrm{dw} \text {, Tensile cracks up to } 30 \% \text { of hight, } 16 \\
\text { Mpa comp. stress at } 0.5 \mathrm{dw} \text { in concrete }\end{array}$ \\
\hline 26 & d & 0.15 & 151 & 8771 & 165 & 4465 & $\begin{array}{l}\text { tensile yeilding in } 20 \% \text { of long. reinfo. at } 0.1 \mathrm{dw} \text {, Tensile cracks up to } 50 \% \text { of hight, } 22 \\
\text { Mpa comp. stress at } 0.5 \mathrm{dw} \text { in concrete }\end{array}$ \\
\hline 27 & d & 0.20 & 201 & 11695 & 220 & 5058 & $\begin{array}{l}\text { tensile yeilding in } 30 \% \text { of long. reinfo. at to } 0.3 \mathrm{dw} \text {. Tensile cracks up to } 55 \% \text { of hight, } 26 \\
\text { Mpa comp. stress at } 0.5 \mathrm{dw} \text { in concrete }\end{array}$ \\
\hline 28 & d & 0.25 & 217 & 12604 & 270 & 5230 & $\begin{array}{l}\text { tensile yeilding in } 40 \% \text { of long. reinfo. at to } 0.5 \mathrm{dw} \text {, Tensile cracks up to } 65 \% \text { of hight, } 30 \\
\text { Mpa comp. stress at } 0.50 \mathrm{dw} \text { in concrete }\end{array}$ \\
\hline 29 & d & 0.32 & 231 & 13421 & 350 & 5478 & $\begin{array}{l}\text { Reinfo. yielding in tension, concrete crushing at } 0.16 \mathrm{~d}_{w} \text { to } 0.55 \mathrm{~d}_{\mathrm{w}} \text { region, average } \\
\text { shear stress of } 1.1 \mathrm{MPa} \text { in concrete near } 0.43 \mathrm{~d}_{\mathrm{w}}\end{array}$ \\
\hline
\end{tabular}

PGA = Peak ground acceleration $(g)$

$U \boldsymbol{X}=$ Maximum lateral displacement of c.g. of oscillating mass $(\mathrm{mm})$

$V x=$ Maximum amount of base-shear developed during an episode of excitation (MN) 


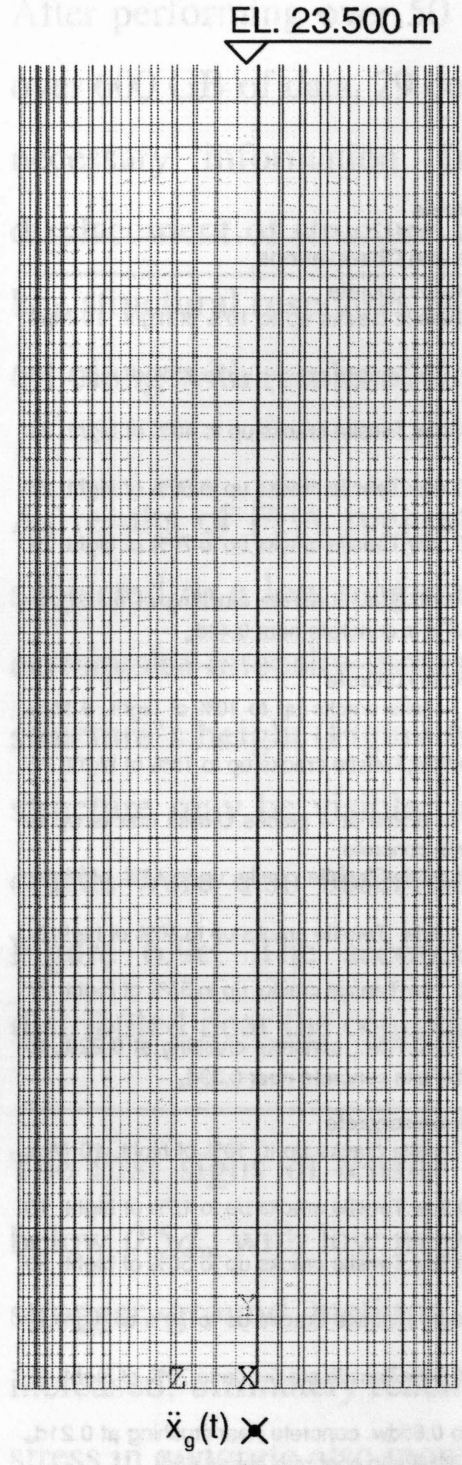

a)

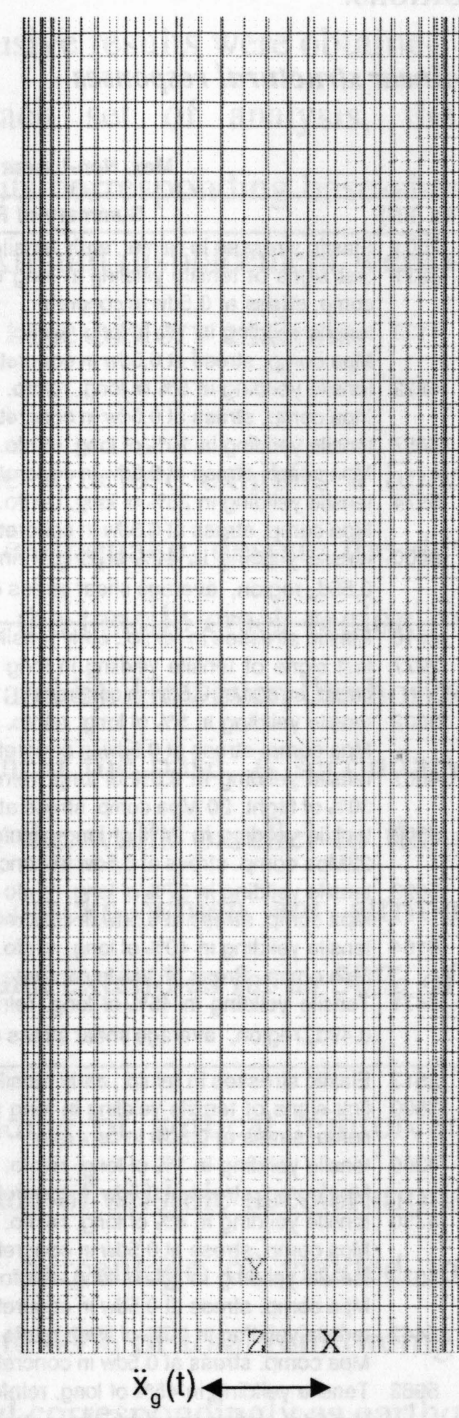

b)

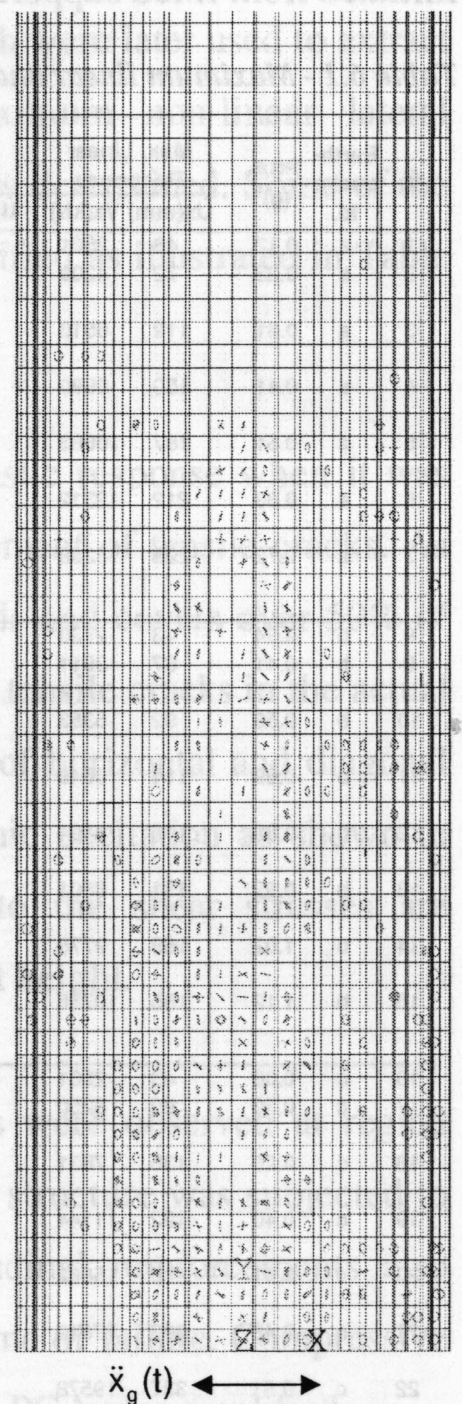

c)

Figure 6.9 - Development of cracks on the body of the shaft. a) Horizontal crack pattern on the wall facing seismic excitation, b) Horizontal and diagonal crack pattern on the wall parallel to seismic excitation, and c) Vertical crack pattern on the wall parallel to the seismic excitation. 
Shear Stress in Concrete $\left(\tau_{c}\right)$ :

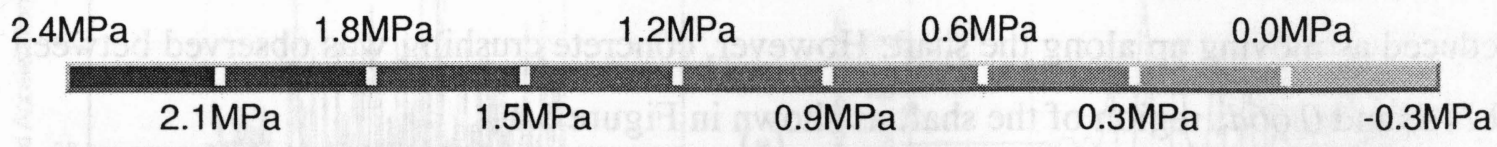
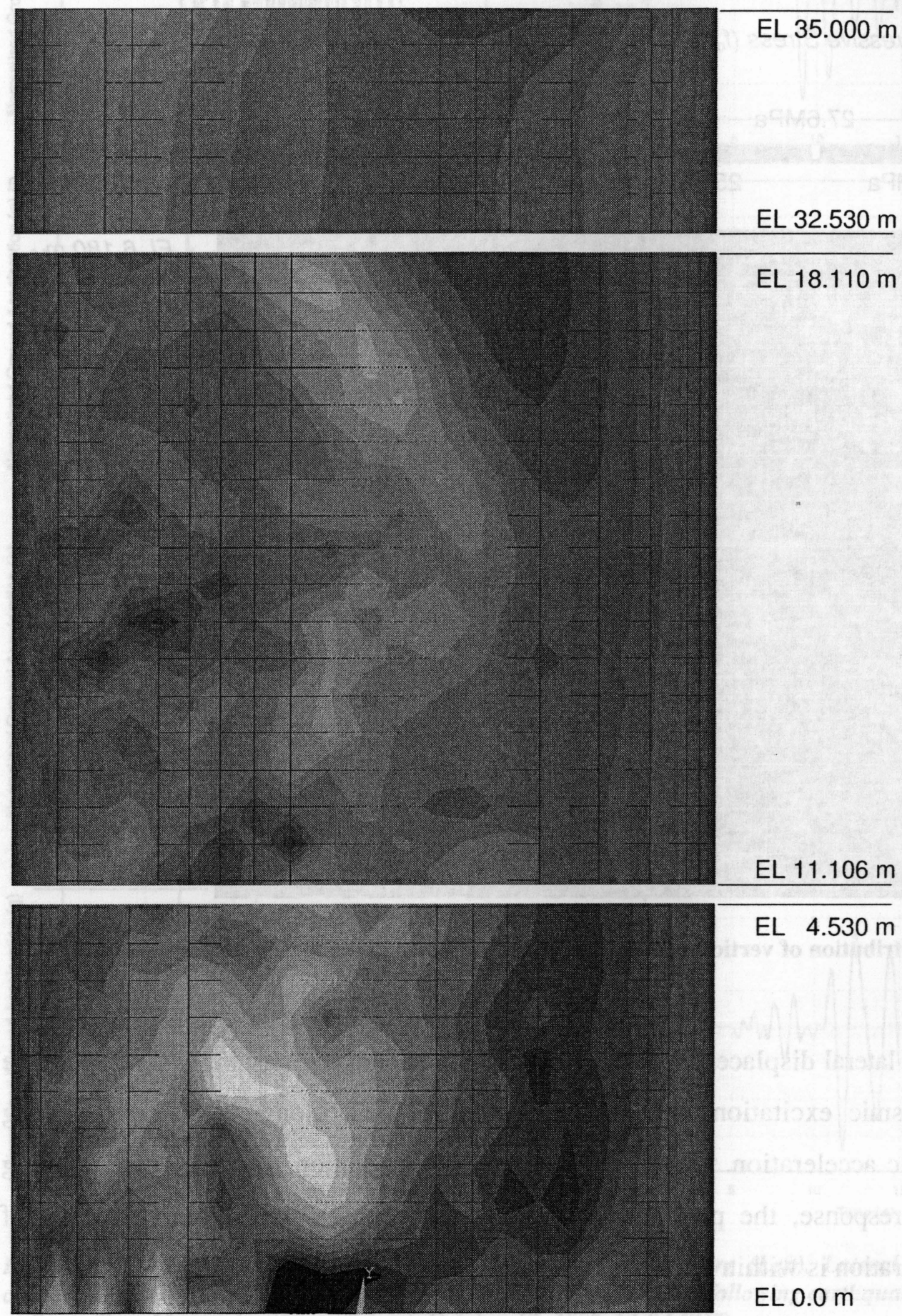

EL $4.530 \mathrm{~m}$

EL $0.0 \mathrm{~m}$

Figure 6.10 - Distribution of shear stress along the length of the shaft at time of peak lacteal 
The maximum compressive stress was observed at the base of structure and it was reduced as moving up along the shaft. However, concrete crushing was observed between $0.11 d_{w}$ and $0.66 d_{w}$ region of the shaft as shown in Figure 6.11 .

Concrete Compressive Stress $\left(f_{c}\right)$ :
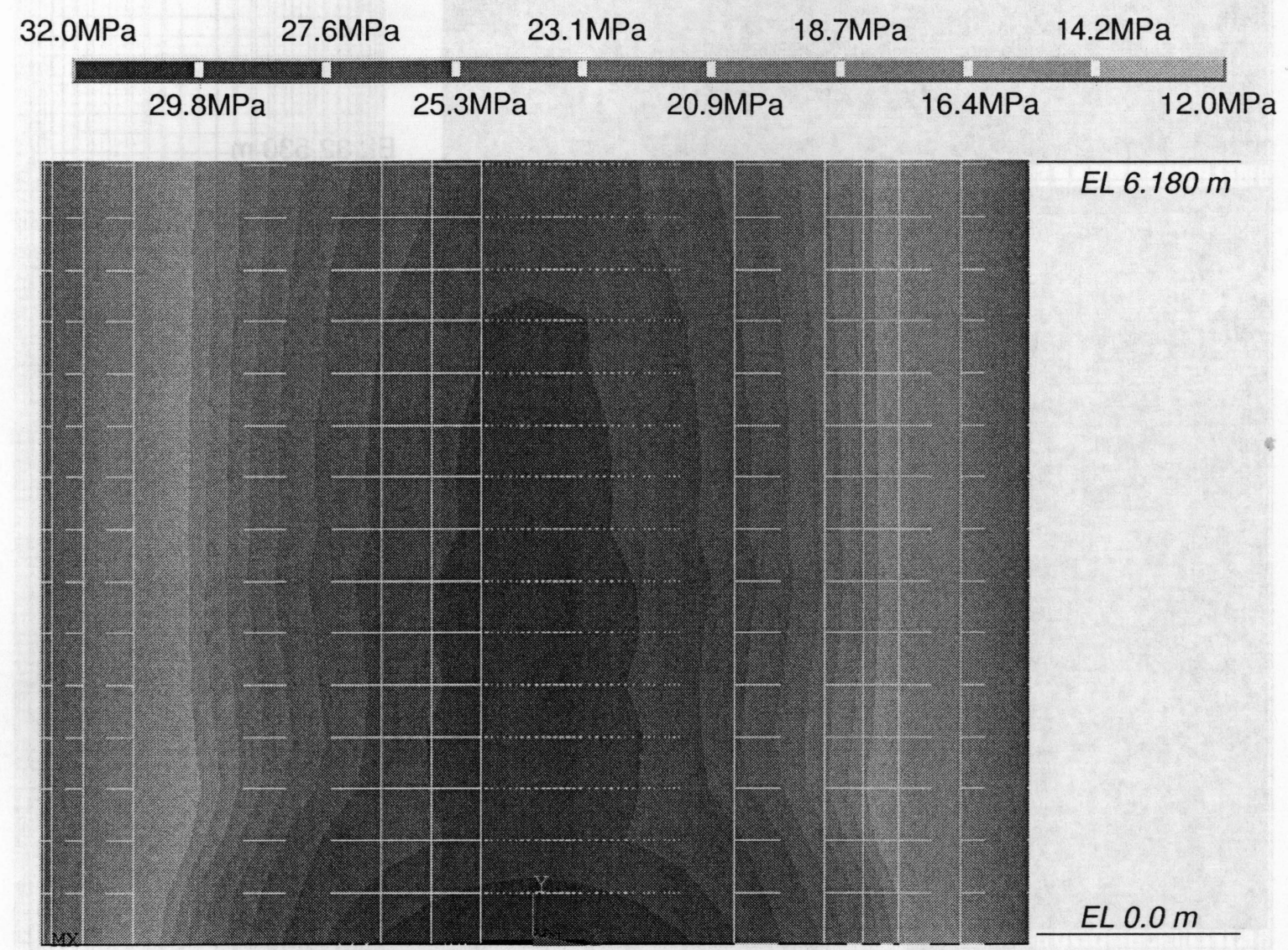

Figure 6.11-Distribution of vertical concrete compressive stress in the shaft near the base of the shaft

The hysteretic lateral displacements at the centroid of impulsive mass of water during the maximum seismic excitations are shown in Figure 6.12, along with corresponding applied seismic acceleration. Comparing the lateral acceleration with the corresponding displacement response, the peak lateral displacement appears when the frequency of seismic acceleration is within the frequency range of inelastic structure. 


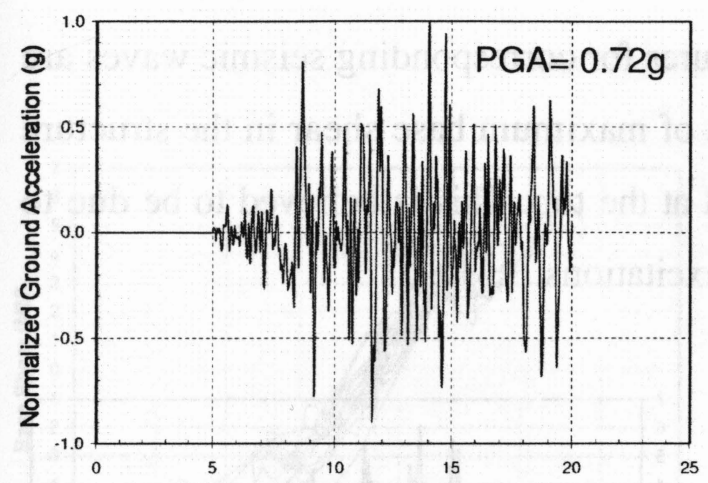

(a)
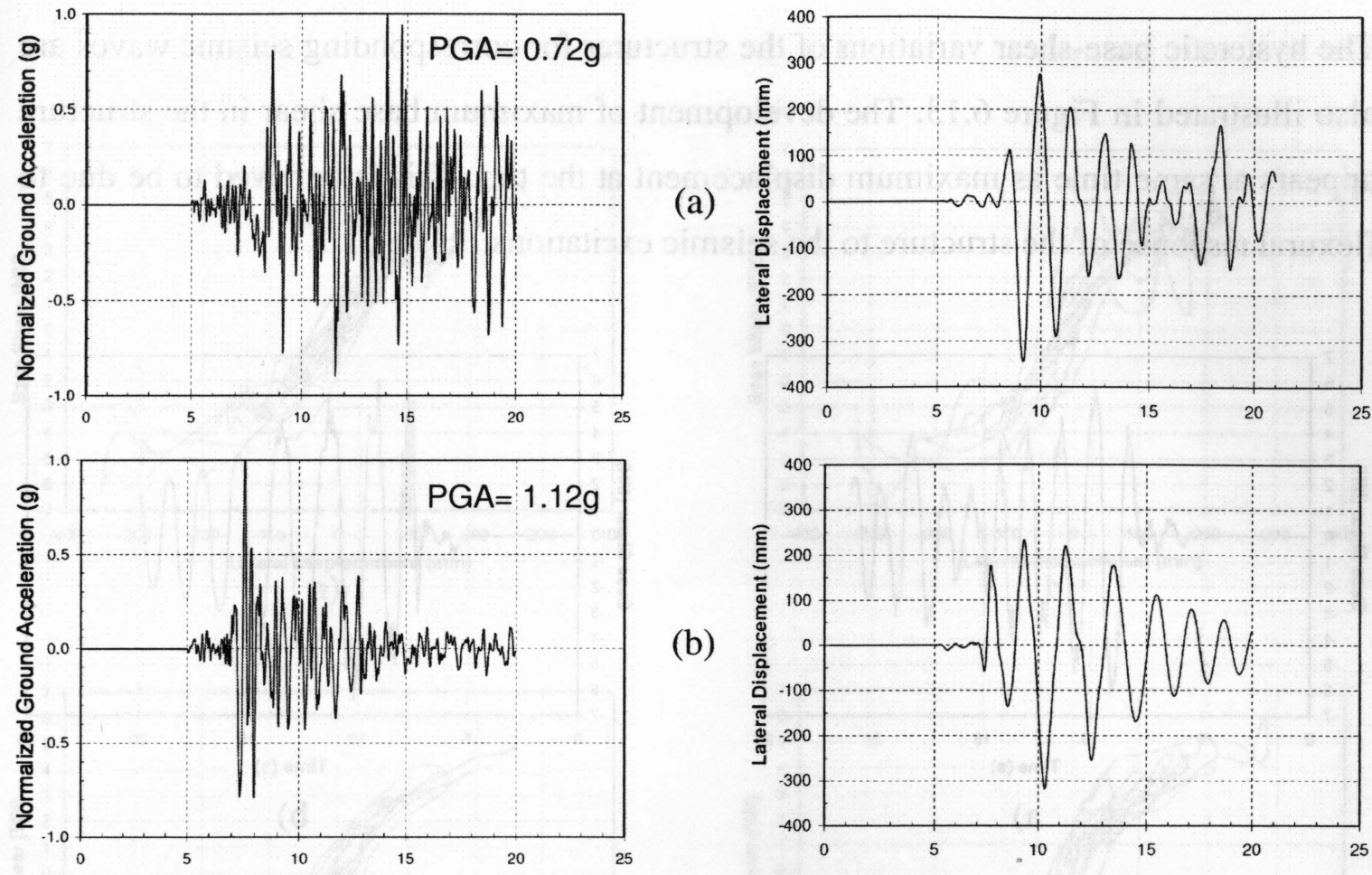

(b)
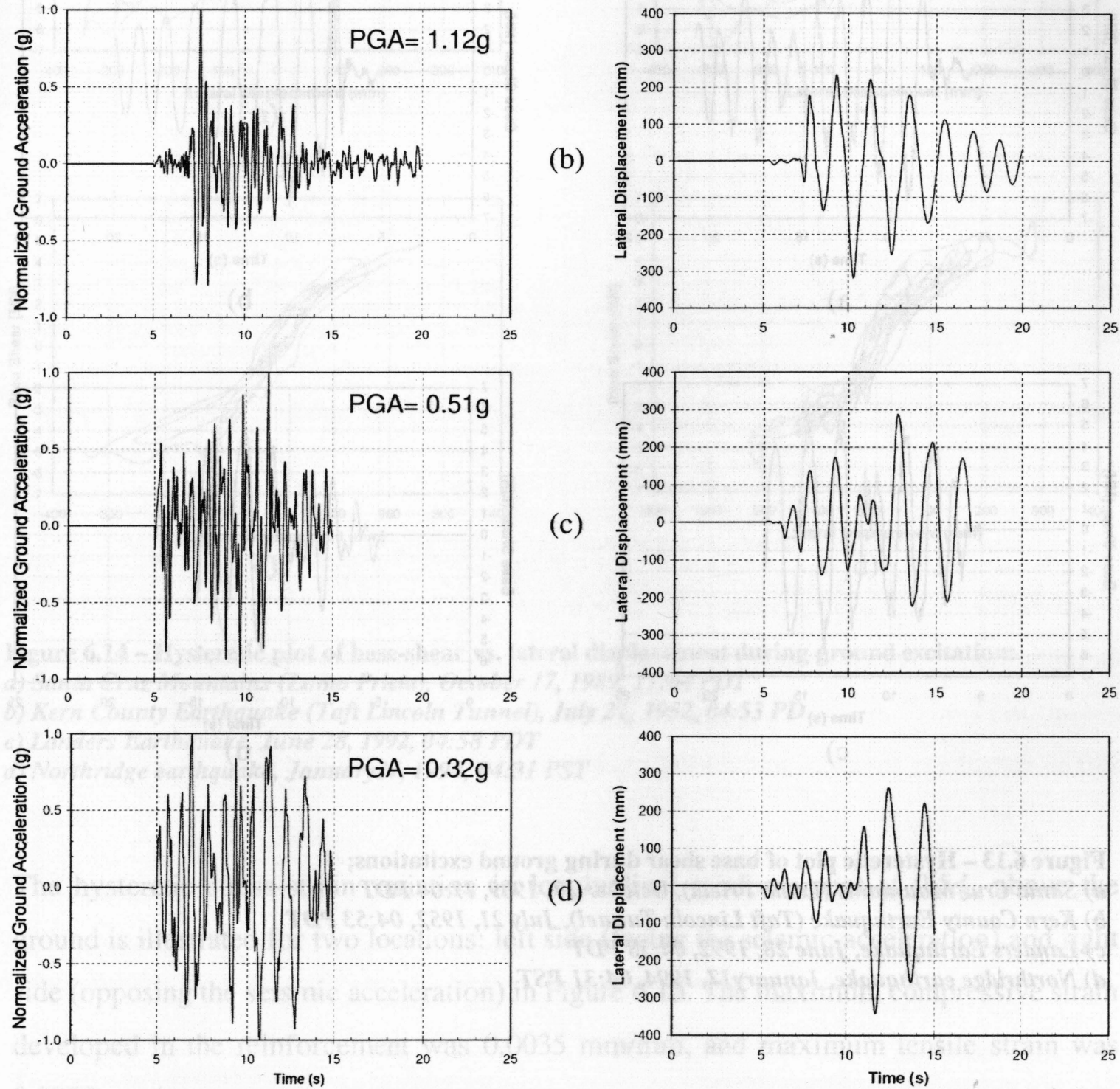

Figure 6.12 - Lateral seismic acceleration applied to the structure (Left), Lateral displacement of concentrated impulsive mass of water (Right), when subjected to the following earthquake:

a) Santa Cruz Mountains (Loma Prieta), October 17, 1989, 17:04 PDT

b) Kern County Earthquake (Taft Lincoln Tunnel), July 21, 1952, 04:53 PDT

c) Landers Earthquake, June 28, 1992, 04:58 PDT

d) Northridge earthquake, January17, 1994, 04:31 PST 
The hysteretic base-shear variations of the structures for corresponding seismic waves are also illustrated in Figure 6.13. The development of maximum base shear in the structure appears at same time as maximum displacement at the top. This is believed to be due to flexural response of the structure to the seismic excitations.

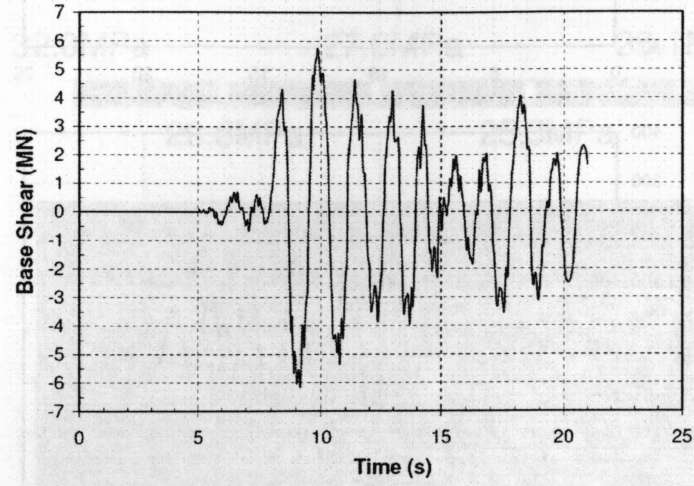

a)

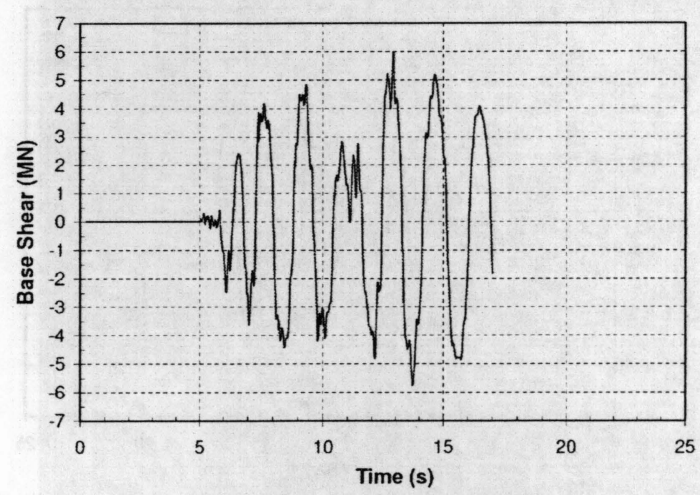

c)

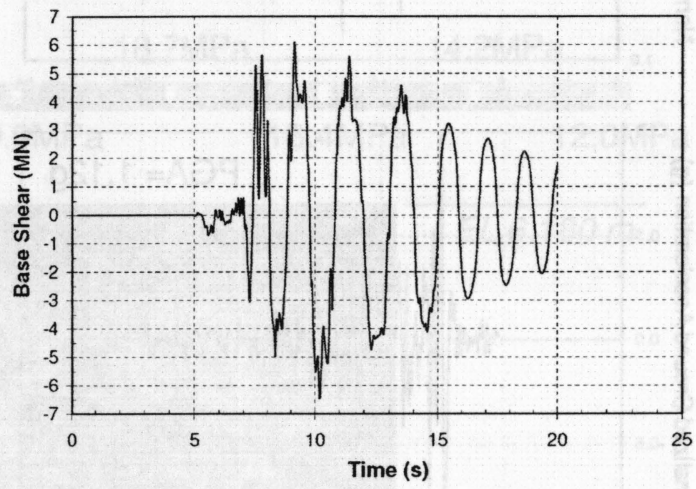

b)

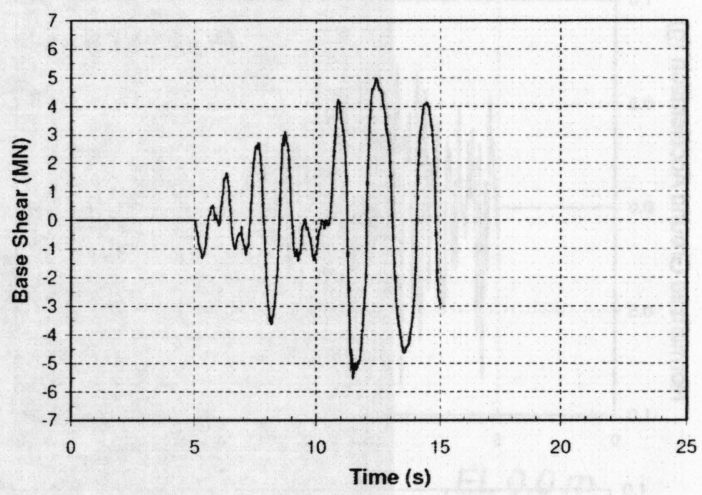

d)

Figure 6.13 - Hysteretic plot of base shear during ground excitations;

a) Santa Cruz Mountains (Loma Prieta), October 17, 1989, 17:04 PDT

b) Kern County Earthquake (Taft Lincoln Tunnel), July 21, 1952, 04:53 PDT

c) Landers Earthquake, June 28, 1992, 04:58 PDT

d) Northridge earthquake, January17, 1994, 04:31 PST

The hysteretic displacements at centroid of tank and base-shear data are then combined to generate the structural response of FE model as shown in Figure 6.14. The base shear lateral displacement plot of seismic response suggests that a nominal amount of ductility exists in the system. 


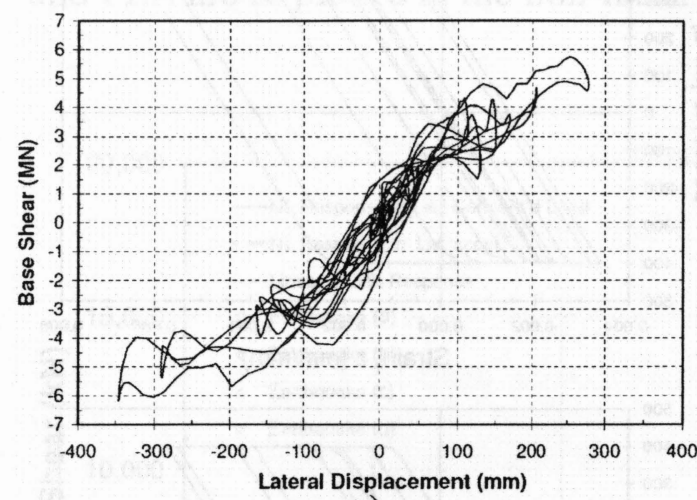

a)

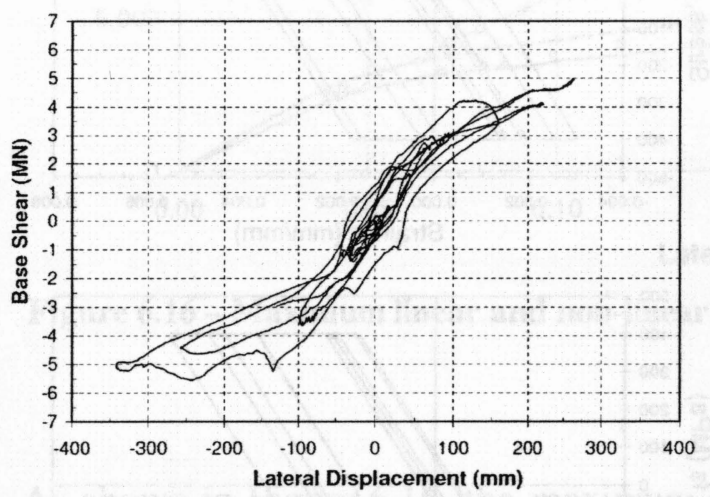

c)

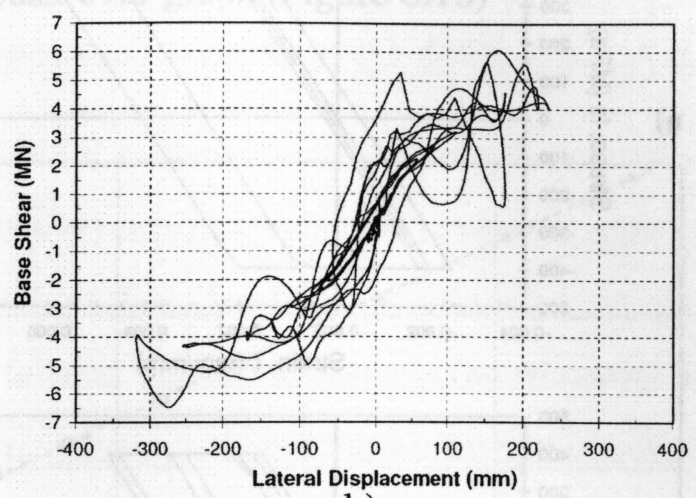

b)

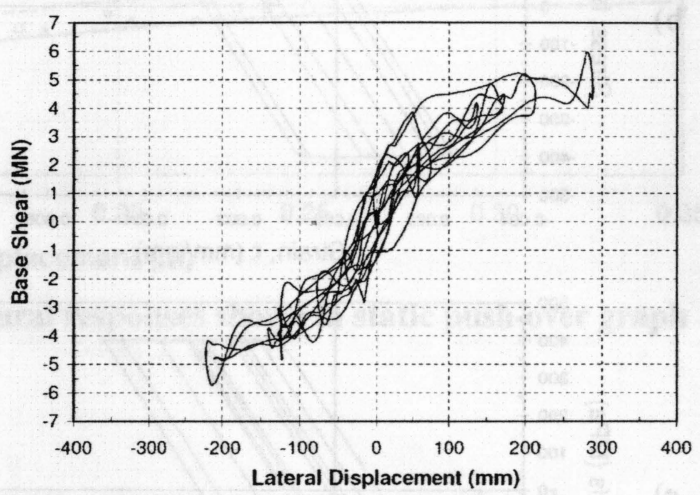

d)

Figure 6.14 - Hysteretic plot of base-shear vs. lateral displacement during ground excitation:

a) Santa Cruz Mountains (Loma Prieta), October 17, 1989, 17:04 PDT

b) Kern County Earthquake (Taft Lincoln Tunnel), July 21, 1952, 04:53 PD

c) Landers Earthquake, June 28, 1992, 04:58 PDT

d) Northridge earthquake, January17, 1994, 04:31 PST

The hysteretic stress-strain variation in longitudinal reinforcement at $0.5 d_{w}$ above the ground is illustrated for two locations: left side (facing the seismic acceleration) and right side (opposing the seismic acceleration) in Figure 6.15. The maximum compressive strain developed in the reinforcement was $0.0035 \mathrm{~mm} / \mathrm{mm}$, and maximum tensile strain was $0.0075 \mathrm{~mm} / \mathrm{mm}$. 


\section{Left}

a)

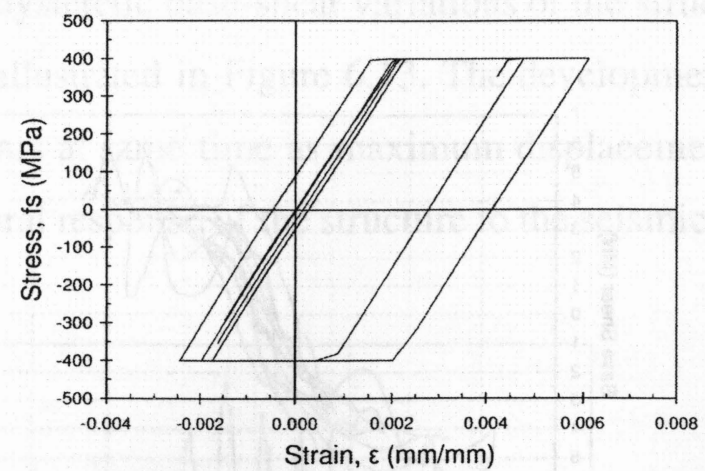

b)

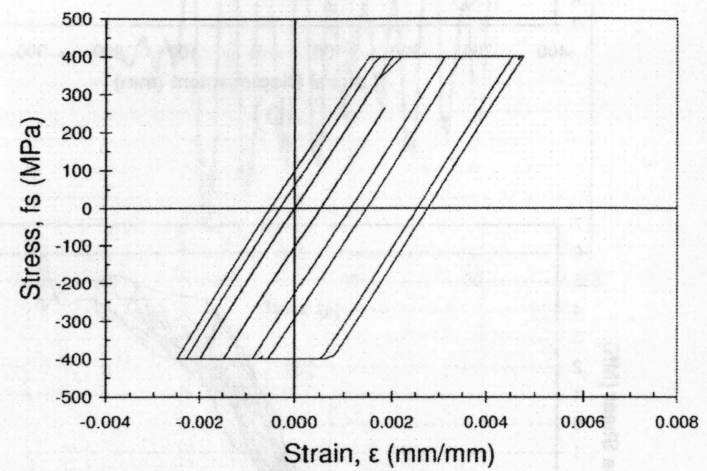

c)

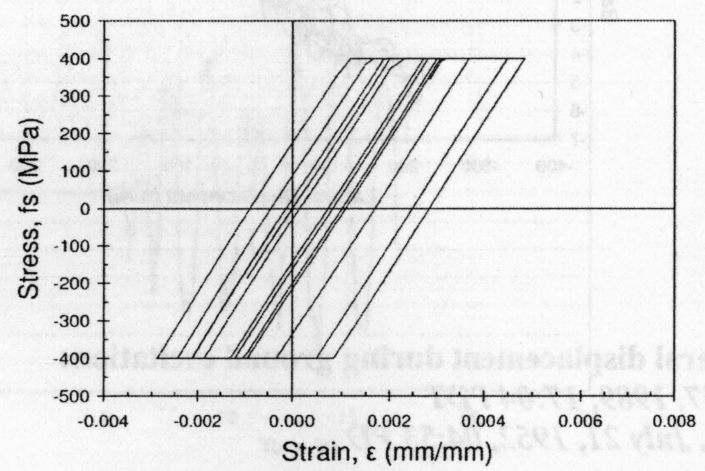

d)

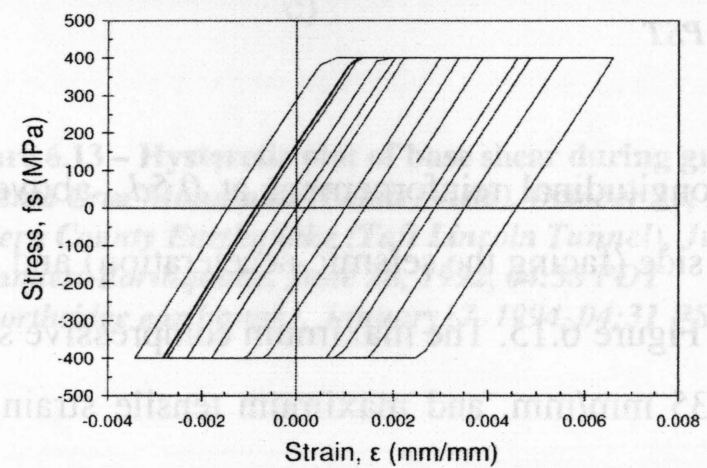

Risht
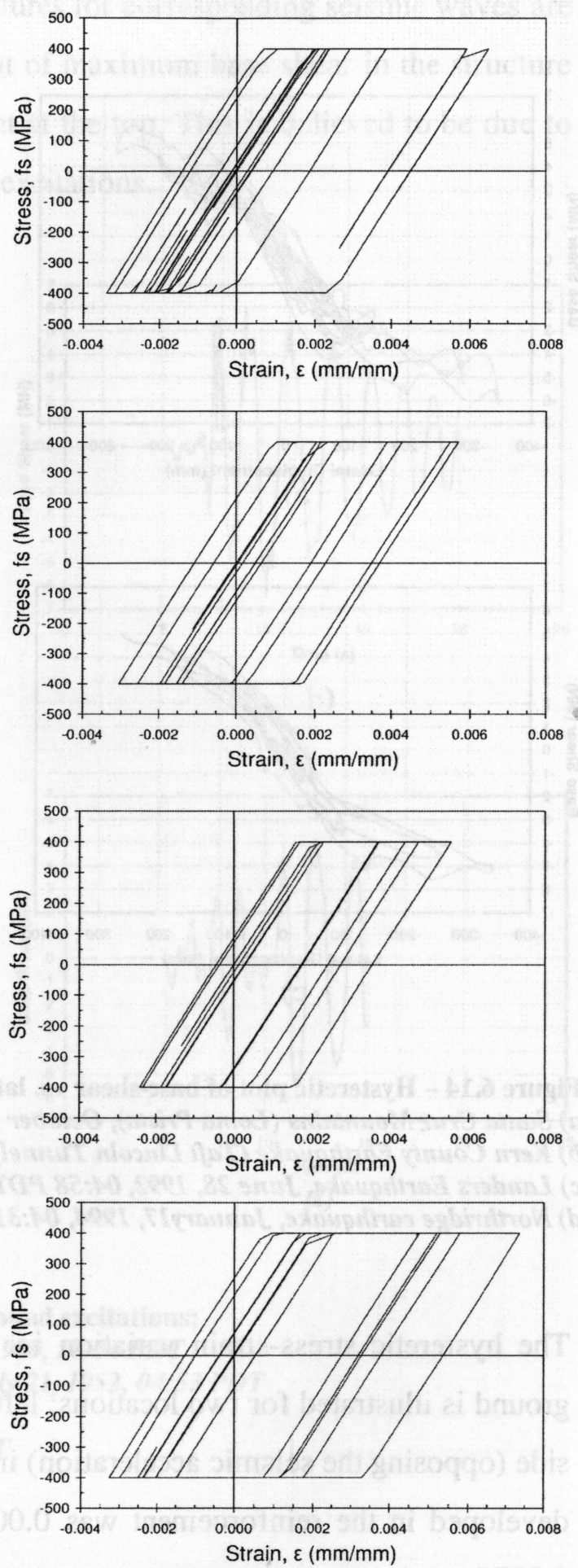

Figure 6.15 - Hysteretic stress-strain plot of a selected longitudinal reinforcement at $0.5 d_{w}$ above the ground at left (a) and right (b) side of the shaft structure subjected to seismic acceleration:

a) Santa Cruz Mountains (Loma Prieta), October 17, 1989, 17:04 PDT

b) Kern County Earthquake (Taft Lincoln Tunnel), July 21, 1952, 04:53 PDT

c) Landers Earthquake, June 28, 1992, 04:58 PDT

d) Northridge earthquake, January17, 1994, 04:31 PST 
The maximum linear and non-linear structural responses calculated from spectral analysis and FEA are re plotted in the non-linear static push-over graph (Figure 6.16)

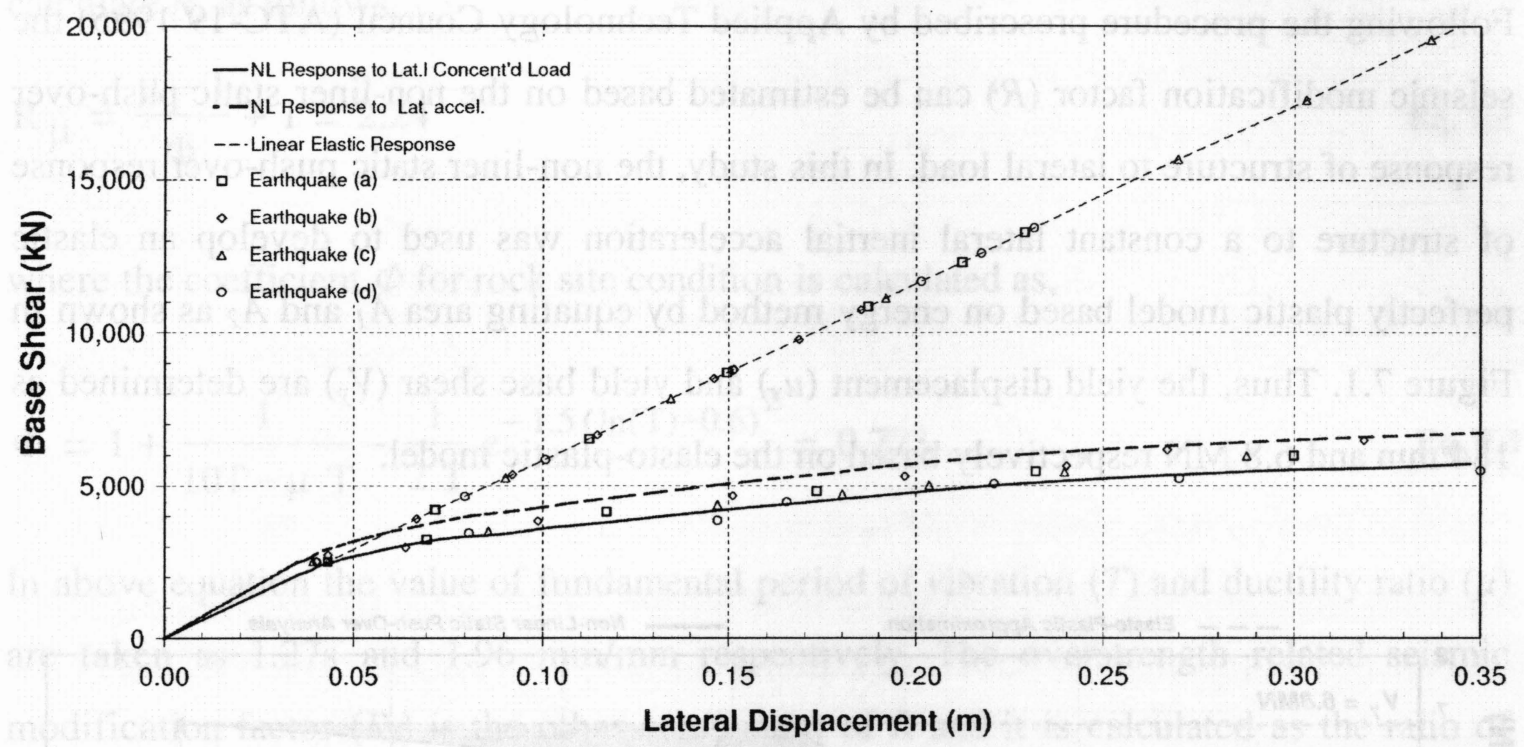

Figure 6.16 - Maximum linear and non-linear structural responses shown in static push-over graph

As shown in Figure 6.16, the maximum non-linear seismic responses are slightly greater than the response due to concentrated lateral load. But these values are less than those subjected to lateral constant inertial acceleration indicating the non-linear distribution of inertial forces along the shaft structure during seismic excitation. The relationship between linear and non-linear structural responses is discussed in the next Chapter of this thesis. 


\section{CALCULATION OF RESPONSE MODIFICATION FACTOR}

\subsection{Static Push-Over Analysis Approach}

Following the procedure prescribed by Applied Technology Council (ATC-19 1995) the seismic modification factor $(R)$ can be estimated based on the non-liner static push-over response of structure to lateral load. In this study, the non-liner static push-over response of structure to a constant lateral inertial acceleration was used to develop an elastic perfectly plastic model based on energy method by equating area $A_{1}$ and $A_{2}$ as shown in Figure 7.1. Thus, the yield displacement $\left(u_{y}\right)$ and yield base shear $\left(V_{y}\right)$ are determined as $184 \mathrm{~mm}$ and $6.8 \mathrm{MN}$ respectively based on the elasto-plastic model.

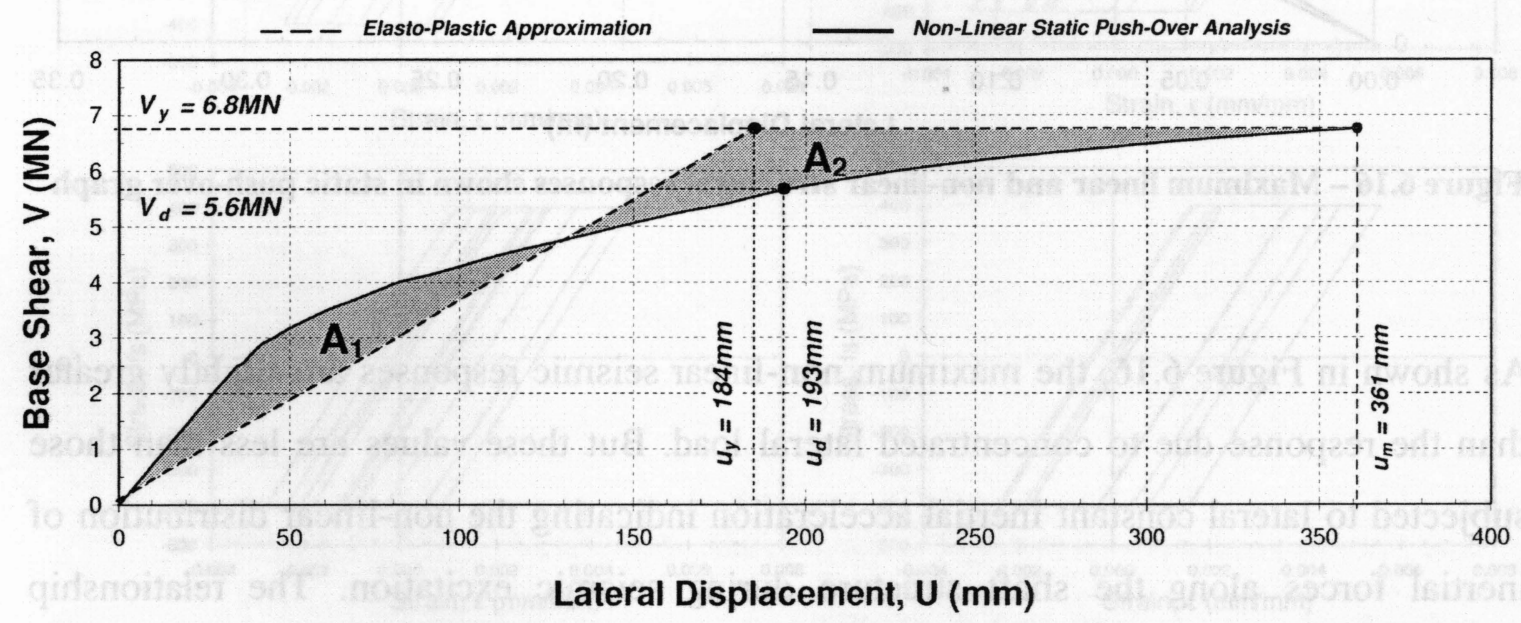

Figure 7.1 - Elasto plastic approximation of non-linear responses of structure

As discussed in pervious Chapters, the structure is capable of demonstrating a substantial amount of lateral displacement and reaching the maximum lateral drift limit prior to failure. However, this does not ensure that the structure possess a large ductility $\left(\mu_{c}\right)$. The ductility ratio $\left(\mu_{c}\right)$ is calculated as the ratio of maximum displacement $\left(u_{m}\right)$ to yield displacement $\left(u_{y}\right)$ as follows,

$\mu_{\mathrm{c}}=\frac{\mathrm{u}_{\mathrm{m}}}{\mathrm{u}_{\mathrm{y}}}=\frac{361}{184}=1.96$ 
Once the maximum available ductility $\left(\mu_{c}\right)$ in the system is determined, the ductility related seismic reduction factor $\left(R_{\mu}\right)$ can be calculated using one of available relationships. In this study, the Miranda and Bertero (1994) relationship is used to calculate $R_{\mu}$ as follows,

$$
\mathrm{R}_{\mu}=\frac{\mu-1}{\Phi}+1=2.24
$$

where the coefficient $\Phi$ for rock site condition is calculated as,

$$
\Phi=1+\frac{1}{10 \mathrm{~T}-\mu \mathrm{T}}-\frac{1}{2 \mathrm{~T}} \mathrm{e}^{-1.5(\ln (\mathrm{T})-0.6)^{2}}=0.773
$$

In above equation the value of fundamental period of vibration $(T)$ and ductility ratio $(\mu)$ are taken as $1.27 \mathrm{~s}$ and $1.96 \mathrm{~mm} / \mathrm{mm}$ respectively. The overstrength related seismic modification factor $\left(R_{s}\right)$ is the other component of $R$ and it is calculated as the ratio of maximum available strength of structure $\left(V_{m}\right)$ to design base shear $\left(V_{d}\right)$ as follows,

$$
\mathrm{R}_{\mathrm{s}}=\frac{\mathrm{V}_{\mathrm{m}}}{\mathrm{V}_{\mathrm{d}}}=\frac{6.8 \mathrm{MN}}{5.6 \mathrm{MN}}=1.21
$$

In above equation, the design base shear $\left(V_{d}\right)$ is the factored strength of structure obtained from theoretical calculation. Subsequently, seismic reduction factor $(R)$ can be calculated as the product of ductility, over-strength and redundancy related reduction factors as follows,

$$
\mathrm{R}=\mathrm{R}_{\mu} \mathrm{R}_{\mathrm{S}} \mathrm{R}_{\mathrm{R}}=2.24 \times 1.21 \times 1.00=2.7
$$

Where, the redundancy related reduction factor $\left(R_{R}\right)$ is taken as 1.0 since no reliable redundancy is available in the system. It should be noted that the relationship used to calculate the ductility related modification factor $\left(R_{\mu}\right)$ does not incorporate the specific characteristic of earthquakes for rock site conditions. However, the characteristic period of earthquake is considered for soft soil conditions. 
In order to investigate the influence vertical reinforcement ratio $\left(\rho_{s_{-} \text {horiz }}\right)$ in variation of seismic reduction factor $(R)$, the structure was designed for two lower MCE acceleration response spectra $\left(S_{l}\right)$ of $0.43 \mathrm{~g}$ and $0.35 \mathrm{~g}$ (Appendix E). The required amount of vertical reinforcement $\left(\rho_{s_{-} \text {horiz }}\right)$ was determined as $0.75 \%$ and $0.50 \%$ in each case respectively. Following the static push-over approach the seismic reduction factor (R) was calculated as 3.43 and 3.65 in each case respectively.

\subsection{Non-linear Time-History Analysis Approach}

As an alternate method, a better estimation of actual seismic reduction factor $(R)$ can be achieved through time-history non-linear analysis as suggested by ATC-19 (1995). Using available data, seismic force reduction/modification factor $(R)$ was calculated for each time-history analysis as the ratio of maximum linear elastic base-shear $\left(V_{e}\right)$ to maximum inelastic base-shear $\left(V_{i e}\right)$ as follows,

$$
\mathrm{R}=\frac{\mathrm{V}_{\mathrm{e}}}{\mathrm{V}_{\text {ie }}}
$$

Additionally, the corresponding value of maximum ductility demand $\left(\mu_{d}\right)$ in each case was calculate as the ratio of maximum inelastic displacement $\left(u_{i e}\right)$ to yield displacement $\left(u_{\text {yield }}\right)$ as follows,

$$
\mu_{\mathrm{d}}=\frac{\mathrm{u}_{\mathrm{ie}}}{\mathrm{u}_{\text {yield }}}
$$

The variation of seismic reduction factor $(R)$ for different ductility demands $\left(\mu_{d}\right)$ are then illustrated in Figure 7.2 for each set of seismic excitations. Using a statistical regression technique, $2^{\text {nd }}$ and $3^{\text {rd }}$ degree polynomial curves are fitted to each set of data. As analytical data suggests, $R$-factor increases upon increasing earthquake intensity which is expressed in the form of ductility demand. This increase is anticipated since in equation 
7.6, the elastic response of structure $\left(V_{e}\right)$ increases linearly while inelastic response $\left(V_{i e}\right)$ remains approximately constant. This behavior is also in agreement with experimental results presented in ATC-19 (1995). The statistical fitted curve also implies that the growth of seismic reduction factor eventually stabilizes and converges to a distinct value in each case as earthquake intensity reaches its maximum sustainable amplitude.

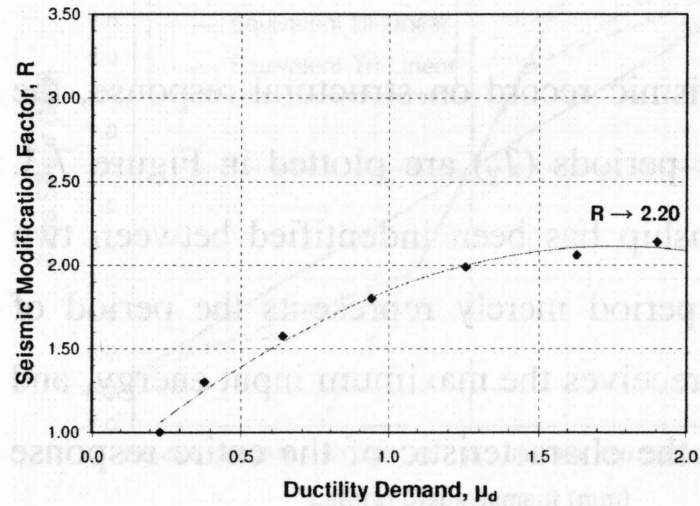

a)

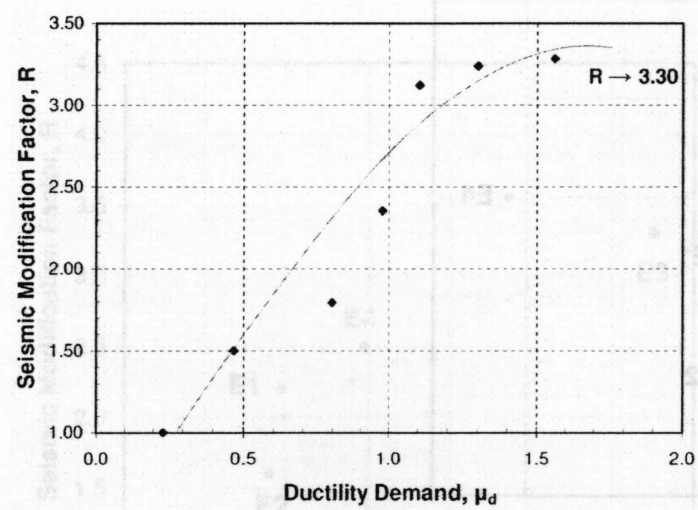

c)

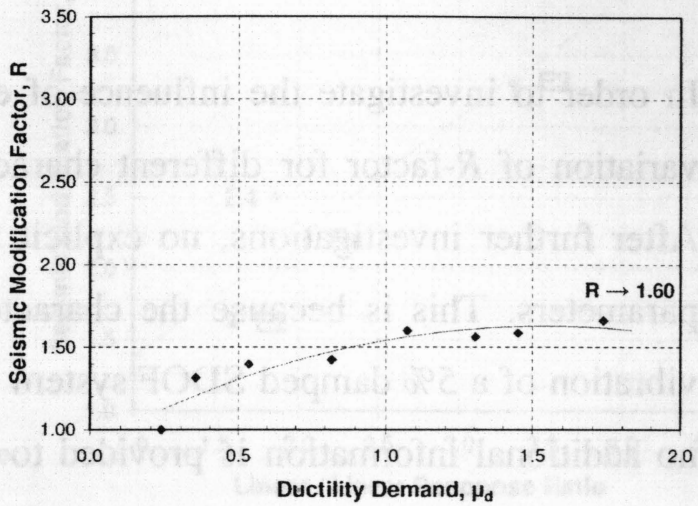

b)

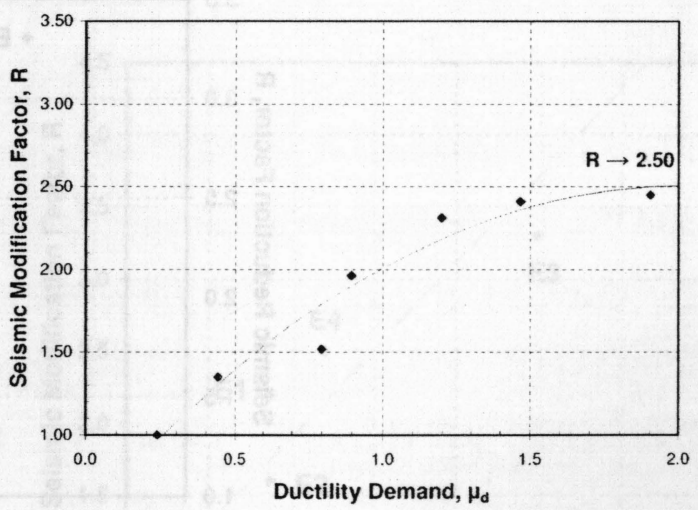

d)

Figure 7.2 - Variation of seismic reduction factor vs. ductility demand in seismic record.

a) Santa Cruz Mountains (Loma Prieta), October 17, 1989, 17:04

b) Kern County Earthquake (Taft Lincoln Tunnel), July 21, 1952, 04:53 PD

c) Landers Earthquake, June 28, 1992, 04:58 PDT

d) Northridge earthquake, January17, 1994, 04:31 PST

Additionally, the converged values of R-factors are different in each earthquake (1.6, 2.2, $2.5 \& 3.5$ ) which signifies the influence of earthquake characteristic on response of structure. This feature is distinguished in NBCC-05 by limiting the seismic accelerations used in time-history analysis to those which produce the similar elastic response curve as specified in the Code. 
The influence of characteristic period of earthquake or pre-dominant period of ground motion $\left(T_{g}\right)$ in ductility related reduction factor $\left(R_{\mu}\right)$ is also identified by many researcher and its effects is particularly studied in detail by Tong et al (2007). However, these studies are generally performed on mathematically developed elastic perfectly-plastic models for a wide range of fundamental period of vibrations $(T)$ and the influence of different earthquakes on one model is eliminated during averaging process.

In order to investigate the influence of each seismic record on structural response, the variation of $R$-factor for different characteristic periods $\left(T_{g}\right)$ are plotted in Figure 7.3. After further investigations, no explicit relationship has been indentified between two parameters. This is because the characteristic period merely represents the period of vibration of a $5 \%$ damped SDOF system which receives the maximum input energy, and no additional information is provided to unfold the characteristic of the entire response spectra.

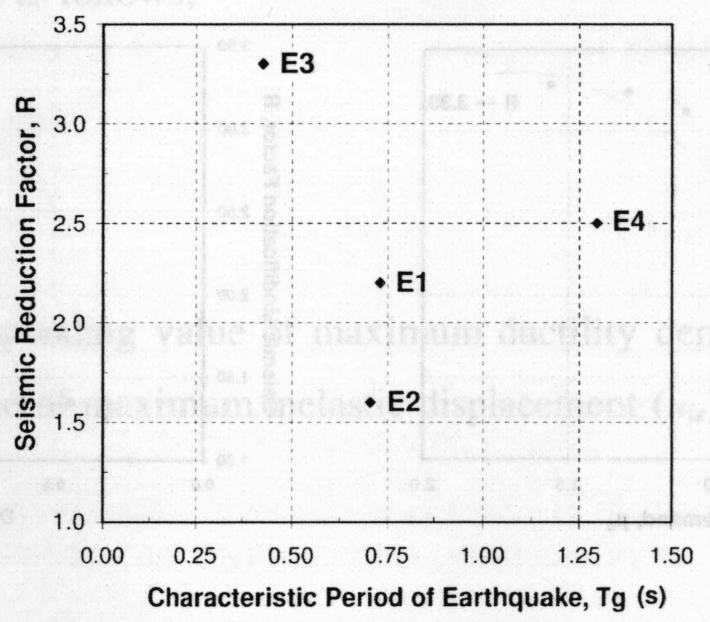

Figure 7.3 - Variation of seismic reduction factor $v$ s. characteristics period of earthquake.

E1) Santa Cruz Mountains (Loma Prieta), October 17, 1989, 17:04 PDT

E2) Kern County Earthquake (Taft Lincoln Tunnel), July 21, 1952, 04:53 PDT

E3) Landers Earthquake, June 28, 1992, 04:58 PDT

E4) Northridge earthquake, January17, 1994, 04:31 PST

However, a rational relationship can be established between $R$-factor and the ratio of dynamic responses of linear elastic model and equivalent elastic linear/bi-linear/tri-linear systems ( $\left.V_{\text {elastic }} / V_{\text {equiv. elastic }}\right)$. The structural stiffness of equivalent linear/bi-linear/trilinear elastic SDOF systems are approximations of dynamic hysteretic response of 
structure to seismic excitations as shown in Figure 7.4a. Using the equivalent elastic models, the response to the seismic excitation is calculated using Newmark-Hall step-bystep method (Clough and Penzien 2003, Chopra 1995) and the results are shown in Figure $7.4 \mathrm{~b}, 7.4 \mathrm{c}$ and $7.4 \mathrm{~d}$.
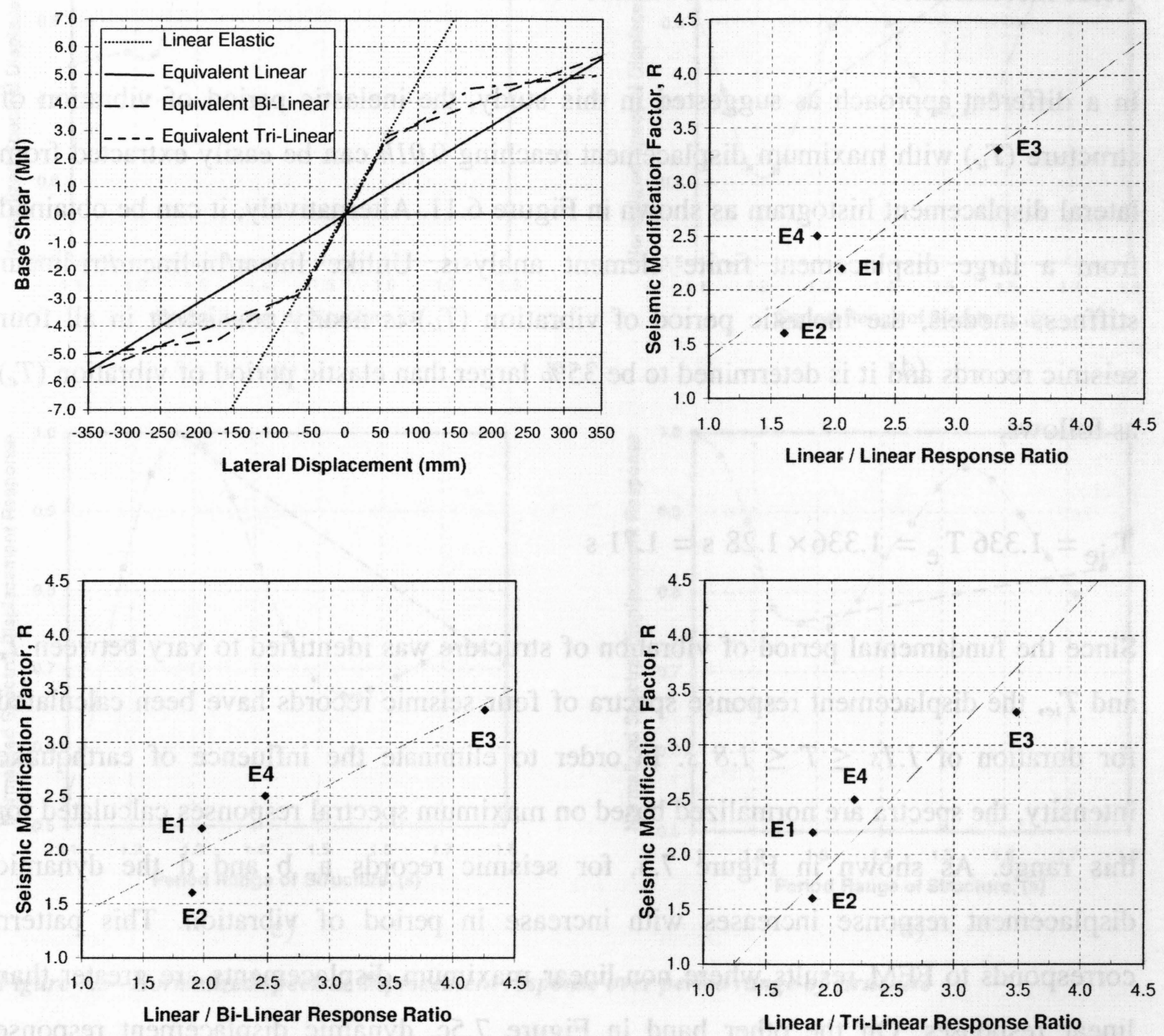

Figure 7.4 - a) Linear, bi-linear and tri-linear approximation of base shear vs. lateral displacement of centroid of tank. Variation of seismic reduction factor vs. response ratio of elastic linear system and equivalent b) linear, c) bi-linear and d) tri-linear elastic models.

E1) Santa Cruz Mountains (Loma Prieta), October 17, 1989, 17:04 PDT

E2) Kern County Earthquake (Taft Lincoln Tunnel), July 21, 1952, 04:53 PD

E3) Landers Earthquake, June 28, 1992, 04:58 PDT

E4) Northridge earthquake, January17, 1994, 04:31 PST 
Although the results from equivalent models are in general agreement with response modification factor $(R)$, they fail to offer a simple definitive prediction of seismic reduction factor. Additionally, calculating an equivalent structural stiffness requires painstaking statistical analysis by averaging force-displacement time-history plot which yields inconsistence values for each seismic record.

In a different approach as suggested in this study, the inelastic period of vibration of structure $\left(T_{i e}\right)$ with maximum displacement reaching $0.01 \mathrm{~h}$ can be easily extracted from lateral displacement histogram as shown in Figure 6.11. Alternatively, it can be obtained from a large displacement finite element analysis. Unlike linear/bi-linear/tri-linear stiffness models, the inelastic period of vibration $\left(T_{i e}\right)$ is nearly consistent in all four seismic records and it is determined to be $35 \%$ larger than elastic period of vibration $\left(T_{e}\right)$ as follows,

$$
\mathrm{T}_{\mathrm{ie}}=1.336 \mathrm{~T} \mathrm{e}=1.336 \times 1.28 \mathrm{~s}=1.71 \mathrm{~s}
$$

Since the fundamental period of vibration of structure was identified to vary between $T_{e}$ and $T_{i e}$, the displacement response spectra of four seismic records have been calculated for duration of $1.1 \mathrm{~s} \leq T \leq 1.8 \mathrm{~s}$. In order to eliminate the influence of earthquake intensity, the spectra are normalized based on maximum spectral responses calculated for this range. As shown in Figure 7.5 , for seismic records $a, b$ and $d$ the dynamic displacement response increases with increase in period of vibration. This pattern corresponds to FEM results where non-linear maximum displacements are greater than linear responses. On the other hand in Figure 7.5c, dynamic displacement response diminishes despite the increase in period of vibration. A similar pattern is also observed in non-linear responses in the third seismic record as shown in Figure 7.5c. 


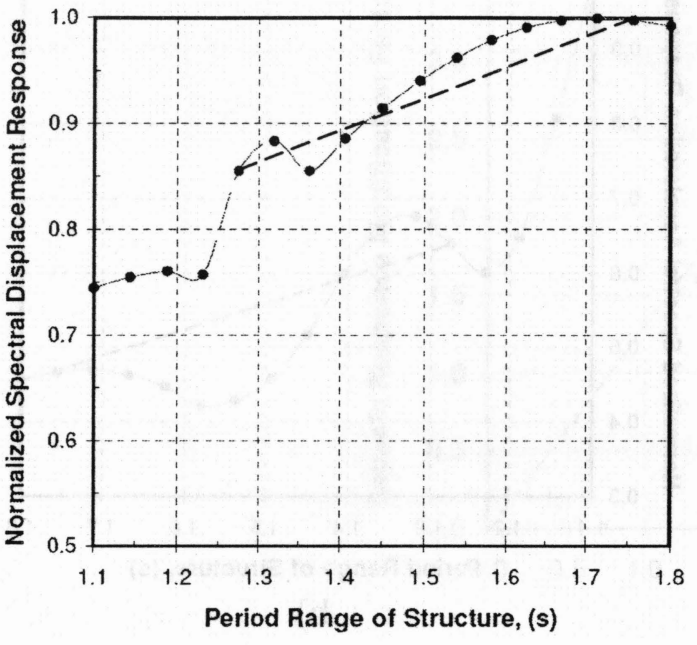

a)

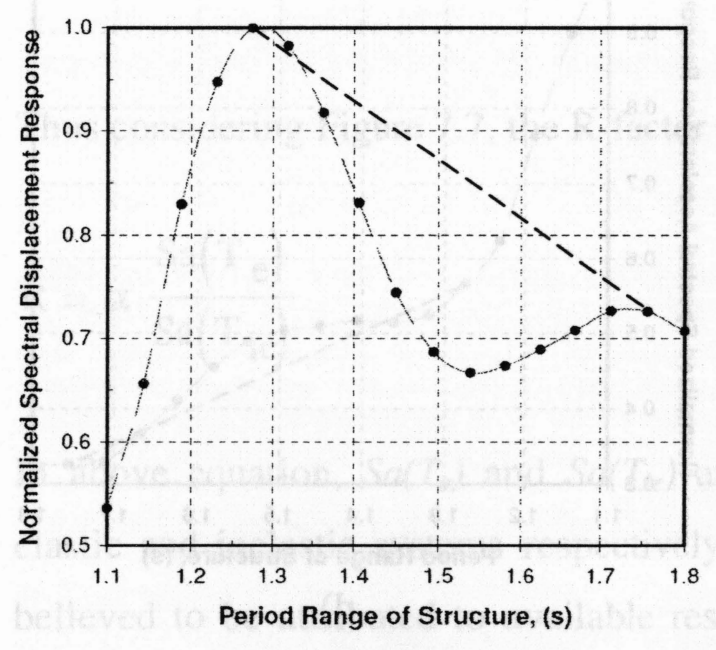

c)

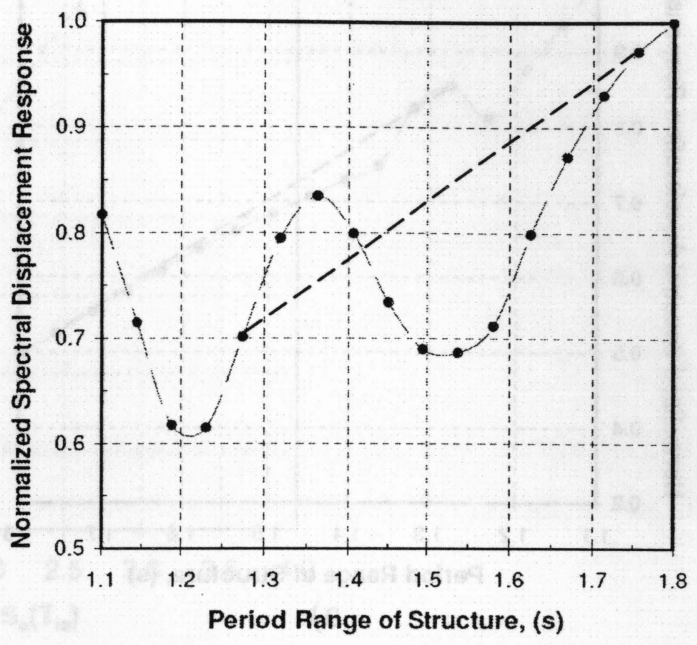

b)

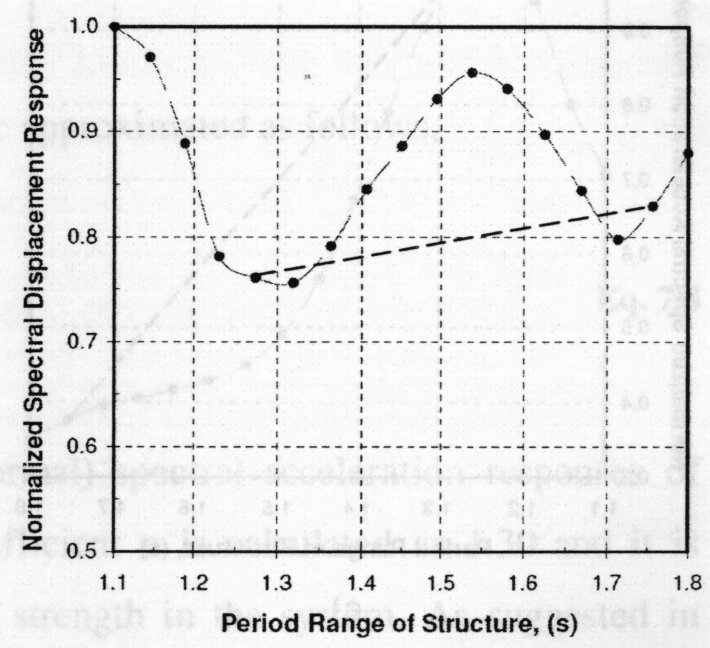

d)

Figure 7.5- Normalized spectral displacement response over period range of structure

Similarly, the normalized spectral acceleration responses are plotted for the specified period as shown in Figure 7.6. Although as a general trend, the acceleration response spectra declines as period of vibrations increases in the specified range, it does not follow a smooth line and in fact it might experience local fluctuations which might influence the final results. 


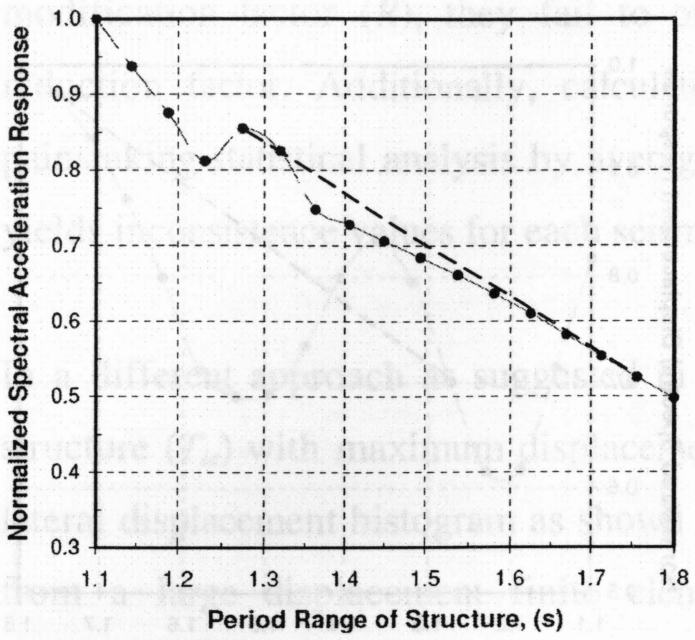

a)

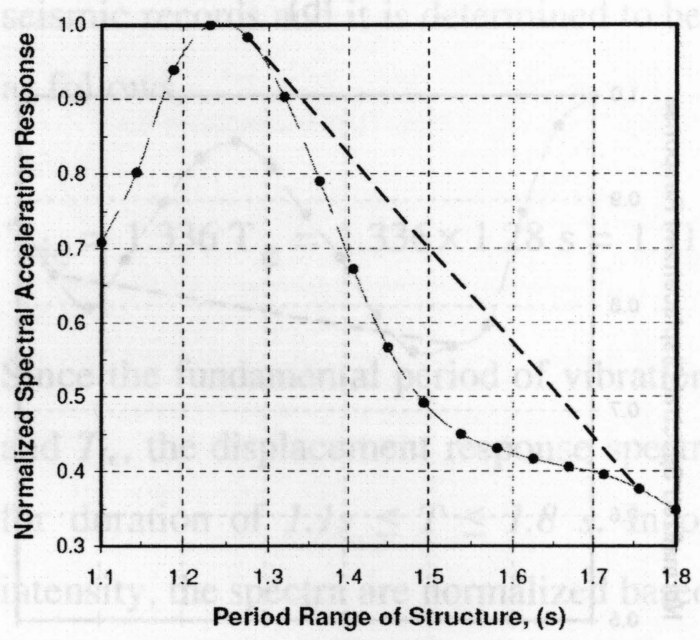

c)

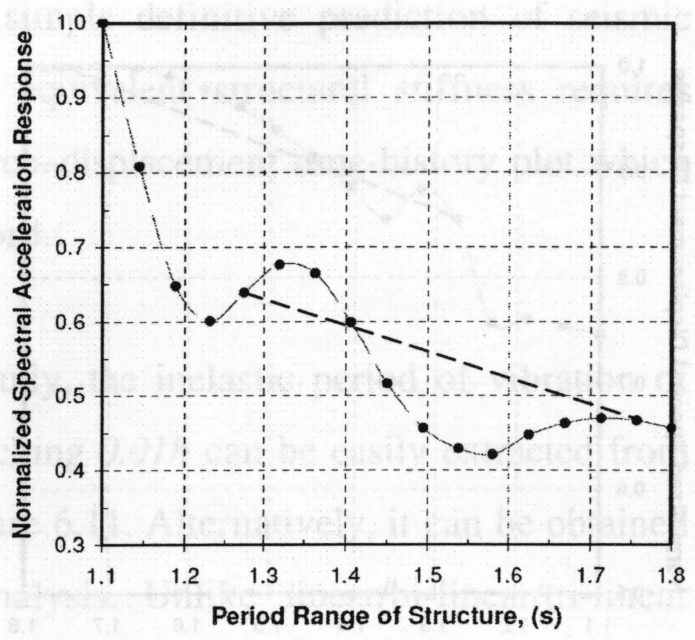

b)

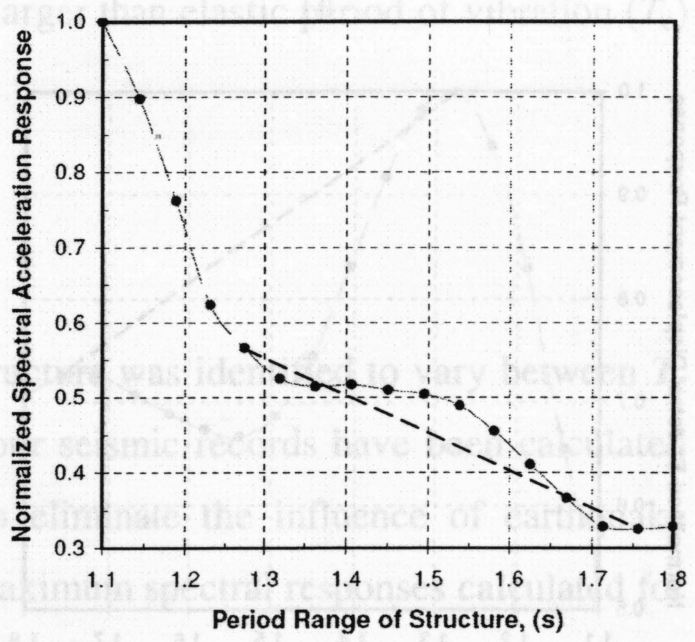

d)

Figure 7.6 - Normalized spectral acceleration response over period range of structure

Knowing the elastic and in-elastic large-displacement period of vibrations, the corresponding elastic spectral responses for each seismic record are calculated. Based on obtained data, a linear relationship is found between variation of seismic reduction factor $(R)$ and ratio of spectral responses as shown in Figure 7.7. 


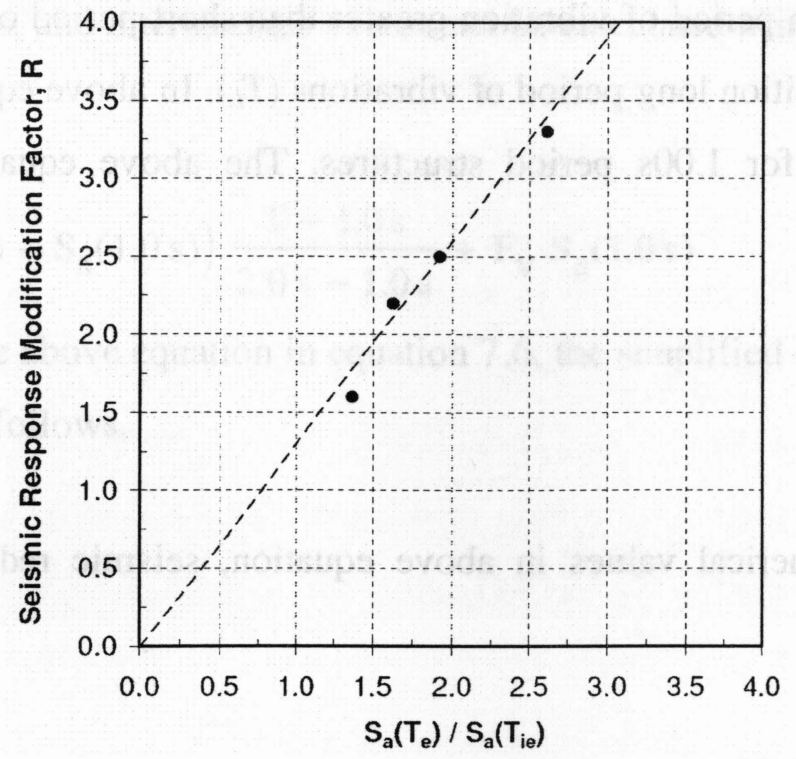

Figure 7.7 - Variation of seismic reduction factor $(R)$ vs. ratio of spectral responses of elastic and inelastic period of vibrations

Thus considering Figure 7.7, the R-factor can be approximated as follows,

$\mathrm{R}=\alpha \frac{\mathrm{Sa}\left(\mathrm{T}_{\mathrm{e}}\right)}{\mathrm{Sa}\left(\mathrm{T}_{\mathrm{ie}}\right)}$

In above equation, $S a\left(T_{e}\right)$ and $S a\left(T_{i e}\right)$ are (normal) spectral acceleration responses of elastic and inelastic systems respectively. Coefficient $\alpha$ is calculated as 1.30 and it is believed to be attributed to available reserved strength in the system. As suggested in equation 7.8, the variation of seismic reduction factor is independent of earthquake intensity and is closely related to frequency content of seismic wave. Thus, using the spectral acceleration response curve of ASCE 7-05 which is developed based on a large number of past earthquake patterns, an average value R-factor can be calculated as follows,

$$
\mathrm{R}=\alpha \frac{\left(\frac{\mathrm{S}_{\mathrm{D} 1}}{\mathrm{~T}_{\mathrm{e}}}\right)}{\left(\frac{\mathrm{S}_{\mathrm{D} 1}}{\mathrm{~T}_{\mathrm{ie}}}\right)}
$$


for the structures with period of vibration greater than short period of vibration limit $\left(T_{s}\right)$ but less than the transition long period of vibrations $\left(T_{L}\right)$. In above equation, $S_{D 1}$ is design acceleration spectra for 1.00 s period structures. The above equation can be further simplified as,

$\mathrm{R}=\alpha \frac{\mathrm{T}_{\mathrm{ie}}}{\mathrm{T}_{\mathrm{e}}}$

Substituting the numerical values in above equation, seismic reduction factor $(R)$ is calculated as,

$$
\mathrm{R}=1.30 \times \frac{1.77 \mathrm{~s}}{1.28 \mathrm{~s}}=1.80
$$

Thus, considering the coefficients of elastic acceleration response curve and following the suggested method, the seismic reduction factor $(R)$ is calculated as 1.8 , which is $10 \%$ smaller than the ASCE 7-05's recommended value of 2.0 and it is about $33 \%$ and $25 \%$ smaller than the value of 2.7 and 2.4 obtained from static and time-history analysis respectively. It should be noted that since the purpose of reduction factor is to make use of all reserved strength available in the structure, the FEM was prepared without applying strength reduction factor $(\varphi)$ to the material properties.

Similarly, using the prescribed method of National Building Code of Canada (NBCC), design spectral acceleration values can be calculated as,

$\mathrm{S}(\mathrm{T})=\mathrm{F}_{\mathrm{v}} \mathrm{S}_{\mathrm{a}}(1.0 \mathrm{~s})$

Eq. 7.11

and,

$$
S(T)=F_{v} S_{a}(2.0 s)
$$


For $\mathrm{T}=1.0 \mathrm{~s}$ and $2.0 \mathrm{~s}$, and intermediate values can be calculated using linear interpolation as follows,

$\mathrm{S}(\mathrm{T})=\mathrm{F}_{\mathrm{v}}\left(\mathrm{S}_{\mathrm{a}}(2.0 \mathrm{~s})-\mathrm{S}_{\mathrm{a}}(1.0 \mathrm{~s})\right) \frac{\mathrm{T}-1.0 \mathrm{~s}}{2.0 \mathrm{~s}-1.0 \mathrm{~s}}+\mathrm{F}_{\mathrm{v}} \mathrm{S}_{\mathrm{a}}(1.0 \mathrm{~s})$

After substituting the above equation in equation 7.6, the simplified equation for R-factor can be expressed as follows,

$\mathrm{R}=\alpha \frac{\mathrm{T}_{\mathrm{e}}-\beta}{\mathrm{T}_{\mathrm{ie}}-\beta}$

Where,

$\beta=\frac{\mathrm{S}_{\mathrm{a}}(2 . \mathrm{s} 0)-2 \mathrm{~S}_{\mathrm{a}}(1.0 \mathrm{~s})}{\mathrm{S}_{\mathrm{a}}(2.0 \mathrm{~s})-\mathrm{S}_{\mathrm{a}}(1.0 \mathrm{~s})}$

Eq. 7.15

As NBCC's (2005) provided seismic data suggests, the curvature of spectral acceleration response curve varies locally. Thus, the outcome of equation 7.14 will be also influenced by local seismic data. Substituting the prescribed local spectral response data in equation $7.14, R$-factors were calculated for different regions of Canada and the results are plotted in Figure 7.8. 


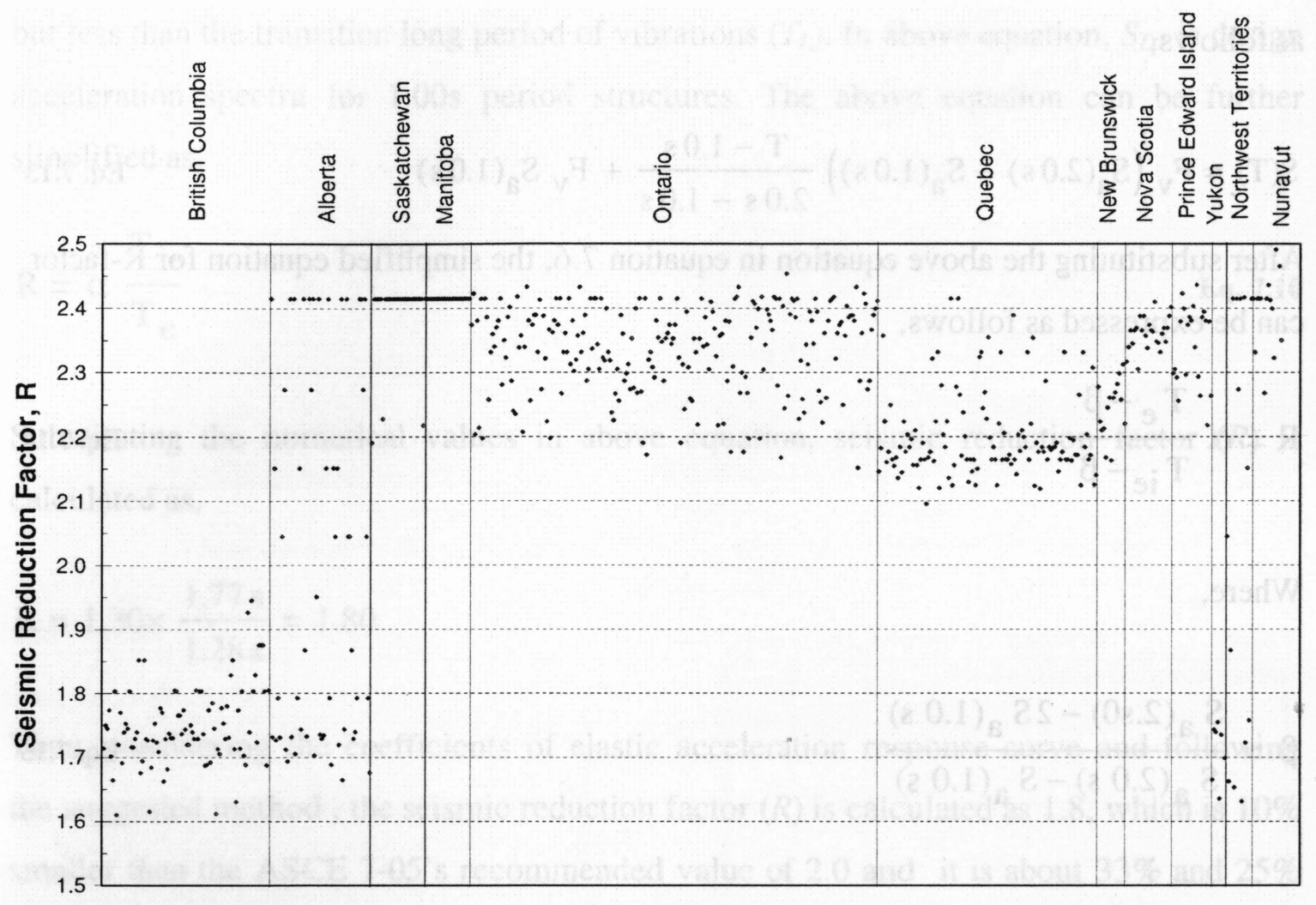

Canadian Provinces and Territories

Figure 7.8 - Variation of seismic reduction factor, $R$, calculated based on NBCC's regional mapped spectral acceleration response parameters; $S_{a}(2.0 s)$ and $S_{a}(1.0 s)$.

It has been identified that the value of seismic reduction factor in the studied structure is expected to reduce from 2.5 to 1.6 when moving from the low risk region in the east to higher risk region in West of Canada. In the high risk region the slope of normalized spectral response curvature is smaller than the one in low risk region despite the fact that the seismic spectral response coefficients are larger. 


\section{CONCLUSIONS, SUMMARY AND RECOMMENDATION FOR FUTURE WORK}

\subsection{Summary}

Being one of the vital infra-structures in many rural and urban areas around the world, elevated water tanks are capable of storing a substantial amount of potable water and potential energy. Besides providing a steady flow of water in peak demand hours of the day, they offer a huge economical advantage over many years of operation by eliminating the need for costly pumping facility. Most importantly, the existences of elevated water tanks become a vital commodity for the survivors of a natural disaster.

Among two conventionally used framing systems for supporting elevated tanks; concrete shaft and structural framing, many design aspects of the latter have previously been identified and improved over many years of extensive research in building industry. However, limited literature exists that explores specific characteristic of concrete shaft supported elevated water tanks and their seismic response in particular. Although the tubular geometry of the shaft offers simplicity and cost efficiency to the construction, it sacrifices the structural performance such as redundancy, toughness, over-strength, energy dissipation, and the most importantly ductility.

In this study, various design aspects of concrete shaft staging suggested by current codes, guidelines and researches were investigated, in addition to a comprehensive study in advanced dynamics of structure, earthquake engineering and advanced finite element analysis. This study also includes the influence of shaft geometry in the failure modes of buckling and formation of accidental eccentricities, which determines the axial strength of the shaft. The actual and idealized distribution of shear stresses within the cross section in the presentence of wall openings was also studied.

As part of literature review, the dynamic equilibrium of the forces in the single degree of freedom system was briefly explained using the principals of dynamics of structures. Following the fundamentals of elastic response of structure to stochastic loading, the 
pseudo-spectral response to seismic waveforms and corresponding soil amplification factors were briefly described, the characteristic of code based responses spectra and the prescribed procedure for calculating seismic base shear were also described. Finally, seismic reduction factor which is one of the main features in seismic response calculation is further studied by investigating its notable components such as ductility and overstrength factor in available literatures. The performance of concrete shaft staging elevated water tanks in recent earthquake in India, Bhuj 2001, was also described.

In this thesis the response of a concrete shaft staging elevated water tank, whose geometry was determined from an actual dimensions of an elevated water tank was investigated. However, the wall thickness and ratio of reinforcement was modified to satisfy high seismic demand of the selected location. Following the prescribed method of ACI 371-08 and ASCE 7-05, the lateral seismic demand of the structure was determined using the recommended value of seismic reduction factor $(R=2.0)$. Assuming a linear strain variation in the cross-section, the wall thickness and ratio of vertical and circumferential reinforcements was designed for axial, flexural and shear forces accordingly.

A finite element model of the structure was prepared using available elements in ANSYS. In the FE model, concrete was modeled using solid65 element which is specially designed to model concrete behavior such as cracking, crushing and tensile stress relaxation through modifying stiffness matrix. Additionally, unconfined stress-strain curve was assigned to non-linear concrete material. The reinforcement bars were modeled using available link8 element, which is a 3-dimensional truss element with tension and compression capabilities. A bilinear elasto-plastic stress-strain relationship was used to model the material properties of the reinforcement.

A FE free-vibration analysis was performed to determine the fundamental period of vibration of structure along with displacement function of the shaft. A generalized single degree of freedom model was developed using principals of dynamics of structure for first mode of vibration, where the displacement function for the model was initially 
defined based on an assumed shape function and displacement of center of impulsive mass of water.

Two static push-over analyses were performed on the model where lateral forces were applied to the structure once in the form of concentrated lateral load to the center of mass and the second time as a lateral acceleration to the entire structure. The results from static push-over analysis were then implemented into the axial/lateral force interaction diagram in order to verify the initial design assumption, compare FEM and theoretical calculations. Additionally, the nodal vertical displacement in non-linear static push-over analysis was extracted from results. Then, using statistical regression method, a polynomial curve was fitted to vertical displacement data in each horizontal crosssection. Knowing the variation of nodal displacement throughout the section, total vertical strains between the nodes were determined for the lower section of the shaft.

In the next stage of this study, four seismic records were selected in such a way that the majority of their energy content, as determined through Fourier amplitude spectrum, is delivered throughout the frequency ranges that includes elastic period of vibration and anticipated period of cracked structure. The seismic acceleration records were normalized based on their peak ground accelerations (PGA). Then, a PGA was found for each record that produced the same spectral responses for elastic period of vibration. Using the calculated PGA as an indicator of earthquake intensity, a total 50 PGA's were selected for FEA.

The processed seismic records were then applied to the FEM in the form of lateral inertial acceleration. After performing over 50 non-linear time-history (transient) analyses, 29 conclusive results were obtained. Maximum elastic and inelastic base-shear and maximum displacement at the centroid of the tank in the each set of results were determined, and the structural response and development of stresses, strains and cracks were investigated. 
The seismic reduction factor for the studied structure was calculated first using the nonlinear static pushover analysis approach, and then based on the results of time-history FEA. In an attempt to develop a simplified mathematical model for calculating R-factor, three elastic models were developed with linear, bi-liner and tri-linear approximation of structural stiffens.

Furthermore, a relationship has been established between $\mathrm{R}$ factor and spectral responses of elastic and inelastic structure. Using suggested equation, the estimated value of $R$ factor was calculated based on the spectral acceleration response data of ACSE 7-05 and NBCC 2005 for different regions of Canada.

\subsection{Conclusions}

Based on studies performed as described in this thesis, the following conclusions are drawn.

1) The fundamental period of vibration of un-cracked structure calculated using linear elastic free-vibration FEA was determined to be $1.12 \mathrm{~s}$ which is about $12 \%$ smaller than $1.27 \mathrm{~s}$ period calculated based on simplified lumped mass approximation method prescribed by ACI 371-08.

2) The elastic displacement shape of shaft structure is influenced by the shear deformation mode shape. This is determined through Rayleigh's principal energy conservation method for optimization of lateral displacement shape function in a generalized single degree of freedom approximation of the structure. An improved equation for approximation of the lateral displacement shape function of shaft structure in empty and full conditions were also suggested which can be used in development of a mathematical elastic models of structure in future. 
3) The axial load - bending moment interaction diagram calculated at $0.5 d_{w}$ above the ground using the suggested mathematical equations for non-linear distribution of stress in the cross section has been verified to be in a good agreement with calculated interaction diagram using static non-linear push-over FEA. The shear strength of structure was also determined to be considerably larger than the estimated value by ACI 318-08 and ACI 371-08, which signifies the beneficial effects of large axial force on shear strength of structure.

4) The variation of axial strain in the cross-section at time of failure was identified as nearly linear at $0.33 d_{w}$ over the base and above. However, a significant non-linearity was observed within the disturbed region below $0.33 d_{w}$ elevation due to influence of fixed based connection. The stress-strain response curve of the concrete near the foundation was also influenced by imposed boundary conditions resulting in nearly $30 \%$ increase in specific compressive stress and softer post peak strain softening behavior.

5) The results of non-linear time-history FEA reveals that the maximum base-shear developed during each seismic excitation is slightly greater than the calculated base-shear for corresponding displacement in static push-over analysis with lateral concentrated load. However, the response was smaller than uniform lateral inertial acceleration, emphasizing the non-linear distribution of inertial forces along the shaft structure during seismic excitation. Investigating the non-linear response to seismic acceleration at the time of maximum lateral displacement, many horizontal tensile cracks were observed over $50 \%$ of the body of the shaft. Additionally, a number of vertical tensile cracks were developed near $0.22 d_{w}$ over base originating from hoop tensile stresses.

6) Although the maximum compressive stress was observed at the base of structure, concrete crushing occurred only at about $0.5 d_{w}$ region of the shaft. Furthermore, more than $40 \%$ of longitudinal reinforcements in tension experienced inelastic stresses at time of maximum displacement. 
7) A parabolic shear stress distribution was observed only in upper region of the shaft where the structure is still un-cracked. This was transformed into a more uniform shear stress distribution pattern in mid section of the structure with development of tensile cracks. However, an entirely non-liner shear stress distribution with maximum shear stresses of 1.2MPa was observe at critical lower section in the concrete shaft.

8) Using the energy method for elasto-plastic approximation of structural behavior, the available capacity of ductility was calculated merely as 1.96 , as a low ductility was expected for this type of structures. Similarly, following the prescribed static analysis approach of ATC-19, the seismic reduction/modification factor was calculated approximately as 2.7 , which is about $35 \%$ larger than the ASCE's prescribed value of 2.0 . Alternatively, the average value of R-factor was calculated as 2.4 through non-linear time-history finite element analysis, which is still about $17 \%$ greater than the codeprescribed value. However, the average reduction factor was calculated using only the results of selected four seismic records

9) Investigating the relationship between seismic record and the calculated reduction factor, no explicit relationship has been found between the dominant period of vibration of each earthquake $\left(T_{g}\right)$ and the generated reduction factor. Additionally, the elastic linear/bi-linear/tri-linear approximations of structural behavior did not yield an accurate simplified mathematical model for calculation of maximum dynamic response. However, a close linear relationship was observed between R-factor and the ratio of spectral acceleration responses of elastic and inelastic large displacement period of vibrations. As the suggested relationship implies, the structural performance and amount of seismic force reduction in particular is influenced by the specific characteristic of seismic excitations. Seismic reduction capacity comprised many other factors which may not be affected by characteristic of seismic wave. 
10) Following the suggested relationship, the value of reduction factor can be estimated for any given seismic excitation. While performing a large number of non-linear timehistory FEA was not possible in this study, the ASCE's standardized seismic response spectra was used instead to generate a better approximation of $\mathrm{R}$ factor. Hence, the reduction factor was calculated as 1.8 which is $10 \%$ less than ASCE's recommended value of 2.0 .

11) The R-factor was determined to vary from 1.6 to 2.5 for different regions of Canada using available local spectral parameters. The highest amount of reduction is suggested for less active regions, since the slope of response acceleration spectra between $1.0 \mathrm{~s}$ and $2.0 \mathrm{~s}$ normalized at $1.0 \mathrm{~s}$, is larger than the one in active regions.

\subsection{Recommendations for Future Work}

Investigation of structural response to seismic acceleration can be continued using a lager number of seismic records having larger variety of energy content.

The influence of different aspect ratio of the shaft geometry, wall thickness, reinforcement ratio and specific compressive strength of concrete on structural performance can be further studied through a careful selection of wide range of elevated water tower structures.

The effects of different support conditions including un-anchored foundation, baseisolation, and soil-structure interaction can be further investigated./

The influence of wall openings and intermediate floors on structural strength and behavior can be further investigated and current design approaches can be verified with analytical results.

A FEM of tank vessel can be also added to the mathematical model, and the effect of sloshing of stored water during earthquake can also be investigated. 


\begin{abstract}
Although the concrete shaft staging elevated water towers in general do not exhibit a large amount of ductility as well as redundancy and energy dissipations, they posses a simple geometry which can be defined through limited number of parameters. Thus, it is suggested that seismic reduction factor calculation procedure for elevated water towers to be further developed in order to incorporate the design parameters. This can be used in practice for calculating the actual modification factor, instead of using a single value for all types of structures.
\end{abstract}




\section{References}

American Concrete Institute Committee 307, 2008. Code Requirements for Reinforced Concrete Chimneys (ACI 307-08) and Commentary, Farmington Hills, Mi, USA.

American Concrete Institute Committee 318, 2008. Building Code Requirements for Structural Concrete (ACI 318-08) and Commentary. Farmington Hills, Mi, USA.

American Concrete Institute Committee 350, 2006. Code Requirements for environmental Engineering Concrete Structures and Commentary (ACI 350-06). Farmington Hills, Mi, USA.

American Concrete Institute Committee 350, 2006. Seismic Design of Liquid-Containing Concrete Structures and Commentary (ACI 350.3-06). Farmington Hills, Mi, USA.

American Concrete Institute Committee 371, 1998. Guide for the Analysis, Design, and Construction of Concrete Pedestal Towers, USA.

American Concrete Institute Committee 371, 2008. Guide for the Analysis, Design, and Construction of Elevated Concrete and Composite Steel-Concrete Water Storage Tanks, Farmington Hills, Mi, USA.

American Society of Civil Engineers, 2005. Minimum Design Loads for Buildings and Other Structures ASCE/SEI 7-05, American Society of Civil Engineers.

ANSYS® Academic Research, v. 10.0, ANSYS, Inc.

Applied Technology Council, 1995, Structural response modification factors ATC-19. Redwood City, California.

Barbosa, A.F. and Ribeiro G.O. 1998. Analysis of Reinforced Concrete Structures Using ANSYS Nonlinear Concrete Model, Federal University of Minas Gerais, Department of Structural Engineering.

BIS IS:1893, 1984. Criteria for Earthquake resistance design structures, New Delhi, India.

BIS IS:1893, 1998. Criteria for Earthquake resistance design structures, Draft version, New Delhi, India.

BIS 2002 IS:1893 Criteria for Earthquake resistance design strures,Draft version, new Dehli, India.

Borzi, B., Elnashai, A.S. 2000. Refined Force Reduction Factors for Seismic Design, Engineering Structures, Vol. 22, pp. 1244-1260 . 
Building Safety Council 1994. NEHRP recommended provision for seismic regulations for new buildings and other structures. 1994 edition, Part 1: provisions (FEMA 222A), Washington DC.

Chen, W.F. and Liew, J.Y.R. 2003. The Civil Engineering Handbook Second Edition, CRC PRESS.

Chopra, A.K. 1995. Dynamics Of Structures: Theory and Applications to Earthquake Engineering. Prentice Hall.

City of Toronto 2008. Drinking water Treatment Process and Storage System, City of Toronto 1998-2008.

Clough R.W. and Penzien J. 2003. Dynamics of Structures, Third Edition, Computers \& Structures, Inc.

Elmorsi, M., Kianoush, M.R and Tso W.K. 1998. Nonlinear Analysis of Cyclically Loaded Reinforced Concrete Structures. ACI Structural Journal, Vol. 95, No. 6, pp. 725739.

Elnashai, A. S. and Mwafy, A. M. 2002. Over-strength and Reduction Factors of Multistory Reinforced Concrete Buildings, Design of Tall Buildings Vol. 11, pp. 329351.

Fajfar, P. 1995. The $10^{\text {th }}$ European Conference on Earthquake Engineering, Balkema, pp. 2969-2974.

Finn, L. and Wightman, A. 2003. Ground Motion amplification factors for NBCC 2005. Canadian Journal of Civil Engineering, No. 30, pp. 272-278.

Frano, R.L. and Forasassi, G. 2008. Buckling of Imperfect Thin Cylindrical Shell under Lateral Pressure, Science and Technology of Nuclear Installations, Article ID 685805.

Gaberson, H. 2007. Shock Analysis Using the Pseudo Velocity Shock Spectrum - Part 1, 78th Shock \& Vibration Symposium.

Haroun, M.A and Ellaithy, H.M. 1985. Seismically Induced Fluid Force on Elevated Tanks, Journal of technical topics in Civil Engineering, Vol. 11, No. 1.

Hough, S.E., Martin, S., Bilham, R. and Atkinson G.M, 2002. The 26 January 2001 M7.6 Bhuj-India Earthquake: Observed and Predicted Ground Motions, Bulletin of the Seismological Society of America, Vol. 92, No. 6, pp. 2061-2079.

Ibrahim, R. A. and Soundarajan A. 1983. Nonlinear Parametric Liquid Sloshing Under Wide Brand Random Excitation, Journal of Sound and Vibration, Vol.1, Issue 91, pp. 119-134. 
Idriss, I.M. 1990. Response of soft soil sites during earthquakes. Proc. H. Bolton Seen memorial symposium, Berkley California, Vol. II.

International Code Council, Inc. 2006, International Building Code IBC, USA:ICC.

Iyengar, R.N. and Kanth, S.T.G. 2002. Strong Ground Motion at Bhuj City During the Kutch Earthquake, Currant Science, Vol. 82, No. 11.

Lawrence, K.L. 2005. ANSYS ${ }^{\circledR}$ Tutorials Releases 9.0. Schroff Development Corporation.

Livaog, R.L. and Dogangu, A. 2006. Simplified Seismic Analysis Procedures for Elevated Tanks Considering Fluid-Structure-Soil Interaction, Journal of Fluids and Structures Vol. 22, pp. 421-439.

MacGregor, J.G. 1997. Reinforced Concrete Mechanics and Design Third Edition. Prentice Hall.

Miranda, E., and Bertero, V.V. 1994. Evaluation of Strength Reduction Factors, Earthquake Spectra, Vol. 10, No. 2, pp. 357-379.

Mitchell, D., Tremblay, R., Karacabeyli, E., Paultre, P., Saatcioglu, M. and Anderson, D.L. 2003, Seismic Force Modification Factors for the Proposed 2005 Edition of the National Building Code of Canada, Canadian Journal of Civil Engineers, Vol. 30, pp. 308-27.

Mofid, M. and Yavari,A. 2000. On the Kern of a General Cross Section, International Journal of Solids and Structures, Vol. 37, pp. 2377-2403.

Mofid, M., Alizadegam, R., Ahori, B. and Yavari, A. 2001, Computing the Kern of a General Cross-Section, Advances in Engineering Software, Vol. 32, pp. 949-955.

Mohamad-Hussein, A. and Shao, J.F. 2007. Modeling of Elastoplastic Behavior with Non-Local Damage in Concrete Under Compression, Computers and Structures Vol. 85, pp. 1757-1768.

Nakasone, N., Stolarski, T.A. and Yoshimoto, S. 2006. Engineering Analysis with ANSYS $^{\oplus}$ Software. Elsevier Butterworth-Heinemann.

Nassar, A. and Krawinkler, H. 1991. Seismic Demands for SDOF, Report No. 95. The John A. Blume Earthquake Eng. Center, Stanford University. 
National Research Council of Canada 2005, National Building Code of Canada Volume 1 and 2, Canada: NRCC.

National Research Council of Canada 2005, User's Guide - NBC 2005 Structural Commentaries (Part 4 of Division B). Canada: NRCC.

Nawy, G.E. 2005. Reinforced Concrete a Fundamental Approach Fifth edition ACI 31805 Code Edition. Pearson Prentice Hall.

Newmark N.M. and Hall, W. J. 1982. Earthquake Spectra and Design. Monograph published by the Earthquake Engineering Research Institute.

Pinfold, G.M., 1989. Reinforced concrete chimney and towers, Viewpoint publication cement and concrete association, London.

Rai, D.C. , Eeri, M. 2002. Seismic Retrofitting of R/C Shaft Support of Elevated Tanks, Earthquake Spectra, Vol. 18, No. 4, pp. 745-760.

Rai, D.C. 2002. Review of Code Design Forces for Shaft Supports of Elevated Water Tanks, Proceedings of 12th Symposium on Earthquake Engineering, pp. 1407-1418.

Rai, D.C. and Singh, B. 2004, Seismic Design Of Concrete Pedestal Supported Tanks. 13th World Conference on Earthquake Engineering Vancouver, B.C., Canada, Paper No. 230.

Rai, D.C. et al. 2002. 2001 Bhuj, India Earthquake Reconnaissance Report: Elevated Tanks, Earthquake Spectra, Supplement to Vol. 18, pp. 279-295.

Saiidi, M. and Sozen, M.A. 1981. Simple nonlinear seismic analysis of R/C structures. Journal of the Structural Division, Vol. 107, No. 5, pp. 937-953.

Shenton III, H.W. and Hampton, F.P. 1999. Seismic Response of Isolated Elevated Water Tanks. Journal of Structural Engineering, Vol. 125, No. 9, pp. 965-976.

Shepherd, R. 1972, Two Mass Representation of Water Tower Structures. Journal of Sound and Vibration Vol. 3, pp. 391-396.

Stevens, N. J., Uzumeri, S. M., and Collins, M. P. 1987. Analytical Modeling of Reinforced Concrete Subjected to Monotonic and Reversed Loadings. Department of Civil Engineering, No. 87-1, University of Toronto, Toronto, Canada.

Timoshenko, S.P. and Woinowsky-Krieger, S. 1959. Theory of Plates and Shells, McGraw-Hill Book Company, Inc., New York.

Tong, G., Huang, J. 2005. Seismic Force Modification Factor for Ductile Structures. Journal of Zhejiang University Science, Vol. 8, pp. 813-825. 
Tong, G., Zhao, Y. 2007, Inelastic Yielding Strength Demand Coefficient Spectra, Soil Dynamics and Earthquake Engineering, Article in Press.

Tong, G. and Zhao, Y. 2007. Seismic Force Modification Factors for Modified-Clough Hysteretic Model, Engineering Structures Vol. 29, pp. 3053-3070.

University of Alberta, 2001. ANSYS ${ }^{\circledR}$ Tutorial, University of Alberta.

Vidic T, Fajfar P. and Fischinger M. 1994. Consistent inelastic design spectra: Strength and displacement. Earthquake Engineering and Structural Dynamics, No. 23, pp. 507521.

Xiao, R. Y. and Chin, C. S. (2002). Nonlinear Finite Element Modeling of the Tension Softening of Conventional and Fibrous Cementitious Composites, Civil \& Computational Engineering Centre School of Engineering University of Wales Swansea.

Zahn, F.A., Park, R., Priestley, M.J.N. 1990. Flexural Strength and Ductility of Circular Hollow Reinforced Concrete Columns Without Confinement on Inside Face. ACI Structural Journal, Vol. 87, No.2. 


\section{Appendix A- Geometric Properties of Circular Segment}

$$
\begin{aligned}
& \mathrm{dl}=\frac{\mathrm{dx}}{\sin (\theta)}=\frac{\mathrm{r}_{\mathrm{w}} \mathrm{dx}}{\mathrm{h}}=\frac{\mathrm{r}_{\mathrm{w}} \mathrm{dx}}{\sqrt{\mathrm{r}_{\mathrm{w}}{ }^{2}-\left(\mathrm{r}_{\mathrm{w}}-\mathrm{x}\right)^{2}}} \\
& d A=2 d l h_{w}=\frac{2 r_{w} h_{w}}{\sqrt{r_{w}{ }^{2}-\left(r_{w}-x\right)^{2}}} d x \\
& \int \sigma d A+2 \tau d x t=\int(\sigma+d \sigma) d A \\
& 2 \tau \mathrm{dxt}=\int \mathrm{d} \sigma \mathrm{dA}=\int \frac{\mathrm{dM} \cdot \mathrm{y}}{\mathrm{I}} \mathrm{dA} \\
& \tau=\frac{1}{2 t I} \int \frac{d M}{d x} y d A=\frac{V}{2 t I} \int y d A=\frac{V}{2 t I} \\
& \bar{y}=\frac{15 \mathrm{t}\left(12 \mathrm{R}+\mathrm{t}^{2}\right)}{4 \mathrm{R}} \times \frac{\sin \left(\frac{\alpha}{2}\right)}{\frac{\pi \alpha}{2}} \\
& \mathrm{~A}=\alpha \mathrm{Rt} \\
& \tau(\alpha)=\frac{V}{t I} \times \frac{15 t\left(12 R+t^{2}\right)^{2} \sin \left(\frac{\alpha}{2}\right)}{4 R \pi} \times \alpha R
\end{aligned}
$$

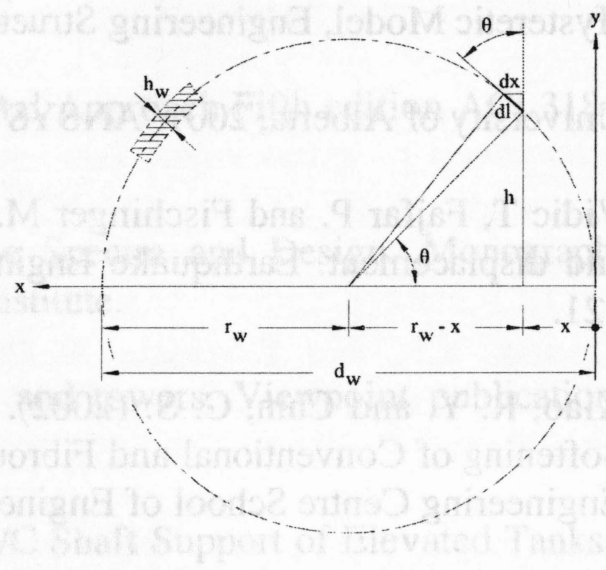




\section{Appendix B - Dynamic equations of a single degree of freedom System}

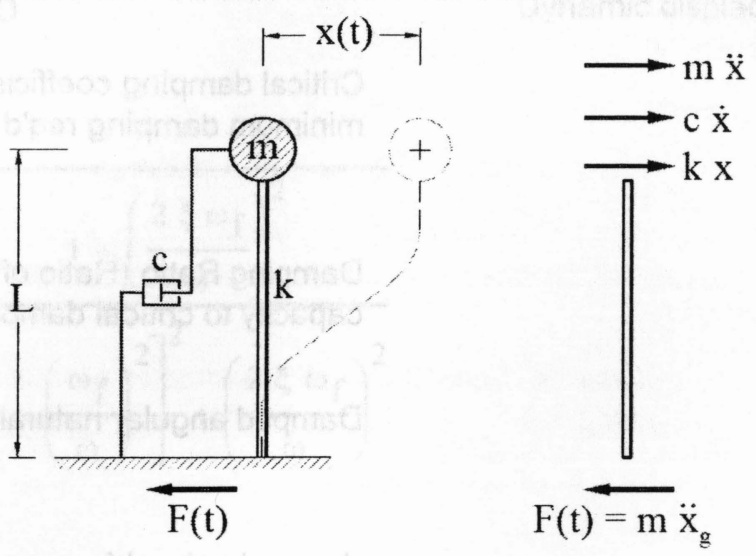

1. Un-Damped Free Vibration (i.e. $c=0$ and $F(t)=0$ )

$$
\begin{aligned}
& \mathrm{m} \cdot \mathrm{x}^{\prime \prime}+\mathrm{k} \cdot \mathrm{x}=0 \quad \text { or } \quad \mathrm{x}^{\prime \prime}+\omega^{2} \mathrm{x}=0 \quad \text { Equilibrium of dynamic forces } \\
& \omega=\sqrt{\frac{\mathrm{k}}{\mathrm{m}}} \\
& \mathrm{f}=\frac{\omega}{2 \pi} \\
& T=\frac{1}{f} \\
& x(t)=A \sin (\omega t)+B \cos (\omega t) \\
& \text { Displacemnt (motion) function of the mass } \\
& \text { relative to fixed point of reference, }(\mathrm{m})
\end{aligned}
$$

$\mathrm{x}_{\text {dynamic }}=\sqrt{\mathrm{A}^{2}+\mathrm{B}^{2}}$ 


\section{Damped Free Vibration $(F(t)=0)$}

$\mathrm{m} \cdot \mathrm{x}^{\prime \prime}+\mathrm{c} \cdot \mathrm{x}^{\prime}+\mathrm{k} \cdot \mathrm{x}=0$ or $\mathrm{x}^{\prime \prime}+2 \xi \omega \cdot \mathrm{x}^{\prime}+\omega^{2} \cdot \mathrm{x}=0$ Equilibrium of dynamic forces

$\mathrm{c}_{\mathrm{cr}}=2 \sqrt{\mathrm{k} \mathrm{m}}=2 \mathrm{m \omega}$

Critical damping coefficient, $(\mathrm{N} / \mathrm{s})$ (i.e.

$$
\begin{aligned}
& \xi=\frac{c}{c_{c r}} \\
& \omega_{d}=\omega \sqrt{1-\xi^{2}} \\
& f_{d}=\frac{\omega}{2 \pi} \\
& T_{d}=\frac{1}{f_{d}}
\end{aligned}
$$$$
\text { minimum damping req'd to prevent oscillation) }
$$

Damping Ratio (Ratio of structural damping capacity to critical damping coefficient)

Damped angular natural frequency, rad/s

damped natural frequency of the structure, $1 / \mathrm{s}$

damped natural period of the structure, $s$

$$
x(t)=\left(A \cos \left(\omega^{\prime} D t\right)+B \sin \left(\omega^{t} t\right)\right) \exp (-\xi \omega t) \text { if } \xi^{2}<1
$$

\section{Damped Forced Vibration $\left(F(t)=F \sin \left(\omega_{f} t\right)\right)$}

$$
\begin{aligned}
& m x^{\prime \prime}+c x^{\prime}+k x=-P_{f} \sin \left(\omega_{f} t\right) \\
& x^{\prime \prime}+2 \xi \omega x^{\prime}+\omega^{2} x=-a \sin \left(\omega_{f} t\right) \\
& x_{\text {static }}=\frac{-a}{\omega^{2}}=\frac{-F}{k} \\
& D=\frac{\sqrt{\left[1-\left(\frac{\omega_{f}}{\omega_{0}}\right)^{2}\right]^{2}+\left(\frac{2 \xi \omega}{\omega_{f}}\right)^{2}}}{\sqrt{\omega}}
\end{aligned}
$$

Static Displacment of structure

Dynamic displacement amplification factor 


$$
\mathrm{x}_{\text {dynamic }}=\mathrm{x}_{\text {static }} \times \mathrm{D}
$$

$$
\mathrm{D}_{\mathrm{a}}=\frac{\mathrm{x}^{\prime \prime}+\mathrm{x}_{\mathrm{g}}}{\mathrm{x}_{\mathrm{g}}}=\sqrt{\frac{1+\left(\frac{2 \xi \omega_{\mathrm{f}}}{\omega}\right)^{2}}{\left[1-\left(\frac{\omega_{\mathrm{f}}}{\omega}\right)^{2}\right]^{2}+\left(\frac{2 \xi \omega_{\mathrm{f}}}{\omega}\right)^{2}}}
$$

$$
x=C_{1} \sin \left(\omega_{f} t\right)+C_{2} \cos \left(\omega_{f} t\right)
$$




\section{Appendix C- Calculation of Seismic base shear}

\section{Input:}

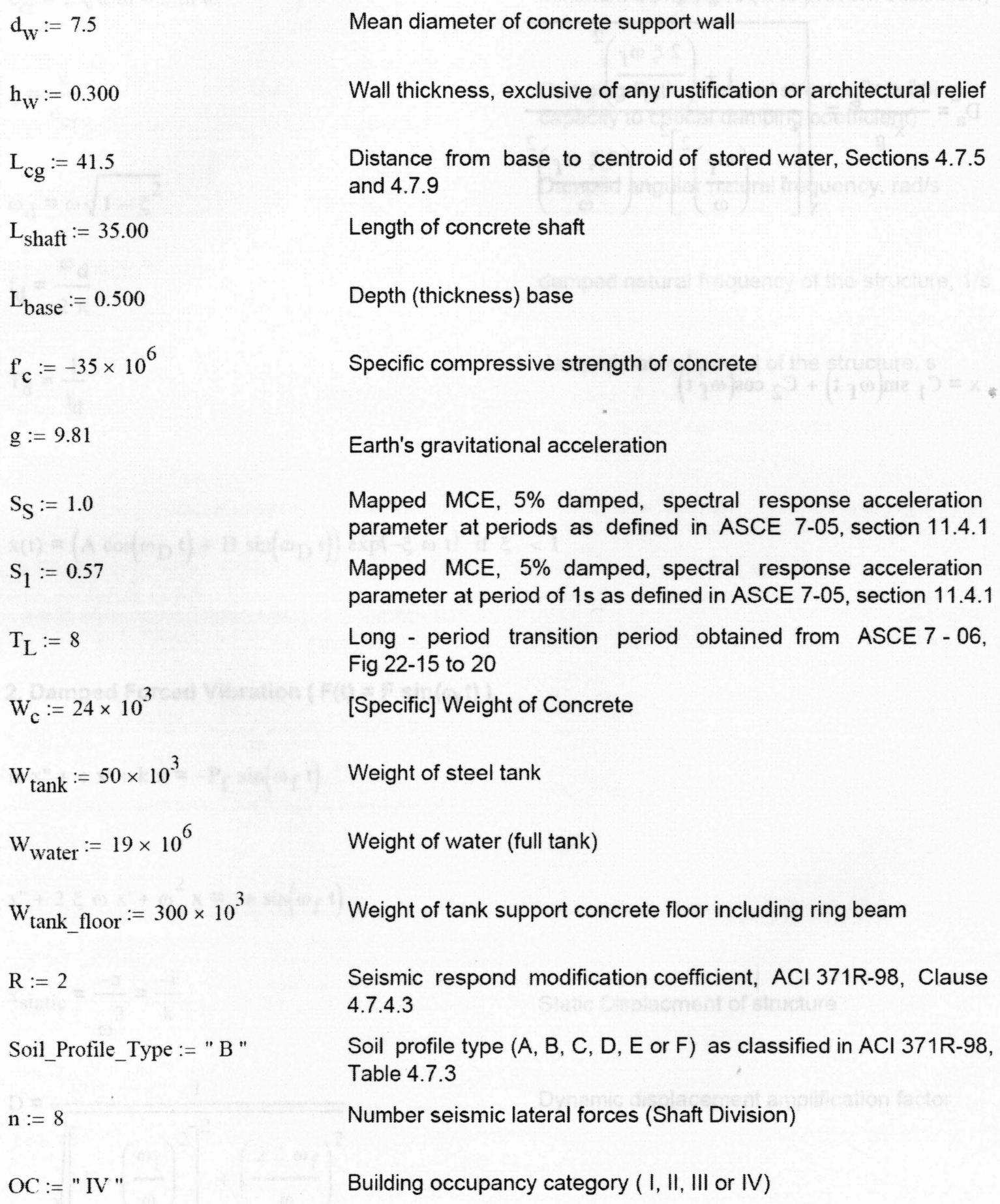




\section{Calculation}

$$
\begin{array}{ll}
\mathrm{E}_{\mathrm{c}}:=4700000 \times \sqrt{\mathrm{f}_{\mathrm{c}} \mid \Rightarrow \mathrm{E}_{\mathrm{c}}=27806 \times 10^{6}} & \begin{array}{l}
\text { Modulus of elasticity of concrete, } \\
\text { ACl 318M-05, Clause 8.5.1 }
\end{array} \\
\mathrm{W}_{\text {shaft }}:=\pi \mathrm{d}_{\mathrm{W}} \mathrm{h}_{\mathrm{W}} \mathrm{W}_{\mathrm{c}} \mathrm{L}_{\text {shaft }} \Rightarrow \mathrm{W}_{\text {shaft }}=5938 \times 10^{3} & \text { Weight of the shaft structure } \\
\mathrm{W}_{\text {Dead }}:=\mathrm{W}_{\text {tank }}+\mathrm{W}_{\text {tank_floor }}+\mathrm{W}_{\text {shaft }} \Rightarrow \mathrm{W}_{\text {Dead }}=6288 \times 10^{3} & \\
& \text { Dead load of structure, ACl } \\
& 371 \mathrm{R}-98, \text { Clause 4.2.2.1 }
\end{array}
$$

$$
\mathrm{W}_{\text {Gravity }}:=\mathrm{W}_{\text {Dead }}+\mathrm{W}_{\text {water }} \Rightarrow \mathrm{W}_{\text {Gravity }}=25288 \times 10^{3} \quad \begin{aligned}
& \text { Gravity load, } \mathrm{ACI} 371 \mathrm{R}-98, \text { Clause } \\
& 4.7 .1 .2 \text { and } 4.7 .6 .3
\end{aligned}
$$

$$
\begin{aligned}
& \mathrm{W}_{\text {Lump }}:=\mathrm{W}_{\text {water }}+\mathrm{W}_{\text {tank }}+\mathrm{W}_{\text {tank_floor }}+\frac{2}{3} \times \mathrm{W}_{\text {shaft }} \\
& \Rightarrow \mathrm{W}_{\text {Lump }}=23308 \times 10^{3}
\end{aligned}
$$$$
\mathrm{I}_{\mathrm{c}}:=\frac{1}{8} \pi \mathrm{d}_{\mathrm{w}} \mathrm{h}_{\mathrm{w}}\left(\mathrm{d}_{\mathrm{w}}{ }^{2}+\mathrm{h}_{\mathrm{w}}{ }^{2}\right) \Rightarrow \mathrm{I}_{\mathrm{c}}=49.7805
$$

$$
\mathrm{k}_{\mathrm{c}}:=\frac{3 \mathrm{E}_{\mathrm{c}} \mathrm{I}_{\mathrm{c}}}{\mathrm{L}_{\mathrm{cg}}^{3}} \Rightarrow \mathrm{k}_{\mathrm{c}}=58099 \times 10^{3}
$$

$$
\mathrm{T}:=2 \pi \sqrt{\frac{\mathrm{W}_{\text {Lump }}}{\mathrm{g} \mathrm{k}_{\mathrm{c}}}} \Rightarrow \mathrm{T}=1.271
$$

The single lumped-mass structure weight, ACI 371R-98, Clause 4.7.5.2

The moment of inertia of gross concrete section about centroidal axis, neglecting reinforcement. $\mathrm{ACl}$ 371R-98, Clause A4.7.5.2

The structure lateral stiffness, determined from the deflection of concrete support structure as cantilever beam length $\mathrm{Lcg}$ subjected to concentrated end load. ACl 371R-98, Clause A4.7.5.2

The fundamental period of vibration for a single lumped-mass approximation. $\mathrm{ACl} 371 \mathrm{R}-98$, Clause 4.7.5.2

$$
\mathrm{I}:=\mid \begin{aligned}
& 1.00 \text { if } \mathrm{OC}=" \mathrm{I} " \\
& 1.00 \text { if } \mathrm{OC}=" \mathrm{II} " \\
& 1.25 \text { if } \mathrm{OC}=" \mathrm{III} " \\
& 1.50 \text { if } \mathrm{OC}=\text { "IV" }
\end{aligned} \Rightarrow \mathrm{I}=1.500
$$


ACl 371R-98, Table 4.7.1 - Seismic coefficients $F_{a}$ and $F_{v}$

\begin{tabular}{|c|c|c|c|c|c|c|c|c|c|c|}
\hline \multirow{2}{*}{ Site Class } & \multicolumn{3}{|c|}{$\begin{array}{c}\text { Mapped Maximum Considered Earthquake Spectral } \\
\text { Response Acceleration Parameter }\left(\mathrm{F}_{\mathrm{a}}\right) \text { at Short Period }\end{array}$} & \multicolumn{3}{c|}{$\begin{array}{c}\text { Mapped Maximum Considered Earthquake Spectral } \\
\text { Response Acceleration Parameter }\left(\mathrm{F}_{\mathrm{v}}\right) \text { at 1-S }\end{array}$} \\
\cline { 2 - 12 } & $\mathrm{S}_{\mathrm{S}} \leq 0.25$ & $\mathrm{~S}_{\mathrm{S}}=0.50$ & $\mathrm{~S}_{\mathrm{S}}=0.75$ & $\mathrm{~S}_{\mathrm{S}}=1.00$ & $\mathrm{~S}_{\mathrm{S}} \geq 1.25$ & $\mathrm{~S}_{\mathrm{S}} \leq 0.25$ & $\mathrm{~S}_{\mathrm{S}}=0.50$ & $\mathrm{~S}_{\mathrm{S}}=0.75$ & $\mathrm{~S}_{\mathrm{S}}=1.00$ & $\mathrm{~S}_{\mathrm{S}} \geq 1.25$ \\
\hline $\mathrm{A}$ & 0.8 & 0.8 & 0.8 & 0.8 & 0.8 & 0.8 & 0.8 & 0.8 & 0.8 & 0.8 \\
\hline $\mathrm{B}$ & 1.0 & 1.0 & 1.0 & 1.0 & 1.0 & 1.0 & 1.0 & 1.0 & 1.0 & 1.0 \\
\hline $\mathrm{C}$ & 1.2 & 1.2 & 1.1 & 1.0 & 1.0 & 1.7 & 1.6 & 1.5 & 1.4 & 1.3 \\
\hline $\mathrm{D}$ & 1.6 & 1.4 & 1.2 & 1.1 & 1.0 & 2.4 & 2.0 & 1.8 & 1.6 & 1.5 \\
\hline $\mathrm{E}$ & 2.5 & 1.7 & 1.2 & 0.9 & 0.9 & 3.5 & 3.2 & 2.8 & 2.4 & 2.4 \\
\hline $\mathrm{F}$ & \multicolumn{8}{|c|}{ See ASCE 7-05, Section 11.4.7 } & \multicolumn{6}{c|}{ See ASCE 7-05, Section 11.4 .7} \\
\hline
\end{tabular}

$\mathrm{F}_{\mathrm{a}}:=$ From_Table $_{\mathrm{a}} \quad \Rightarrow \quad \mathrm{F}_{\mathrm{a}}=1.000$

Short-period site coefficient (at $0.2 \mathrm{~s}$ period). ASCE 7-05, Clause 11.4.3

$\mathrm{F}_{\mathrm{V}}:=$ From_Table $_{\mathrm{v}} \quad \Rightarrow \quad \mathrm{F}_{\mathrm{v}}=1.000$

Long-period site coefficient (at $1.0 \mathrm{~s}$ period). ASCE 7-05, Clause 11.4.3

$\begin{array}{lll}\mathrm{S}_{\mathrm{MS}}:=\mathrm{F}_{\mathrm{a}} \mathrm{S}_{\mathrm{S}} & \Rightarrow & \mathrm{S}_{\mathrm{MS}}=1.000 \\ \mathrm{~S}_{\mathrm{M} 1}:=\mathrm{F}_{\mathrm{v}} \mathrm{S}_{1} & \Rightarrow & \mathrm{S}_{\mathrm{M} 1}=0.570 \\ \mathrm{~S}_{\mathrm{DS}}:=\frac{2}{3} \mathrm{~S}_{\mathrm{MS}} & \Rightarrow & \mathrm{S}_{\mathrm{DS}}=0.667\end{array}$

$\mathrm{S}_{\mathrm{D} 1}:=\frac{2}{3} \mathrm{~S}_{\mathrm{M} 1} \quad \Rightarrow \quad \mathrm{S}_{\mathrm{D} 1}=0.380$

$\mathrm{T}_{0}:=0.20 \frac{\mathrm{S}_{\mathrm{D} 1}}{\mathrm{~S}_{\mathrm{DS}}} \quad \Rightarrow \quad \mathrm{T}_{0}=0.114$

The MCE, $5 \%$ damped, spectral response at short period adjusted for site class effects as defined in ASCE 7-05, Clause 11.4.3

The MCE, $5 \%$ damped, spectral response at a period of $1 \mathrm{~s}$ adjusted for site class effects as defined in ASCE 7-05, Clause 11.4.3

Design $5 \%$ damped spectral response acceleration parameter at short periods as defined in ASCE 7-05, Clause 11.4.4

Design 5\% damped spectral response acceleration parameter at period of $1 \mathrm{~s}$ as defined in ASCE 7-05, Clause 11.4.4

Period of vibration of structure as defined in ASCE 7-05, Clause 11.4.5.3

$\mathrm{T}_{\mathrm{S}}:=\frac{\mathrm{S}_{\mathrm{D} 1}}{\mathrm{~S}_{\mathrm{DS}}} \quad \Rightarrow \quad \mathrm{T}_{\mathrm{S}}=0.570$

Period of vibration of structure as defined in ASCE 7-05, Clause 11.4.5.3 

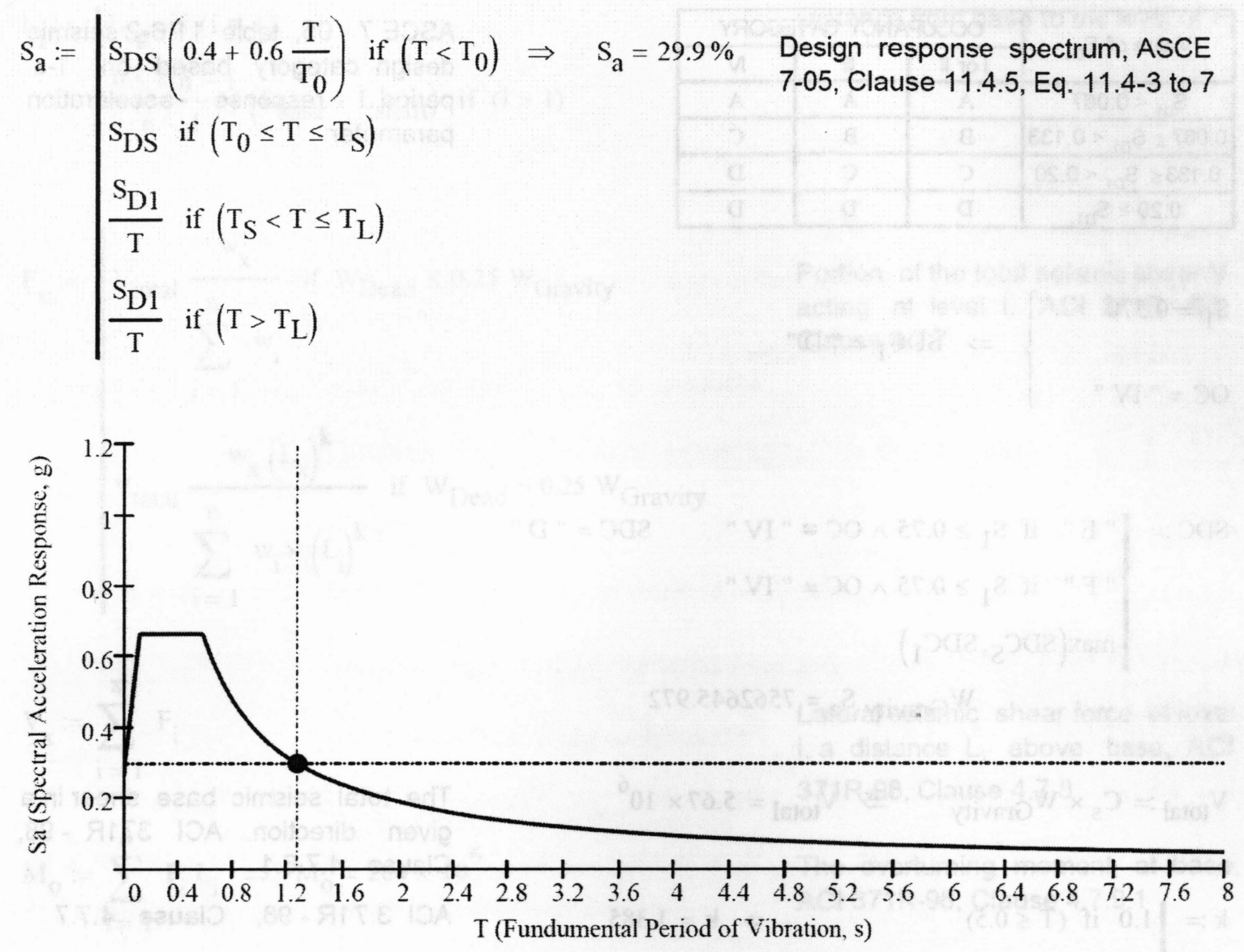

$\mathrm{C}_{\mathrm{S}}:=\max \left(\min \left(\frac{\mathrm{S}_{\mathrm{D} 1} \cdot \mathrm{I}}{\mathrm{T} \cdot \mathrm{R}}, \frac{\mathrm{S}_{\mathrm{DS}} \cdot \mathrm{I}}{\mathrm{R}}\right), 0.044 \mathrm{~S}_{\mathrm{DS}} \mathrm{I}\right) \Rightarrow \mathrm{C}_{\mathrm{s}}=0.22$

\begin{tabular}{|c|c|c|c|}
\hline \multirow{2}{*}{ Value of $S_{D S}$} & \multicolumn{3}{|c|}{ OCCUPANCY CA TEGORY } \\
\cline { 2 - 4 } & Ior II & III & N \\
\hline$S_{D S}<0.167$ & A & A & A \\
\hline $0.167 \leq S_{D S}<0.33$ & B & B & C \\
\hline $0.33 \leq S_{D S}<0.50$ & C & C & D \\
\hline $0.50 \geq S_{D S}$ & D & D & D \\
\hline
\end{tabular}

$\left.\begin{array}{l}\mathrm{S}_{\mathrm{DS}}=0.667 \\ \mathrm{OC}=" \mathrm{IV} "\end{array}\right\} \Rightarrow \mathrm{SDC}_{\mathrm{S}}=" \mathrm{D} "$
Seismic respond coefficient, $\mathrm{ACl}$ 371R-98, Clause 4.7.6.2, and ASCE 7-05, Clause 15.7.10.7, Eq. 15.7-24 to 26 .

ASCE $7-05$, table $11.6-1$ seismic design category based on short period response acceleration parameter 


\begin{tabular}{|c|c|c|c|}
\hline \multirow{2}{*}{ Value of $\mathrm{S}_{\mathrm{D} 1}$} & \multicolumn{3}{|c|}{ OCCUPANCY CATEGORY } \\
\cline { 2 - 4 } & I or II & Ill & N \\
\hline $\mathrm{S}_{\mathrm{D} 1}<0.067$ & $\mathrm{~A}$ & $\mathrm{~A}$ & $\mathrm{~A}$ \\
\hline $0.067 \leq \mathrm{S}_{\mathrm{D} 1}<0.133$ & $\mathrm{~B}$ & $\mathrm{~B}$ & $\mathrm{C}$ \\
\hline $0.133 \leq \mathrm{S}_{\mathrm{D} 1}<0.20$ & $\mathrm{C}$ & $\mathrm{C}$ & $\mathrm{D}$ \\
\hline $0.20 \geq \mathrm{S}_{\mathrm{D} 1}$ & $\mathrm{D}$ & $\mathrm{D}$ & $\mathrm{D}$ \\
\hline
\end{tabular}

ASCE 7 - 05, table 11.6-2 seismic design category based on 1-s period response acceleration parameter

$\left.\begin{array}{l}\mathrm{S}_{1}=0.570 \\ \mathrm{OC}=" \mathrm{IV} "\end{array}\right\} \Rightarrow \mathrm{SDC}_{1}=" \mathrm{D} "$

$\mathrm{SDC}:=\mid \begin{array}{ll}" \mathrm{E} " & \text { if } \mathrm{S}_{1} \geq 0.75 \wedge \mathrm{OC}=" \mathrm{IV} " \quad \mathrm{SDC}=" \mathrm{D} " \\ \mathrm{~F} " & \text { if } \mathrm{S}_{1} \geq 0.75 \wedge \mathrm{OC} \neq " \mathrm{IV} " \\ \max \left(\mathrm{SDC}_{\mathrm{S}}, \mathrm{SDC}_{1}\right) & \mathrm{W}_{\text {Gravity }} \mathrm{S}_{\mathrm{a}}=7562645.972\end{array}$

$\mathrm{V}_{\text {total }}:=\mathrm{C}_{\mathrm{s}} \times \mathrm{W}_{\text {Gravity }} \Rightarrow \mathrm{V}_{\text {total }}=5.67 \times 10^{6}$

The total seismic base shear in a given direction. $\mathrm{ACl} 371 \mathrm{R}-98$, Clause 4.7.6.1

$k:=\mid \begin{aligned} & 1.0 \text { if }(T \leq 0.5) \\ & (0.5 T+0.75) \text { if }(0.5<T \leq 2.5) \\ & 2.0 \text { if }(T>2.5)\end{aligned} \Rightarrow k=1.385$

ACl 371R-98, Clause 4.7.7

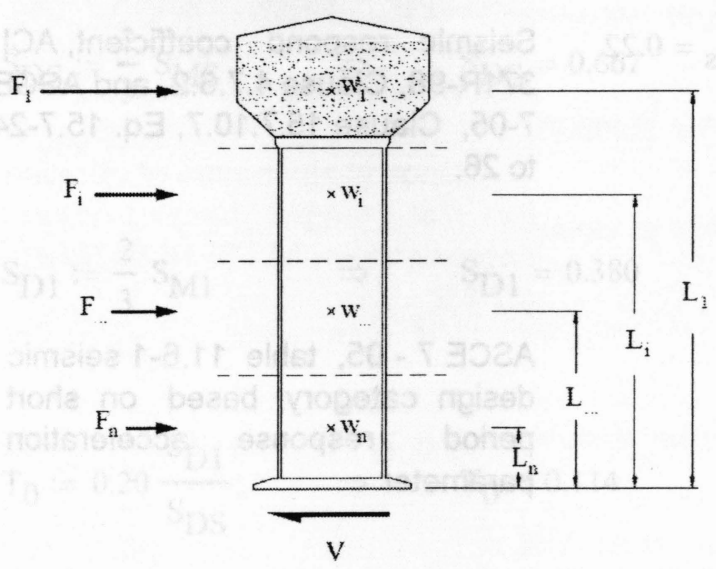

Distribution of seismic forces over the height of the structure in proportion to the structure weight, ACl 371R-98, Clause 4.7.7

$$
w_{i}:=\mid \begin{aligned}
& w_{\text {tank }}+W_{\text {water }}+W_{\text {tank_floor }} \text { if } i=1 \\
& \frac{1}{n-1}\left(w_{\text {shaft }}\right) \text { if } i>1
\end{aligned}
$$

Portion of total mass weight whose centroid is at level $i$, a distance $L_{i}$ above the base. $\mathrm{ACl} 371 \mathrm{R}-98$, Clause 4.7.7 


$$
\begin{aligned}
& \mathrm{L}_{\mathrm{i}}:=\mid \begin{array}{l}
\mathrm{L}_{\mathrm{cg}} \text { if }(\mathrm{i}=1) \\
\frac{0.5+\mathrm{n}-\mathrm{i}}{\mathrm{n}-1}\left(\mathrm{~L}_{\text {base }}+\mathrm{L}_{\text {shaft }}\right) \text { if }(\mathrm{i}>1)
\end{array} \\
& \mathrm{F}_{\mathrm{x}}:=\mid \begin{array}{l}
\mathrm{v}_{\text {total }} \frac{\mathrm{w}_{\mathrm{x}}}{\mathrm{n}} \text { if } \mathrm{w}_{\text {Dead }} \leq 0.25 \mathrm{w}_{\text {Gravity }} \\
\mathrm{v}_{\text {total }} \frac{\mathrm{w}_{\mathrm{x}}\left(\mathrm{L}_{\mathrm{x}}\right)^{\mathrm{k}}}{\sum_{\mathrm{i}=1}^{\mathrm{n}} \mathrm{w}_{\mathrm{i}} \times\left(\mathrm{L}_{\mathrm{i}}\right)^{\mathrm{k}}} \text { if } \mathrm{W}_{\text {Dead }}>0.25 \mathrm{~W}_{\text {Gravity }}
\end{array} \\
& \mathrm{V}_{\mathrm{x}}:=\sum_{\mathrm{i}=1}^{\mathrm{x}} \mathrm{F}_{\mathrm{i}} \\
& M_{0}:=\sum_{i=1}^{n} F_{i} L_{i} \Rightarrow M_{0}=204 \times 10^{6} \\
& M_{x}:=\max \left[\sum_{i=1}^{n} F_{i}\left(L_{i}-L_{x}\right), M_{o}\left(1-0.5 \frac{L_{x}}{L_{c g}}\right)\right]
\end{aligned}
$$

Distance from base to the level of $F_{i}$

Portion of the total seismic shear $\mathrm{V}$ acting at level i. $\mathrm{ACl} 371 \mathrm{R}-98$, Clause 4.7 .7

Lateral seismic shear force at level $i$, a distance $L_{i}$ above base, $\mathrm{ACl}$ 371R-98, Clause 4.7.8

The overturning moment at base, ACl 371R-98, Clause 4.7.9.1

The overturning moment acting at level $x$ of the structure, $\mathrm{ACl} 371 \mathrm{R}-98$ , Clause 4.7.9.2 


\section{Calculation Summary:}

\subsection{Input}

$$
\begin{array}{lll}
\mathrm{L}_{\mathrm{cg}}=41.500 & \mathrm{~S}_{\mathrm{S}}=1.000 & \mathrm{~W}_{\text {tank }}=50 \times 10^{3} \\
\mathrm{~L}_{\text {shaft }}=35.000 & \mathrm{~S}_{1}=0.570 & \mathrm{~W}_{\text {water }}=19000 \times 10^{3} \\
\mathrm{~L}_{\text {base }}=0.50 & \mathrm{R}=2 & \mathrm{~W}_{\text {tank_floor }}=300 \times 10^{3} \\
\mathrm{~d}_{\mathrm{W}}=7.500 & \text { Soil_Profile_Type }=" \mathrm{~B} " & \mathrm{~W}_{\text {shaft }}=5938 \times 10^{3} \\
\mathrm{~h}_{\mathrm{W}}=0 & \mathrm{n}=8.000 & \\
\mathrm{f}_{\mathrm{c}}=-35 \times 10^{6} & \mathrm{OC}=" \mathrm{IV} " & \\
& \mathrm{~T}_{\mathrm{L}}=8.000 &
\end{array}
$$

\subsection{Output:}

$$
\begin{array}{lllll}
\mathrm{E}_{\mathrm{c}}=27806 \times 10^{6} & \mathrm{I}=1.500 & \mathrm{~S}_{\mathrm{DS}}=0.667 & \mathrm{~W}_{\text {Dead }}=6.3 \times 10^{6} & \mathrm{k}=1.385 \\
\mathrm{I}_{\mathrm{c}}=49.780 & \mathrm{~F}_{\mathrm{a}}=1.000 & \mathrm{~S}_{\mathrm{D} 1}=0.380 & \mathrm{~W}_{\text {Gravity }}=25.3 \times 10^{6} & \mathrm{~V}_{\text {total }}=5.67 \times 10^{6} \\
\mathrm{k}_{\mathrm{c}}=58.10 \times 10^{6} & \mathrm{~F}_{\mathrm{v}}=1.000 & \mathrm{~S}_{\mathrm{a}}=29.9 \% & \mathrm{~W}_{\text {Lump }}=23.3 \times 10^{6} & \mathrm{M}_{\mathrm{o}}=203.76 \times 10^{6} \\
\mathrm{~T}=1.271 & \mathrm{~S}_{\mathrm{MS}}=1.000 & \mathrm{C}_{\mathrm{S}}=22.4 \% & & \\
& \mathrm{~S}_{\mathrm{M} 1}=0.570 & & \\
& \mathrm{~T}_{0}=0.114 & & \\
& \mathrm{~T}_{\mathrm{S}}=0.570 &
\end{array}
$$

Seismic Output Data (Units: $\mathrm{m}, \mathrm{N}$ )

\begin{tabular}{rrrrrc}
\hline $\mathbf{i}$ & \multicolumn{1}{c}{$\mathbf{L}_{\mathbf{i}}$} & \multicolumn{1}{c}{$\mathbf{W}_{\mathbf{i}}$} & \multicolumn{1}{c}{$\mathbf{F}_{\mathbf{i}}$} & $\mathbf{V}_{\mathbf{i}}$ & $\mathbf{M}_{\mathbf{i}}$ \\
\hline 1 & 41.500 & $19,350,000$ & $4,340,185$ & $4,340,185$ & $101,878,556$ \\
2 & 32.964 & 848,230 & 190,257 & $4,530,442$ & $122,832,923$ \\
3 & 27.893 & 848,230 & 190,257 & $4,720,699$ & $135,282,799$ \\
4 & 22.821 & 848,230 & 190,257 & $4,910,956$ & $147,732,674$ \\
5 & 17.750 & 848,230 & 190,257 & $5,101,213$ & $160,182,549$ \\
6 & 12.679 & 848,230 & 190,257 & $5,291,470$ & $172,632,424$ \\
7 & 7.607 & 848,230 & 190,257 & $5,481,727$ & $185,082,299$ \\
8 & 2.536 & 848,230 & 190,257 & $5,671,984$ & $197,532,175$
\end{tabular}




\section{Appendix D - Designing Support Structure for Axial and Lateral Loads}

1 Input:

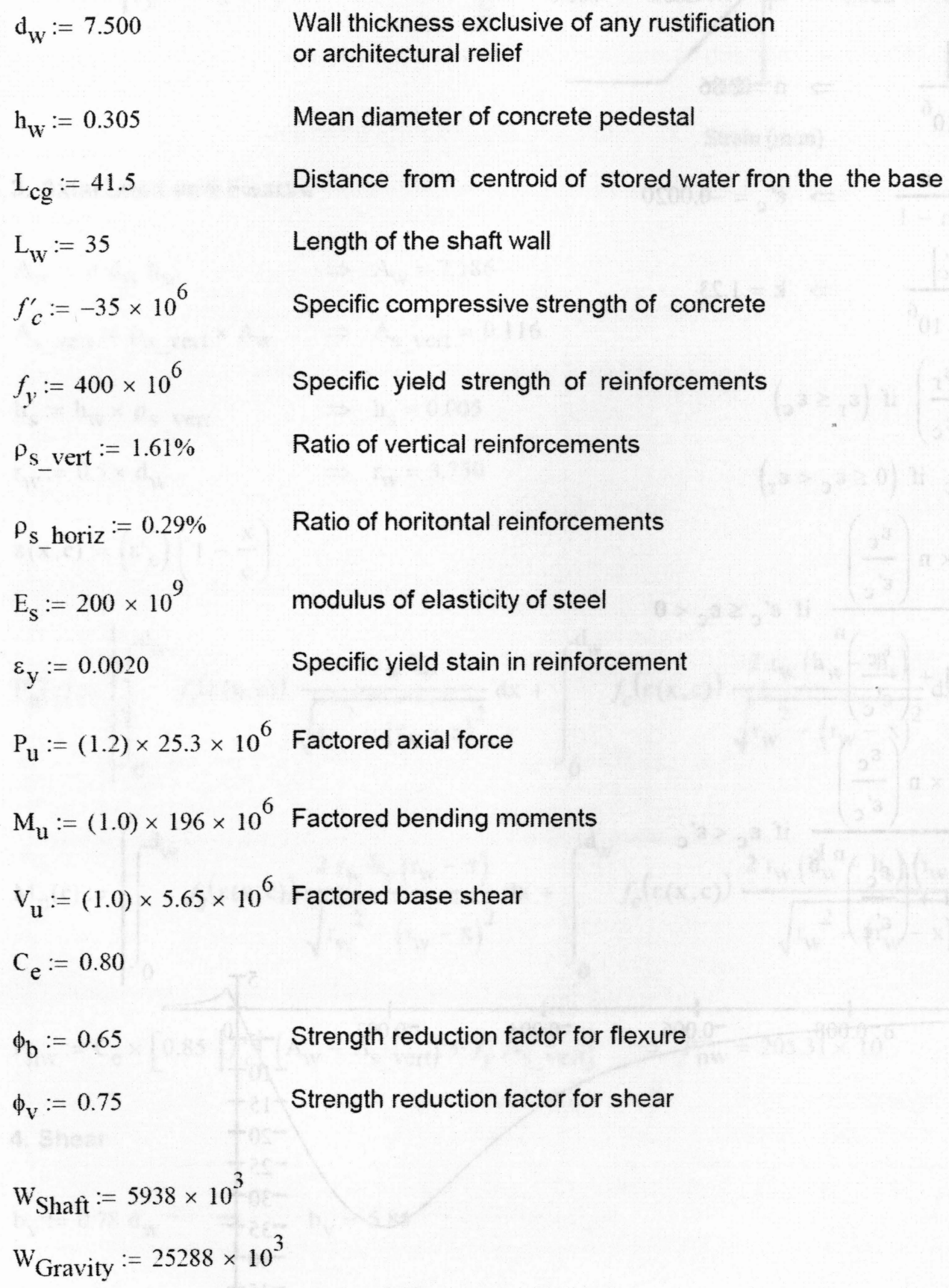




\section{Calculation:}

$\mathrm{E}_{\mathrm{c}}:=3320 \times 10^{3} \times \sqrt{\left|f_{c}^{\prime}\right|}+6900 \times 10^{6} \Rightarrow \mathrm{E}_{\mathrm{c}}=26541 \times 10^{6}$

$f_{r}:=0.62 \times 10^{3} \times \sqrt{\left|f_{c}^{\prime}\right|} \Rightarrow f_{r}=3.67 \times 10^{6}$

$\varepsilon_{\mathrm{r}}:=\frac{f_{r}}{\mathrm{E}_{\mathrm{c}}} \quad \Rightarrow \varepsilon_{\mathrm{r}}=0.00014$

$\mathrm{n}:=0.8+\frac{\left|f_{c}^{\prime}\right|}{17 \times 10^{6}} \quad \Rightarrow \mathrm{n}=2.86$

$\varepsilon_{\mathrm{c}}^{\prime}:=-\frac{\left|f_{c}^{\prime}\right|}{\mathrm{E}_{\mathrm{c}}} \times \frac{\mathrm{n}}{\mathrm{n}-1} \quad \Rightarrow \varepsilon_{\mathrm{c}}^{\prime}=-0.0020$

$\mathrm{k}:=0.67+\frac{\left|f_{c}^{\prime}\right|}{62 \times 10^{6}} \quad \Rightarrow \mathrm{k}=1.23$

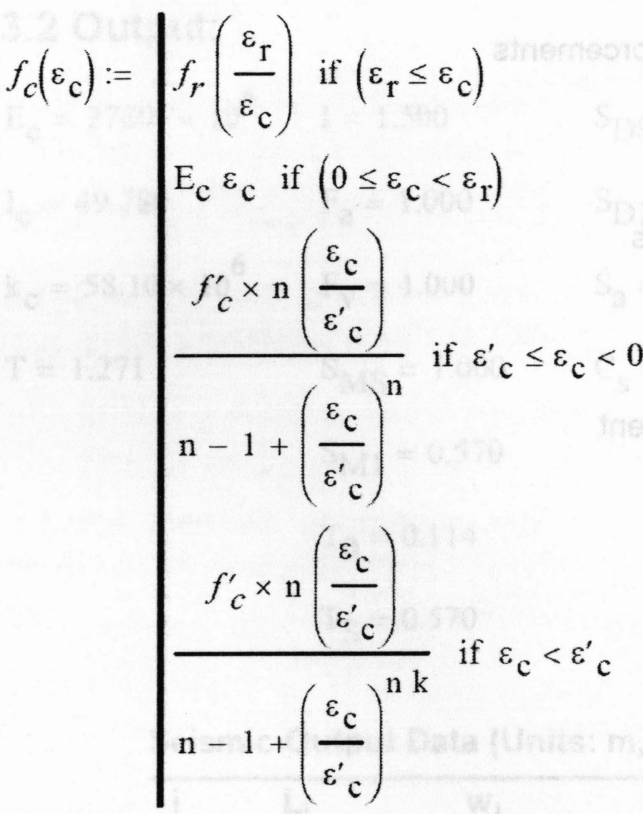

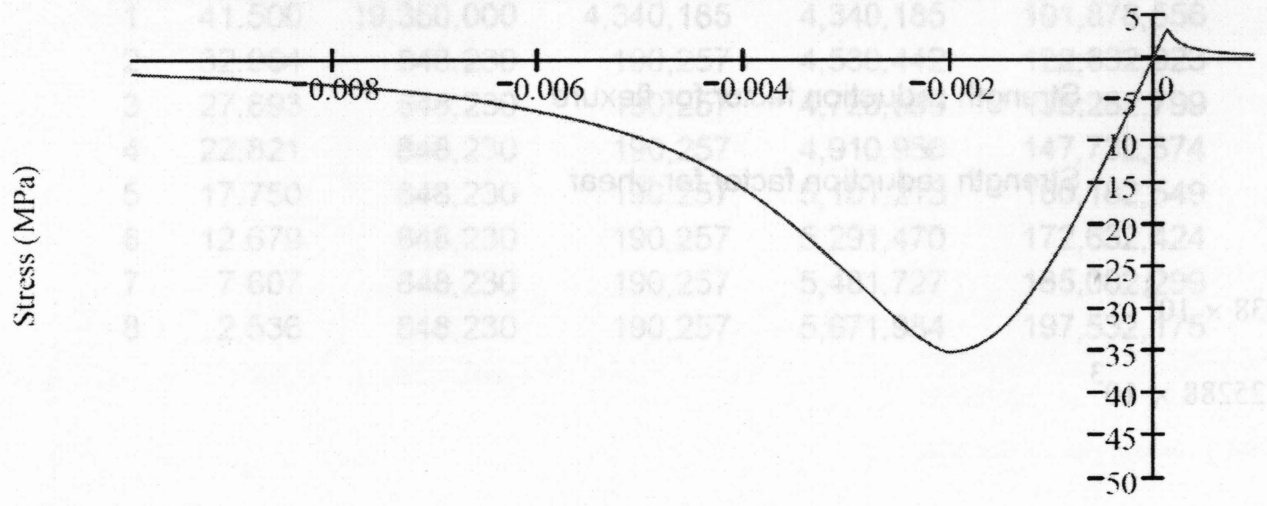

Strain $(\mathrm{mm} / \mathrm{mm})$ 


$$
f_{s}\left(\varepsilon_{\mathrm{s}}\right):=\mid \begin{aligned}
& -f_{y} \text { if } \varepsilon_{\mathrm{s}} \leq-\varepsilon_{\mathrm{y}} \\
& \frac{f_{y}}{\varepsilon_{\mathrm{y}}} \varepsilon_{\mathrm{s}} \text { if }-\varepsilon_{\mathrm{y}}<\varepsilon_{\mathrm{s}} \leq \varepsilon_{\mathrm{y}} \\
& f_{y} \text { if } \varepsilon_{\mathrm{s}}>\varepsilon_{\mathrm{y}}
\end{aligned}
$$

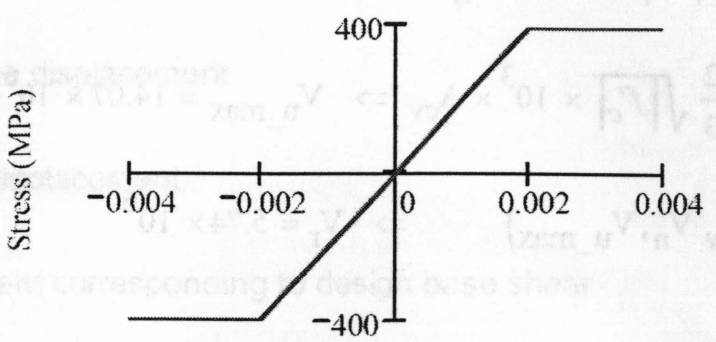

Strain $(\mathrm{m} / \mathrm{m})$

\section{Axial Load and Flexure}

$$
\begin{aligned}
& A_{W}:=\pi d_{w} h_{w} \quad \Rightarrow A_{w}=7.186 \\
& A_{\text {S_vert }_{-}}:=\rho_{\mathrm{S}_{-} \text {vert }} \times A_{W} \quad \Rightarrow A_{S_{-} \text {vert }}=0.116 \\
& \mathrm{~h}_{\mathrm{S}}:=\mathrm{h}_{\mathrm{W}} \times \rho_{\mathrm{s}_{-} \text {vert }} \quad \Rightarrow \mathrm{h}_{\mathrm{s}}=0.005 \\
& \mathrm{r}_{\mathrm{W}}:=0.5 \times \mathrm{d}_{\mathrm{w}} \quad \Rightarrow \mathrm{r}_{\mathrm{w}}=3.750 \\
& \varepsilon(\mathrm{x}, \mathrm{c}):=\left(\varepsilon^{\prime} \mathrm{c}\right)\left(1-\frac{\mathrm{x}}{\mathrm{c}}\right) \\
& P_{n}(c):=\left|\int_{0}^{\mathrm{d}_{w}} f_{s}(\varepsilon(\mathrm{x}, \mathrm{c})) \frac{2 \mathrm{r}_{\mathrm{w}} \mathrm{h}_{\mathrm{s}}}{\sqrt{\mathrm{r}_{\mathrm{w}}^{2}-\left(\mathrm{r}_{\mathrm{w}}-\mathrm{x}\right)^{2}}} \mathrm{dx}+\int_{0}^{\mathrm{d}_{\mathrm{w}}} f_{c}(\varepsilon(\mathrm{x}, \mathrm{c})) \frac{2 \mathrm{r}_{\mathrm{w}}\left(\mathrm{h}_{\mathrm{w}}-\mathrm{h}_{\mathrm{s}}\right)}{\sqrt{\mathrm{r}_{\mathrm{w}}{ }^{2}-\left(\mathrm{r}_{\mathrm{w}}-\mathrm{x}\right)^{2}}} d x\right| \\
& M_{n}(c):=\left|\int_{0}^{d_{w}} f_{s}(\varepsilon(x, c)) \frac{2 r_{w} h_{s}\left(r_{w}-x\right)}{\sqrt{r_{w}{ }^{2}-\left(r_{w}-x\right)^{2}}} d x+\int_{0}^{d_{w}} f_{c}(\varepsilon(x, c)) \frac{2 r_{w}\left(h_{w}-h_{s}\right)\left(r_{w}-x\right)}{\sqrt{r_{w}{ }^{2}-\left(r_{w}-x\right)^{2}}} d x\right| \\
& \mathrm{P}_{\mathrm{nW}}:=\mathrm{C}_{\mathrm{e}} \times\left[0.85\left|f_{c}^{\prime}\right|\left(\mathrm{A}_{\mathrm{W}}-\mathrm{A}_{\mathrm{s}_{-} \text {vert }}\right)+f_{y} \mathrm{~A}_{\mathrm{S}_{-} \text {vert }}\right] \Rightarrow \mathrm{P}_{\mathrm{nW}}=205.31 \times 10^{6}
\end{aligned}
$$

\section{Shear}

$$
\begin{array}{lll}
\mathrm{b}_{\mathrm{v}}:=0.78 \mathrm{~d}_{\mathrm{w}} & \Rightarrow & \mathrm{b}_{\mathrm{v}}=5.85 \\
\mathrm{~A}_{\mathrm{cv}}:=2 \mathrm{~b}_{\mathrm{v}} \mathrm{h}_{\mathrm{w}} \quad \Rightarrow & \mathrm{A}_{\mathrm{cv}}=3.57
\end{array}
$$




$$
\begin{aligned}
& \alpha_{\mathrm{c}}:=\max \left(\min \left(0.5-\frac{0.21 \mathrm{M}_{\mathrm{u}}}{\mathrm{d}_{\mathrm{w}} \mathrm{V}_{\mathrm{u}}}, \frac{1}{4}\right), \frac{1}{6}\right) \quad \Rightarrow \quad \alpha_{\mathrm{c}}=0.167 \\
& \mathrm{~V}_{\mathrm{n}}:=\left(\alpha_{\mathrm{c}} \sqrt{\left|f_{c}^{\prime}\right|} \times 10^{3}+\rho_{\mathrm{s} \_ \text {horiz }} f_{y}\right) \mathrm{A}_{\mathrm{cv}} \Rightarrow \mathrm{V}_{\mathrm{n}}=7.66 \times 10^{6} \\
& \mathrm{~V}_{\mathrm{u}_{-} \max }:=\frac{2}{3} \sqrt{\left|f_{c}^{\prime}\right|} \times 10^{3} \times \mathrm{A}_{\mathrm{cv}} \Rightarrow \mathrm{V}_{\mathrm{u}_{-} \max }=14.07 \times 10^{6} \\
& \mathrm{~V}_{\mathrm{r}}:=\min \left(\phi_{\mathrm{v}} \mathrm{V}_{\mathrm{n}}, \mathrm{V}_{\mathrm{u}_{-} \max }\right) \quad \Rightarrow \mathrm{V}_{\mathrm{r}}=5.74 \times 10^{6}
\end{aligned}
$$

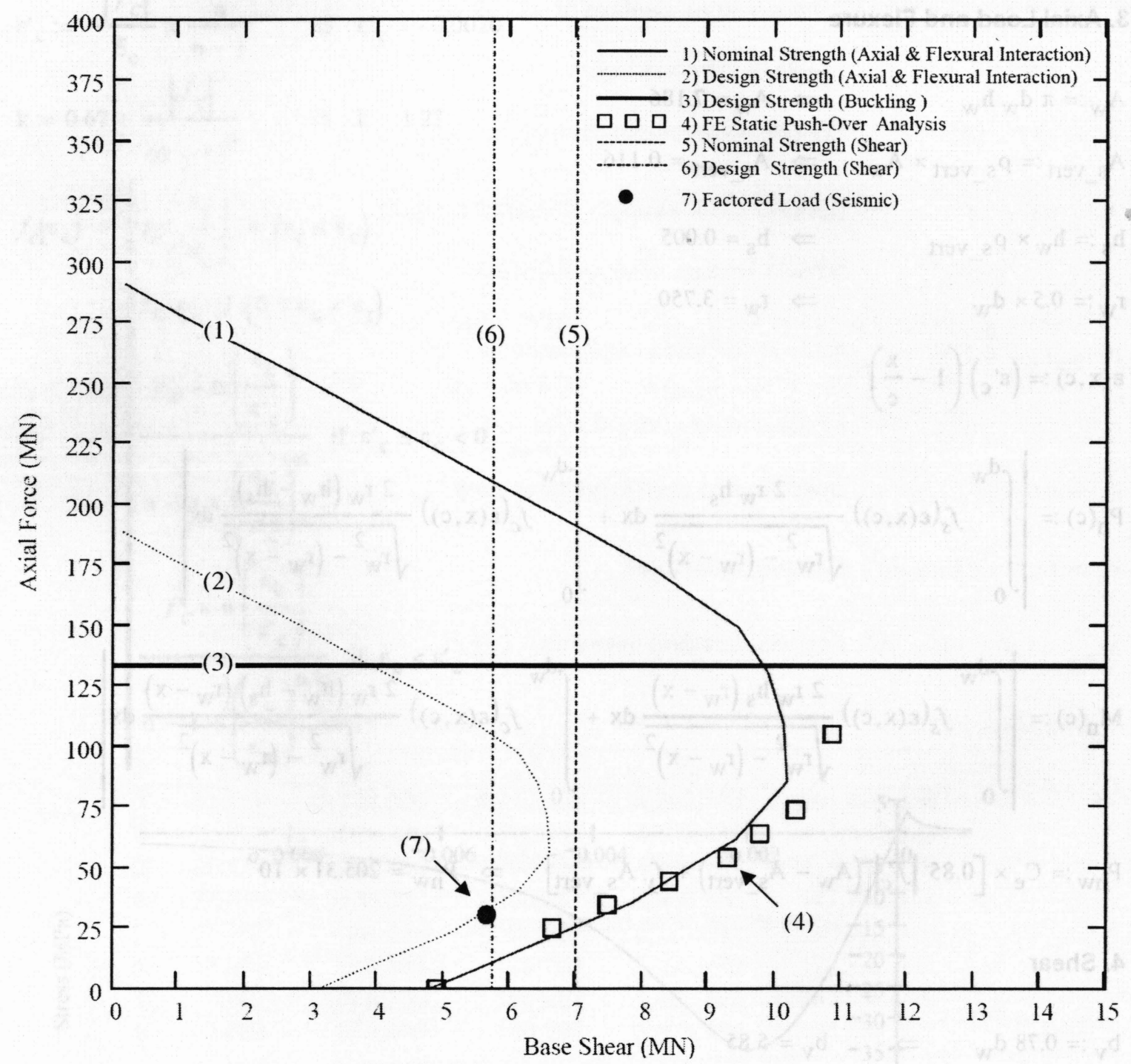




\section{Appendix E - Seismic Redution Factor (R) Calculation}

1. Input:

$\begin{array}{ll}\mathrm{u}_{\mathrm{m}}:=350 & \text { Maximum available displacement } \\ \mathrm{u}_{\mathrm{y}}:=127 & \text { Equivalent Yield displacement } \\ \mathrm{u}_{\mathrm{d}}:=148 & \text { Lateral displacement corresponding to design base shear } \\ \mathrm{T}:=1.27 & \text { Equivalent yield base shear } \\ \mathrm{v}_{\mathrm{y}}:=4.38 & \text { Design Base shear } \\ \mathrm{v}_{\mathrm{d}}:=3.88 & \text { Redundancy related seismic reduction factor } \\ \mathrm{R}_{\mathrm{R}}:=1.0 & \end{array}$

\section{Calculations:}

\subsection{Ductility related modification factor}

$$
\begin{aligned}
& \mu:=\frac{\mathrm{u}_{\mathrm{m}}}{\mathrm{u}_{\mathrm{y}}} \Rightarrow \mu=2.76 \\
& \Phi:=1+\frac{1}{10 \mathrm{~T}-\mu \mathrm{T}}-\frac{1}{2 \mathrm{~T}} \mathrm{e}^{-1.5(\ln (\mathrm{T})-0.6)^{2}} \Rightarrow \Phi=0.78 \\
& \mathrm{R}_{\mu}:=\frac{\mu-1}{\Phi}+1 \quad \Rightarrow \quad \mathrm{R}_{\mu}=3.24
\end{aligned}
$$

Available ductility in the system

Ductility related seismic modification factor, Bereto and Miranda (1989)

2.2 Reserved strength related modification factor

$$
\mathrm{R}_{\mathrm{S}}:=\frac{\mathrm{V}_{\mathrm{y}}}{\mathrm{V}_{\mathrm{d}}} \quad \Rightarrow \quad \mathrm{R}_{\mathrm{S}}=1.13
$$

Reserved strength related seismic modification factor

\subsection{Overall seismic reduction/modification factor}

$$
\mathrm{R}:=\mathrm{R}_{\mu} \times \mathrm{R}_{\mathrm{S}} \times \mathrm{R}_{\mathrm{R}} \Rightarrow \mathrm{R}=3.65
$$

Overall seismic reduction/modification factor 

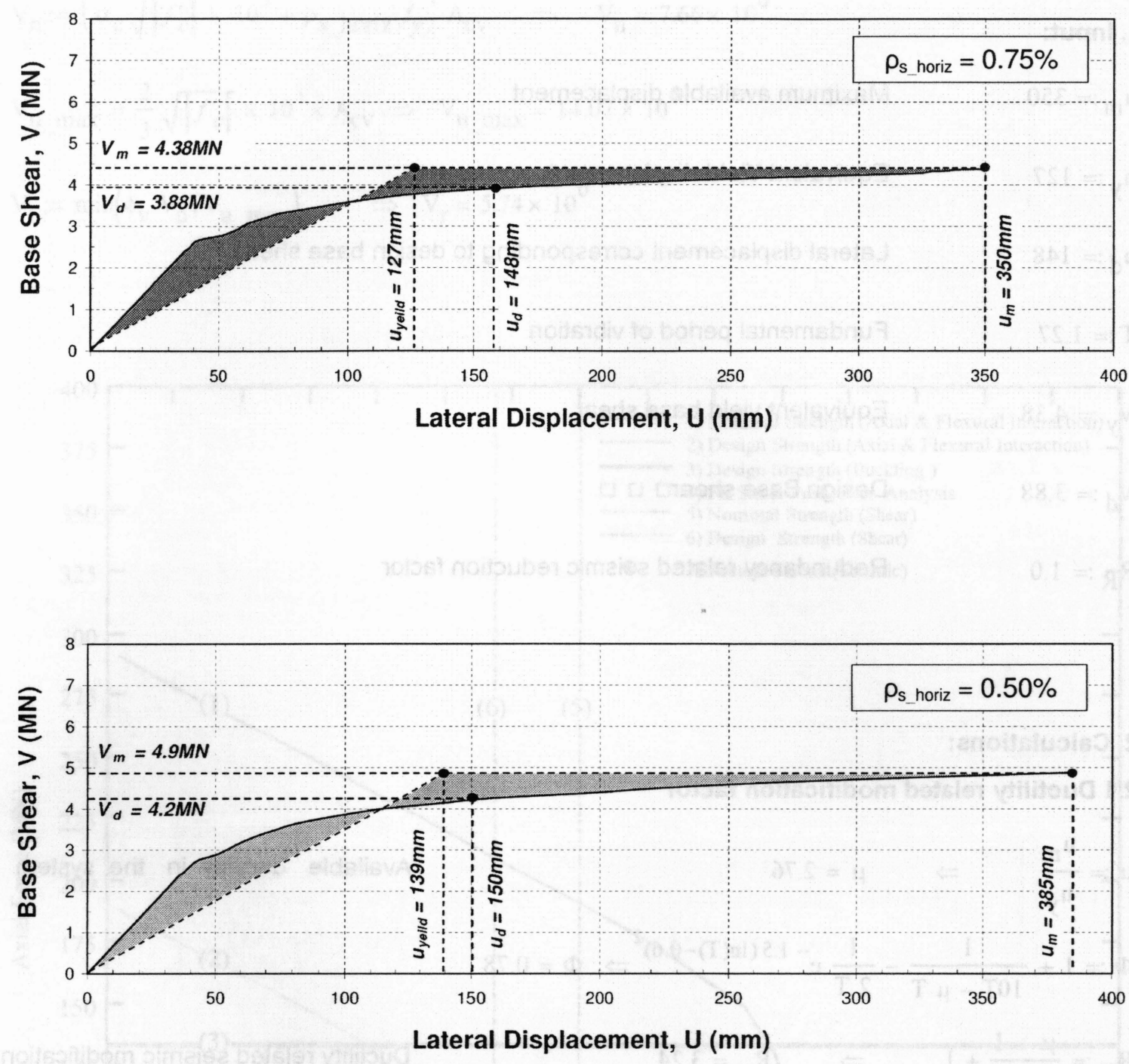